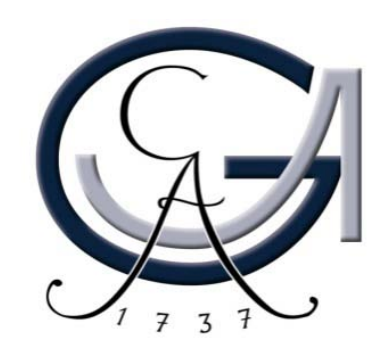

\title{
Der Einfluss mechanischer Last auf das Potential multipotenter adulter Keimbahnstammzellen zur kardialen Regeneration
}

\author{
Dissertation \\ zur Erlangung des mathematisch-naturwissenschaftlichen \\ Doktorgrades \\ „Doctor rerum naturalium“ \\ der Georg-August-Universität Göttingen
}

vorgelegt von

Diana Kaiser

aus Friedrichroda 
Referent: $\quad$ Prof. Uwe Groß

Institut für medizinische Mikrobiologie

Georg-August-Universität Göttingen

Korreferent: Prof. Wolfgang Brück

Abteilung für Neuropathologie

Universitätsmedizin der Georg-August-Universität Göttingen

Tag der mündlichen Prüfung:19.01.2011 


\section{Inhaltsverzeichnis}

Abkürzungsverzeichnis .....................................................................................................IV

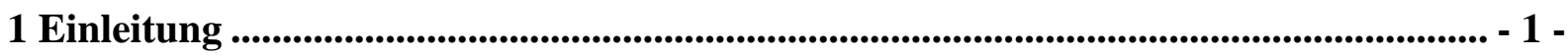

1.1 Herzinsuffizienz und Therapiemöglichkeiten ........................................................ - 1 -

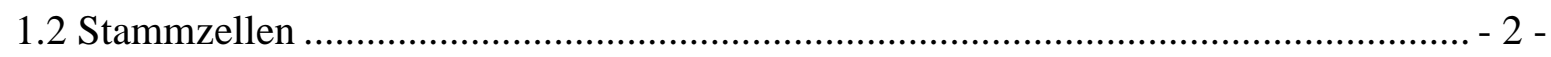

1.2.1 Embryonale Stammzellen......................................................................... - 3 -

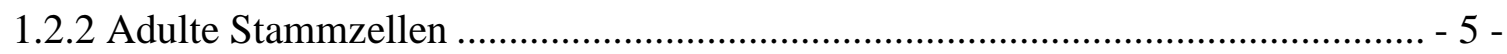

1.2.2.1 Knochenmark-Stammzellen ............................................................. - 6 -

1.2.2.2 Kardiale Stammzellen........................................................................ - 7 -

1.2.2.3 Adulte Keimbahnstammzellen ............................................................... - 11 -

1.2.3 Künstlich reprogrammierte Stammzellen ........................................................ - 12 -

1.3 Zellbasierte Therapie bei Herzerkrankungen ........................................................ - 13 -

1.3.1 Knochenmarkzellen-basierte Therapien .......................................................... - 14 -

1.3.2 Therapien mit murinen und humanen pluripotenten Stammzellen .................... - 15 -

1.3.3 Therapien mit kardialen Stammzellen und Vorläuferzellen.............................. - 17 -

1.4 Die Wirkung mechanischer Last auf Stammzellen in vitro und in vivo.................... - 18 -

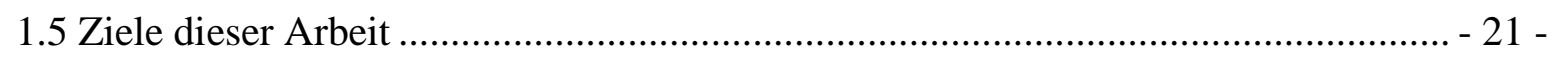

2 Material und Methoden .............................................................................................. - 22 -

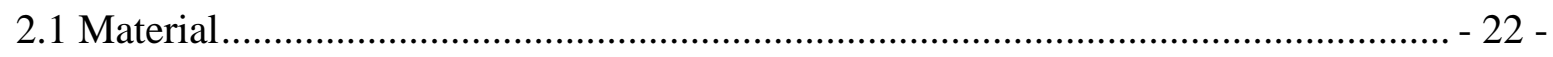

2.1.1 Versuchstiere .................................................................................... -22 -

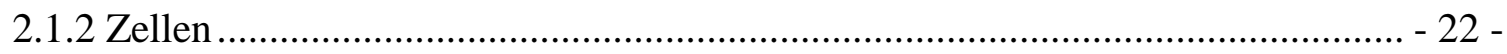

2.1.3 Lösungen, Faktoren und Zellkulturmedien .................................................. - 23 -

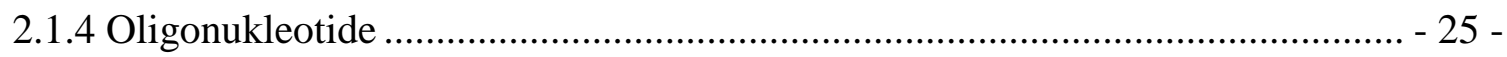

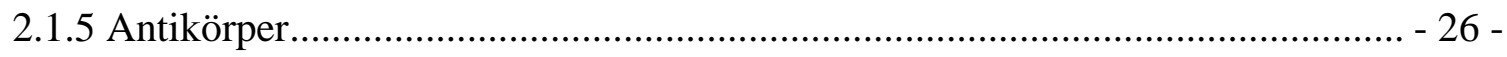

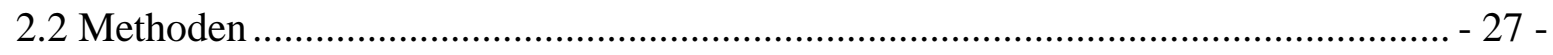


2.2.1 Zellbiologische Methoden ........................................................................ - 27 -

2.2.1.1 Passagieren der Zellen ......................................................................... - 28 -

2.2.1.2 Kultivierung der MEFs und OP9-Zellen ................................................. - 28 -

2.2.1.3 Kultivierung der undifferenzierten maGSCs.......................................... - 29 -

2.2.1.4 Co-Kultur von maGSCs mit OP9-Zellen ............................................... - 29 -

2.2.1.5 In vitro Dehnungs-Experimente mit maGSCs........................................ - 30 -

2.2.2 In vivo Maus-Modelle.............................................................................. - 31 -

2.2.2.1 Schmerztherapie, Narkose und Intubation.............................................. - 31 -

2.2.2.2 Aorto-cavale Shunt-Operation............................................................ - 32 -

2.2.2.3 Transaortic constriction (TAC) ............................................................ 32 -

2.2.2.4 DiI-Färbung der maGSCs.................................................................... - 33 -

2.2.2.5 Stammzell-Injektion ins Myokard ........................................................... - 33 -

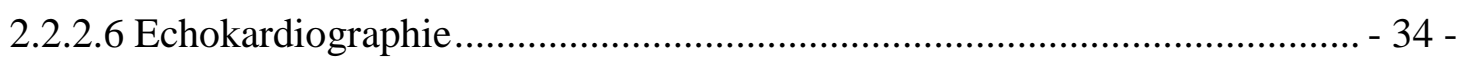

2.2.3 Immunhisto-, Immunzyto- und Histochemie ................................................ - 34 -

2.2.3.1 Herstellung der Gewebeschnitte ......................................................... - 34 -

2.2.3.2 HE und MG-Färbungen ........................................................................ - 35 -

2.2.3.3 Immunfluoreszenzfärbungen an Paraffinschnitten................................... - 36 -

2.2.3.4 Immunhistologische Färbung .............................................................. 36 -

2.2.3.5 Immunfluoreszenzfärbungen an Zellen ................................................ - 37 -

2.2.3.6 Durchflusszytometrie und Fluorescence activated cell sorting (FACS)..... - 38 -

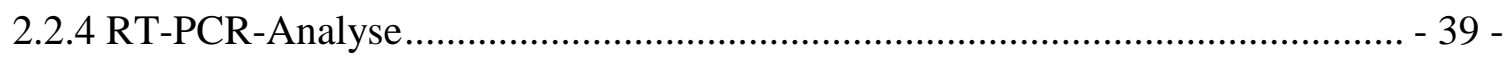

2.2.5 Gelelektrophorese, relative Quantifizierung und Statistik .............................. - 40 -

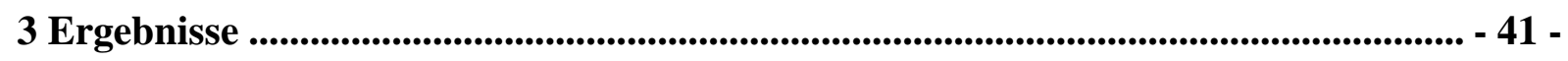

3.1 Das Schicksal undifferenzierter maGSCs in gesunden Mausherzen ......................... - 41 -

3.2 Der Einfluss einer vermehrten Last im Herzen auf die Differenzierung der injizierten

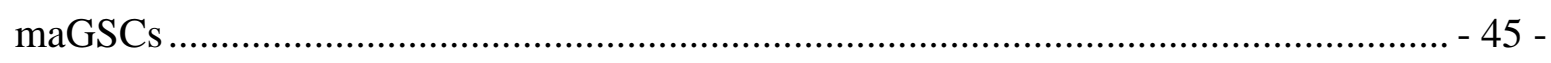

3.2.1 Etablierung einer Vorlast oder Nachlast im Maus-Modell............................... - 45 - 
3.2.2 Vermehrte Bindegewebsbildung nach maGSC-Transplantation in Last-induzierten Mausherzen. $-48-$

3.2.3 Das Schicksal undifferenzierter maGSCs in Shunt- und TAC-operierten Mäusen- 53 -

3.2.4 Echokardiographie der Shunt- und TAC-operierten Mäuse. $-56-$

3.3 MaGSCs in immundefizienten RAG2 ${ }^{-/-} \mathrm{Cgc}^{-/-}$Mäusen $-61-$

3.4 Generation kardiovaskulärer Vorläuferzellen $-64-$

3.4.1 Etablierung eines Co-Kultursystems für die Generation kardiovaskulärer Vorläuferzellen $-65-$

3.4.2 Charakterisierung der vordifferenzierten maGSCs am Tag 5 $-71-$

3.4.3 Kardiovaskuläres Differenzierungspotential der maGSCs mittels OP9-CoKultursystem $-76-$

3.4.4 Differenzierungspotential der Flk1 ${ }^{+}$Zellen $-80-$

3.5 In vitro-Dehnungsversuche mit maGSCs . $-81-$

4 Diskussion $-84-$

4.1 MaGSCs als alternative Zellquelle für Herzregeneration. $-85-$

4.2 Das Schicksal von maGSCs in normalen und Shunt oder TAC operierten Mäusen. - 86 -

4.3 Welchen Einfluss hat die in vitro Dehnung auf maGSCs? - $88-$

4.4 Vermehrte Fibrose im Herzen der CsA-immunsupprimierten Mäuse nach Zelltransplantation $-90-$

4.5 Tragen die maGSCs zu einer besseren Herzfunktion in Last-induzierten Mäusen bei? ...91 -

4.6 Einfluss des Immunsuppressivums Ciclosporin A auf maGSCs bezüglich

Teratomentwicklung in vivo $-93-$

4.5 Erfolgreiche Etablierung von Flk1 ${ }^{+}$kardiovaskulären Vorläuferzellen aus maGSCs .- 96

5 Zusammenfassung $-101-$

6 Literaturverzeichnis $103-$ 


\section{Abkürzungsverzeichnis}

AA Activin A

AMI acute myocardial infarction, akuter Myokardinfarkt (auch MI genannt)

bidest. bidestilliert

Bp Basenpaare

ß-ME ß-Mercaptoethanol

BSA Bovines Serumalbumin

cDNA complementary DNA, komplementäre DNA

CM-DiI Chlormethylbenzamido-Derivate des 1,1'-Dioctadecyl-3,3,3'3' tetramethylindocarbocyanin-perchlorat

CsA Ciclosporin A

Cy3 Indocarbocyanin

d day, Tag

DAPI 4', 6-Diamidino-2-phenylindoldihydrochlorid

DEPC Diethylpyrocarbonat

DMEM Dulbeccos modifiziertes Eagle Medium

DMSO Dimethylsulfoxid

DNA desoxyribonucleic acid, Desribonukleinsäure

DNase Desoxyribonuklease

dNTP'-Desoxynukleotid-Triphosphat

DPBS Dulbeccos Phosphat-gepufferte Salzlösung (auch PBS)

EB embryoid body

EDTA Ethylendiamintetraessigsäure

EF Ejektionsfraktion

EGFP enhanced green fluorescent protein

ES-Zellen embryonale Stammzellen

f forward, vorwärts

FACS Fluorescence activated cell sorting, Fluoreszenz-aktivierte Zellsortierung

FCS fetal calf serum, Fetales Kälberserum

FITC Fluorescein-5-isothiocyanat

Flk1 fetal liver kinase 1, Fetale Leberkinase 1, auch vascular endothelial growth factor receptor -2 (VEGF-R2)

FS fractional shortening, Verkürzungsfraktion 
g Gramm

GAPDH Glycerinaldehyd-3-Phosphat-Dehydrogenase

HSCs hematopoietic stem cells, hämatopoetische Stammzellen

HW/BW heart weight/body weight, Herzgewicht/Körpergewicht

ICM inner cell mass, innere Zellmasse

IMDM Iscoves modifiziertes Dulbecco Medium

KHK koronare Herzerkrankung

l Liter

LIF leukemia inhibitory factor

LVEDD left ventricular enddiastolic diameter, linksventrikulärer enddiastolischer

Diameter

$\mathrm{m}$

milli $\left(10^{-3}\right)$

$\mathrm{M}$

Molar (Mol pro Liter)

maGSC multipotent adult germline stem cell, multipotente adulte Keimbahnstammzelle

M-CSF macrophage colony-stimulating factor, Makrophagen Kolonie-stimulierender Faktor

MEF

mouse embryonic fibroblast, muriner embryonaler Fibroblast

$\min \quad$ Minute

MMC Mitomycin C

mRNA messenger RNA

MSC mesenchymal stem cell, mesenchymale Stammzelle

MTG $\quad \alpha$-Monothioglycerol

n

nano $\left(10^{-9}\right)$ bzw. Anzahl

NEAA non essential amino acids, nicht essentielle Aminosäuren

OD optische Dichte

PCR polymerase chain reaction, Polymerase-Kettenreaktion

PE Phycoerythrin

PFA Paraformaldehyd

PGC primordial germ cells, Keimbahnstammzellen

r reverse, rückwärts

RNase Ribonuklease

RNA ribonucleic acid, Ribonukleinsäure

RT-PCR Reverse Transkriptase-PCR

$\mathrm{S}$

Sekunde 
SSC spermatogonial stem cell, spermatogoniale Stammzelle

Stra8 stimulated by retinoic acid gene 8 homolog (Maus)

$\mathrm{T}_{\mathrm{H}}$

Hybridisierungstemperatur

TAC

transaortic constriction

Taq

Thermus aquaticus

TB

Tris-Borsäure-gepufferte Kochsalzlösung

$\mathrm{V}$

Volt

VEGF vascular endothelial growth factor, vaskulärer endothelialer Wachstumsfaktor

$\mathrm{W}$ Woche

Z Zyklenanzahl

ZTE

Zentrale tierexperimentelle Einrichtung (der Universitätsmedizin Göttingen) 


\section{Einleitung}

\subsection{Herzinsuffizienz und Therapiemöglichkeiten}

Es gibt viele verschiedene Herzerkrankungen, die zu einer Herzinsuffizienz führen können. Dazu gehören z.B. die koronare Herzerkrankung (KHK), die dilatative Kardiomyopathie, die Myokarditis, kongenitale Vitien und gutartige Herztumore.

Die KHK ist eine Erkrankung der Herzkranzgefäße, die durch verschiedene Vorerkrankungen hervorgerufen wird und meist in einer Herzinsuffizienz endet (Dickstein et al. 2008). Bei der KHK bedingen Ablagerungen in den Gefäßen eine Versteifung der Gefäßwände und eine Verminderung des Gefäßquerschnitts, wodurch Durchblutung und Sauerstoffversorgung der Herzmuskulatur vermindert sind. Die Herzinsuffizienz kann auch durch einen Herzinfarkt verursacht werden, bei dem durch eine Unterbrechung der Blutzufuhr im Herzen ein bestimmtes Areal des Herzens abstirbt und funktionsuntüchtig wird. Dadurch wird das Herz mit weniger Sauerstoff versorgt und zeigt eine verminderte Leistungsfähigkeit (Dickstein et al. 2008). Außerdem entsteht ein Verlust von Herzmuskelgewebe, da viele Kardiomyozyten absterben. Ein Untergang von Kardiomyozyten kann auch später bei der Entstehung einer Herzschwäche auftreten (Anversa et al. 1996). Eine weitere Ursache für die Entwicklung einer Herzinsuffizienz können Klappenerkrankungen sein, wobei diese entweder verengt oder undicht sind. Dadurch verringern sich Pumpleistung und Sauerstoffversorgung des Herzens. Letztlich können konzentrische oder exzentrische Hypertrophien die Folge sein, die mit einem Remodeling des Herzens einhergehen. Eine Herzinsuffizienz kann auch durch Stoffwechselerkrankungen, bestimmte Proteineinlagerungen (Amyloidose) oder strukturelle Herzerkrankungen wie dilatativen Kardiomyopathien, hervorgerufen werden, deren Ursache z.B. in Mutationen in Genen, die für kontraktile Filamente kodieren, liegt.

Bei einer fortgeschrittenen Herzinsuffizienz erhöht sich die Wahrscheinlichkeit für das Auftreten von Begleiterscheinungen, wie Herzrhythmusstörungen, sowie akuten, lebensbedrohlichen Komplikationen, wie Herzinfarkt und plötzlichem Herztod.

Die Herzinsuffizienz betrifft vor allem ältere Menschen (über 65 Jahre) und mehr Männer als Frauen. Ist die Erkrankung noch nicht weit fortgeschritten, kann man eine kausale Therapie, z.B. eine Revaskularisation (durch Einsetzen eines Stents oder eine Bypass-Operation) oder einen Klappenersatz in Erwägung ziehen. Ist allerdings eine chronische Herzinsuffizienz diagnostiziert, zählen Wirkstoffe aus der Gruppe der Blutdrucksenker wie ACE-Hemmer, Betablocker und Diuretika zur Basistherapie. 
Nach Angaben der WHO sterben weltweit immer mehr Menschen an den Folgen von Erkrankungen des Herz-Kreislaufsystems, 2004 waren es ca. 17,1 Millionen Menschen. Das entspricht 29\% aller Todesfälle weltweit. Im Jahr 2030 werden laut Schätzungen der WHO wahrscheinlich 23,6 Millionen Personen an Herz-Kreislauferkrankungen sterben. Es ist also von größter Relevanz, neue Therapien zur Behandlung von Herz-Kreislauferkrankungen zu entwickeln, da alle bisherigen Therapieansätze nur bis zu einem bestimmten Punkt helfen. Denn obwohl große Fortschritte im Bereich der medikamentösen Therapie, der Herzchirurgie, der Verwendung von unterstützenden Systemen und auf dem Gebiet der Herztransplantation zu verzeichnen sind, stirbt mehr als die Hälfte der Patienten mit Herzversagen innerhalb von 5 Jahren nach Diagnosestellung.

Da die funktionelle Regeneration von geschädigtem Myokard eine große Herausforderung darstellt, sollten Strategien zur Verhinderung von kardialem Remodeling und Organversagen entwickelt werden. Dabei spielen vor allem zellbasierte Therapien mit fetalen Kardiomyozyten und Myoblasten sowie mit embryonalen und adulten Stammzellen und Vorläuferzellen eine große Rolle.

\subsection{Stammzellen}

Stammzellen sind in der Lage sich über einen unbestimmten Zeitraum selbst zu erneuern (self-renew) und können in mindestens einen spezifischen Körperzelltyp differenzieren. Stammzellen lassen sich je nach Herkunft oder bezüglich ihres Differenzierungspotentials einteilen. Sie können aus Embryonen (embryonale Stammzellen, ES-Zellen), aus erwachsenen Organismen (adulte Stammzellen) sowie aus somatischen Zellen durch Überexpression bestimmter pluripotenter Transkriptionsfaktoren (induzierte pluripotente Stammzellen, iPS-Zellen) gewonnen werden.

Bezüglich ihres Differenzierungspotentials, kann man Stammzellen in bestimmte Klassen einteilen (Abb. 1). Totipotente Stammzellen sind dazu fähig, sich in alle 216 bildenden Gewebe des menschlichen Körpers zu differenzieren (inklusive der Plazenta und der embryonalen Annexe; z.B. die Zygote und Blastomeren bis zum 8-Zell-Stadium). Pluripotente Stammzellen können sich in die Derivate aller drei Keimblätter (Endoderm, Ektoderm und Mesoderm) und in Keimbahnzellen differenzieren (z.B. ES-Zellen), während multipotente Stammzellen noch in eine Vielzahl von Zelltypen differenzieren können (z.B.hämatopoetische Stammzellen). Unipotente Stammzellen können sich nur zu einem einzigen Zelltyp entwickeln (z.B. neuronale Stammzellen). 


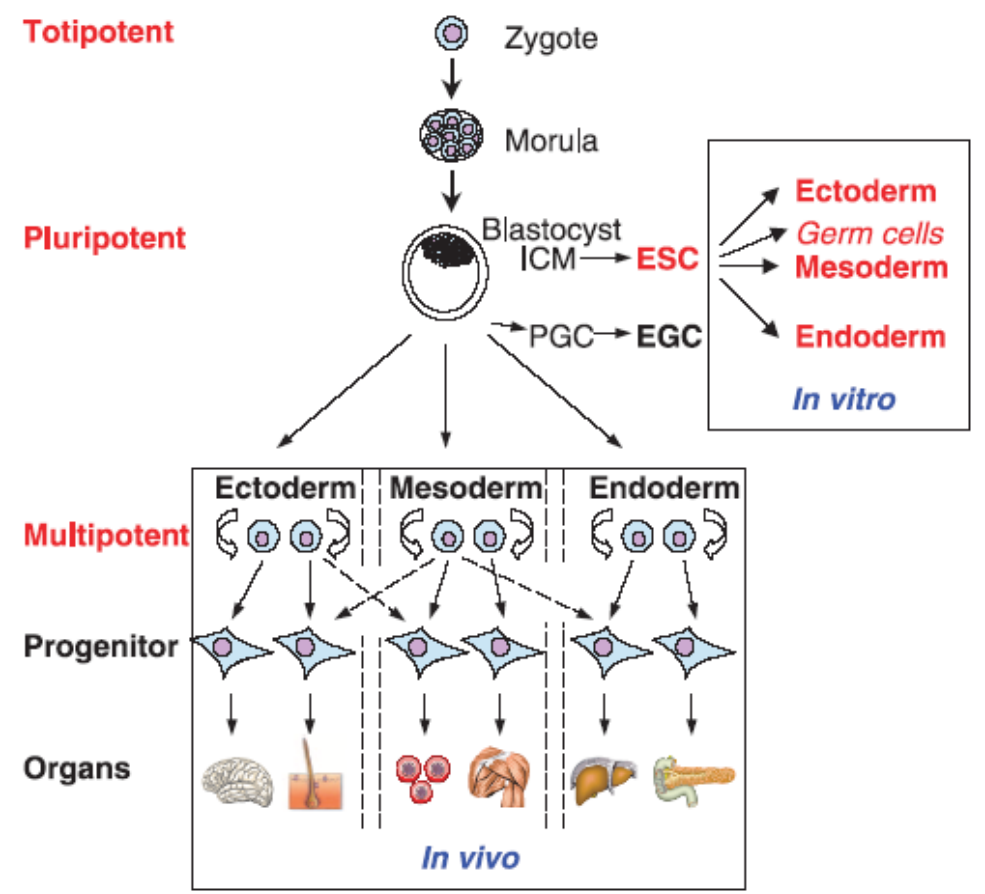

Abbildung 1: Stammzell-Hierarchie. Die Zygote und Blastomeren bis zum 8-Zell-Stadium werden als totipotent bezeichnet, da sich aus ihnen ein komplexer Organismus entwickeln kann. Im Stadium der Blastozyste sind nur noch die Zellen der inneren Zellmasse (inner cell mass, ICM) in der Lage, sich in alle 3 Keimblätter (Ektoderm, Mesoderm und Endoderm) und Keimbahnzellen zu differenzieren. Multipotente Stammzellen und Vorläuferzellen existieren in adulten Geweben, um beschädigte oder abgestorbene Zellen zu ersetzen. ES-Zellen (hier: ESC, embryonic stem cells) aus der ICM können sich in vitro in alle somatischen Zelllinien und in weibliche und männliche Keimzellen differenzieren (Wobus and Boheler 2005).

\subsubsection{Embryonale Stammzellen}

ES-Zellen werden aus der inneren Zellmasse (inner cell mass, ICM) im Embryonalstadium der Blastozyste für experimentelle Zwecke gewonnen und sind in vivo und in vitro in der Lage, sich in Zellen aller drei Keimblätter sowie in Zellen der Keimbahn auszudifferenzieren (Abb. 1). Daher bezeichnet man sie als pluripotente Zellen.

1981 wurden zum ersten Mal ES-Zellen aus Blastozysten der Maus isoliert (Evans and Kaufman 1981; Martin 1981). Diese Zellen neigen in vitro dazu, spontan zu differenzieren, was durch bestimmte Faktoren unterbunden werden kann, die die Selbsterneuerung der Zellen fördern (Chambers and Smith 2004; Smith 2005). ES-Zellen können eigentlich unbegrenzt vermehrt werden, wozu auch die hohe Aktivität des Enzyms Telomerase beiträgt. Damit unterscheiden sich die ES-Zellen von anderen (sogenannten primären) Körperzellen, die ihre Teilungsaktivität in vitro meist schnell einstellen (replikative Seneszenz).

Murine ES-Zellen (mES-Zellen) exprimieren Pluripotenzmarker wie den Transkriptionsfaktor Oct4 (Octamer binding transcription factor 4) und die alkalische Phosphatase (Scholer et al. 
1989a; Resnick et al. 1992; Wobus 2001). Diese Zellen können in vitro in verschiedene Zelltypen aller drei Keimblätter differenzieren, wie z.B. in Kardiomyozyten (Westfall et al. 1997; Guan et al. 1999; Wei et al. 2005), glatte Muskelzellen (Drab et al. 1997) und Skelettmuskelzellen (Rohwedel et al. 1994), in verschiedene neuronale Zelltypen (Kawasaki et al. 2000; Lee et al. 2000) sowie in pankreatische Zellen (Hori et al. 2002) und Hepatozyten (Hamazaki et al. 2001). Die aus mES-Zellen differenzierten Kardiomyozyten zeigen entwicklungsabhängig kardial-spezifische Gene, Proteine und Ionen-Kanäle und weisen typische Charakteristika von Herzzellen im frühen kardialen Entwicklungsstadium auf (Westfall et al. 1997; Guan et al. 1999; Wei et al. 2005).

Dass mES-Zellen auch zu Keimzellen differenzieren können, wurde 2003 erstmals im Mausmodell gezeigt (Hubner et al. 2003). Transplantiert man diese Stammzellen in eine sich entwickelnde Blastozyste, müssen sie Teil eines chimären Organismus werden (Bongso and Richards 2004), d.h. dass mES-Zellen nach Transfer in pseudo-schwangere Tiere am Aufbau aller fötalen Gewebe beteiligt sind. Dadurch kann man zielgerichtet Gene in Mäusen ausschalten und gewinnt schneller Knockout-Mäuse als mit anderen Techniken. Diese Mäuse sind wichtige Modell-Organismen für die biologisch-medizinische Forschung, da somit auch humane Krankheiten im Tiermodell untersucht werden können.

Humane ES-Zellen (hES-Zellen) wurden erstmals 1998 etabliert (Thomson et al. 1998). Sie werden aus sogenannten „übrigen“ Embryonen gewonnen, die durch In-vitro-Fertilisation entstanden sind, aber nicht mehr für Fortpflanzungszwecke gebraucht und daher tiefgefroren gelagert werden. Die Forschung mit hES-Zellen wird von einer ethischen Kontroverse begleitet, da ihre Gewinnung über eine Zerstörung früher humaner Embryonen erfolgt. Die Diskussionen befassen sich vor allem mit der Frage, ob der frühe Embryo als menschliches Wesen unter den Würdeschutz des Grundgesetzes fällt. In Deutschland ist es nach dem Embryonenschutzgesetz verboten, humane Embryonen für Forschungszwecke zu generieren, zu klonen oder zu zerstören. Die Forschung an importierten hES-Zellen ist unter strengen Auflagen möglich und durch das Stammzellgesetz geregelt. Bis zum Frühjahr 2008 durften nur hES-Zellen nach Deutschland importiert werden, die vor dem 1.1.2002 gewonnen wurden. Im April 2008 verabschiedete der Deutsche Bundestag eine neue Stichtagsregelung. Nun dürfen Stammzellen importiert werden, die vor dem 1.5.2007 generiert wurden.

Humane ES-Zellen können unbegrenzt und in ihrem pluripotenten Zustand in Kultur gehalten werden. Aber auch in vitro-Differenzierungen in verschiedene Zelltypen, wie z.B. neuronale Progenitorzellen und Neuronen (Reubinoff et al. 2001; Schuldiner et al. 2001), Hepatozyten (Rambhatla et al. 2003), myeloide Zellen (Kaufman and Thomson 2002) und in 
Endothelzellen (Levenberg et al. 2002) waren erfolgreich. Darüber hinaus können sie auch in Kardiomyozyten differenziert werden (Kehat et al. 2001; Xu et al. 2002). Diese aus hESZellen entstandenen Kardiomyozyten ähneln fetalen oder embryonalen Kardiomyozyten, denn sie zeigen spontane Kontraktilität und exprimieren kardiale Transkriptionsfaktoren wie Nkx2.5 (auch Csx, cardiac specific homebox gene), Mef2c (myocyte enhancer factor 2c) und GATA4 (GATA binding protein 4). Außerdem lassen sich strukturelle Proteine wie MHC (myosin heavy chain), MLC2a und -2v (atriale und ventrikuläre Form der myosin light chain) und Desmin nachweisen. Elektrophysiologische Studien zeigten atriale, ventrikuläre und Schrittmacher-Aktionspotentiale in den aus hES-Zellen gewonnenen Kardiomyozyten (He et al. 2003). Außerdem reagieren diese Zellen auf eine Vielzahl von pharmakologischen Substanzen wie Adrenorezeptoren (Reppel et al. 2004). Diese Kardiomyozyten können strukturelle und elektromechanische Verbindungen mit kultivierten Rattenkardiomyozyten herstellen und funktional integrieren um zu kontrahieren (Kehat et al. 2004; Xue et al. 2005).

\subsubsection{Adulte Stammzellen}

Adulte Stammzellen kommen im Gegensatz zu ES-Zellen in jedem erwachsenen Individuum vor. Sie haben ein geringeres Differenzierungspotential als ES-Zellen und dennoch entstehen aus ihnen während des gesamten Lebens des Organismus neue, spezialisierte Zellen, die das Gewebe, in dem sie sich befinden, aufrecht erhalten und reparieren. Adulte Stammzellen wurden in bestimmten Organen (z.B. Knochenmark, Haut, Hoden, Fettgewebe, Nabelschnur, Gehirn, Leber oder Bauchspeicheldrüse) identifiziert. Dies warf die Frage nach der Transplantierbarkeit dieser Stammzellen auf. Hämatopoetische Stammzellen (hematopoietic stem cells, HSCs) z.B. werden schon seit 40 Jahren transplantiert. Wenn man die Differenzierung der relativ neu entdeckten adulten Stammzellen z.B. im Gehirn oder im Herzen in vitro kontrollieren könnte, wären sie eine gute Quelle für zellbasierte Therapien. Ein weiterer Vorteil der adulten Stammzellen ist die geringere Tendenz zur malignen Entartung im Vergleich zu ES-Zellen.

Obwohl adulte Stammzellen eigentlich in die vom Gewebe oder dem Organ vorbestimmte Richtung differenzieren, wurde in einigen Studien berichtet, dass sie sich zu Zellen aus anderen Organen oder Geweben entwickeln können (Grimaldi et al. 1997; Bouwens 1998; Rose et al. 2008; Sarig et al. 2010). Dieses Keimblatt-übergreifende Differenzierungspotential wird Transdifferenzierung oder Plastizität genannt. 


\subsubsection{Knochenmark-Stammzellen}

Viele Plastizitäts-Experimente zum Nachweis der Transdifferenzierung wurden mit Knochenmark-Stammzellen durchgeführt. Dabei konnte u.a. gezeigt werden, dass sich adulte Knochenmark-Stammzellen zu Skelettmuskelzellen (Ferrari et al. 1998; Gussoni et al. 1999; LaBarge and Blau 2002), Hepatozyten (Lagasse et al. 2000), neuronalen Zellen (Kopen et al. 1999), Kardiomyozyten (Jackson et al. 2001; Orlic et al. 2001), vaskulärem Endothel (Asahara et al. 1997) und Epithel von Haut, Lunge und Darm (Krause et al. 2001) entwickeln können. Im Knochenmark findet man HSCs, side population-Zellen (SP-Zellen), endotheliale Progenitorzellen (endothelial progenitor cells, EPCs), mesenchymale Stammzellen (mesenchymal stem cells, MSCs) und multipotente adulte Progenitorzellen (Abb. 2).

HSCs sind multipotent, für die ständige Erneuerung des Blutes zuständig und können sich in alle Blutzelltypen differenzieren: rote Blutzellen, B-Lymphozyten, T-Lymphozyten, natural killer cells, Neutrophile, Basophile, Eosinophile, Monozyten und Makrophagen (Abb. 2). Eine Studie zur Transdifferenzierung zeigte, dass sich C-Kit positive HSCs nach Injektion in die Randzone infarzierter Mausherzen zu Kardiomyozyten, vaskulären endothelialen Zellen und glatten Muskelzellen entwickelten. Außerdem führten sie zu einer 60\%igen Regeneration des infarzierten Ventrikels und zu einer verbesserten Herzfunktion (Orlic et al. 2001). Eine weitere Studie demonstrierte, dass sich C-Kit positive HSCs in infarzierten Herzen effizient in Kardiomyozyten und Gefäße, aber nicht in hämatopoetische Zellen differenzieren (Kajstura et al. 2005). Obwohl diese Studien das Transdifferenzierungspotential von HSCs nachwiesen, wurde in anderen Studien gezeigt, dass transplantierte HSCs keinen kardialen Phänotyp erreichen, sondern nur in die hämatopoetische Richtung differenzieren (Balsam et al. 2004; Murry et al. 2004; Nygren et al. 2004). Die erzielten Resultate lassen sich eher mit Zellfusion als mit Transdifferenzierung erklären. Die Stammzellen haben in einer Studie das Verhalten von Muskelzellen angenommen, da sie mit nativen Muskelzellen fusioniert sind (AlvarezDolado et al. 2003; Beltrami et al. 2003; Nygren et al. 2004). In den letzten Jahren zeigten Studien mit verschiedenen Stammzelltypen, dass Transdifferenzierung (auch im Herzmuskel) selten stattfindet (Alvarez-Dolado et al. 2003; Oh et al. 2003).

MSCs können sich in Zellen mesenchymalen Ursprungs wie Osteoblasten, Knorpelzellen, Adipozyten und Skelettmuskelzellen differenzieren (Abb. 2). Humane MSCs können über einen längeren Zeitraum kultiviert werden und haben in vitro ein multipotentes Differenzierungspotential (Pittenger et al. 1999). 


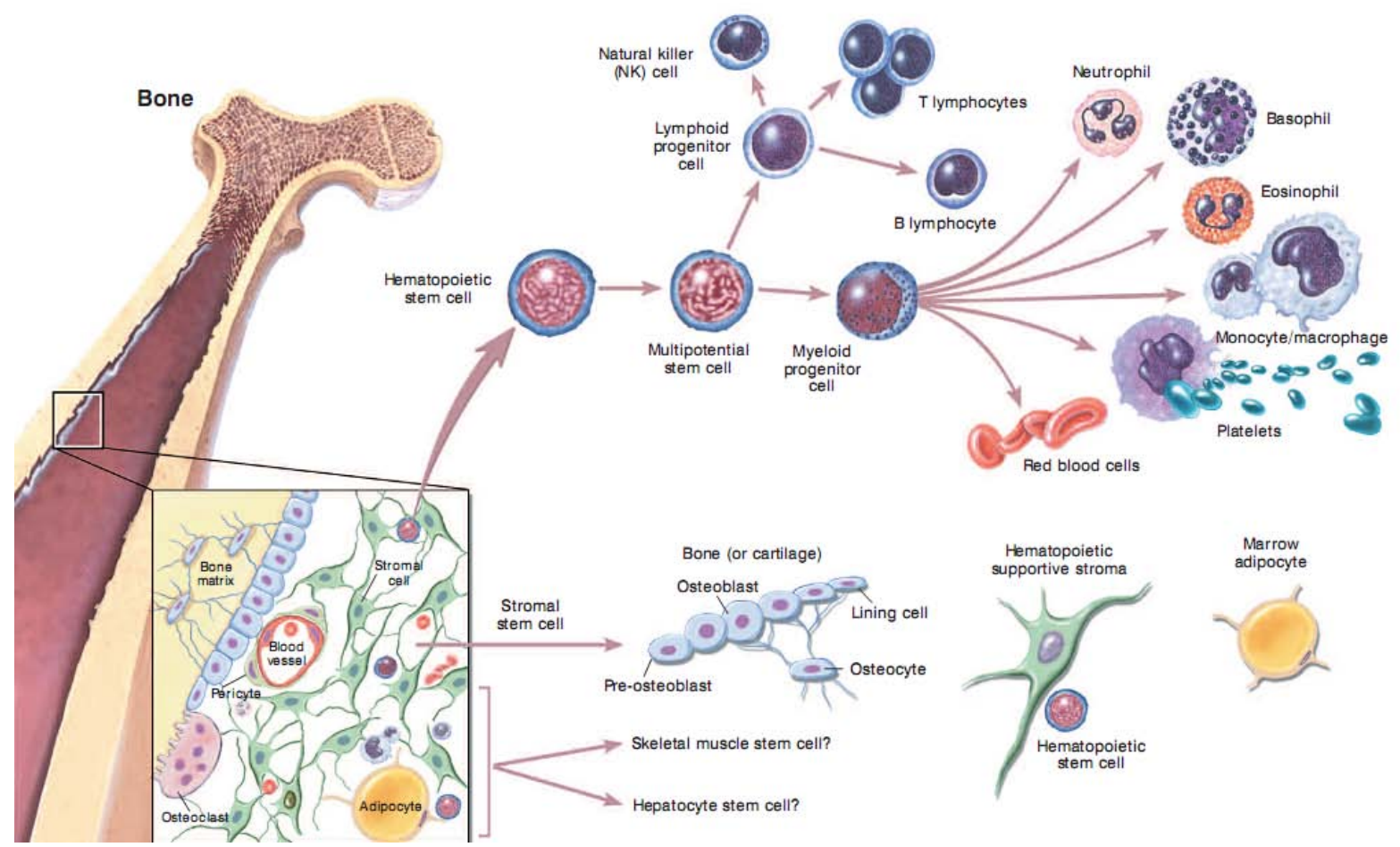

Abbildung 2: Differenzierung von hämatopoetischen und mesenchymalen Stammzellen aus dem Knochenmark. Die multipotenten hämatopoetischen Vorläuferzellen aus HSCs können sich zu myeloiden und lymphoiden Vorläufern entwickeln, aus denen z.B. Erythrozyten, Monozyten oder Bund T-Zellen entstehen. MSCs können sich u.a. zu Knochen-, Knorpel- oder Fettzellen entwickeln (http://stemcells.nih.gov/info/basics/basics4.asp).

Es gibt Hinweise, dass Stammzellen aus dem Knochenmark in den Kreislauf gelangen, zu zirkulierenden EPCs differenzieren und zur Neovaskularisation in adulten Tieren beitragen (Asahara et al. 1999). EPCs weisen endotheliale Markerproteine wie den vascular endothelial growth factor receptor -2 (VEGF-R2 oder fetal liver kinase, Flk1, human: KDR), den von Willebrand-Faktor (vWF) und die endothelial nitric oxide synthase (eNOS) auf (Gehling et al. 2000; Murohara et al. 2000). Einige in vitro-Studien zeigen, dass humane EPCs durch CoKultur mit neonatalen Rattenkardiomyozyten in funktionale Kardiomyozyten transdifferenzieren können (Badorff et al. 2003; Koyanagi et al. 2005b). Dieses Resultat konnte in einer anderen Studie mit ähnlichen Methoden nicht bestätigt werden (Gruh et al. 2006).

\subsubsection{Kardiale Stammzellen}

Lange Zeit dachte man, es gäbe keine Möglichkeit zur Reparatur im adulten Herzen, allerdings haben Studien der letzten Jahre gezeigt, dass residente Stammzellen im Herzen existieren, die sich zu den drei wichtigsten Zelltypen des Herzens differenzieren können: 
Kardiomyozyten, endotheliale Zellen und glatte Muskulatur (Beltrami et al. 2003; Oh et al. 2003; Martin et al. 2004; Messina et al. 2004; Laugwitz et al. 2005; Linke et al. 2005; Kattman et al. 2006; Moretti et al. 2006; Wu et al. 2006).

Beltrami et al. isolierten kardiale Stammzellen aus adulten Rattenherzen durch Verwendung eines Antikörpers gegen C-Kit (Beltrami et al. 2003). Diese C-Kit positiven Zellen waren negativ für hämatopoetische Marker und zeigten keine für Myozyten, Endothelzellen oder Fibroblasten typischen Proteine, exprimierten aber die kardialen Transkriptionsfaktoren Nkx2.5, GATA4 und Mef2. Diese kardialen Stammzellen konnten auch in humanen Herzen gefunden werden und in Patienten mit Aortenstenose und ischämischer Kardiomyopathie neue Kardiomyozyten hervorbringen (Urbanek et al. 2003; Dawn et al. 2005; Urbanek et al. 2005).

Eine weitere kardiale Stammzellpopulation konnte durch den Marker Sca-1 identifiziert werden (Oh et al. 2003). Diese Zellen exprimieren CD31, aber kein C-Kit, CD45 oder Flk1 und weisen nach einer Behandlung mit einem 5-Azacytidin ähnlichen Cytosin in vitro kardiale Marker auf.

Der Transkriptionsfaktor Islet1 (Isl1) kennzeichnet eine weitere kardiale Stammzellpopulation (Laugwitz et al. 2005; Moretti et al. 2006), die sich durch fehlende Expression von C-Kit oder Sca-1 von den oben beschriebenen Populationen unterscheidet (Abb. 3). Die Isl1 ${ }^{+}$Zellen können vollständig in die kardiale Richtung differenzieren, wenn sie mit neonatalen Kardiomyozyten co-kultiviert werden. Zellherkunftsstudien zeigten, dass Isl1 das zweite Herzfeld während der Herzentwicklung markiert (Cai et al. 2003). Verschiedene Studien demonstrierten, dass sich das Säugerherz während der Gastrulation aus zwei unterschiedlichen Vorläuferzellpopulationen bzw. Herzfeldern entwickelt (Kelly et al. 2001; Cai et al. 2003; Abu-Issa et al. 2004). Das erste Herzfeld (first heart field, FHF), das sich aus den frühesten Vorläuferzellen entwickelt, entspringt dem anterioren Mesoderm und formt das cardiac crescent, woraus Ventrikel und Atrien entstehen (Abb. 3, linke Spalte). Zellen aus dem cardiac crescent wandern medial und formen die lineare Herzröhre, die eine innere endokardiale und eine äußere myokardiale Schicht besitzt. Das ausgeformte Herz bildet sich durch rechtsgewundenes looping und Wachstum an den äußeren Polen (Buckingham et al. 2005). Aus dem pharyngealen Mesoderm entsteht eine weitere Gruppe von Vorläuferzellen, das zweite Herzfeld (second heart field, SHF) (Abb. 3). Zellherkunftsstudien belegen, dass das SHF vorrangig zum rechten Ventrikel und dem Ausstrom-Trakt beiträgt (Kelly et al. 2001; Cai et al. 2003; Laugwitz et al. 2005). 


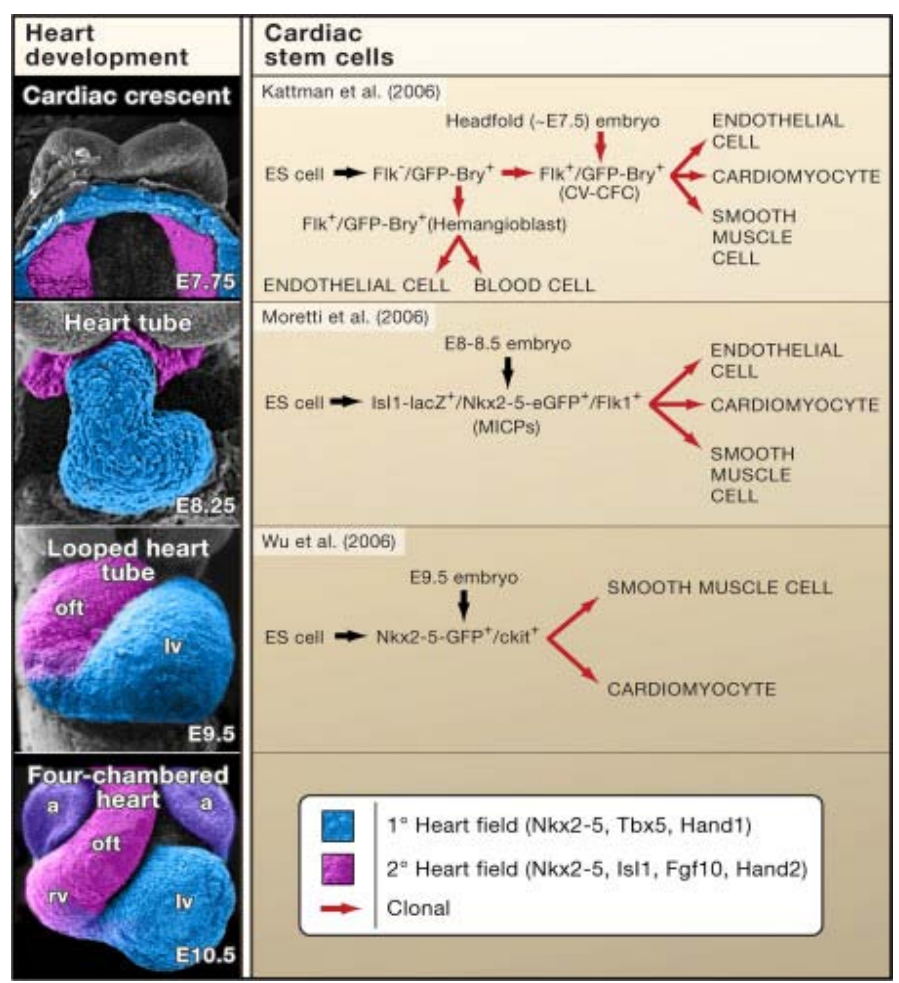

Abbildung 3: Herzentwicklung und kardiale Stammzellen in der Maus. Die verschiedenen Stadien und die dort vorkommenden kardialen Vorläufer/zellen werden gezeigt (Garry and Olson 2006). Links sind die murinen Herzstadien und die aus dem 1. und 2. Herzfeld entstehenden Bereiche mittels Elektronenmikroskopie zu sehen. Rechts werden die Charakteristika und ZelllinienVerbindungen der kardialen Progenitorzellen gezeigt, die in 3 Veröffentlichungen aus dem Jahr 2006 beschrieben wurden (Kattman et al. 2006) (oben), (Moretti et al. 2006) (Mitte) und (Wu et al. 2006) (unten).

Genetische Studien bewiesen, dass in den beiden Herzfeldern verschiedene Gene exprimiert werden. So findet man z.B. die Gene Bmp5, Bmp7 (Solloway and Robertson 1999), Nkx2.5 (Lints et al. 1993; Moses et al. 2001; Stanley et al. 2002), Mef2c (Edmondson et al. 1994) und Tbx20 (Carson et al. 2000; Kraus et al. 2001; Stennard et al. 2005) im FHF im cardiac crescent Stadium. In demselben Stadium werden dagegen im SHF Isl1 (Cai et al. 2003) und Fgf10 (Kelly et al. 2001) exprimiert.

Die Daten aus der Laugwitz-Arbeitsgruppe zeigten, dass aus $\mathrm{Isl1}^{+}$Zellen (hier multipotent Isl1 ${ }^{+}$cardiocasular progenitor cells (MICPs) genannt) Kardiomyozyten, vaskuläre endotheliale Zellen und glatte Muskelzellen entstehen (Laugwitz et al. 2005; Moretti et al. 2006). Isl1 ${ }^{+}$Zellen, die aus der Herzröhre von Mausembryonen (E8.0-8.5) isoliert und auf mesenchymalen Feederzellen kultiviert wurden, weisen Marker der 3 Herzzelltypen auf. Aus ES-Zellen stammende Isl1 ${ }^{+}$Vorläuferzellen (mit GFP am Nkx2.5 Lokus) entwickelten sich zu multipotenten Progenitorzellen, die neben Isl1 auch Nkx2.5 und Flk1 exprimierten (Abb. 3, rechte Spalte, 2. Zeile von oben). 
Die Gruppe um $\mathrm{Wu}$ isolierte eine kardial-spezifische $\mathrm{Nkx}_{2.5^{+}}$Zellpopulation aus Mausembryonen (Wu et al. 2006). Die meisten dieser Zellen differenzierten zu Kardiomyozyten. Durch in vitro-Experimente wurde gezeigt, dass ca. 25\% der Nkx2.5 Zellen auch C-Kit exprimierten. Diese Zellen konnten lange kultiviert werden und entwickelten sich zu Kardiomyozyten und glatten Muskelzellen. Wu et al. hatten somit die Existenz einer bipotenten Vorläuferzelle für die kardiovaskuläre Entwicklung im Säugerherzen nachgewiesen (Abb. 3, rechte Spalte, 2. Zeile von unten).

Kattman et al. zeigten, dass $\mathrm{Flk1}{ }^{-} / \mathrm{GFP}-\mathrm{Bry}^{+}$Progenitoren in vitro zwei verschiedene $\mathrm{Flk1}^{+} /$GFP-Bry $^{+}$Vorläuferzellen hervorbringen (Kattman et al. 2006). Die erste Gruppe verhält sich wie ein Hämangioblast und bringt Endothel- und Blutzellen hervor, während die andere Progenitorpopulation Kardiomyozyten, glatte Muskulatur und Endothelzellen erzeugt. Diese 2. Population exprimiert Flk1, Nkx2.5, GATA4 und Mef2c (Abb. 3, rechte Spalte oben).

Flk1, eine Rezeptor-Tyrosinkinase, steht für Fetale Leberkinase 1 oder VEGF-R2 (human: kinase domain region, KDR). Flk1 charakterisiert Hämangioblasten, die nicht anhand ihrer Morphologie identifiziert werden können, sondern durch die Marker, die sie exprimieren, z.B. CD34 (Fina et al. 1990; Young et al. 1995; Asahara et al. 1997), Bry und Flk1 (Millauer et al. 1993; Yamaguchi et al. 1993; Kabrun et al. 1997). Um das hämatopoetische und das vaskuläre Potential dieser Zellen $\mathrm{zu}$ untersuchen, wurden u.a. in vitro Differenzierungsversuche mit mES-Zellen (Huber et al. 2004) und fate mapping-Experimente im Zebrafisch durchgeführt (Vogeli et al. 2006). Flk1 markiert Progenitorzellen mit einem großen mesodermalen Spektrum (Ema et al. 2006). Lange Zeit wurde angenommen, dass Flk1 vor allem in endokardialen Zellen exprimiert wäre, dann aber wurde gezeigt, dass das VEGF/Flk1-Signal auch die embryonale Entwicklung der kardialen Muskulatur beeinflusst (Takahashi et al. 1999). In lineage-tracing-Studien konnte nachgewiesen werden, dass Flk1 ${ }^{+}$ Vorläuferzellen sich zu Kardiomyozyten und vaskulären Endothelzellen differenzieren können (Motoike et al. 2003; Coultas et al. 2005). Die äußerst wichtige Rolle der VEGF/Flk1Signalübertragung während der kardiovaskulären Entwicklung zeigt sich auch daran, dass Flk1-Knockout Embryonen im 6-8 Somitenpaar-Stadium sterben (Shalaby et al. 1995). In diesen Tieren können sich die mesodermalen und endodermalen Vorläuferzellen nicht weiter differenzieren.

Daten aus Kattmans Labor zeigen, dass cardiovascular colony-forming cells (CV-CFC), die in klonalen Kolonien exklusiv Tbx5 und Isl1 exprimieren, das FHF und das SHF hervorbringen (Kattman et al. 2006). Diese Ergebnisse unterstützen die Schlussfolgerungen, 
dass die beiden Herzfelder aus einem gemeinsamen Vorläufer mit endothelialem Potential entstehen und sich früh in der Entwicklung trennen (Meilhac et al. 2004). Es war möglich, aus Mausembryonen CV-CFC zu isolieren und zu kultivieren, die Marker von endothelialen Zellen, glatten Muskelzellen und kardialen Zellen aufwiesen. Diese und andere Studien (Huber et al. 2004; Ema et al. 2006) unterstützen die Hypothese, dass die Flk1-Expression eine mesodermale Progenitorpopulation kennzeichnet, die sich auch in Kardiomyozyten differenzieren kann. Es ist bereits gelungen, Flk1 ${ }^{+}$Zellen aus murinen ES-Zellen (Christoforou et al. 2008) und iPS-Zellen (Narazaki et al. 2008) zu generieren und sie in kardiovaskuläre Zellen zu differenzieren. Die Induktion einer KardiomyozytenDifferenzierung wurde in der iPS-Studie über eine Co-Kultur mit OP9-Stromazellen durchgeführt.

\subsubsection{Adulte Keimbahnstammzellen}

Während der frühen Embryonalentwicklung findet die Trennung zwischen Keimbahnzellen und somatischen Zellen statt. Im Mausembryo induzieren bone morphogenetic protein (BMP)-Signale eine Zellpopulation von etwa 20 Zellen zu Urkeimzellen, den sogenannten primordial germ cells (PGCs). Diese Zellen entwickeln sich außerhalb des eigentlichen Embryos im extraembryonalen Gewebe und wandeln mittels amöboider Fortbewegung in die Region der Genitalleisten ein. Hier verweilen sie während der Gonadenentwicklung. Aus den wenigen PGCs ist durch mitotische Teilungen ein Pool an Keimbahnstammzellen entstanden. Männliche Keimbahnstammzellen, auch spermatogoniale Stammzellen (spermatogonial stem cells, SSCs) genannt, führen fortlaufend zur Produktion motiler Spermien und liegen an der Basalmembran der Hodentubuli. Der Anteil der SSCs an allen Zelltypen im Hoden ist sehr gering und beträgt ca. 0,02-0,03\% (Tegelenbosch and de Rooij 1993).

Veröffentlichungen der vergangenen Jahre zeigten eine hohe Plastizität der SSCs. Im Jahr 2004 konnten erstmals aus den Testes neonataler Mäuse isolierte SSCs in vitro in pluripotente Stammzellen reprogrammiert werden (Kanatsu-Shinohara et al. 2004). Bereits 2 Jahre später gelang es, SSCs aus adulten Maushoden zu gewinnen und sie in der Zellkultur so zu behandeln, dass sich aus ihnen multipotente Zellen mit den Eigenschaften von ES-Zellen entwickelten (Guan et al. 2006). Diese Zellen wurden als maGSCs (multipotent adult germline stem cells) bezeichnet. In dieser Studie konnte gezeigt werden, dass sich maGSCs in Zelltypen aller drei Keimblätter ausdifferenzieren und Teratome in immundefizienten Mäusen generieren können. Aus den maGSCs konnten mittels spezifischer Differenzierungsprotokolle 
funktionelle Kardiomyozyten (Guan et al. 2007) und neuronale Zellen (Streckfuss-Bomeke et al. 2009) entstehen. Dass die murinen SSCs spontan in ES-Zell-ähnliche Zellen konvertiert werden können, zeigten weitere unabhängige Arbeitsgruppen (Seandel et al. 2007; Ko et al. 2009).

Auch die Isolierung und Reprogrammierung humaner SSCs und ihrer Progenitorzellen zu pluripotenten Stammzellen ist von mehreren Gruppen publiziert worden (Mizrak et al.; Conrad et al. 2008; Golestaneh et al. 2009; Kossack et al. 2009). Inzwischen wird allerdings die Pluripotenz der human adult germline stem cells (haGSCs) von Conrad et al. in Frage gestellt (Ko et al. 2010). Es wurden Genexpressionsanalysen durchgeführt um Pluripotenzmarker in haGSCs, hES-Zellen und Fibroblasten (auch aus anderen Laboren) zu vergleichen. Dabei stellte sich heraus, dass das Genexpressionsmuster der haGSCs eher dem von Fibroblasten als dem von hES-Zellen ähnelt.

Ein Vorteil von adulten Keimbahnstammzellen und aus denen entwickelte Progenitorzellen ist die nicht mehr vorhandene ethische Problematik, da zu ihrer Gewinnung keine Embryonen zerstört werden müssen. Außerdem ist es durch ihre Verwendung möglich, autologe Vorläuferzellen herzustellen und so bei einer späteren Therapie eine Immunabstoßungsreaktion zu umgehen. Allerdings würden bislang nur Männer von dieser möglichen Keimbahnzell-Therapie profitieren. Bisher stehen Verfahren zur Etablierung humaner SSCs und einer SSC-Zelllinie noch aus, die essentiell wären, um humane SSCs zu charakterisieren und ihre Pluripotenz weiter zu untersuchen. Eine Therapie mit humanen SSCs ist derzeit nicht möglich.

\subsubsection{Künstlich reprogrammierte Stammzellen}

Als iPS-Zellen bezeichnet man pluripotente Stammzellen, die durch künstliche Reprogrammierung von nicht-pluripotenten somatischen Zellen entstanden sind. Verschiedene Techniken ermöglichen die Umwandlung der Körperzelle durch von außen angeregte Expression spezieller Gene (Pluripotenz-spezifische Transkriptionsfaktoren). Die iPS-Zellen teilen viele Eigenschaften mit natürlichen ES-Zellen und besitzen hohes medizinisches Potential, da die Forschung an ihnen weniger ethische Probleme aufwirft als die an ES-Zellen. Nachdem 2006 im Labor von S. Yamanaka die ersten iPS-Zellen hergestellt wurden (Takahashi and Yamanaka 2006), ist die Forschung an iPS-Zellen heute einer der sich am schnellsten entwickelnden Bereiche der biologisch-medizinischen Forschung. Es wurde die Hypothese aufgestellt, dass Gene, die in ES-Zellen eine besonders wichtige Rolle spielen, 
auch in der Lage sein könnten, eine somatische Zelle in einen pluripotenten Zustand zurückzuversetzen. Die Reprogrammierung verschiedener Zelltypen in einen pluripotenten Zustand wurde mittels der Kombination der vier Schlüsselgene $c-M y c$, Klf4, Oct4 und Sox2 möglich (Takahashi and Yamanaka 2006; Maherali et al. 2007; Okita et al. 2007; Wernig et al. 2007; Hochedlinger and Plath 2009).

Mehrere Forschergruppen erzeugten bisher iPS-Zellen aus humanen somatischen Zellen (Takahashi et al. 2007; Yu et al. 2007; Park et al. 2008), deren Pluripotenz durch erfolgreiche Differenzierung in Zellen aller drei Keimblätter bestätigt wurde. In der Studie von Yu et al. wurde für die Reprogrammierung statt der vier Pluripotenzgene von Yamanaka eine andere Kombination von Genen eingesetzt: NANOG, LIN28, OCT4 und SOX2. Dadurch wird der Verzicht auf c-Myc möglich, welches ein bekanntes Onkogen ist und daher ein enormes Risiko für medizinische Anwendungen darstellt.

Bei anderen Verfahren zur Reprogrammierung wurden Adeno- statt Retro- oder Lentiviren (Stadtfeld et al. 2008) oder Plasmide (Okita et al. 2008) als Vektoren verwendet, um Pluripotenzgene in die Zelle zu schleusen. Im Jahr 2009 gelang es Forschern, sogenannte Protein-induzierte pluripotente Stammzellen durch das Einbringen von rekombinanten Proteinen zu erzeugen (Zhou et al. 2009). Durch diese alternativen Methoden, die das Genom der Empfängerzelle nicht dauerhaft verändern, erreicht man jedoch eine niedrigere Effizienz als mit der stabilen Transfektion durch die ursprünglichen vier Pluripotenzgene.

Außerdem ist die Erzeugung Patienten-spezifischer iPS-Zellen (ps-iPS-Zellen) möglich. Bisher ist dies z.B. bei Patienten mit Amyotropher Lateralsklerose, Spinaler Muskelatrophie und Diabetes Typ1 (Dimos et al. 2008; Ebert et al. 2009; Maehr et al. 2009) gelungen. Diese Zellen wären hilfreich, um Krankheitsmodelle und Therapiemöglichkeiten noch besser untersuchen zu können. Mit Hilfe der ps-iPS wäre es in Zukunft möglich für jeden Patienten autologe Stammzellen zu generieren. Somit scheint sich für die medizinische Forschung eine Alternative zur Nutzung der ethisch umstrittenen ES-Zellen aufzuzeigen.

\subsection{Zellbasierte Therapie bei Herzerkrankungen}

Bereits 1999 wurde gezeigt, dass fetale Kardiomyozyten im normalen und im verletzten Rattenmyokard vitale Transplantate formen können (Reinecke et al. 1999). Allerdings ist die Forschung mit fetalen Kardiomyozyten limitiert, da ihre Gewinnung ethisch problematisch ist, und sie nach der Geburt nicht mehr zur Verfügung stehen. Daher wurden auch Skelettmuskelzellen, die aus Myoblasten bestehen, und Myoblasten für die kardiale Therapie 
eingesetzt. Wurden Myoblasten in herzkranke Nager und Schafe transplantiert, zeigten sich eine Funktionsverbesserung des Herzens und ein vermindertes Remodeling (Murry et al. 1996; Taylor et al. 1998; Ghostine et al. 2002). Allerdings synchronisierten die transplantierten Myoblasten nicht mit dem Empfängermyokard, d.h. es fand keine elektrophysiologische Kopplung zwischen transplantierten Myoblasten oder Skelettmuskelzellen und den natürlichen Kardiomyozyten statt (Reinecke and Murry 2000; Reinecke et al. 2002; Leobon et al. 2003; Abraham et al. 2005). Aufgrund der nachgewiesenen Herzfunktionsverbesserung wurden Myoblasten auch in klinischen Studien angewandt, allerdings mit wenig Erfolg. Die Myoblasten überlebten zwar im humanen Myokard, hatten aber nur einen geringen oder keinen positiven Einfluss auf die Herzfunktion (Herreros et al. 2003; Dib et al. 2005; Siminiak et al. 2005; Menasche et al. 2008). In einigen Studien mit Myoblasten zeigten sich hohe Raten an ventrikulären Arrhythmien und plötzliche Herztodesfälle, was sich eventuell durch das unterschiedliche Membranpotential der Spenderund Empfängerzellen erklären lässt (Leobon et al. 2003). Aufgrund der Limitierung der fetalen Kardiomyozyten und der aufgetretenen Probleme nach Transplantationen von Myoblasten wurde nach weiteren Quellen für zellbasierte kardiale Therapien gesucht.

\subsubsection{Knochenmarkzellen-basierte Therapien}

Bis zum Jahr 2006 wurden vier unabhängige randomisierte Studien mit autologen Knochenmarkvorläuferzellen an acute myocardial infarction (AMI) Patienten veröffentlicht. Die BOOST-Studie war die erste randomisierte Studie, die zeigte, dass 6 Monate nach der Stammzell-Behandlung eine Funktionsverbesserung des linken Ventrikels auftritt (Wollert et al. 2004). In zwei weiteren Studien zeigten sich eine Funktionsverbesserung des linken Ventrikels und eine Reduktion der Infarktgröße nach Aspiration von Knochenmarkzellen (Janssens et al. 2006; Schachinger et al. 2006a). Auch nach 1 Jahr wurden diese positiven Effekte in den post-AMI-Patienten bestätigt (Schachinger et al. 2006b). Auch MSCs aus dem Knochenmark zeigten zuerst in vorklinischen Infarktstudien an Mäusen eine verbesserte linksventrikuläre Funktion (Tomita et al. 1999; Dai et al. 2005; Shiota et al. 2007), später ebenfalls in einer klinischen Studie an 69 Herzinfarktpatienten (Chen et al. 2004).

In der norwegischen randomisierten ASTAMI-Studie unterschieden sich Zellisolation und Charakterisierungsprotokolle von den oben genannten Studien. Hier wurde bei den 100 postAMI-Patienten keine Verbesserung der Herzfunktion festgestellt (Lunde et al. 2006). Neuere randomisierte Studien begutachten nicht nur den Effekt der Knochenmarkzellen, sondern 
wenden u.a. auch eine Thrombolyse an. Die FINKELL-Studie umfasst 80 Patienten mit STEMI (ST-segment elevation myocardial infarction), deren Thrombose behandelt und denen vor Gabe der Zellen ein Stent eingesetzt wurde (Huikuri et al. 2008). Diese Studie belegt die Sicherheit der Knochenmark-Stammzellen und zeigt eine Verbesserung der linksventrikulären Ejektionsfraktion. In der multizentrischen REGENT-Studie, die 200 AMI-Patienten umfasste, zeigten sich nach 6 Monaten keine signifikanten Verbesserungen (Tendera et al. 2009).

Zusammenfassend lässt sich sagen, dass diese Studien, die mit den in vivo- und in vitro-Daten aus vorherigen Arbeiten (vor allem aus Tiermodellen) korrelieren, die Sicherheit und Anwendbarkeit von Knochenmark-Stammzellen in AMI und/oder ischämischen Patienten zeigen. Allerdings ist eine signifikante und zellbasierte Funktionsverbesserung des Herzens noch nicht bewiesen. Daher war und ist es sinnvoll, nach alternativen Quellen für zellbasierte Regenerationstherapien zu suchen.

\subsubsection{Therapien mit murinen und humanen pluripotenten Stammzellen}

Tierstudien zeigen, dass transplantierte undifferenzierte ES-Zellen in normalen Herzen nur zwei Wochen verbleiben, wohingegen sie in Myokardinfarkt (MI)-Herzen in alle drei großen Herzzelltypen differenzieren: Kardiomyozyten, Endothelzellen und vaskuläre glatte Muskelzellen (Behfar et al. 2002; Min et al. 2002; Hodgson et al. 2004; Singla et al. 2006). Allerdings treten auch Teratome nach Transplantation von undifferenzierten mES-Zellen auf. Daher war es wichtig, die mES-Zellen vorzudifferenzieren und reine Vorläuferzellen zu generieren, um sie für eine zelluläre Therapie nutzen zu können. Die erste Studie zur Prädifferenzierung und Reinheit von mES-Zell-Kardiomyozyten vor der Transplantation ins Mausherz wurde von Loren Fields Labor veröffentlicht (Klug et al. 1996). Hierbei wurden mES-Zellen mit einem fusionierten Gen, das den aMHC-Promotor und die cDNA der Aminoglykosid-Phosphotransferase enthielt, stabil transfiziert. Nach in vitro Differenzierung und einer G418-Selektion lagen sehr reine Kardiomyozyten-Kulturen vor. Wurden diese selektierten Kardiomyozyten in Herzen adulter dystrophischer Mäuse transplantiert, konnten sie noch bis zu 7 Wochen nach Transplantation detektiert werden.

Auch hES-Zellen waren Gegenstand der Forschung, um regenerative Therapiemöglichkeiten zu entwickeln. Jedoch können hES-Zellen nach Transplantation in Versuchstiere Tumore bilden, so dass vor einer klinischen Anwendung gewährleistet sein muss, dass die Transplantate keine undifferenzierten hES-Zellen mehr enthalten. Außerdem ist es möglich, dass transplantierte ES-Zellen zu Arrhythmien führen (Zhang et al. 2002). 
In verschiedenen Studien wurde gezeigt, dass Kardiomyozyten, die aus hES-Zellen generiert wurden, nach der Transplantation in Schweineherzen (Kehat et al. 2004) und Rattenherzen (Laflamme et al. 2005) überlebten, funktional integrierten und in den Rattenherzen auch humanes Myokardium bildeten. In MI-Mausmodellen konnte ein positiver Effekt auf die Herzfunktion nach Transplantation von Kardiomyozyten, die aus hES-Zellen generiert wurden, in das verletzte Myokard nachgewiesen werden (Caspi et al. 2007; Laflamme et al. 2007; Leor et al. 2007). Allerdings wurden in einer dieser Studien auch Teratombildung und fehlende Integration der transplantierten Kardiomyozyten ins Empfängergewebe beobachtet (Leor et al. 2007). Neueste Entwicklungen auf dem Gebiet der Gewebekonstruktion (Tissue Engineering) könnten helfen, diese aus hES-Zellen gewonnenen Kardiomyozyten besser funktional zu integrieren (Stevens et al. 2009). Wurden zu diesen Kardiomyozyten noch vaskuläre und stromale Komponenten zugefügt, verbesserte sich die Überlebensfähigkeit der Gewebetransplantate.

Bisher wurde erst eine Studie veröffentlicht, in der undifferenzierte humane iPS-Zellen in infarzierte Mausherzen transplantiert wurden und zu einer verbesserten Herzfunktion führten (Nelson et al. 2009).

Zusammenfassend lässt sich also sagen, dass pluripotente Stammzellen ein großes Potential für zellbasierte Therapien haben, vor allem die hES-Zellen zeigten aussichtsreiche Resultate bezüglich der Regeneration von geschädigtem Herzgewebe (Goh et al. 2005; Capi and Gepstein 2006). Allerdings bestehen noch viele ethische und klinische Probleme in Bezug auf hES-Zellen, die gelöst werden müssen. Die bisher gewonnenen Ergebnisse bedürfen noch einer strengen Überprüfung, so dass im Gegensatz zu den adulten Stammzellen ein klinischer Einsatz noch nicht möglich ist (Passier and Mummery 2003). Ein wichtiger Punkt ist auch die immunologisch bedingte Abstoßung von Transplantaten durch den Empfänger. Diese Probleme veranlassen Forscher nach weiteren Quellen für zellbasierte Therapien, wie z.B. Vorläuferzellen, zu suchen und sie für die regenerative Medizin nutzbar zu machen. Die maGSCs wurden allerdings bisher noch nicht hinreichend untersucht, um sie in einer zellbasierten Therapie einzusetzen.

Es wäre also ein großer Vorteil für stammzellbasierte Therapien, „ausbalancierte“ Vorläuferzellen zu generieren. Diese Population sollte sich noch in einige Zelltypen differenzieren können, aber keine undifferenzierten Zellen mehr enthalten, die Teratome hervorrufen können. Eine mögliche Zellpopulation zur therapeutischen Anwendung stellen die Flk1 ${ }^{+}$Zellen dar, deren kardiovaskuläres Potential sowohl in vitro als auch in vivo gezeigt wurde (Coultas et al. 2005; Kattman et al. 2006; Yang et al. 2008; Iwasa et al. 2010). Aus 
hES-Zellen gewonnene $\mathrm{KDR}^{+}$Zellen zeigten in vitro und in vivo kardiovaskuläres Potential (Yang et al. 2008). In einer aktuellen Studie konnte beobachtet werden, dass Flk1 ${ }^{+}$ multipotente Keimbahnstammzellen aus neonatalen Maushoden nach Injektion in MI-Mäuse zu einer Funktionsverbesserung des Herzens beitragen (Iwasa et al. 2010).

\subsubsection{Therapien mit kardialen Stammzellen und Vorläuferzellen}

Multipotente C-Kit positive kardiale Stammzellen exprimieren die kardialen Transkriptionfaktoren Nkx2.5, GATA4 und Mef2c (Beltrami et al. 2003). Wurden die Zellen in ischämische Herzen injiziert, formten sie Blutgefäße, und die ventrikuläre Funktion war verbessert. Ratten, die nach einem MI intravaskulär kardiale Stammzellen erhielten, zeigten eine verbesserte linksventrikuläre Funktion nach fünf Wochen. Außerdem verringerte sich die Infarktgröße um 29\%, so dass von einer induzierten Myokardregeneration durch die kardialen Stammzellen ausgegangen wurde (Dawn et al. 2005). Eine Studie, bei der Patienten mit Aortenstenose C-Kit ${ }^{+}$kardiale Stammzellen transplantiert wurden, zeigte, dass sich die Zahl dieser Stammzellen 13fach erhöhte (Urbanek et al. 2003). Es konnten Zellcluster mit kardiogenen Vorläuferzellen beobachtet werden, die in Kardiomyozyten differenzierten. Wachstum und Differenzierung dieser Progenitoren waren durch Hypertrophie erhöht. Dieselbe Gruppe untersuchte die Wirkung aktivierter kardialer Stammzellen in MI-Patienten, wobei sich die Anzahl der Stammzellen in den MI-Patienten stark erhöht zeigte (Urbanek et al. 2005). Stammzellen, die sich in Kardiomyozyten, Endothel- oder glatte Muskelzellen differenzieren waren 85fach verstärkt zu finden. In 35\% der akuten MI-Herzen konnte eine (nicht durch Fusion entstandene) Myokardregeneration beobachtet werden.

Eine weitere Studie zeigte, dass sich Sca-1 positive Vorläuferzellen aus adulten Herzen nach intravenöser Applikation im Myokard von MI-Mäusen ansiedeln (Homing) und Kardiomyozyten generieren konnten (Oh et al. 2003).

SP-Zellen, die sich im Knochenmark befinden (Goodell et al. 1996), sind stark positiv für Sca-1, aber nur schwach positiv für C-Kit, CD34 und CD45 (Martin et al. 2004). In den kardialen SP-Zellen besaß die CD31 negative und Sca-1 positive Population das größte kardiomyogene Potential (Pfister et al. 2005). Nach Transplantation in MI-Mäuse fanden Neovaskularisierung, Kardiomyozytenregeneration und eine verbesserte Herzfunktion statt (Wang et al. 2006). 


\subsection{Die Wirkung mechanischer Last auf Stammzellen in vitro und in vivo}

Mechanischer Stress spielt eine bedeutende Rolle bei der Regulation physiologischer Prozesse. Davon betroffen sind z.B. die Reifung der fetalen Lunge (Liu and Post 2000), die Entwicklung der Herzkammern, Vorhöfe und Blutgefäße (Ingber 2002), mikrovaskuläres Remodeling (Skalak and Price 1996) oder die Reifung von Knochen (Turner et al. 1995) und Knorpel (Grodzinsky et al. 2000).

Da die hämodynamische Kraft im Herzen ein wichtiger Regulator der Herzfunktion, Genexpression und des Phänotyps ist (Scheuermann-Freestone et al. 2001), identifizierte man spezifische Strukturen, die von der hämodynamischen Kraft beeinflusst werden und stellte fest, dass durch Beeinflussung oder Dilatation dieser Strukturen kardiale Dysfunktionen und Krankheiten entstehen können ( $\mathrm{Hu}$ et al. 2003). Es lassen sich zwei Arten von Last unterscheiden, die Vor- und die Nachlast. Als Vorlast wird diejenige Kraft bezeichnet, die am Ende der Diastole zur Dehnung der Kardiomyozyten führt. Nimmt der venöse Füllungsdruck beim Anstieg der Vorlast zu, werden die Herzkammern diastolisch stärker gefüllt und die Muskulatur stärker gedehnt, was zu einer erhöhten Kontraktion mit Zunahme des Schlagvolumens führt (Frank-Starling-Mechanismus). Zusätzlich werden Proteine wie Titin und assoziierte Moleküle gestretcht, was Auswirkungen auf die myokardiale Elastizität und Genexpression hat (Schmidt et al. 2000). Die Nachlast ist eine myokardiale Kraft, an der alle Kardiomyozyten beteiligt sind und die dem Blutauswurf aus den Ventrikeln in den Blutkreislauf entgegenwirkt. Eine Erhöhung der Nachlast bewirkt eine erhöhte Wandbelastung und wirkt sich dadurch direkt auf die jeweilige Herzkammer aus. Eine Nachlast-vermittelte konzentrische Hypertrophie hat, vom hämodynamischen Standpunkt aus gesehen, einen förderlichen Effekt, da der Stress durch die erhöhte Wanddicke nach dem Gesetz von Laplace kompensiert wird (James et al. 2000). Im Gegensatz dazu hat die Vorlastvermittelte exzentrische Hypertrophie einen maladaptiven Effekt, da hier die Wandbelastung nicht kompensiert wird. Eine veränderte Proteinexpression während der Hypertrophie scheint ein wichtiger Punkt beim Entstehen einer Herzschwäche zu sein (Nakajima et al. 2006).

Bei der Shunt-Operation (auch Aortocavales-Fistel-Modell genannt) wird eine Volumenüberlast und damit eine Vorlast induziert, während bei der TAC-Operation (transaortic constriction, auch banding genannt) durch eine Aortenstenose eine Erhöhung des Volumens und eine Nachlast induziert wird. Shunt- und TAC-Operationen sind standardisierte Methoden um Vor- und Nachlast in vivo im Tiermodell auszulösen und führen letztlich zu hypertrophen Herzen. 
Zahlreiche Studien belegen, dass sich Signalwege und Genexpression während der Erhöhung der Last am Herzen ändern (Sun et al. 2007; Yan et al. 2008; Sheehy et al. 2009; Dias et al. 2010; Faerber et al. 2010; Nakayama et al. 2010; Tang et al. 2010; Teekakirikul et al. 2010; van Berlo et al. 2010). Die Ergebnisse einer aktuellen Studie zeigen, dass die exzentrische Hypertrophie in den Shunt-operierten Mäusen positivere Effekte hat, als die konzentrische Hypertrophie der TAC-operierten Mäuse, die mit mehr Entzündung, Fibrose und Kardiomyozytenapoptose einhergeht (Toischer et al. 2010). Im Shunt-Modell wird Akt aktiviert, während sich im TAC-Modell der Calcium-Zyklus ändert und die Calcium/Calmodulin-abhängige Proteinkinase II (CaMKII) aktiviert wird. Beide Mechanismen, Vor- und Nachlast, beeinflussen lastabhängige Ionenkanäle und intrazelluläre Ionenkonzentrationen und damit die kardiale Funktion und Genexpression (El-Armouche et al. 2008). Durch mechanische Dehnung werden Stretch-aktivierte Ionenkanäle angeregt (Hu and Sachs 1997) und Wachstumsfaktoren wie Endothelin-1, TGF-ß und VEGF aus dem Myokard exprimiert und sezerniert. Dadurch werden para- und autokrine Signale zur Verfügung gestellt (Loennechen et al. 2001; van Wamel et al. 2002; Tomanek et al. 2004).

Studien zeigen, dass VEGF eine wichtige Rolle in der Regulation des Myokards spielt, wenn es hämodynamischen Kräften wie z.B. Drucküberlast ausgesetzt ist (Mandinov et al. 2003; Elsherif et al. 2004). Außerdem wurde nachgewiesen, dass VEGF die Differenzierung von mES-Zellen über den Erk-vermittelten Flk1-Signalweg in Richtung Kardiomyozyten stimuliert (Chen et al. 2006). Es ist bisher nicht bekannt, welchen Einfluss Shunt- oder TACOperationen auf transplantierte pluripotente Stammzellen ausüben.

Verschiedene Studien zeigen, dass sich Zellen durch mechanische Last beeinflussen lassen. Mechanischer Stress wird über Integrine oder zytoskeletale Proteine in biochemische Signale umgewandelt und löst somit Signalwege zur schnelleren Proteinsynthese oder zur GenUmprogrammierung in kultivierten Kardiomyozyten, glatten Muskel- oder Endothelzellen aus (Ingber 2002; Sugden 2003; Han et al. 2004).

Bisher wurden einige Studien veröffentlicht, die einen Effekt mechanischer Last auf die Festlegung undifferenzierter Stammzellen in die kardiale oder vaskuläre Linie und die folgende Differenzierung in kardiale oder vaskuläre Zellen zeigen. Nach statischer Dehnung von mES-Zellen war die Anzahl schlagender Zellen in generierten EBs erhöht und die Genexpression durch die Aktivierung von ROS verändert (Schmelter et al. 2006). So wurde in den Zellen nach Dehnung eine erhöhte Expression von HIF-1 $\alpha$, VEGF, Mef2c und GATA4 beobachtet, was auf eine Differenzierung in die kardiovaskuläre Richtung deutet. Die Applikation von Scherkräften bewirkte in mES-Zellen eine Induktion der frühen kardialen, 
glatten Muskulatur und vaskulären Marker wie Flk1, SMA, Mef2c und PECAM (Illi et al. 2005). Murine Flk1 ${ }^{+}$ES-Zellen konnten sich durch Einwirkung von Scherkräften in vaskuläre endotheliale Zellen differenzieren (Yamamoto et al. 2005). Zyklische Dehnung von hESZellen führte zu einem inhibierten Differenzierungspotential und vermehrter Selbsterneuerung (Saha et al. 2006). Die Frequenz der Dehnung hatte keinen Einfluss auf die Differenzierung der hES-Zellen.

Mehrere Studien belegen die Effekte mechanischer Aktivierung auf die Reifung von Kardiomyozyten-ähnlichen Zellen, die aus ES-Zellen differenziert wurden (Guo et al. 2006; Gwak et al. 2008; Shimko and Claycomb 2008). Gwak et al. verwendeten mES-Zellen, selektierten die differenzierten MHC, GATA4 und Nkx2.5 exprimierenden und schlagenden Kolonien und plattierten sie auf speziell beschichtete Platten. Diese wurden über zwei Wochen bei $10 \%$ Dehnung bei einer Frequenz von $1 \mathrm{~Hz}$ gedehnt. Die gedehnten Zellen zeigten eine höhere Expression kardialer Marker als die ungedehnten Kontrollen. Jene Zellen integrierten gut ins Myokard von infarzierten Rattenherzen und schlugen synchron im Gegensatz zu den nicht gedehnten Zellen. Außerdem war in den Rattenherzen mit gedehnten Zellen weniger Fibrose und Apoptose, dafür mehr Angiogenese zu erkennen.

Embryonale Kardiomyozyten der Wachtel, die auf einem flexiblen Substrat kultiviert wurden, schlugen anschließend sehr gut bei einer Frequenz von $1 \mathrm{~Hz}$, während das Schlagen durch eine Kultivierung auf einem starren Untergrund inhibiert wurde (Engler et al. 2008).

Es gibt zwar Belege dafür, dass die Dehnung von Zellen einen Einfluss auf ihre Differenzierung und Entwicklung hat, aber die Mechanismen, über die die mechanische Last undifferenzierte Stammzellen zur Differenzierung in kardiale Zellen stimuliert sind noch nicht vollständig untersucht. 


\subsection{Ziele dieser Arbeit}

Das Ziel der vorliegenden Arbeit war es, herauszufinden, ob maGSCs in der Lage sind zur Herzregeneration beizutragen. Um dies zu untersuchen, wurden undifferenzierte maGSCs in vivo in normale sowie Shunt- oder TAC-operierte Mausherzen von Ciclosporin A immunsupprimierten Mäusen injiziert. Dabei sollte untersucht werden, ob maGSCs durch mechanische Last zur Differenzierung stimuliert werden können. In vivo sollte also in Mäusen, in denen eine erhöhte Vor- oder Nachlast durch Shunt- bzw. TAC-Operationen hervorgerufen wurde, das Verhalten und Schicksal von maGSCs untersucht werden. Es wurde überprüft, ob sich sich die Zellen im überlasteten Herzen ansiedeln, proliferieren oder differenzieren.

Außerdem wurden die undifferenzierten maGSCs in vitro auf BioFlex-Membranen gedehnt und mittels RT-PCR und Durchflusszytometrie analysiert.

Weiterhin sollten undifferenzierte maGSCs in das Myokard immundefizienter Mäuse injiziert werden, die mit oder ohne Ciclosporin A behandelt wurden, um nachzuweisen, welche Eigenschaften die maGSCs in diesen Mäusen haben und wie man sie beeinflussen kann.

Ein weiteres Ziel dieser Arbeit war es, maGSCs in bestimmte, Flk1 ${ }^{+}$kardiovaskuläre Progenitorzellen zu differenzieren und diese Zellen mittels immunchemischer und molekularbiologischer Methoden zu untersuchen, um zu erkennen, welche Merkmale diese Zellen besitzen und wie sie sich weiter differenzieren. Um Flk1 ${ }^{+}$Zellen zu gewinnen, wurde eine Differenzierung via Co-Kultur mit OP9-Stromazellen verwendet. 


\section{Material und Methoden}

\subsection{Material}

\subsubsection{Versuchstiere}

Es wurden weibliche C57BL/6 Mäuse (Alter: 10-12 Wochen) aus der Zentralen tierexperimentellen Einrichtung (ZTE) der Universitätsmedizin Göttingen und von der Firma Janvier und weibliche RAG2 ${ }^{-/-} \operatorname{cgc}^{-/-}$Mäuse (Alter: 10-11 Wochen) (Rideout et al. 2002), zur Verfügung gestellt von Prof. Dr. Dressel aus der Abteilung Zelluläre und molekulare Immunologie der Universitätsmedizin Göttingen, verwendet. Die immundefizienten RAG2 ${ }^{-/-}$ $\mathrm{cgc}^{-/-}$Mäuse besitzen keine B-, T- und NK-Zellen (natural killer cells). Alle verwendeten Tiere waren entsprechend den Haltungsvorschriften in der ZTE in einem 12 h Hell-DunkelRhythmus untergebracht und erhielten speziesspezifisches Futter und Leitungswasser ad libitum. Alle Tierversuche wurden von der Tierschutzkommission des Landes Niedersachsen genehmigt (Tierschutzantrag AZ 33.42502-010/06) und nach den Vorschriften des Tierschutzgesetzes durchgeführt.

\subsubsection{Zellen}

Die aufgeführten Zelllinien stammen alle, wenn nicht anders vermerkt, aus dem StammzellLabor der Abteilung Kardiologie/Pneumologie der Universitätsmedizin der Georg-AugustUniversität Göttingen.

SSC5, SSC15 maGSCs der Linien 5 und 15 aus adulten Stra8-EGFP/Rosa26-Mäusehoden (Guan et al. 2006)

OP9 Stromazelllinie aus dem Schädeldach von op/op-Mäusen (Nakano et al. 1994) mit einer Mutation im M-CSF (macrophage colony-stimulating factor)-Gen, wodurch kein funktionsfähiges M-CSF produziert wird (Riken BRC Cell Bank, RCB1124).

MEF Embryonale Fibroblasten, isoliert aus NMRI Mäusen aus der ZTE der Universitätsmedizin Göttingen. Die konfluent wachsenden Fibroblasten dienten als Versorgerschicht der maGSCs.

NIH/3T3 Fibroblasten, die nach Transfektion Wnt11 produzieren (Pandur et al. 2002). 


\subsubsection{Lösungen, Faktoren und Zellkulturmedien}

DPBS Dulbeccos Phosphat-gepufferte Salzlösung (auch PBS, Invitrogen)

DMEM Dulbeccos modifiziertes Eagle Medium mit 4,5 g/l Glukose (Invitrogen)

0,1\% Gelatine $\quad 1 \%$ Gelatine (Fluka Biochemika) in Aqua tridest., autoklaviert und 1:10 mit Aqua dest. verdünnt

0,2\% Trypsin $\quad 0,2 \%$ Trypsin (Invitrogen) in $1 x$ PBS

0,02\% EDTA $\quad 1 \%$ Ethylendiamintetraessigsäure (EDTA, Sigma) in Aqua tridest. gelöst, pH 7 eingestellt, autoklaviert und 1:50 mit 1x PBS verdünnt

T/E-Lösung $\quad$ 0,1\% Trypsin und 0,01\% EDTA in 1x PBS

Triton X

Verdünnung der 100\%igen Stocklösung (Triton X-100, Sigma) in 1x PBS auf $0,1 \%$ oder $0,2 \%$

BSA-Lösung $\quad 7,5 \%$ BSA-Lösung (Invitrogen) mit 1x PBS auf $0,5 \%$, 1\% oder 4\% verdünnt

4\% PFA-Lösung 4\% Paraformaldehyd (Sigma) in 1x PBS

Methanol/Aceton Methanol (J.T. Baker) und Aceton (Roth), Lagerung bei $-20^{\circ} \mathrm{C}$, vor Gebrauch im Verhältnis 7:3 mischen

1x Citratpuffer 10x Citratpuffer (pH 6; DakoCytomation) 1:10 mit Aqua dest. verdünnt

$3 \% \mathrm{H}_{2} \mathrm{O}_{2}$

30\% Wasserstoffperoxid (Merck) 1:10 mit 1x PBS verdünnt

Hämalaun

nach Mayer

$2 \mathrm{~g}$ Hämatoxylin (Merck) + 0,4 g Natriumiodat (Merck) + $100 \mathrm{~g}$ Aluminiumkaliumsulfat-Dodecahydrat (Merck) mit Aqua dest. auf $2 \mathrm{l}$ aufgefüllt und über Nacht gelöst, dann $100 \mathrm{~g}$ Chloralhydrat (Merck) + 2 g Citronensäure-Monohydrat (Merck) dazu und sechs Wochen gereift

CM-DiI

Chlormethylbenzamido-Derivate des 1,1'-Dioctadecyl-3,3,3'3' tetramethylindocarbocyanin-perchlorat (auch DiI, Invitrogen, Molecular Probes), $50 \mu \mathrm{g}$ in $200 \mu \mathrm{l}$ in Dimethylsulfoxid (DMSO, Sigma) gelöst $(=0,25 \mathrm{mg} / \mathrm{ml})$ 
ß-ME

MMC

MTG

NEAA

L-Glutamin

Activin A

BMP4

FCS

FL-Medium

OP9-Medium

ES-Medium

Differenzierungsmedium

Einfriermedium 50x Stocklösung= $7 \mu$ l ß-Mercaptoethanol (ß-ME, Promega) in $10 \mathrm{ml}$ 1x PBS, steril filtriert und bei $4^{\circ} \mathrm{C}$ für höchstens 7 Tage gelagert

2 mg Mitomycin C (MMC, Serva) in $10 \mathrm{ml}$ PBS gelöst (= $200 \mu \mathrm{g} / \mathrm{ml}$ Stammlösung), aliquotiert bei - $20^{\circ} \mathrm{C}$ gelagert; $50 \mu \mathrm{l}$ MMC Stammlösung pro ml Medium $(10 \mu \mathrm{g} / \mathrm{ml})$

$13 \mu 1 \alpha$-Monothioglycerol (MTG, Sigma) in $1 \mathrm{ml}$ Iscoves modifiziertem Dulbeccos Medium mit 4,5 g/l Glukose (IMDM, Invitrogen); steril filtrieren, Arbeitskonzentration: $3 \mu \mathrm{l} / \mathrm{ml}$ Medium (= $450 \mu \mathrm{M})$

100x nicht essentielle Aminosäuren (NEAA, Invitrogen)

100x L-Glutamin (Invitrogen)

Stocklösung (10 $\mu \mathrm{g} / \mathrm{ml}): 5 \mu \mathrm{g}$ Activin A (Peprotech) in $500 \mu \mathrm{l}$

$0,1 \%$ BSA gelöst, aliquotiert bei $-20^{\circ} \mathrm{C}$ gelagert,

Arbeitskonzentration: $100 \mathrm{ng} / \mathrm{ml}$

Stocklösung $(10 \mu \mathrm{g} / \mathrm{ml}): 5 \mu \mathrm{g}$ BMP4 (R\&D) in $500 \mu \mathrm{l} 4 \mathrm{mM}$ $\mathrm{HCl} / 0,1 \%$ BSA gelöst, aliquotiert bei $-20^{\circ} \mathrm{C}$ gelagert, Arbeitskonzentration: $10 \mathrm{ng} / \mathrm{ml}$

Fetales Kälberserum (fetal calf serum, Lonza) wurde immer für 30 min bei $56^{\circ} \mathrm{C}$ hitzeinaktiviert.

DMEM mit 15\% FCS und 1x L-Glutamin (2 mM); zur Kultivierung der MEFs

MEM alpha Medium (Invitrogen) mit 20\% FCS und 1x $\beta$-ME $(50 \mu \mathrm{M})$

DMEM mit 15\% FCS, 1x NEAA, 1x $\beta$-ME und $10^{3} \mathrm{U} / \mathrm{ml}$ leukemia inhibitory factor (LIF, Chemicon); zur Kultivierung der Stammzellen

IMDM mit $20 \%$ FCS und $1 x$ NEAA, $3 \mu \mathrm{l}$ MTGStammlösung/ml Medium (450 $\mu \mathrm{M})$; zur Differenzierung der maGSCs

DMEM mit 20\% FCS und 8\% DMSO 


\subsubsection{Oligonukleotide}

Alle verwendeten murinen Oligonukleotide (PCR-Primer) wurden von der Firma MWG Biotech bezogen. Die Namen, Sequenzen, Hybridisierungstemperaturen $\left(T_{H}\right)$, Zyklenanzahl (Z) und amplifizierten Fragmentlängen (Bp) sind der Tabelle $1 \mathrm{zu}$ entnehmen. Die in Klammern angegebenen Bezeichnungen sind interne Nummern des Stammzell-Labors.

Tabelle 1: In dieser Arbeit verwendete PCR-Primer

\begin{tabular}{|c|c|c|c|c|}
\hline PCR-Primer & Sequenz $\left(5^{\prime}-3^{\prime}\right)$ & $\mathbf{T}_{\mathrm{H}}\left({ }^{\circ} \mathrm{C}\right)$ & $\mathbf{Z}$ & Bp \\
\hline $\begin{array}{l}\text { ANF_f (F67) } \\
\text { ANF_r (F68) }\end{array}$ & $\begin{array}{l}\text { TGA TAG ATG AAG GCA GGA AGC CGC } \\
\text { AGG ATT GGA GCC CAG AGT GGA CTA GG }\end{array}$ & 63 & 33 & 203 \\
\hline $\begin{array}{l}\text { Bry_f (F09) } \\
\text { Bry_r (F10) }\end{array}$ & $\begin{array}{l}\text { GCT GTG ACT GCC TAC CAGAATG } \\
\text { GAG AGA GAG CGA GCC TCC AAA C }\end{array}$ & 52 & 33 & 231 \\
\hline $\begin{array}{l}\text { C-Kit_f (F89) } \\
\text { C-Kit_r (F90) }\end{array}$ & $\begin{array}{l}\text { ATT ATG AAC GCC AGG AGA CG } \\
\text { AGG CCT CGT ATT CAA CAA CC }\end{array}$ & 58 & 37 & 216 \\
\hline $\begin{array}{l}\text { Flk1_f (F79) } \\
\text { Flk1_r (F80) }\end{array}$ & $\begin{array}{l}\text { CCT ACC CCA CAC ATT ACA TGG } \\
\text { TTT TCC TGG GCA CCT TCT ATT }\end{array}$ & 55 & 35 & 200 \\
\hline $\begin{array}{l}\text { GAPDH_f (A79) } \\
\text { GAPDH_r (A80) }\end{array}$ & $\begin{array}{l}\text { GCA GTG GCA AAG TGG AGA TT } \\
\text { TCT CCA TGG TGG TGA AGA CA }\end{array}$ & 56 & 31 & 250 \\
\hline $\begin{array}{l}\text { GATA4_f (K47) } \\
\text { GATA4_r (K48) }\end{array}$ & $\begin{array}{l}\text { CTG TCA TCT CAC TAT GGG CA } \\
\text { CCA AGT CCG AGC AGG AAT TT }\end{array}$ & 57 & 34 & 257 \\
\hline $\begin{array}{l}\text { Isl1_f (F43) } \\
\text { Isl1_r (F44) }\end{array}$ & $\begin{array}{l}\text { ACG TCT GAT TTC CCT GTG TGT TGG } \\
\text { TCG ATG TGG TAC ACC TTA GAG CGG }\end{array}$ & 63 & 34 & 275 \\
\hline $\begin{array}{l}\text { Mef2c_f (K59) } \\
\text { Mef2c_r (K60) }\end{array}$ & $\begin{array}{l}\text { GGT AAC ACA GGC GGT CTG AT } \\
\text { TTG TTG AAA TGG CTG ATG GA }\end{array}$ & 62 & 31 & 349 \\
\hline $\begin{array}{l}\text { MHC_f (F51) } \\
\text { MHC_r (F52) }\end{array}$ & $\begin{array}{c}\text { CTG CTG GAG AGG TTA TTC CTC G } \\
\text { GGA AGA GTG AGC GGC GCA TCA AGG }\end{array}$ & 64 & 32 & 301 \\
\hline $\begin{array}{l}\text { MLC2v_f (F57) } \\
\text { MLC2v_r (F58) }\end{array}$ & $\begin{array}{l}\text { TGT GGG TCA CCT GAG GCT GTG GTT CAG } \\
\text { GAA GGC TGA CTA TGT CCG GGA GAT GC }\end{array}$ & 60 & 30 & 189 \\
\hline $\begin{array}{l}\text { Nkx2.5_f (K43) } \\
\text { Nkx2.5_r (K44) }\end{array}$ & $\begin{array}{l}\text { CGA CGG AAG CCA CGC GTG CT } \\
\text { CCG CTG TCG CTT GCA CTT G }\end{array}$ & 62 & 35 & 180 \\
\hline $\begin{array}{l}\text { Oct4_f (F37) } \\
\text { Oct4_r (F38) }\end{array}$ & $\begin{array}{c}\text { GGC GTT CTC TTT GGA AAG GTG TTC } \\
\text { CTC GAA CCA CAT CCT TCT CT }\end{array}$ & 61 & 38 & 312 \\
\hline
\end{tabular}




\subsubsection{Antikörper}

In den Tabellen 2 und 3 sind alle verwendeten Antikörper mit ihren spezifischen Epitopen, ihren Isotypen, der Herkunft und der verwendeten Verdünnung aufgeführt.

Tabelle 2: Verwendete primäre Antikörper

\begin{tabular}{|c|c|c|c|}
\hline $\begin{array}{c}\text { Antigen } \\
\text { Klon }\end{array}$ & Spezies/Isotyp & Firma/Kat.Nr. & Verdünnung \\
\hline $\begin{array}{l}\text { Brachyury (Bry) } \\
40\end{array}$ & Maus IgG & $\begin{array}{l}\text { Abcam } \\
20680\end{array}$ & $1: 100$ \\
\hline $\begin{array}{l}\text { Fetal liver kinase (Flk1) } \\
\text { Avas } 12 \alpha 1\end{array}$ & Ratte IgG2a & $\begin{array}{l}\text { BD Pharmingen } \\
555307\end{array}$ & $1: 100$ \\
\hline $\begin{array}{c}\text { Phycoerythrin (PE)-Flk1 } \\
\text { Avas } 12 \alpha 1\end{array}$ & Ratte IgG2a & $\begin{array}{l}\text { BD Pharmingen } \\
555308\end{array}$ & $1: 100$ \\
\hline $\begin{array}{l}\text { GATA4 } \\
\text { H112 }\end{array}$ & Kaninchen IgG & $\begin{array}{l}\text { Santa Cruz Biotechnology } \\
\text { sc-9053 }\end{array}$ & $1: 100$ \\
\hline $\begin{array}{l}\text { Islet1 (Isl1) } \\
\text { 39.4D5 }\end{array}$ & Maus IgG2b & $\begin{array}{c}\text { Developmental Studies Hybridoma } \\
\text { Bank }\end{array}$ & - \\
\hline $\begin{array}{c}\text { Alpha Myosin heavy chain } \\
(\alpha \mathrm{MHC}) \\
\text { MF20 }\end{array}$ & Maus IgG & $\begin{array}{c}\text { Developmental Studies Hybridoma } \\
\text { Bank }\end{array}$ & - \\
\hline $\begin{array}{l}\text { Nestin } \\
\text { Rat-401 }\end{array}$ & Maus $\operatorname{IgG}_{1}$ & $\begin{array}{c}\text { Developmental Studies Hybridoma } \\
\text { Bank } \\
\text { MAB5326 } \\
\end{array}$ & $1: 10$ \\
\hline $\begin{array}{l}\text { Nkx2.5 } \\
\text { H114 }\end{array}$ & Kaninchen IgG & $\begin{array}{l}\text { Santa Cruz Biotechnology } \\
\text { sc-14033 }\end{array}$ & $1: 100$ \\
\hline $\begin{array}{l}\text { Nkx2.5 } \\
\text { A-16 }\end{array}$ & Ziege IgG & $\begin{array}{l}\text { Santa Cruz Biotechnology } \\
\text { sc-12514 }\end{array}$ & $1: 100$ \\
\hline $\begin{array}{l}\text { Oct4 } \\
40\end{array}$ & Maus IgG & $\begin{array}{l}\text { BD Biosciences } \\
611202\end{array}$ & $1: 100$ \\
\hline $\begin{array}{l}\text { Smooth muscle alpha actin (SMA) } \\
\text { 1A4 }\end{array}$ & Maus $\operatorname{IgG}_{2 \mathrm{a}}$ & $\begin{array}{l}\text { Sigma } \\
\text { A2547 }\end{array}$ & 1:12.000 \\
\hline $\begin{array}{l}\text { kardiales Troponin } \mathrm{T} \text { (cTnT) } \\
\text { Ab-1 }\end{array}$ & Maus IgG & $\begin{array}{l}\text { Neomarkers } \\
\text { MS-295-P1 }\end{array}$ & $1: 20$ \\
\hline von-Willebrand-Faktor (vWF) & Kaninchen IgG & $\begin{array}{l}\text { DAKO } \\
\text { A0082 }\end{array}$ & $1: 100$ \\
\hline
\end{tabular}


Tabelle 3: Verwendete sekundäre Antikörper

\begin{tabular}{|c|l|c|}
\hline Sekundäre Antikörper & Herkunft & Verdünnung \\
\hline Cy3 Schaf anti-Maus IgG & Jackson ImmunoResearch Laboratory & $1: 600$ \\
\hline Cy3 Ziege anti-Kaninchen IgG & Jackson ImmunoResearch Laboratory & $1: 600$ \\
\hline Cy3 Ziege anti-Ratte IgG & Jackson ImmunoResearch Laboratory & $1: 600$ \\
\hline FITC Ziege anti-Maus IgG & Jackson ImmunoResearch Laboratory & $1: 200$ \\
\hline FITC Esel anti-Ziege IgG & Jackson ImmunoResearch Laboratory & $1: 200$ \\
\hline FITC Ziege anti-Kaninchen IgG & Jackson ImmunoResearch Laboratory & $1: 200$ \\
\hline FITC Ziege anti-Ratte IgG & Jackson ImmunoResearch Laboratory & $1: 200$ \\
\hline & & $1: 150$ \\
\hline
\end{tabular}

\subsection{Methoden}

\subsubsection{Zellbiologische Methoden}

Alle Zellkultur-Arbeiten wurden unter sterilen Bedingungen unter einer Umluft-Sterilbank (Heraeus Instruments) durchgeführt. Die Zellen wurden, wenn nicht anders beschrieben, bei 445 g für 5 min zentrifugiert. Die Kultivierung der verschiedenen Zellen erfolgte in einem Inkubator der Firma Heraeus Instruments bei $37^{\circ} \mathrm{C}$, 95\% Luftfeuchtigkeit und $5 \% \mathrm{CO}_{2}$. Täglich wurde eine mikroskopische Kontrolle durchgeführt, um die Proliferationsrate und den Differenzierungsgrad sowie eventuelle Kontaminationen der Zellkulturansätze zu ermitteln. Zellkulturschalen (Nunc) wurden mit 0,1 ml Gelatinelösung (0,1\%) pro cm² Wachstumsfläche beschichtet. Um Zellen als Proben für die Immunfluoreszenz-Färbungen zu kultivieren, wurden vier sterile Deckgläser (Menzel) in den Zellkulturschalen ausgelegt und mit Gelatine benetzt. Die Inkubation erfolgte mindestens für $3 \mathrm{~h}$ bei $4^{\circ} \mathrm{C}$, bevor die Schalen nach Absaugen der Gelatine verwendet werden konnten. 


\subsubsection{Passagieren der Zellen}

Das Passagieren (Umsetzen) der Zellen diente der Reduktion der Zelldichte und der Vermeidung von Zellstress und unerwünschten Differenzierungsvorgängen. Das Umsetzen erfolgte in Abhängigkeit der verwendeten Zelllinie. MEFs und OP9-Zellen wurden in Abhängigkeit der erreichten Konfluenz (ca. 70-80\%) alle 2-3 Tage passagiert. Um den undifferenzierten Zustand der maGSCs zu erhalten, wurden diese alle 1-2 Tage umgesetzt. Für das Passagieren wurden die Zellen mit einer T/E-Lösung behandelt. Nach kurzer Exposition bei Raumtemperatur wurde die T/E-Lösung abgenommen und die Enzymreaktion durch Zugabe des FCS im zukünftigen Zellkulturmedium abgestoppt. Durch mehrmaliges Auf- und Abpipettieren wurden die Zellen in Einzelzellsuspension gebracht und je nach Verwendungszweck im Medium aufgenommen und entweder in der gewünschten Zellzahl ausplattiert, eingefroren oder für Versuche verwendet.

Für die Zellzahlbestimmung wurde das Zellpellet je nach Größe mit 1-5 ml des zukünftigen Mediums resuspendiert und ein kleiner Tropfen unter das Deckgläschen einer ThomaZählkammer pipettiert. Es wurden 4-mal 16 Gruppenquadrate ausgezählt und der Wert gemittelt. Dieser Wert wurde durch die Anzahl der gezählten Gruppenquadrate (64) dividiert und mit dem Faktor $10^{6}$ multipliziert, um die Gesamtzellzahl pro Milliliter zu erhalten.

Die Kryokonservierung dient der langfristigen Konservierung lebender Zellen und Aufrechterhaltung der Zelllinien. Dabei wurden die kultivierten Zellen trypsiniert und das Zellpellet nach der Zentrifugation mit $1 \mathrm{ml}$ Einfriermedium resuspendiert. Anschließend wurde die Zellsuspension in ein beschriftetes Kryoröhrchen (Starlab) überführt. Der Einfriervorgang erfolgte in mit Isopropanol gefüllten Einfrierboxen (Nalgane), in denen die Zellen langsam auf $-80^{\circ} \mathrm{C}$ abgekühlt wurden, bevor sie in flüssigem Stickstoff für längere Zeiträume gelagert werden konnten.

Um Zellen aufzutauen, wurden die Kryoröhrchen im Wasserbad bei $37^{\circ} \mathrm{C}$ für $1-3 \mathrm{~min}$ erwärmt. Im Anschluss wurde die Zellsuspension mit einer Glaspipette in ein $15 \mathrm{ml}$ Röhrchen (Sarstedt) mit $10 \mathrm{ml}$ FL-Medium überführt und zentrifugiert. Nach der Zentrifugation wurde der Überstand abgenommen, das Zellpellet mit dem zukünftigen Medium resuspendiert und in der gewünschten Menge ausplattiert.

\subsubsection{Kultivierung der MEFs und OP9-Zellen}

Die konfluent wachsenden MEFs dienten als Versorgerschicht (feeder layer), um die spontane Differenzierung der maGSCs zu verhindern. Die MEFs wurden aus 15-17 Tage alten 
Mausembryonen isoliert und in FL-Medium auf $10 \mathrm{~cm}$ Zellkulturschalen (Nunc) als einzelne Zellschicht (Monolayer) maximal bis zur 4. Passage kultiviert. Um die MEFs für die Kultivierung von maGSCs zu verwenden und um eine weitere Proliferation zu verhindern, wurden sie zuvor mit MMC für 3 h bei $37^{\circ} \mathrm{C}$ inkubiert. Danach wurden die Zellen 3x mit PBS gewaschen, mit 0,2\% Trypsin abgelöst und je nach Zelldichte 1:10 bis 1:15 auf zuvor mit 0,1\% Gelatine-beschichtete 6 cm Zellkulturschalen (Nunc) umgesetzt.

OP9-Zellen sind konfluent wachsende Stromazellen, die zur Co-Kultur mit maGSCs verwendet wurden, um eine Differenzierung einzuleiten. Die OP9-Zellen wurden als Monolayer auf $10 \mathrm{~cm}$ Zellkulturschalen mit OP9-Medium maximal bis zur 30. Passage kultiviert. Um die OP9-Zellen für die Kultivierung mit maGSCs verwenden zu können und eine weitere Proliferation zu verhindern, wurden diese ebenso wie die MEFs mit MMC für $3 \mathrm{~h}$ bei $37^{\circ} \mathrm{C}$ inkubiert. Anschließend wurden die Zellen 3x mit PBS gewaschen und bis zur weiteren Verwendung in OP9-Medium kultiviert oder mit einer T/E-Lösung trypsiniert und 1:3 bis 1:8 auf zuvor mit Gelatine-beschichtete $6 \mathrm{~cm}$ oder $10 \mathrm{~cm}$ Zellkulturschalen passagiert.

\subsubsection{Kultivierung der undifferenzierten maGSCs}

Die undifferenzierten maGSCs wurden auf MMC-inaktivierten MEFs in ES-Medium kultiviert. In Abhängigkeit der Morphologie und Proliferation wurden sie alle 24-48 h auf frische MEFs passagiert. Dazu wurde das ES-Medium abgesaugt und die Zellen 2x mit einer T/E-Lösung behandelt. Nach kurzer Exposition bei Raumtemperatur wurde die T/E-Lösung entfernt, die Zellen mit einer $2 \mathrm{ml}$ Glaspipette in frischem ES-Medium resuspendiert und auf neue Zellkulturschalen mit MEFs umgesetzt.

\subsubsection{Co-Kultur von maGSCs mit OP9-Zellen}

Um maGSCs in Richtung Mesoderm differenzieren zu lassen, wurden 3x10 ${ }^{4}$ maGSCs der Linien SSC5 bzw. SSC15 nach Preplating auf mitotisch inaktiven OP9-Zellen (ca. 70-80\% konfluent) in $10 \mathrm{~cm}$ Zellkulturschalen gesetzt und mit Differenzierungsmedium kultiviert. Alle 2-3 Tage wurde ein halber Mediumwechsel mit frischem Differenzierungsmedium durchgeführt. Das Preplating beruht auf dem unterschiedlichen Adhäsionsverhalten der maGSCs und MEFs oder OP9-Zellen. Hierbei wurden alle Zellen trypsiniert, abgelöst und auf Gelatine-beschichtete Zellkulturschalen überführt. Die maGSCs verfügen über eine geringere Adhärenz als die MEFs oder OP9-Zellen und konnten so nach ca. 45 min bis $1 \mathrm{~h}$ durch 
Abspülen des Überstandes, in dem sich die maGSCs befanden, von den bereits adhärenten MEFs oder OP9-Zellen separiert werden.

Am Tag 5 wurden die vordifferenzierten maGSCs auf neue OP9-Zellen ausplattiert (teils mit Deckgläsern) und in Differenzierungsmedium kultiviert oder FACS-analysiert, um anschließend die sortierten Zellpopulationen wieder auf OP9-Zellen in Differenzierungsmedium weiter zu kultivieren.

\subsubsection{In vitro Dehnungs-Experimente mit maGSCs}

Für die Dehnungsversuche der maGSCs auf einer 6-Well (Vertiefungen)-BioFlexZellkulturschale (Dunnlab) wurde diese zunächst mit einer 1:20 in $\mathrm{H}_{2} \mathrm{O}$ verdünnten Collagen I -Lösung (Sigma) über Nacht bei $4^{\circ} \mathrm{C}$ inkubiert. Nach 2-maligem Waschen mit 1xPBS erfolgte eine Inkubation der 6-Well-Schale mit $1 \%$ Gelatine bei $4^{\circ} \mathrm{C}$ über Nacht. Anschließend wurden pro Well $8 \times 10^{4}$ MEFs ausplattiert, auf die am nächsten Tag pro Well $15 \times 10^{4}$ SSC5 überführt und in ES-Medium kultiviert wurden. Nach $24 \mathrm{~h}$ wurden die Zellen in einer speziellen Apparatur (ausgeliehen von Prof. Linke, Universität Bochum, selbst gebaut, Abb. 4) mit Vakuumpumpe für 15, 30 und $60 \mathrm{~min}$ bei $0,5 \mathrm{~Hz}$ gedehnt. Danach wurden entweder sofort oder nach Inkubation bei $37^{\circ} \mathrm{C}$ für $4 \mathrm{~h}$ oder $24 \mathrm{~h}$ PCR-Proben genommen.

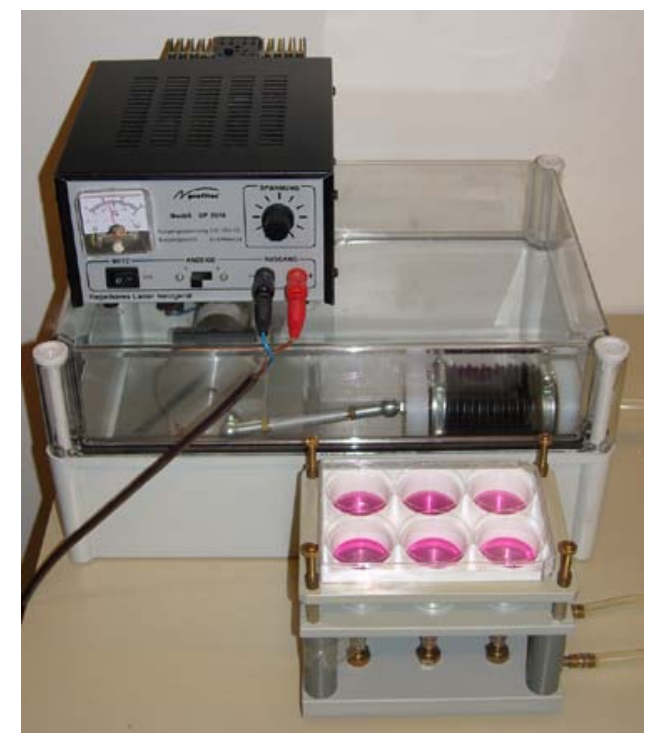

Abbildung 4: 6-Well-BioFlex-Zellkulturschale mit angeschlossener Vakuumpumpe. Im Vordergrund ist die eingespannte Bio-Flex-Schale zu sehen, wobei sich in den drei oberen Wells die ungedehnten Zellen (Kontrollen) befinden und in den unteren drei Wells die zu dehnenden Zellen. Im Hintergrund steht die Vakuumpumpe, die mit der Bio-Flex-Schale und einem regelbaren Netzgerät verbunden ist. 
Außerdem wurden die Zellen bei weiteren Versuchen $1 \mathrm{~h}$ oder $2 \mathrm{~h}$ lang bei $1 \mathrm{~Hz}$ gedehnt. Anschließend wurden die Zellen auf OP9-Zellen gesetzt, um an d5 eine Durchflusszytometrie mit einem Phycoerythrin (PE)- gekoppelten-Flk1-Antikörper durchzuführen.

\subsubsection{In vivo Maus-Modelle}

\subsubsection{Schmerztherapie, Narkose und Intubation}

Damit die Tiere keinen Schmerzstress während der Operation (OP) erleiden, wurde ihnen $1 \mathrm{~h}$ vor der OP Temgesic ${ }^{\circledR}$ (Wirkstoff: Buprenorphin, Essex Pharma GmbH), ein OpioidAnalgetikum, verabreicht $(0,1 \mathrm{mg} / \mathrm{kg})$. Nach der OP wurden die Mäuse beobachtet und evtl. nach 4 h eine weitere Dosis Buprenorphin verabreicht. Ansonsten erhielten die Mäuse nach der OP für 7 Tage das Schmerzmittel Metamizol im Trinkwasser. Zeigten die Mäuse auch nach 1 Tag noch starke Schmerzen, wurde erneut Buprenorphin injiziert. Die Mäuse wurden jeden Tag begutachtet und gewogen. Sollten die Mäuse weitere Anzeichen von starken Schmerzen zeigen, mehr als 20\% ihres Körpergewichtes verlieren oder sich untypisch verhalten (keine Fellpflege, keine Aufnahme von Nahrung, Aggression usw.), wurde ein Tierarzt der ZTE konsultiert. Zusammen mit dem Tierarzt wurde entschieden, ob das Tier noch schmerztherapiert oder getötet wird.

Alle OPs fanden unter Isofluran-Narkose (2\%) mit ca. $1 \mathrm{l} \mathrm{O}_{2} / \mathrm{min}$ mit Hilfe eines Stereoskops statt.

Da bei den OPs in dieser Arbeit der Thorax geöffnet wurde, mussten die Mäuse intubiert werden, damit kein Pneumothorax auftrat. Dazu wurde die Maus in Isofluran-Narkose in Rückenlage an den Extremitäten fixiert. Mit einer Schlaufe aus 5-0 Ligatur um die Vorderzähne der Maus wurde die Maus am Kopf fixiert und der Hals leicht überstreckt. Eine Inzision in der Mittellinie des Halses und die Darstellung der Trachea wurden durchgeführt, um den Endotrachealtubus (Hugo-Sachs-Elektronik) unter Sicht zu platzieren. Dazu wurde die Zunge leicht aus dem Mund gezogen und der Tubus vorsichtig durch das Maul 5-8 mm vom Larynx aus in die Trachea eingeführt, ohne dabei Strukturen in der Pharynx zu verletzen. Der Tubus wurde mit einem speziellen Beatmungsgerät für Mäuse (MiniVent, Hugo-SachsElektronik) verbunden und die Maus mit einer Frequenz von ca. 150/min und einem Atemzugvolumen von ca. $150 \mu \mathrm{l}$ beatmet. 


\subsubsection{Aorto-cavale Shunt-Operation}

Nach Überprüfen der Narkosetiefe durch einen gezielten Schmerzreiz (Kneifen zwischen den Zehen des Hinterlaufes mit einer Pinzette) wurden die Mäuse mittels handelsüblicher Enthaarungscreme am Bauch und am ventralen Hals enthaart und an den Extremitäten in Rückenlage auf der Unterlage fixiert. Anschließend wurde die Bauchhöhle eröffnet und der Darm in einer feuchten Kompresse ausgelagert. Die Hauptschlagader (Aorta abdominalis) wurde dargestellt und oberhalb des Abgangs der Nierenarterien abgeklemmt. Die Aorta wurde dann mit einer Kanüle (26G) unterhalb der Nierenarterien punktiert und die Nadel in die danebenliegende Vena cava inferior eingeführt. Diesen Vorgang wiederholte man mit einer 23G-Kanüle, um den Shunt zu erweitern.

Die Einstichstelle in die Aorta wurde anschließend mit Cyanoacrylatkleber verschlossen. Die Klemme auf der Aorta wurde entfernt und die Durchgängigkeit der geschaffenen Verbindung dadurch bestätigt, dass sich arterielles und venöses Blut in der anschwellenden Vena cava sichtbar mischten.

Die operierten Mäuse wurden in Narkose beobachtet und bei Anzeichen einer nicht erfolgreichen OP (Shunt verschließt sich wieder) noch in der Narkose getötet. Ansonsten wurden die Bauchhaut und die Haut in einer zweiten Schicht jeweils mit Einzelknopfnähten verschlossen. Anschließend wurde die Narkose beendet und die Mäuse bis zur eigenständigen Atmung weiterhin beatmet. Bis zum vollständigen Erwachen wurden die operierten Mäuse auf einer Wärmeplatte und von wachen Tieren getrennt gelagert. Alternativ zu dem oben beschriebenen OP-Protokoll wurde an den Tieren der Sham-Gruppen (Kontroll-Gruppen) folgender Eingriff vorgenommen: Die Aorta wurde dargestellt und ebenfalls abgeklemmt. Allerdings wurde kein Shunt erzeugt, sondern ebenfalls ein Tropfen Cyanoacrylatkleber neben der Aorta platziert. Der übrige Verlauf unterscheidet sich nicht von der Shunt-Gruppe.

\subsubsection{Transaortic constriction (TAC)}

Es wurde ein operativer Eingriff zur Reduktion des Durchmessers der transversalen Aorta durchgeführt. Nach Wirkungseintritt der Narkose wurden die Mäuse an Brust und ventralem Hals mittels handelsüblicher Enthaarungscreme enthaart. Nach erneuter Kontrolle der Narkosetiefe durch einen Schmerzreiz wurden die Mäuse an den Extremitäten in Rückenlage auf der Unterlage fixiert. Nach Eröffnen der Haut mit einem ca. 1-1,5 cm langen Querschnitt oberhalb des Sternums wurde zunächst der Aortenbogen dargestellt. Dazu wurde in stumpfer Präparation entlang der muskulären Strukturen die Trachea aufgesucht und die Arteria carotis 
communis dargestellt. Entlang dieser Leitstruktur wurde die Aorta aufgesucht. Dabei war es unter Umständen nötig, das OP-Gebiet durch einen kleinen Schnitt in das Manubrium sterni $\mathrm{zu}$ erweitern. Nach Erreichen des transversalen Aortenbogens wurde dieser vorsichtig mobilisiert und ein chirurgischer Faden (6-0) unter der Aorta hindurch geführt. Eine auf die Aorta gelegte stumpfe 26G-Kanüle diente beim Knoten der Standardisierung der Stenose.

Abschließend wurde die Muskulatur des Halses mit einer Naht mittig adaptiert und die Haut mit drei Einzelnähten geschlossen. Bis zum Erwachen aus der Narkose wurden die Tiere auf einer Wärmeplatte und von wachen Tieren getrennt aufbewahrt. Bei Tieren der Sham-Gruppe wurde keine TAC-OP durchgeführt, sondern nur der Aortenbogen mobilisiert.

\subsubsection{DiI-Färbung der maGSCs}

Die maGSCs wurden nach einem Preplating gezählt und anschließend mit dem Cell Tracker $^{\mathrm{TM}}$ DiI gefärbt. Dafür wurde eine Färbelösung aus $500 \mu \mathrm{l}$ DMEM und $60 \mu \mathrm{l}$ DiIStocklösung angesetzt. Nach der Zellzählung wurden die Zellen zentrifugiert und z.B. 1x10 ${ }^{7}$ Zellen mit 500 l DMEM resuspendiert. Anschließend wurde die Färbelösung zugegeben und die Zellsuspension erst 5 min bei $37^{\circ} \mathrm{C}$ und dann 15 min bei $4^{\circ} \mathrm{C}$ unter Lichtausschluss und gelegentlichem Schwenken inkubiert. Es folgten Waschschritte mit DMEM und 1x PBS und eine erneute Zellzählung. Daraufhin konnten die Zellen in der gewünschten Konzentration in Heparin/ $\mathrm{NaCl}$ gelöst und bis zur baldigen Myokardinjektion bei $4{ }^{\circ} \mathrm{C}$ aufbewahrt werden.

\subsubsection{Stammzell-Injektion ins Myokard}

Die Stammzell-Injektion ins Myokard wurde in normalen und Shunt- oder TAC-operierten Mäusen durchgeführt. Die Maus wurde nach der Intubation leicht seitlich gelagert und die Haut über dem Herzen (linke laterale Thoraxwand) mit einem ca. $1 \mathrm{~cm}$ langen Schnitt eröffnet. Der Brustkorb wurde durch einen Schnitt durch den Zwischenrippenraum eröffnet. Die Thoraxwand wurde mit Haken gespreizt und das Herz nach Durchtrennung des Perikards dargestellt. Es erfolgte die Injektion von undifferenzierten DiI-markierten Stammzellen oder des $\mathrm{NaCl}(0,9 \%$, Braun) als Kontrolle. In jedes Mausherz wurden insgesamt 3x10 Zellen in 4 Injektionen $\mathrm{zu}$ je $5 \mu \mathrm{l}$ Zellsuspension (oder $4 \mathrm{x} 5 \mu \mathrm{l} \mathrm{NaCl}$ ) in die linksventrikuläre Herzvorderwand platziert. Anschließend wurden die Thoraxwand und die Haut in einer zweiten Schicht jeweils mit Einzelknopfnähten verschlossen.

Damit die Mäuse die transplantierten Stammzellen nicht abstoßen, wurde ihnen täglich das Immunsuppressivum Ciclosporin A (CsA, Novartis) in einer Konzentration von $20 \mu \mathrm{g} / \mathrm{kg}$ 
Körpergewicht intraperitoneal injiziert. Auch die Mäuse ohne Zellinjektion (also NaClinjizierte Mäuse) bekamen CsA.

\subsubsection{Echokardiographie}

Bei den Shunt- und TAC-operierten Tieren wurde zur Charakterisierung der Pumpfunktion des Herzens und zur Bestimmung der Dimensionen zu bestimmten Zeitpunkten eine echokardiographische Kontrolle durchgeführt. Die Messungen erfolgten jeweils 2 Wochen (2 w) und 4 Wochen $(4 \mathrm{w})$ nach OP.

Für diese Untersuchung wurden die Mäuse im Thoraxbereich enthaart und mittels 1\% Isofluran sediert. Durch die Echokardiographie im B-Mode konnten die Septumdicke, die Dicke der Hinterwand, der linksventrikuläre enddiastolische Diameter (LVEDD), der linksventrikuläre endsystolische Diameter (LVESD), das endsystolische (ESV) und enddiastolische Volumen (EDV) und die Herzfrequenz (500-600 Schläge/min) ermittelt werden. So konnten die nachfolgend erläuterten und später graphisch dargestellten Parameter beurteilt werden.

Als Ejektionsfraktion (EF) wird der Anteil des bei einer Herzkontraktion ausgeworfenen Blutes bezeichnet. Das Schlagvolumen (SV) wird ins Verhältnis zum Gesamtblutvolumen der Herzkammer gesetzt und kann berechnet werden, indem man das ESV vom EDV subtrahiert $(\mathrm{EF}=\mathrm{SV} / \mathrm{EDV}=(\mathrm{EDV}-\mathrm{ESV}) / \mathrm{EDV})$

Die Verkürzungsfraktion (Fractional shortening, FS) bezeichnet die Verkürzung des Herzens während des Pumpvorganges und ist ein Maß für die Pumpfunktion des linken Ventrikels. Das FS wird aus dem größten und kleinsten Durchmesser der linken Herzkammer berechnet und als relativer Wert angegeben (FS = (LVEDD-LVESD)/LVEDD).

Außerdem wurde bei den TAC-operierten Tieren der Druck-Gradient bestimmt. Dazu wurde die Stenose per colour-Doppler dargestellt und die Fließgeschwindigkeit des Blutes per pulsewave-Doppler gemessen. Der Gradient wurde mit Hilfe der vereinfachten Bernoulli-Formel errechnet und sollte zwischen 40 und 90 mmHg betragen.

\subsubsection{Immunhisto-, Immunzyto- und Histochemie}

\subsubsection{Herstellung der Gewebeschnitte}

Direkt nach dem Finalisieren der Mäuse durch cervikale Dislokation wurden die Herzen entnommen, mit 0,9\% NaCl perfundiert und in Phosphat-gepuffertem Formalin (pH 7; Roth ${ }^{\circledR}$ ) 
für $4 \mathrm{~h}$ bei Raumtemperatur oder über Nacht bei $4^{\circ} \mathrm{C}$ fixiert. Für die immunhistochemischen Analysen mussten die Gewebeproben in Paraffin (Paraplast Plus ${ }^{\circledR}$ Tissue Embedding Medium; McCormick ${ }^{\mathrm{TM}}$ Scientific) eingebettet werden. Vor dem Paraffinieren wurde das Formalin mit Aqua dest. wieder ausgewaschen. In einem Gewebeinfiltrationsautomat der Firma Leica (Benchtop Tissue Processor 1020) wurde dem Gewebe über eine aufsteigende Alkoholreihe das Wasser entzogen. Anschließend wurde der Alkohol durch Chloroform (Th. Geyer) ersetzt, welches sich letztendlich in Paraffin löste. Das paraffinierte Gewebe wurde danach manuell mittels einer Paraffinausgießstation (Leica) in Paraffinblöcke gegossen. Das Gewebe konnte mit einem Rotationsmikrotom (Leica) in $6 \mu \mathrm{m}$ feine Schnitte geschnitten werden, nachdem das Paraffin ausgehärtet war. Die Schnitte wurden zunächst in einem $45^{\circ} \mathrm{C}$ warmen Wasserbad gespreitet und danach mit Hilfe eines feuchten Pinsels auf beschichtete Superfrost ${ }^{\circledR}$ Plus Objektträger (Thermo Scientific) überführt. Die Objektträger wurden für $1 \mathrm{~h}$ in einem Trockenschrank bei $45^{\circ} \mathrm{C}$ getrocknet. Bis zur weiteren Verwendung wurden die Schnitte bei Raumtemperatur gelagert.

\subsubsection{HE und MG-Färbungen}

Die Hämatoxylin-Eosin (HE)-Färbung der Gewebeschnitte wurde in der Pathologie der Universitätsmedizin Göttingen durchgeführt und dient der Unterscheidung von Zellkern und Zytoplasma. Zu Beginn der HE-Färbung wurden die Gewebeschnitte durch Xylol (J.T. Baker) entparaffiniert (4x je 2 min). Anschließend wurden die Schnitte in einer absteigenden Alkoholreihe (2x 100\%, 2x 96\%, 1x 75\% und Aqua dest. je 2 min) bewässert. Danach folgten die Zellkernfärbung mit Hämalaun (3x je 2 min), Spülen mit Leitungswasser (2 min) und die Zytoplasmafärbung mit Eosin (2x 2 min). Zum Schluss wurden die Schnitte in einer aufsteigenden Akoholreihe entwässert (Aqua dest., 2x 96\%, 2x 100\%, 3x Xylol je 2 min) und mit Xylol-löslichem Entellan ${ }^{\circledR}$ eingedeckt.

Die Masson-Goldner-Trichrom (MG)-Färbung dient der Abgrenzung von kollagenen Strukturen gegen Epithel- und Muskelgewebe und zur Darstellung von Fibrosen und wurde wie folgt durchgeführt: Zuerst wurden die Gewebeschnitte wie für die HE-Färbung in einer absteigenden Alkoholreihe entparaffiniert. Anschließend erfolgten eine progressive Zellkernfärbung mit Eisenhämatoxylin nach Weigert für $10 \mathrm{~s}$, Spülen mit Aqua dest. und fließendem Aqua dest. für 5 min. Danach wurden die Schnitte kurz in Essigsäure (1\%) inkubiert, mit Aqua dest. gespült und für 40-45 s in Ponceau Xylidin (Sigma) gefärbt. Es folgten drei Waschschritte mit Aqua dest., Spülen mit 1\% Essigsäure und Inkubation mit 
Phosphomolybdänsäure für 7 min. Anschließend wurden die Schnitte mit Aqua dest. und 1\% Essigsäure gespült und mit dem Bindegewebsfarbstoff Methylenblau (Sigma) $35 \mathrm{~s}$ gefärbt. Nach erneuter kurzer Spülung mit Aqua dest. und 1\% Essigsäure, wurden die Färbung der Schnitte mit Essigsäure (2 min) differenziert und die Schnitte mit 100\% Alkohol mit 1\% Essigsäure entwässert. Danach folgten 2x 5 min Inkubation in Xylol und das Eindecken in Entellan ${ }^{\circledR}$ (Merck).

\subsubsection{Immunfluoreszenzfärbungen an Paraffinschnitten}

Die Gewebeschnitte wurden vor der eigentlichen Immunreaktion mit Xylol entparaffiniert und mittels absteigender Alkoholreihe rehydriert. Die Proteine vernetzen sich durch die Paraffinierung der Gewebe und verlieren dadurch ihre Immunreaktivität. Diese kann durch 15-minütiges Köcheln in 1x Citratpuffer teilweise wiederhergestellt werden (AntigenDemaskierung). Nachdem die Gewebeschnitte abgekühlt waren, wurden sie dreimal mit 1x PBS gewaschen. Um spätere unspezifische Bindungen der Antikörper zu minimieren, wurden die Schnitte in einer Feuchtkammer mit 4\% BSA-Lösung für $1 \mathrm{~h}$ bei $37^{\circ} \mathrm{C}$ geblockt. Schnitte, die auf im Zellkern lokalisierte Proteine untersucht werden sollten, wurden vor dem Blocken zusätzlich für 15 min mit 4\% BSA-Lösung/0,2\% Triton X bei Raumtemperatur inkubiert, um die Zell- und Kernmembranen zu permeabilisieren. Nach dem Blocken wurden die Gewebeschnitte mit dem primären Antikörper für $1 \mathrm{~h}$ bei $37^{\circ} \mathrm{C}$ inkubiert. Die Antikörper wurden in 0,5\% BSA-Lösung verdünnt (Tabelle 3). Anschließend wurden die Gewebeschnitte dreimal mit 1x PBS gewaschen und mit dem sekundären Antikörper versehen. Es folgten eine weitere Inkubation in der feuchten Kammer für $1 \mathrm{~h}$ bei $37^{\circ} \mathrm{C}$ und 3-maliges PBS-Waschen. Um die Zellkerne zu visualisieren, wurden die Schnitte 10 min mit 4',6-Diamidino-2phenylindoldihydrochlorid (DAPI; 0,4 $\mu \mathrm{g} / \mathrm{ml}$ ) bei Raumtemperatur inkubiert. Danach wurden die Schnitte 3x mit PBS und 1x mit Aqua dest. gewaschen und mit Vectashield Mounting Medium (Linaris) eingedeckt.

\subsubsection{Immunhistologische Färbung}

Für eine Immunfluoreszenz-unabhängige immunhistologische Färbung mit Antikörpern wurden die Gewebeschnitte zunächst entparaffiniert und 15 min in 1x Citratpuffer geköchelt. Nach dem Spülen in A. dest. (2x $5 \mathrm{~min}$ ) und in $1 \mathrm{x}$ PBS (3x $5 \mathrm{~min}$ ) wurde die endogene Perodidaseaktivität minimiert, indem man die Schnitte 10 min in 3\%igem Wasserstoffperoxid bei Raumtemperatur inkubierte. Anschließend wurden die Schnitte dreimal mit PBS 
gewaschen und die unspezifischen Bindungsstellen in einer Feuchtkammer mit 4\% BSALösung für $1 \mathrm{~h}$ bei $37^{\circ} \mathrm{C}$ geblockt. Sollten Zellkern-Proteine untersucht werden, inkubierte man die Schnitte zusätzlich für 30 min mit 4\% BSA-Lösung/0,2\% Triton X-100 bei Raumtemperatur. Anschließend wurden die Gewebeschnitte mit dem primären Antikörper in 0,5\% BSA-Lösung (in dieser Arbeit nur Oct4 und Ki67) versehen und für 1,5 h bei Raumtemperatur in einer feuchten Kammer inkubiert. Es folgten drei PBS-Waschschritte und die Visualisierung der Antikörper und somit der zu untersuchenden Proteine mit Hilfe der SuperPicture $^{T M}$ Polymer Detection Kits der Firma Invitrogen ${ }^{\mathrm{TM}}$ nach Angaben des Herstellers. Dabei wurde ein HRP Polymer Konjugat auf die Primärantikörper gegeben, welches nach Zugabe von Wasserstoffperoxid in einer chemischen Reaktion dem farblosen Chromogen 3,3'-Diaminobenzidin eine bräunliche Färbung verleiht. Die Zellkerne wurden mit Hämalaun nach Mayer für 10 min gefärbt. Anschließend wurden die Schnitte in Leitungswasser gewaschen und erst in 96\%, dann in 100\% Ethanol (Chemie-Vertrieb Hannover) und in Xylol inkubiert. Zuletzt wurden die Gewebeschnitte mit Deckgläsern (Thermo Scientific) und Entellan ${ }^{\circledR}$ versiegelt.

\subsubsection{Immunfluoreszenzfärbungen an Zellen}

Die Immunfluoreszenzfärbungen erlauben die Beobachtung und Charakterisierung der Proteinexpression mit Hilfe der indirekten Immunfluoreszenz. Die maGSCs wurden an d5 auf $6 \mathrm{~cm}$ Schalen mit Deckgläsern und OP9-Zellen umgesetzt und in Differenzierungsmedium weiter kultiviert. Um die maGSCs via Immunfluoreszenzfärbungen analysieren zu können wurden sie während der Differenzierung an d5, d5+5, d5+10, d5+15 und d5+20 fixiert. Hierfür wurden die Zellen 3x mit PBS gewaschen und entweder mit einer 4\%igen PFALösung für 20 min bei Raumtemperatur oder mit einer Methanol/Aceton-Lösung (7:3) für $10 \mathrm{~min}$ bei $-20^{\circ} \mathrm{C}$ inkubiert bzw. fixiert. Anschließend wurden die Zellen 3x mit PBS gewaschen, mit einer 1\% BSA-Lösung zur Vermeidung unspezifischer Signalbildung blockiert und direkt weiter verwendet oder bei $4^{\circ} \mathrm{C}$ aufbewahrt.

Für die Färbungen in einer feuchten Kammer wurden $100 \mu \mathrm{l}$ des primären Antikörpers in geeigneter Verdünnung in 1\% BSA (Tabelle 2) auf jedes Deckglas gegeben und für $1 \mathrm{~h}$ bei $37^{\circ} \mathrm{C}$ inkubiert. Anschließend wurden die Zellen auf den Deckgläsern 3x mit PBS gewaschen. Danach wurde der sekundäre Antikörper in $150 \mu \mathrm{l}$ geeigneter Verdünnung in 1\% BSA (s. Tabelle 3) $1 \mathrm{~h}$ bei $37^{\circ} \mathrm{C}$ auf jedem Deckglas inkubiert. Darauf folgten wieder drei PBSWaschschritte. Die Anfärbung der Zellkerne erfolgte mit $150 \mu$ DAPI für 10 min bei 
Raumtemperatur unter Lichtausschluss. Anschließend wurden die Deckgläser wieder 3x mit PBS und zusätzlich 1x mit frischem Aqua dest. gewaschen, bevor sie mit Vectashield Mounting Medium (Linaris) eingedeckt wurden. Die Ränder der Deckgläser wurden mit Nagellack versiegelt, um Austrocknung zu verhindern.

Die Auswertung der Präparate erfolgte an dem Fluoreszenzmikroskop Axio Observer A1 von Zeiss mit Verwendung von Emissionsfiltern für $\mathrm{Cy3}^{\mathrm{TM}}$ und DiI (Exitation BP 546/12, beam splitter FT 580, Emission LP 590), DAPI (Exitation 365, beam splitter FT 395, Emission BP 445/50), Fluorescein-5-isothiocyanat (FITC) und EGFP (Exitation BP 470/40, beam splitter FT 495, Emission BP 525/50) und mit Hilfe des digitalen Bildverarbeitungsprogrammes AxioVision (Zeiss).

\subsubsection{Durchflusszytometrie und Fluorescence activated cell sorting (FACS)}

Mit Hilfe der Durchflusszytometrie konnten $\mathrm{zu}$ unterschiedlichen Zeitpunkten Fluoreszenzproteine quantitativ nachgewiesen werden. Für die Analyse wurden die Zellen (1$2 \times 10^{6}$ ) in ein 1,5 ml Reaktionsgefäß (Eppendorf) überführt und zentrifugiert. Danach wurden der Überstand abgenommen und $100 \mu$ des gewünschten primären Antikörpers in geeigneter Verdünnung mit 0,5\% BSA-Lösung (Tabelle 2) zu den Zellen gegeben und für 45 min bei $37^{\circ} \mathrm{C}$ inkubiert. Anschließend wurden die Zellen 3x mit PBS gewaschen, bevor sie für 45 min bei $37^{\circ} \mathrm{C}$ mit $100 \mu \mathrm{l}$ des zweiten Antikörpers in geeigneter Verdünnung in 0,5\% BSA-Lösung (Tabelle 3) inkubiert wurden. Darauf folgend wurden die Ansätze erneut 3x mit PBS gewaschen und zum Messen in $400 \mu \mathrm{l}$ 1\% BSA aufgenommen. Die Messung erfolgte am Flowzytometer FACScan ${ }^{\circledR}$ bzw. FACS Canto von Becton-Dickinson mittels FACS Diva Software. Die Auswertung der Messung fand mit Hilfe des Programmes WinMDI 2.9 statt. MaGSCs der Linie SSC5, die ein Stra8-GFP-Konstrukt enthalten, dienten als Positivkontrolle für die FITC-Fluoreszenz und wurden für Einzelfärbungen eingesetzt. Als Negativkontrolle und für Doppelfärbungen dienten maGSCs der Linie SSC15, die nicht fluoreszieren.

Um die vordifferenzierten kardialen Progenitorzellen von anderen Zellen zu trennen und weiter kultivieren zu können, wurde am Tag 5 zusätzlich eine FACS-Analyse durchgeführt. Zuvor wurden die Zellen einem Preplating unterzogen und mit einem PE-gekoppelten Flk1Antikörper für 35 min inkubiert. Nach 2-maligem Waschen mit PBS wurden die Zellen sortiert. Dabei sind drei Populationen dargestellt: die Flk1 ${ }^{+}$, die Flk1/GFP ${ }^{-}$und die Flk1 ${ }^{-}$ $/ \mathrm{GFP}^{+}$Zellen. Diese Populationen wurden mittels der FACS Aria Software eingegrenzt, 
sortiert und anschließend auf $6 \mathrm{~cm}$ Zellkulturschalen mit oder ohne OP9-Zellen (teils auf Deckgläsern) in Differenzierungsmedium kultiviert.

\subsubsection{RT-PCR-Analyse}

Die Expressionsänderung verschiedener gewebespezifischer Gene wurde auf mRNA-Ebene über die Reverse Transkriptase-Polymerase-Kettenreaktion (reverse transcriptase-polymerase chain reaction, RT-PCR) von isolierter mRNA mit anschließender PCR nachgewiesen. Die Proben für die RT-PCR wurden während der gesamten Differenzierungsversuche an d0, d5, d5+5, d5+10, d5+15 genommen. Hierzu wurden die zu untersuchenden Zellen 3x mit PBS gewaschen und anschließend mit $500 \mu$ RNA Lysis-Puffer lysiert. Das Lysat wurde in ein $1,5 \mathrm{ml}$ Reaktionsgefäß (Eppendorf) überführt und, wenn nicht sofort verwendet, bei $-20^{\circ} \mathrm{C}$ gelagert.

Die Gesamt-RNA aus Zellen wurde mit dem SV Total RNA Isolation System-Kit (Promega) nach Angaben des Herstellers extrahiert. Die Bestimmung der RNA-Konzentration fand mit Hilfe eines Bio-Photometers (Eppendorf) über die Messung der optischen Dichte bei $260 \mathrm{~nm}$ $\left(\mathrm{OD}_{260}\right)$ und bei $280 \mathrm{~nm}\left(\mathrm{OD}_{280}\right)$ statt. Die RNA-Konzentrationen für alle Proben wurden auf $40 \mathrm{ng} / \mu \mathrm{l}$ eingestellt.

Für die Reverse Transkription (RT) wurden von jeder Probe 200 ng RNA in einem Gesamtvolumen von $20 \mu \mathrm{l}$ eingesetzt. Zusätzlich enthielt jeder RT-Ansatz $4 \mu \mathrm{l} \mathrm{MgCl}_{2}$ (25 mM, Applied Biosystems), $2 \mu \mathrm{l}$ 10x PCR-Puffer II (Applied Biosystems), $1 \mu \mathrm{l}$ RNase

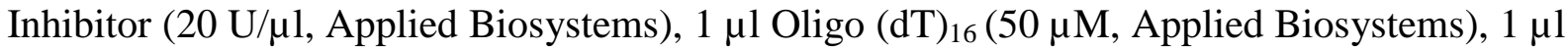
MuLV Reverse Transkriptase (50 U/ $\mu$ l, Applied Biosystems), 0,8 $\mu$ l dNTP-Mix (100 mM, Bioline) mit einer das Gesamtvolumen auf $20 \mu \mathrm{l}$ ergänzenden Menge DEPC- $\mathrm{H}_{2} \mathrm{O}$ (Sigma). Die RT erfolgte im ThermoCycler (SensoQuest) beginnend mit $10 \mathrm{~min}$ bei $22^{\circ} \mathrm{C}$, einer Elongation für 50 min bei $42^{\circ} \mathrm{C}$ und anschließender Denaturierung der Reverse Transkriptase bei $95^{\circ} \mathrm{C}$ für $10 \mathrm{~min}$. Sofern die einzelsträngige komplementäre DNA (complementary DNA, cDNA) nicht direkt für die folgende PCR-Reaktion eingesetzt wurde, fand die Aufbewahrung bei $-20^{\circ} \mathrm{C}$ statt.

Die PCR-Reaktionen wurden in $50 \mu \mathrm{l}$ Ansätzen mit den in Tabelle 1 aufgeführten PCRPrimern durchgeführt. Jeder Ansatz enthielt $2 \mu \mathrm{l}$ cDNA (1:10), 30,6 $\mu$ l DEPC- $\mathrm{H}_{2} \mathrm{O}$ (Sigma), $10 \mu \mathrm{l}$ 5x GoTaq Puffer (Promega), 3,2 $\mu \mathrm{l}$ dNTP-Mix (10 mM, Bioline), $2 \mu \mathrm{l}$ forward (f)Primer (10 pmol/ $\mu \mathrm{l}), 2 \mu \mathrm{l}$ reverse (r)-Primer $(10 \mathrm{pmol} / \mu \mathrm{l})$ und $0,2 \mu \mathrm{l}$ GoTaq Polymerase $(1 \mathrm{U}$, 
Promega). Die jeweiligen PCR-Programme unterschieden sich lediglich durch ihre Hybridisierungstemperaturen $\left(\mathrm{T}_{\mathrm{H}} ; 52-64^{\circ} \mathrm{C}\right)$ und die Anzahl der Zyklen (Tabelle 1). Die Hybridisierungszeit der PCR-Primer lag bei 15 s und die Amplifikation der DNA-Abschnitte wurde bei $72^{\circ} \mathrm{C}$ für $30 \mathrm{~s}$ durchgeführt.

\subsubsection{Gelelektrophorese, relative Quantifizierung und Statistik}

Für die Gelelektrophorese wurde ein Agarose-Ethidiumbromid-Gel verwendet. Dazu wurde DNA-Agar (Serva) in einer Konzentration von 1,5\% in 1x TB-Puffer in einer Mikrowelle aufgekocht und mit Ethidiumbromid (Serva, 0,5 $\mu \mathrm{g} / \mathrm{ml}$ Endkonzentration) versetzt. Zu den PCR-Proben wurden vor dem Auftragen auf das Gel 0,2 Volumina 6x DNA-Ladepuffer (Fermentas) zugegeben, um das Einsinken in die Geltaschen zu gewährleisten. Es wurden standardmäßig $15 \mu \mathrm{l}$ pro Probe aufgetragen und die Elektrophorese bei $100 \mathrm{~V}$ für 45-60 min durchgeführt. Zur Größenbestimmung wurde ein DNA-Größenstandard von 100 Bp (MBI Fermentas) verwendet. Die Visualisierung der DNA erfolgte durch das in die DNA interkalierende Ethidiumbromid, das mit Hilfe eines UV-Transilluminators bei einer Wellenlänge von $254 \mathrm{~nm}$ sichtbar gemacht und mittels des MultiImage Light Cabinet (Alpha Innotech Corporation) dokumentiert wurde.

Zur Quantifizierung einzelner DNA-Banden wurde das zu untersuchende Gen mit Hilfe des Computerprogramms Alpha Ease FC (Biozym Scientific) ausgewertet. Dazu wurde die Expression der Zielsequenz relativ zur Expression der dazugehörigen Gapdh-Bande bestimmt und nach Normalisierung der Werte der Quotient gebildet. Die Resultate wurden als Mittelwerte dargestellt. Bei mindestens drei unabhängigen Experimenten ( $n=3)$, wurden die Mittelwerte mit Standardabweichung dargestellt und die Signifikanzen mit dem Student's ttest analysiert (GraphPad Prism 4.0). ${ }^{*} \mathrm{p}<0,05$ wurde als signifikant angesehen, ${ }^{* *} \mathrm{p}<0,01$ als sehr signifikant und $* * * \mathrm{p}<0,001$ als hochsignifikant. 


\section{Ergebnisse}

\subsection{Das Schicksal undifferenzierter maGSCs in gesunden Mausherzen}

Multipotente Keimbahnstammzellen aus dem Hoden adulter Mäuse weisen ES-ZellEigenschaften auf und können so spontan in funktionelle Kardiomyozyten differenzieren (Guan et al. 2006; Guan et al. 2007).

Um nach Transplantation von maGSCs in das normale, gesunde Maus-Myokard deren Proliferation und Differenzierung zu untersuchen, wurden in vivo-Versuche durchgeführt. $5 \times 10^{5}$ undifferenzierte DiI-gefärbte maGSCs wurden in das Myokard von weiblichen C57BL/6 Mäusen, die durch Ciclosporin A-Behandlung immunsupprimiert waren, injiziert. Mittels Fluoreszenzmikroskopie und histologischer Färbungen konnten die DiI-Zellen und das Empfängergewebe analysiert werden. Die HE-Färbung diente der Unterscheidung von Zellkernen und Zytoplasma durch das unterschiedliche Anfärben der Zellbereiche. Zellkerne erscheinen blau, das Zytoplasma rot. Die MG-Färbung wurde zur Abgrenzung kollagener Strukturen gegen Epithel- und Muskelgewebe und zur Darstellung von Fibrosen durchgeführt. Zellkerne erscheinen nach dieser Färbung braun/schwarz, Zytoplasma schwach orange bis rot, Erythrozyten leuchtend orange, Muskulatur rot und vermehrtes Bindegewebe (Fibrose) leuchtend bzw. intensiv blau.

Mittels Fluoreszenzmikroskopie konnten 2 d nach Zelltransplantation DiI-markierte Zellen detektiert werden (Abb. 5A). HE-Analysen in parallelen Myokardschnitten zeigten gehäufte blaue Zellkernfärbungen in kleinen dichten Zellclustern, die sich deutlich vom Empfängermyokard abgrenzten (Abb. 5D). An diesen Stellen befanden sich auch DiI-Signale (Abb. 5A), so dass spezifisch nachgewiesen werden konnte, dass es sich bei den dichten Zellclustern um die transplantierten maGSCs handelte. Nach $1 \mathrm{w}$ konnten ebenfalls DiImarkierte Zellen gefunden werden (Abb. 5B). Anhand einer HE-Färbung wurde visualisiert, dass diese Zellen mit größeren Zellkernen in großen, blau gefärbten Clustern bzw. Zellansammlungen angelegt waren (Abb. 5E). Auch $4 \mathrm{w}$ nach Transplantation konnten immer noch DiI-gefärbte Zellen detektiert werden (Abb. 5C), die mittels HE-Analyse allerdings nicht mehr in Zellclustern mit großkernigen Zellen nachweisbar waren, sondern verstreut mit länglichen Nuclei vorlagen (Abb. 5F). Mittels MG-Färbung konnten ebenfalls Unterschiede im zelltransplantierten Empfängermyokard aufgezeigt werden. Im Gegensatz zu den Herzschnitten 2 d nach Transplantation (Abb. 5G) wurde in den Schnitten nach 1 w (Abb. 5H) und $4 \mathrm{w}$ (Abb. 5I) Fibrose anhand der hellblauen Färbung nachgewiesen. Auf histologischer Ebene wies keines der Herzen 4 w nach Zelltransplantation Tumore oder Teratome auf. 

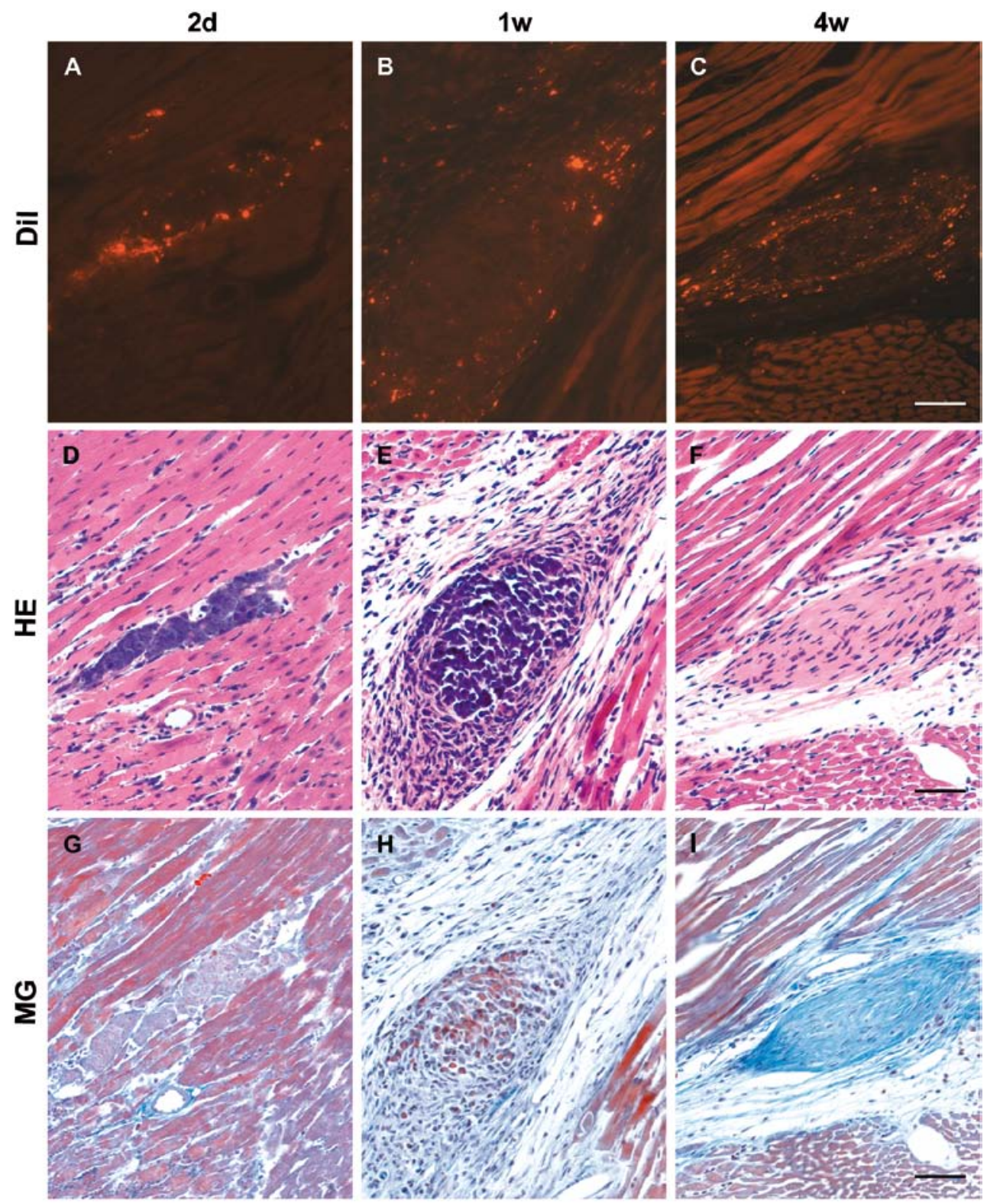

Abbildung 5: Histologische Untersuchung an normalen Mausherzen $2 \mathrm{~d}, 1 \mathrm{w}$ und $4 \mathrm{w}$ nach Injektion von undifferenzierten maGSCs. A-C: DiI-markierte Zellen zu den verschiedenen Zeitpunkten. D-F: HE-Färbungen und G-I: MG-Färbungen. Zu jedem Zeitpunkt waren DiI-gefärbte Zellen zu finden. Nach $2 \mathrm{~d}$ sieht man injizierte Zellen mittels HE-Färbung in kleinen, nach $1 \mathrm{w}$ in größeren Clustern und nach $4 \mathrm{w}$ etwas weiter verteilt. Fibrose konnte nur nach 1 und $4 \mathrm{w}$ nachgewiesen werden. Skalierung $50 \mu \mathrm{m}$.

Um die Pluripotenz und das Proliferationsspotential der injizierten Zellen zu untersuchen, wurden immunhistochemische Analysen mit Antikörpern gegen Oct4 und Ki67 durchgeführt. Oct4 ist ein Keimbahn-spezifischer Transkriptionsfaktor, der pluripotente Zellen charakterisiert (Scholer et al. 1989b). Ki67 ist ein Proliferationsmarker (Bullwinkel et al. 2006). In den Herzen mit Zelltransplantation wurden $1 \mathrm{w}$ nach Zellinjektion große Aggregate mit Oct $^{+}$Zellen gefunden (Abb. 6A). In parallelen Schnitten zeigten HE-Färbungen 
dunkelblaue Zellaggregate, die auf transplantierte undifferenzierte und unreife Zellen im linken Ventrikelmyokard hinweisen (nicht gezeigt). Viele der injizierten Zellen waren nach $1 \mathrm{w}$ Oct $4^{+}$und $\mathrm{Ki}^{+} 7^{+}$(Abb. 6A und C), was auf ihre Pluripotenz und das bestehendes Proliferationspotential hindeutet. Allerdings waren die Zellen mit den länglichen Zellkernen (siehe HE-Färbung Abb. 5E), die am Rand der Zellaggregate zu sehen waren, Oct4- (Abb. 6A), aber Ki67 ${ }^{+}$(Abb. 6C), was bedeutet, dass diese Zellen nicht mehr pluripotent sind, aber nach proliferieren. Nach $4 \mathrm{w}$ konnten weder Oct $4^{+}$noch $\mathrm{Ki} 7^{+}$Zellen gefunden werden (Abb. 6B und D), was auf einen Verlust des Pluripotenzpotentials und der Proliferationskapazität schließen lässt.

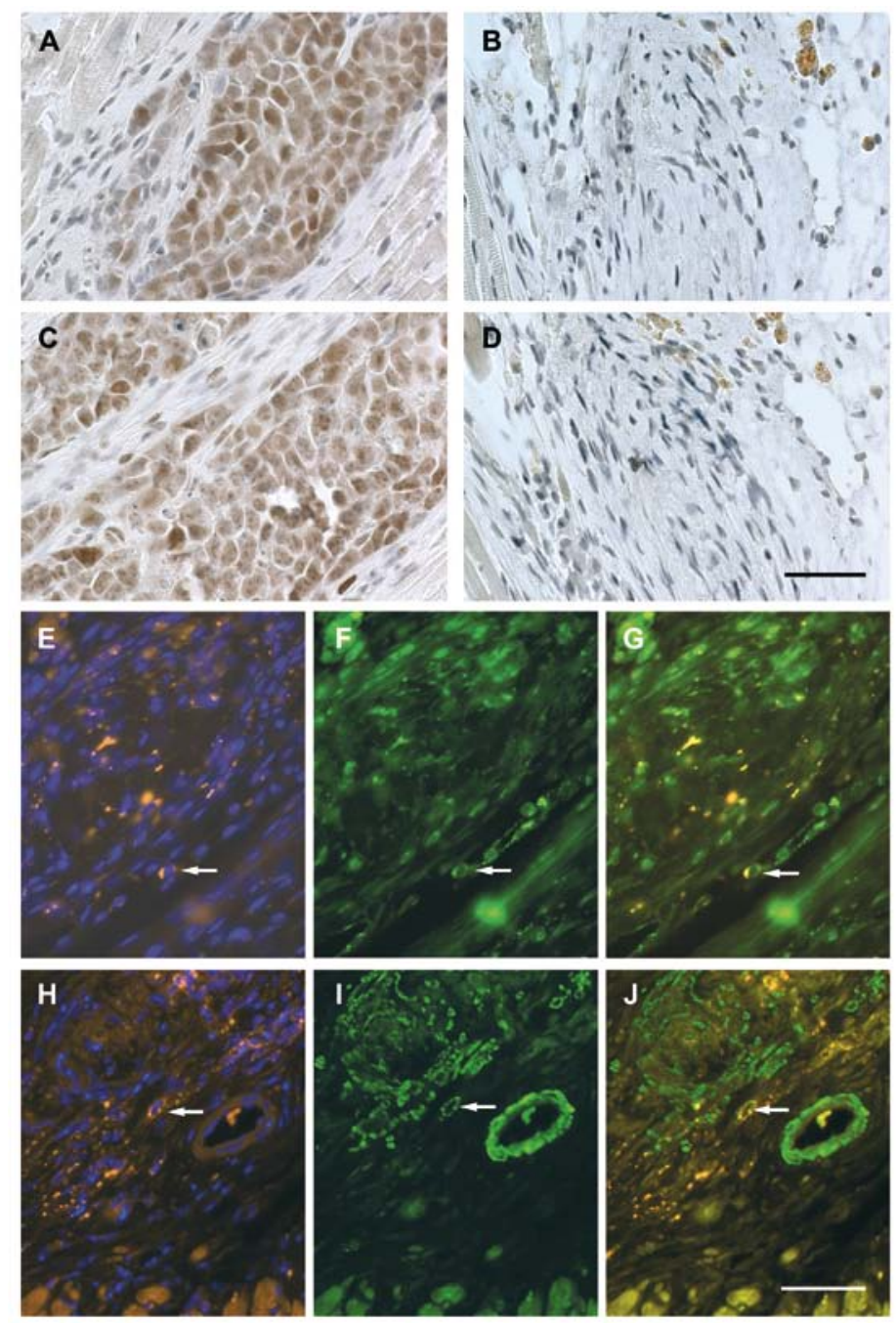

Abbildung 6: Das Schicksal der ins Myokard transplantierten Zellen. A-D: Histologische Schnitte, die $1 \mathrm{w}$ nach Transplantation Oct $4^{+}$und Ki67 $7^{+}$Zellen zeigen (A und C, braun), die allerdings nach $4 \mathrm{w}$ nicht mehr nachzuweisen waren (B und D). E-J: Immunfärbungen der transplantierten Zellen nach 4 w. E-G zeigt eine vWF-Färbung und H-J eine SMA-Färbung. In F und I sind jeweils die vWF bzw. SMA positiven Zellen zu sehen und in $G$ und $J$ die Überlagerungen der entsprechenden DiIZellen und der vWF- bzw. SMA-Färbungen (Pfeile). Die Zellkerne sind mittels DAPI-Färbung visualisiert. Skalierung $50 \mu \mathrm{m}$. 
Um zu überprüfen, ob und in welche Richtung die Zellen differenzieren, wurden indirekte Immunfluoreszenz-Färbungen durchgeführt, um smooth muscle alpha actin (SMA), den vonWillebrand-Faktor (vWF) und das kardiale Troponin T (cTnT) nachzuweisen. SMA ist ein Markerprotein für Zellen der glatten Muskulatur (Skalli et al. 1989), während der vWF von vaskulären Endothelzellen gebildet wird, die die Innenwand eines Blutgefäßes auskleiden (Vincentelli et al. 2003). Das Protein cTnT wird im Herzmuskel von den Kardiomyozyten gebildet und dient oft als Nachweis von Schädigungen des Herzens, da es dabei ins Blut freigesetzt wird (Rottbauer et al. 1996).

Wurden die Herzschnitte $4 \mathrm{w}$ nach maGSC-Transplantation gegen vWF (Abb. 6E-G) und SMA (Abb. 6H-J) gefärbt, zeigten sich nur vereinzelte positive DiI-markierte Zellen (Abb. 6E-J), was darauf hinweist, dass sich die transplantierten Zellen in vaskuläre endotheliale und glatte Muskelzellen differenzieren können.

Um zu analysieren, ob die injizierten maGSCs auch in die kardiale Richtung differenzieren, wurden Immunfärbungen gegen cTnT durchgeführt (Abb. 7). Nach 1 w (Abb. 7A) und nach $4 \mathrm{w}$ (Abb. 7D) konnten DiI-positive Zellen detektiert werden, die negativ für cTnT waren. Das Myokard dagegen ist deutlich cTnT angefärbt (Abb. 7B, C, E, F). In der Überlagerung sieht man, dass alle DiI-positiven Zellen eindeutig cTnT negativ sind (Abb. 7C und F).
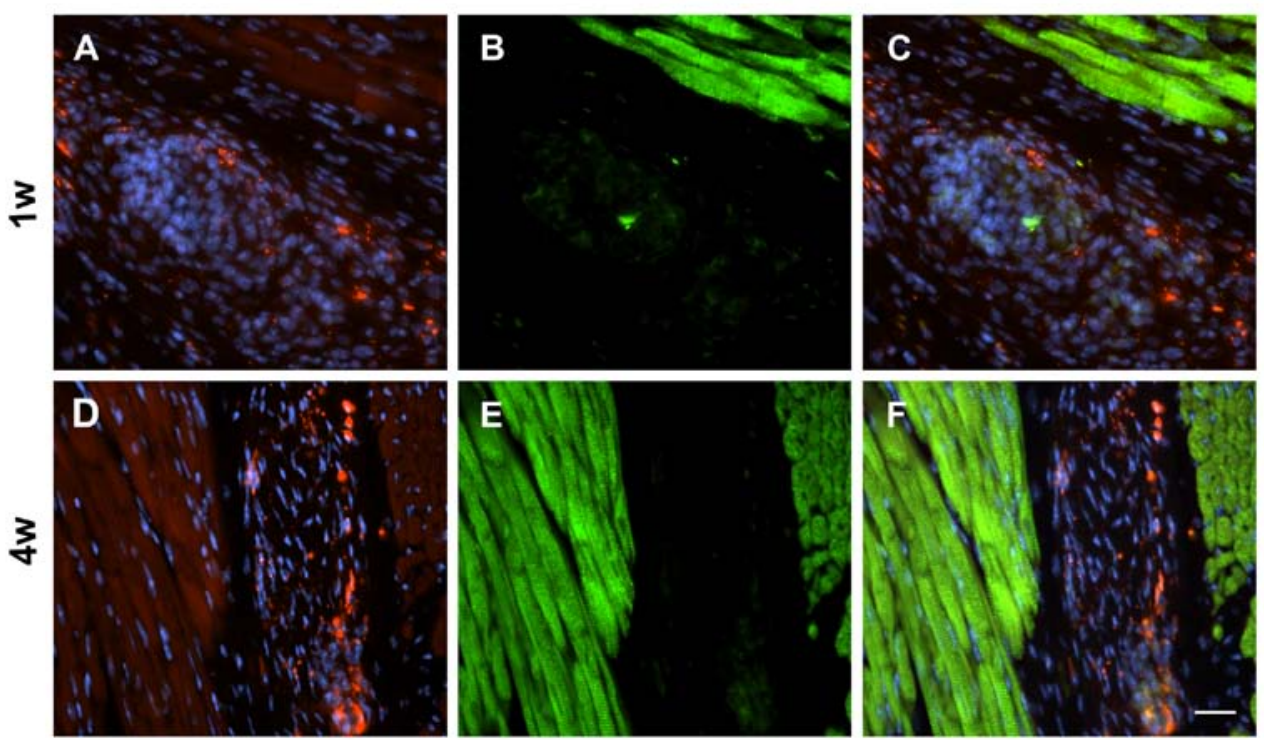

Abbildung 7: MaGSCs differenzieren nach Transplantation in normale Mausherzen nicht in die kardiale Richtung. Immunfluoreszenzfärbungen gegen cTnT zeigten, dass die DiI-markierten Zellen (A, D) negativ für cTnT waren, nach $1 \mathrm{w}$ (B) und $4 \mathrm{w}$ (E). C zeigt die Überlagerung von A und B. In F ist die Überlagerung von D und E zu sehen. Die Zellkerne sind mit DAPI angefärbt. Skalierung $25 \mu \mathrm{m}$. 
Zusammenfassend lässt sich sagen, dass die undifferenzierten maGSCs nach Transplantation in normale Mausherzen in der Lage sind zu proliferieren und in vaskuläre endotheliale und glatte Muskulatur-Zellen differenzieren können. Manche Zellen verlieren nach $1 \mathrm{w}$ ihre Pluripotenz, wachsen aber noch $\left(\mathrm{Oct} 4^{-} / \mathrm{Ki} 67^{+}\right)$. Nach $4 \mathrm{w}$ konnten keine proliferierenden Zellen und auch keine Tumore oder Teratome nachgewiesen werden. Außerdem konnten die transplantierten maGSCs zwar in vaskuläre endotheliale und glatte Muskelzellen differenzieren, aber nicht in Kardiomyozyten. Diese Daten wurden im Fachjournal Circulation Research publiziert (Guan et al. 2007).

\subsection{Der Einfluss einer vermehrten Last im Herzen auf die Differenzierung der injizierten maGSCs}

Um zu überprüfen, wie sich die maGSCs im Vergleich zu normalen, gesunden Mausherzen in mechanisch belasteten Mausherzen entwickeln, sollten undifferenzierte maGSCs in Mäuse injiziert werden, bei denen eine erhöhte Last im Herzen durch Shunt- und TAC-OPs induziert wurde.

\subsubsection{Etablierung einer Vorlast oder Nachlast im Maus-Modell}

Zur Induktion einer Vorlast oder Nachlast im Maus-Modell wurden ca. $12 \mathrm{w}$ alte weibliche C57BL/6-Mäuse Shunt- oder TAC-OPs unterzogen. Bei der Shunt-OP wurde durch eine Punktion der Aorta abdominalis und der Vena cava infererior eine Verbindung zwischen den beiden Gefäßen hergestellt, so dass das sauerstoffreiche Blut aus der Aorta in die Vene floss und somit zu einer Vorlast der Ventrikel führte (siehe 2.2.2.2). Bei der TAC-OP dagegen wurde eine Nachlast des linken Ventrikels durch Verengung des Aortenbogens herbeigeführt (siehe 2.2.2.3). Um zu überprüfen, ob diese OPs die Mausherzen wie erwartet beeinflussen und ob die Methoden in unserem Labor richtig etabliert waren, wurden die operierten Mausherzen mittels HE- und MG-Färbungen histologisch untersucht.

Nach 2 und 4 w konnten in der Myokardstruktur der Shunt-operierten und NaCl-injizierten Mäuse keine Unterschiede im Vergleich zu den Sham-Tieren festgestellt werden (Abb. 8AD). Zu den beiden Zeitpunkten war die Herzmuskulatur in den Shunt-operierten und ShamTieren normal, d.h. regelmäßig und aus quergestreiften Muskelfasern aufgebaut, und zeigte keine Auffälligkeiten. Die Zellkerne der Myozyten konnten gut angefärbt werden, waren mittelständig und zeigten keine Abnormalitäten. Auch in der MG-Analyse ließ sich die quergestreifte Muskulatur gut visualiseren (Abb. 8 E-H). Außerdem waren die Glanzstreifen (Disci intercalares) zu erkennen (Abb. 8E), durch die die Kardiomyozyten miteinander 
verbunden sind. $\mathrm{Zu}$ beiden Zeitpunkten konnte ebenfalls kein Unterschied zwischen den Shunt-operierten und den Sham-Tieren beobachtet werden (Abb. 8E-H). Weder $2 \mathrm{w}$ noch $4 \mathrm{w}$ nach Shunt-OP trat Fibrose auf (Abb. 8G, H).
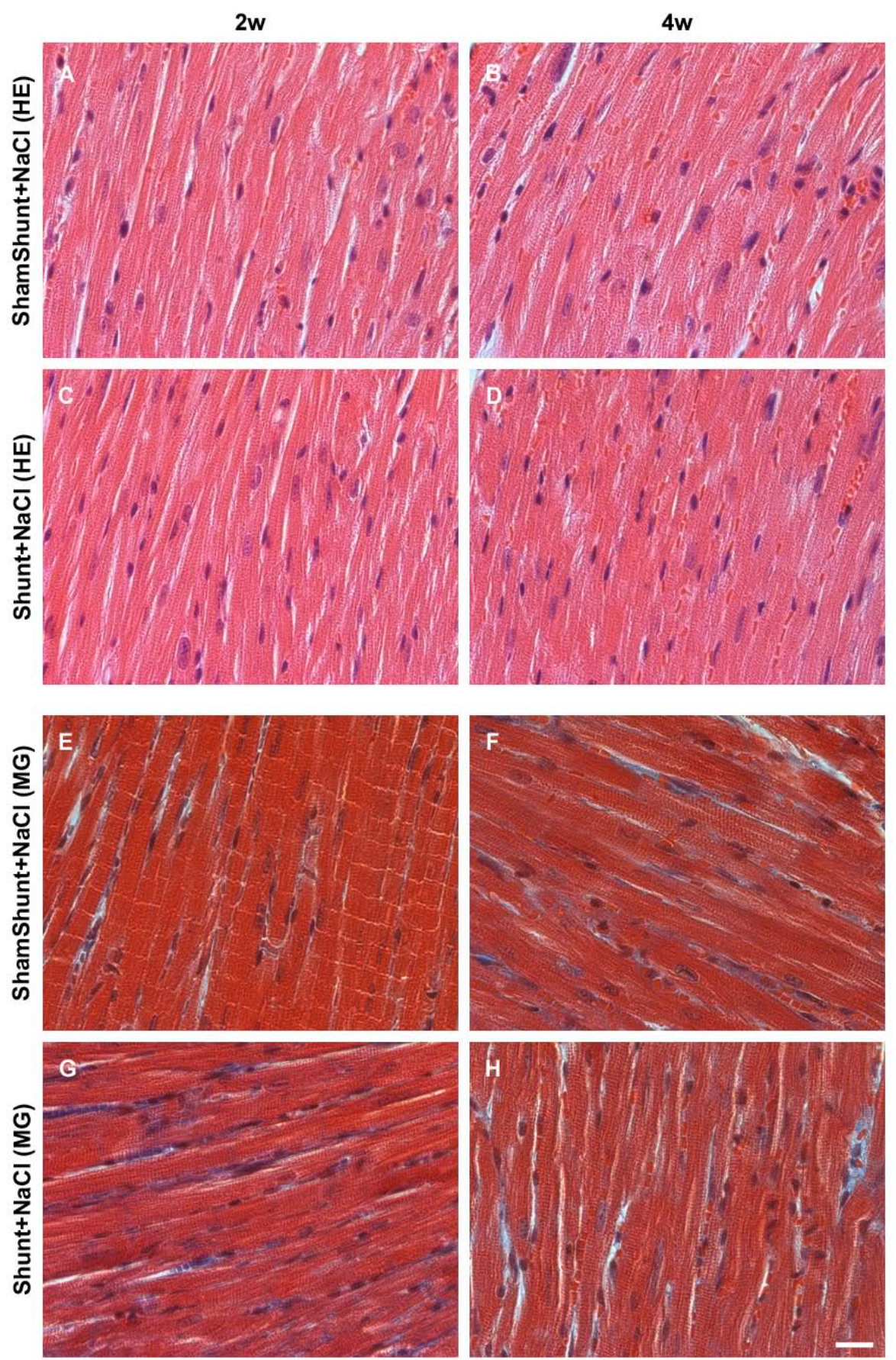

Abbildung 8: HE- und MG-Färbungen der Mausherzen nach Shunt- oder Sham-OP ohne Zellinjektion. A-D: HE-Färbungen und E-H: MG-Färbungen. A, B und E, F: Sham-Tiere. C, D und G, H: Shunt-operierte Tiere. Nach der HE-Färbung ist keine Veränderung der Muskulatur 2 und $4 \mathrm{w}$ nach OP in den Sham und Shunt-Tieren zu erkennen (A-D). Es konnte auch keine Fibrose in den Sham- bzw. Shunt-Mäusen nach 2 w oder 4 w festgestellt werden (E-H). Skalierung $20 \mu \mathrm{m}$. 

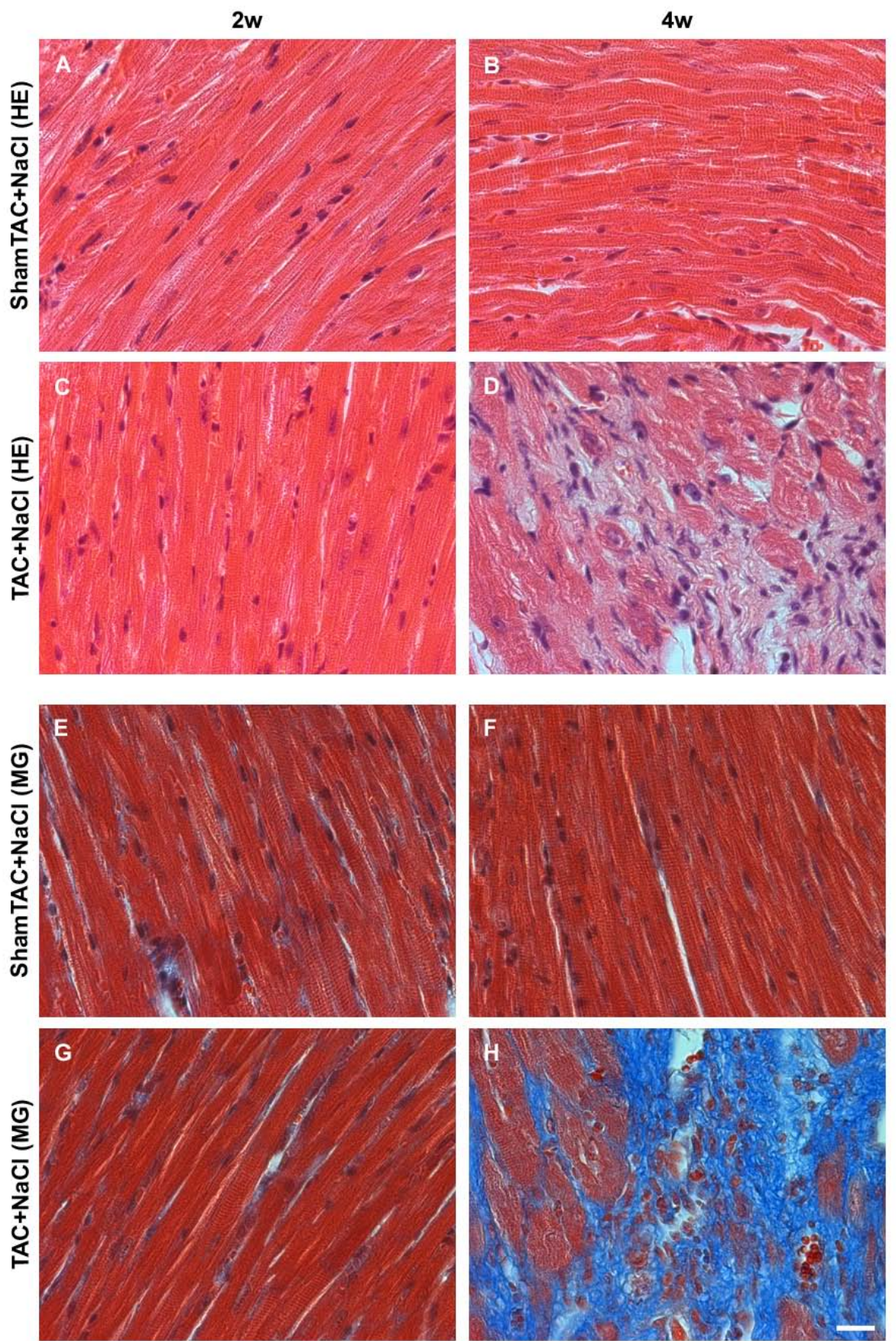

Abbildung 9: HE- und MG-Färbungen der Mausherzen nach TAC- oder Sham-OP ohne Zellinjektion. A-D: HE-Färbungen und E-H: MG-Färbungen. A, B und E, F: Sham-Tiere. C, D und G, H: TAC-operierte Tiere. Nach der HE-Färbung war keine Veränderung der Muskulatur $2 \mathrm{w}$ nach OP in den Sham und TAC-Tieren zu sehen (A, B), aber nach $4 \mathrm{w}$ zeigte sich eine Auflockerung der Myokardstruktur in den TAC-Tieren im Vergleich zu den Sham-Tieren (C, D). $2 \mathrm{w}$ nach OP lagen keine Veränderungen des Bindegewebes bei Sham- und TAC-Mäusen vor (E, F). Nach $4 \mathrm{w}$ konnte in den TAC-Tieren eine stark vermehrte Fibrose im Vergleich zu den Sham-Tieren festgestellt werden (G, H). Skalierung $20 \mu \mathrm{m}$.

Die Myokardstruktur war sowohl in den Sham- als auch in den TAC-operierten Tieren mit NaCl-Injektion 2 w nach OP unverändert (Abb. 9A, B), und die Disci intercalares waren gut 
zu erkennen (Abb. 9B). Nach 4 w konnten allerdings drastische Veränderungen im Myokard der TAC-Tiere im Vergleich zu den Kontrolltieren beobachtet werden (Abb. 9C, D): Die Muskulatur war stark aufgelockert und zeigte keine regelmäßigen quergestreiften Muskelfasern mehr. Die Zellkerne waren vergrößert und lagen nicht mehr mittelständig in den Kardiomyozyten vor. Die MG-Untersuchung zeigte keinen Unterschied zwischen den Nachlast-induzierten Mäusen und den Kontroll-Mäusen nach 2 w (Abb. 9E, F), im Gegensatz zu dem 4 w-Zeitpunkt. Hier konnte in den TAC-operierten Tieren eine starke Vermehrung des Bindegewebes beobachtet werden (blau gefärbte Fibrose, Abb. 9H).

Zusammenfassend lässt sich sagen, dass die Shunt-OP die Myokardstruktur kaum beeinflusst, während die TAC-OP zu starken Veränderungen der Myokardstruktur und Fibrose 4 w nach Intervention führt.

\subsubsection{Vermehrte Bindegewebsbildung nach maGSC-Transplantation in Last-induzierten Mausherzen}

Sowohl Shunt- und TAC-operierten Mäusen als auch in ihren jeweiligen Kontroll-Tieren

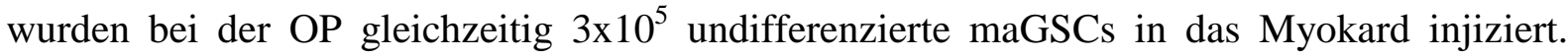
Nach 2 d, 2 und 4 w wurden die Mäuse finalisiert, die Herzen entnommen, perfundiert und fixiert. In keinem der Mausherzen wurden Teratome festgestellt.

Zur Phänotypisierung dieser Herzen und zur Überprüfung, welchen Einfluss die injizierten Zellen in den durch Shunt- und TAC-OP belasteten Herzen ausübten, wurden die Mausherzen histologisch untersucht. Die Paraffinschnitte der Herzen wurden entweder nur bezüglich DiIpositiver Zellen analysiert oder zusätzlich HE- und MG-Färbungen unterzogen, um das Gewebe zu charakterisieren.

In den Sham-Mäusen der Shunt-Gruppe wurden zu jedem Zeitpunkt DiI-positive Zellen detektiert, jedoch mehr nach $2 \mathrm{~d}$ und $2 \mathrm{w}$ als nach $4 \mathrm{w}$ (Abb. 10A-C). In der HE-Färbung konnte man nach $2 \mathrm{~d}$ großkernige Zellen in dichten Zellansammlungen sehen (Abb. 10D-F). Nach 2 und $4 \mathrm{w}$ hatten sich die Zellen verteilt und waren in größeren Strukturen aufzufinden. Die MG-Färbung zeigte nach 2 und 4 w die stärkste Fibrose (Abb. 10G-I). 

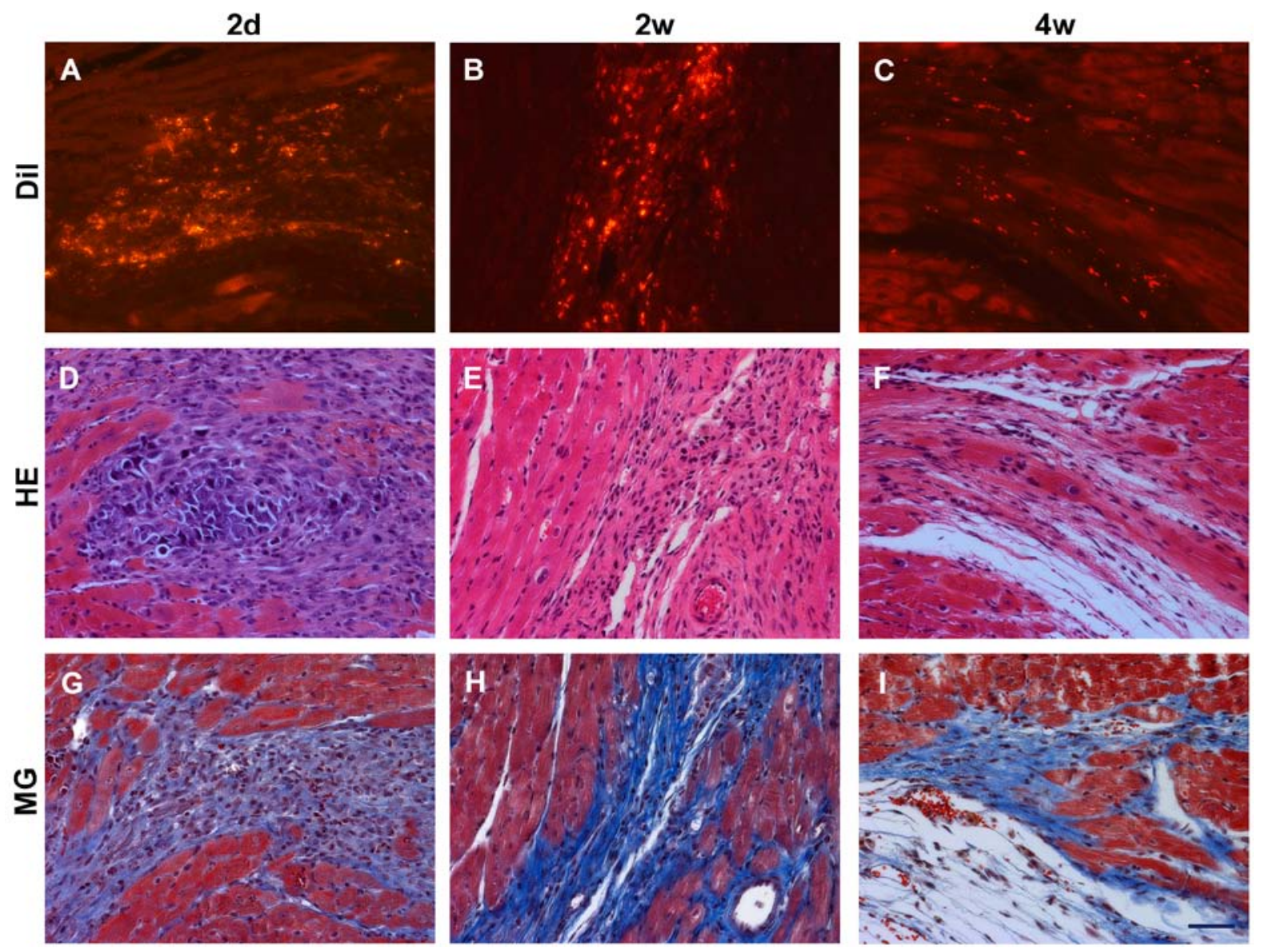

Abbildung 10: Histologische Untersuchungen der Herzen Sham (Shunt) operierter Mäuse nach 2 d, 2 w und 4 w. A-C: DiI-Zellen, D-F: HE-Färbungen und G-I: MG-Färbungen. DiI-positive Zellen waren zu jedem Zeitpunkt zu detektieren (A-C). Nach 2 d sah man Zellklumpen der injizierten Zellen mit dunkelblauen Nuclei (D), nach 2 und $4 \mathrm{w}$ waren die Zellen vereinzelter und hatten längliche Nuclei (D, E). Fibrose war nach $2 \mathrm{~d}$ kaum nachweisbar (G), aber stark nach $2 \mathrm{w}$ (H) und $4 \mathrm{w}$ (I) vorhanden. Skalierung $50 \mu \mathrm{m}$.

In den Tieren nach Shunt-OP und Zellinjektion waren, wie bei den Sham-Tieren (Abb. 10), nach $2 \mathrm{~d}$ und $2 \mathrm{w}$ viele DiI-positive Zellen zu detektieren, im Gegensatz zu $4 \mathrm{w}$ (Abb. 11AC), was durch Zellproliferation erklärt werden könnte. Es war nach $4 \mathrm{w}$ aber eindeutig zu erkennen, dass in bestimmten Bereichen DiI-positive Zellen vorhanden waren, da sich das Myokardgewebe verändert hatte. Korrelierend mit den Sham-Tieren konnte man $2 \mathrm{~d}$ nach Zellinjektion in der HE-Färbung Zellansammlungen in dichten Zellaggregaten erkennen (Abb. 11D). Nach 2 und $4 \mathrm{w}$ verteilten sich die injizierten Zellen mehr und zeigten teilweise längliche Zellkerne (Abb. 11E-F), wie auch in den Kontroll-Mäusen. In der MG-Färbung zeigte sich $2 \mathrm{~d}$ nach OP kaum Fibrose, die allerdings nach 2 und $4 \mathrm{w}$ stark ausgeprägt war (Abb. 11G-I). Dieses Ergebnis konnte zuvor bei den Kontrolltieren (Abb. 10) beobachtet werden. Somit hatte die Shunt-OP keinen Einfluss auf die Fibrosebildung. 
2d
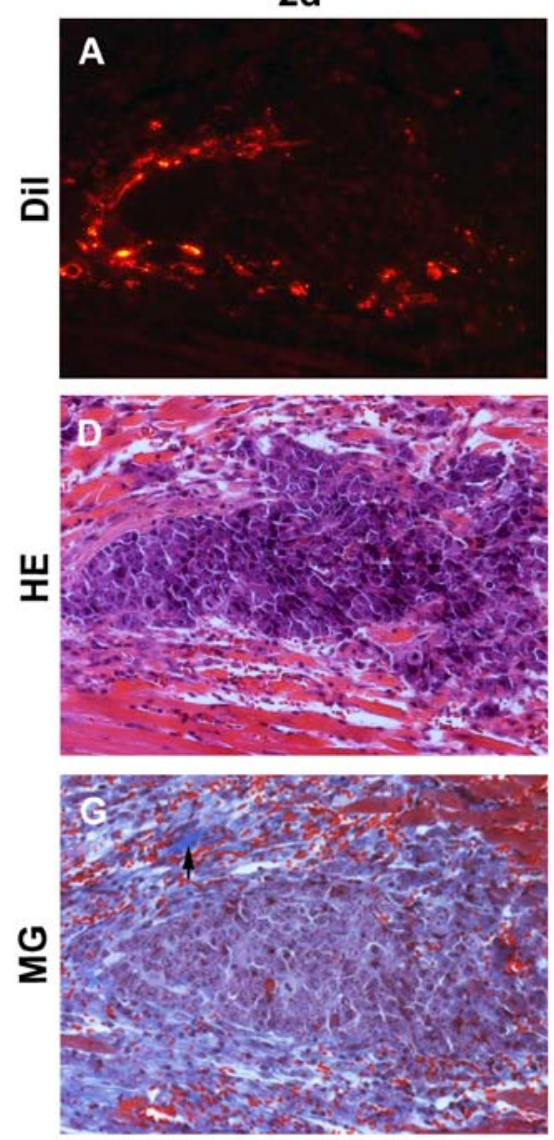

$2 w$
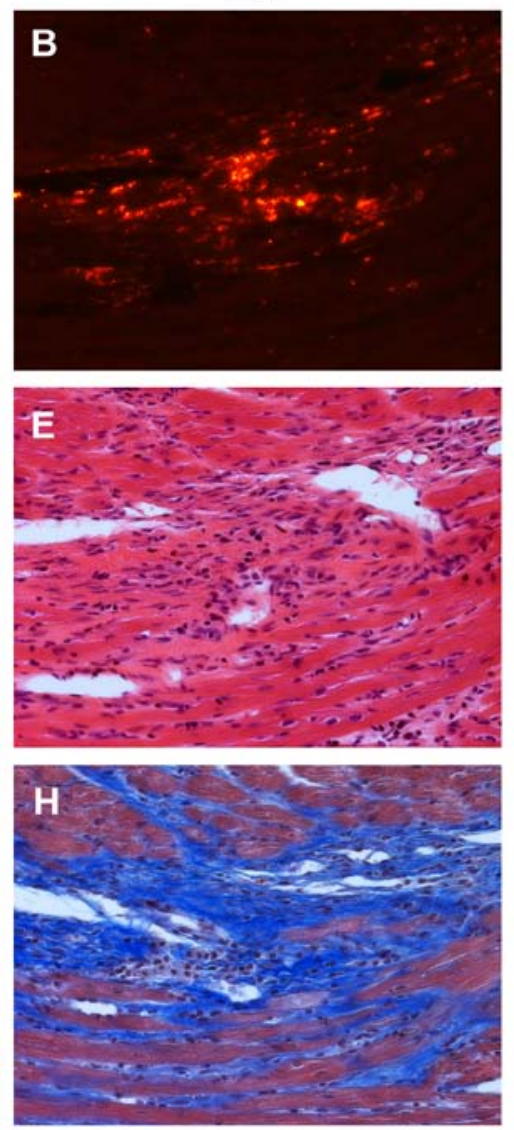

$4 w$
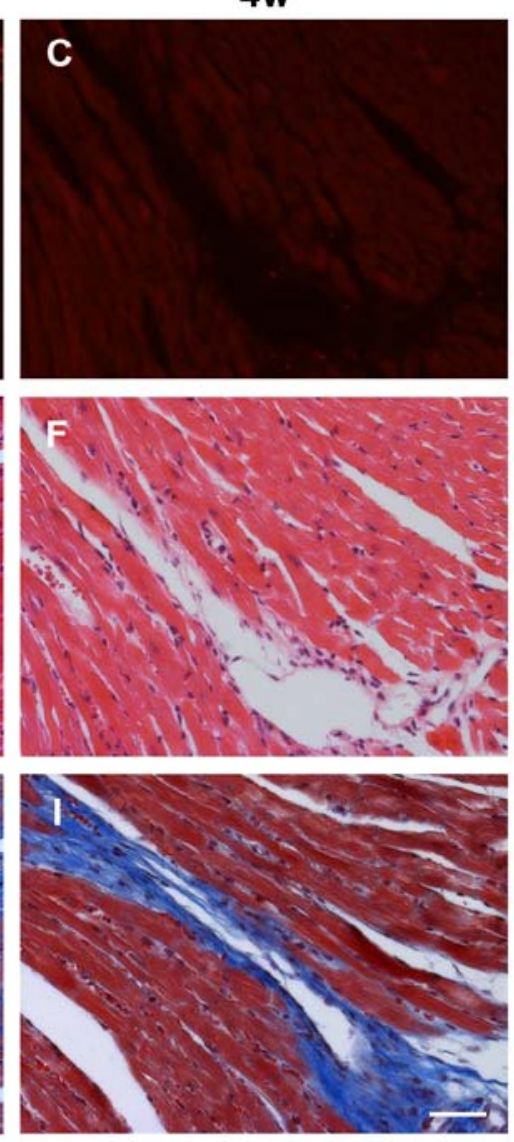

Abbildung 11: Histologische Untersuchungen von Mausherzen 2d, 2w und 4w nach Shunt-OP und Zelltransplantation. A-C: DiI-Zellen, D-F: HE-Färbungen und G-I: MG-Färbungen. Abnahme DiI-positiver Zellen 4w nach Injektion im Vergleich zu 2d und 2w (A-C). Starke Ansammlung von Zellen nach 2d (D), im Gegensatz zu eher verstreuten oder vereinzelten Zellen nach 2 und 4w (E, F). Fibrose konnte nur im geringen Maß nach 2d (G, Pfeil), aber stärker nach 2w (H) und 4w (I) detektiert werden. Skalierung $50 \mu \mathrm{m}$.

Zwischen den Shunt-operierten Tieren und deren Kontrollen konnten also kaum Unterschiede durch die histologischen Untersuchungen und die DiI-Kontrolle aufgezeigt werden. DiI positive Zellen konnten in den Sham- und in den Shunt-Mäusen zu jedem Zeitpunkt detektiert werden. In beiden Maus-Gruppen fanden sich dichte Zellansammlungen nach 2 d, später vereinzelten sich die Zellen und die Nuclei verlängerten sich. Fibrose zeigte sich vor allem $2 \mathrm{w}$ und $4 \mathrm{w}$ nach OP in den beiden Gruppen.

Um auch die Entwicklung der transplantierten Zellen in den durch TAC-OP Nachlastinduzierten Mäusen und ihren Sham-Tieren charakterisieren und einschätzen zu können, wurden die gleichen histologischen Analysen wie in den durch Shunt-OP Vorlast-induzierten Mäusen und deren Kontroll-Mäusen durchgeführt. 
In den Sham-Tieren der TAC-Gruppe konnten DiI-positive Zellen zu allen Zeitpunkten nachgewiesen werden, allerdings etwas in geringerem Umfang $4 \mathrm{w}$ nach Zelltransplantation (Abb. 12A-C). In der HE-Färbung erschienen die injizierten Zellen in Zellansammlungen (gut sichtbar anhand der vermehrten blau gefärbten Zellkerne) besonders deutlich nach 2 und $4 \mathrm{w}$ (Abb. 12D-F). In den Herzgeweben wurde Fibrose insbesondere nach 2 und 4 w mittels MGFärbung festgestellt (Abb. 12 G-H).
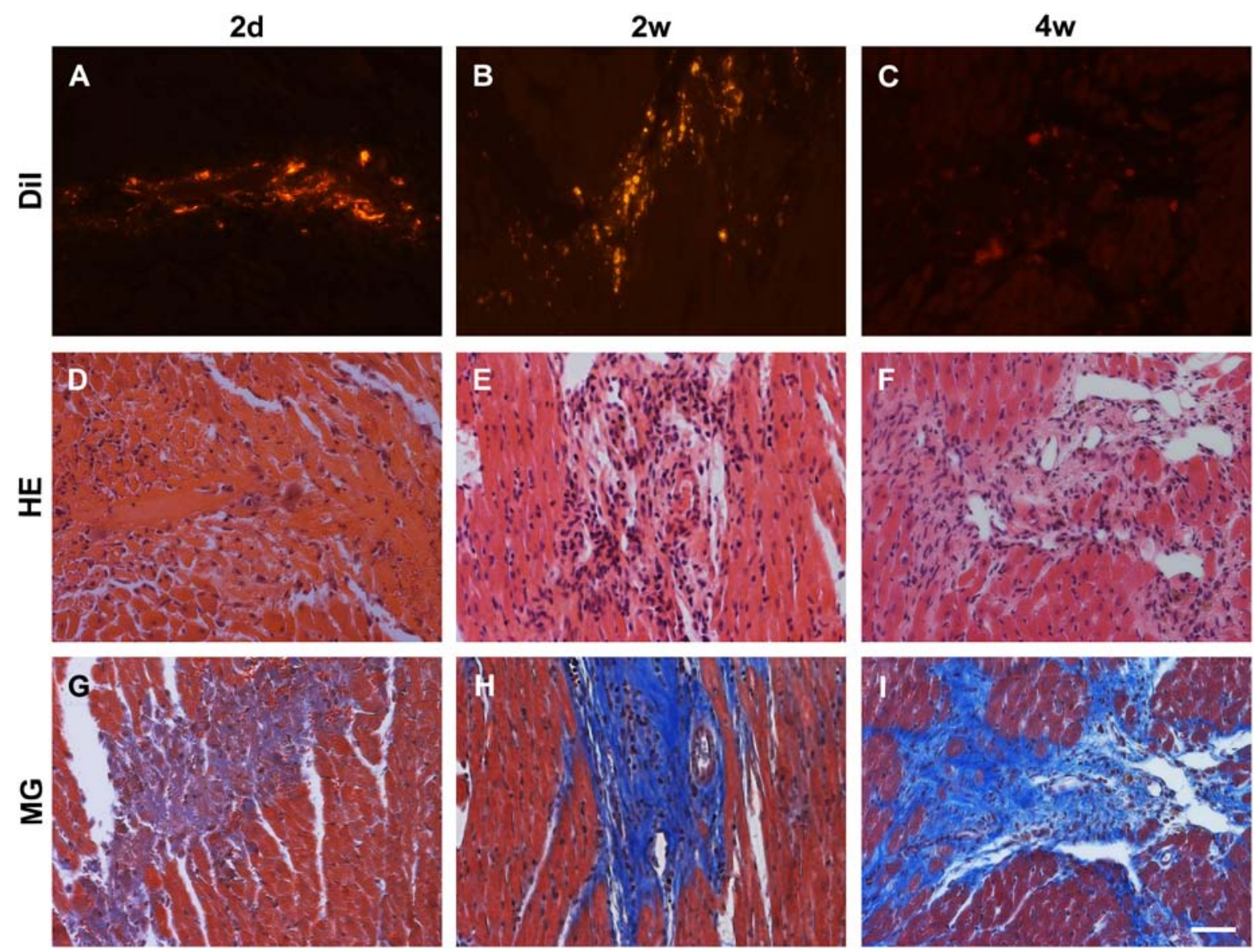

Abbildung 12: Histologische Untersuchungen der Herzen Sham (TAC) operierter Mäuse nach 2 d, 2 w und 4 w. A-C: DiI-Zellen, D-F: HE-Färbungen und G-I: MG-Färbungen. DiI-positive Zellen waren zu jedem Zeitpunkt zu detektieren (A-C). Nach 2d sah man die injizierten Zellen mit den dunkelblauen Nuclei (D), nach $2 \mathrm{w}$ waren dichte Zellstrukturen zu erkennen (E) und nach $4 \mathrm{w}$ waren die Zellen etwas vereinzelt und hatten teilweise längliche Nuclei (F). Fibrose war nach $2 \mathrm{~d}$ zu kaum zu detektieren (G), aber stark ausgeprägt nach 2 und $4 \mathrm{w}(\mathrm{H}, \mathrm{I})$. Skalierung $50 \mu \mathrm{m}$.

In den Tieren nach TAC-OP waren DiI-gefärbte maGSCs nach 2 d im Myokard nachweisbar, was durch die Ansammlung der Zellen an derselben Stelle mittels HE-Färbung bestätigt wurde (Abb. 13A, D). Zu diesem Zeitpunkt war nur eine leichte Vermehrung des Bindegewebes (leichte Fibrose) mittels MG-Färbung zu detektieren (Abb. 13G), ähnlich wie in den Kontroll-Tieren (Abb. 12). 2 und $4 \mathrm{w}$ nach TAC-OP und Zellinjektion waren immer 
noch DiI-positive Zellen im Herzgewebe zu identifizieren, was zeigt, dass sich diese Zellen im Gewebe angesiedelt haben (Abb. 13B, C). Auch zu den späteren Zeitpunkten konnten Zellansammlungen der transplantierten Zellen durch HE-Färbung nachgewiesen werden (Abb. 13E, F). Nach $2 \mathrm{w}$ wurde an der Transplantationsstelle eine starke Zunahme von fibrotischem Gewebe im Vergleich zu 2 d detektiert (Abb. 13H), was sich nach 4 w bestätigte (Abb. 13I).
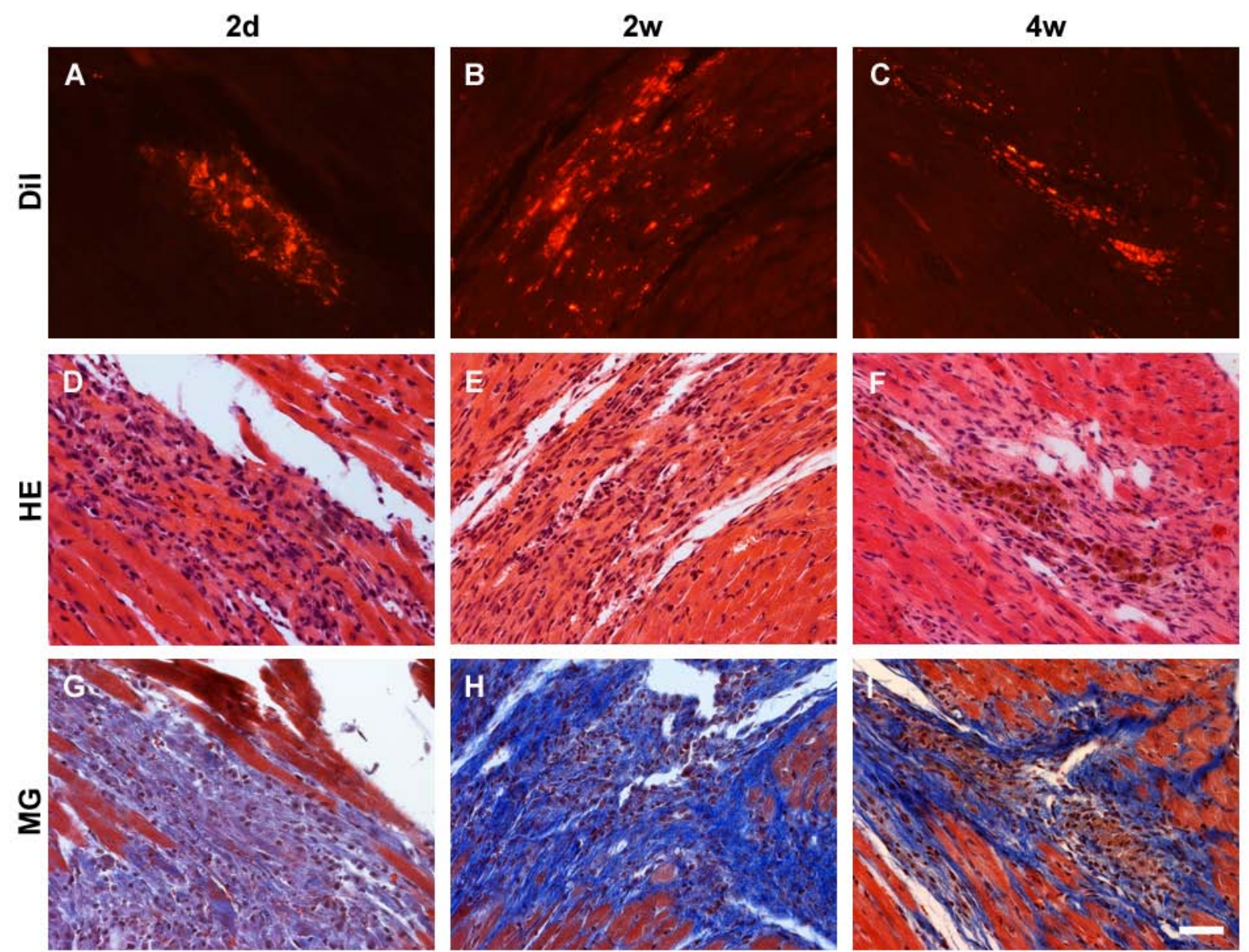

Abbildung 13: Histologische Untersuchungen der Herzen zelltransplantierter TAC-operierter Mäuse nach 2 d, 2 w und 4 w. A-C: DiI-Zellen, D-F: HE-Färbungen und G-I: MG-Färbungen. DiIpositive Zellen waren zu jedem Zeitpunkt nachzuweisen (A-C). Injizierte Zellen mit dunkelblauen Nuclei waren zu jedem Zeitpunkt gut zu erkennen. Nach $2 \mathrm{~d}$ und $2 \mathrm{w}$ (D, E) erschienen die injizierten Zellen etwas kompakter als nach $4 \mathrm{w}(\mathrm{F})$. Fibrose war nach $2 \mathrm{~d}$ kaum nachzuweisen, aber verstärkt nach $2 \mathrm{w}(\mathrm{H})$ und $4 \mathrm{w}$ (I). Skalierung $50 \mu \mathrm{m}$.

Zwischen den TAC-Mäusen und deren Kontrollen mit Zelltransplantation ließen sich kaum Unterschiede durch die HE- und MG-Färbung feststellen. Zu allen Zeitpunkten konnten DiIpositive Zellen detektiert und durch HE-Färbung bestätigt werden. Fibrose wurde ebenfalls zu allen Zeitpunkten beobachtet (sehr schwach nach 2 d) und war sowohl in den TAC- als auch den Sham-Tieren nach 2 und 4 w am stärksten ausgeprägt. 
Vergleicht man TAC- und Shunt-operierte Mäuse sind kaum Differenzen in der histologischen Analyse durch HE- und MG-Färbung der Herzgewebe zu erkennen. In beiden Gruppen konnten die DiI-markierten, injizierten maGSCs zu allen Zeitpunkten detektiert und Zellansammlungen durch HE-Färbungen bestätigt werden. Es konnte eine eindeutige FibroseBildung in den Mausherzen nach Zellinjektion beobachtet werden (Vergleich Abb. 8, 9 zu Abb. 10, 11, 12, 13). In den Shunt- und Sham-Mäusen mit NaCl-Injektion war nach 2 und $4 \mathrm{w}$ keine Fibrose zu detektieren, während nach Zellinjektion zu allen Zeitpunkten eine vermehrte Bindegewebsbildung zu beobachten war. Fibrose konnte in den TAC- und Sham-Tieren mit $\mathrm{NaCl}$ nach $2 \mathrm{w}$ kaum analysiert werden, im Gegensatz zu starker Fibrose in den TAC-Tieren mit $\mathrm{NaCl}$ nach 4 w. In den Tieren mit Zellinjektion zeigte sich in allen Gruppen (Shunt-, TAC- und jeweilige Kontrolltiere) vermehrtes Bindegewebe zu allen Zeitpunkten, allerdings war es 2 d nach OP nur sehr schwach zu detektieren.

\subsubsection{Das Schicksal undifferenzierter maGSCs in Shunt- und TAC-operierten Mäusen}

Um zu überprüfen, ob die injizierten Zellen noch pluripotent sind, wurden immunhistochemische Analysen gegen Oct4 durchgeführt. Dabei wurde festgestellt, dass die injizierten Zellen nach $2 \mathrm{~d}$ größtenteils noch Oct4 ${ }^{+}$sind (Abb. 14A, D), diesen Marker allerdings nach 2 und 4 w nicht mehr exprimieren (Abb. 14B, C, E, F). Zu den späteren Zeitpunkten konnten nur die blau gefärbten Zellkerne der transplantierten Zellen und der Empfängerzellen detektiert werden. Dieses Ergebnis zeigte sich sowohl in den Lastinduzierten Mäusen (Shunt und TAC-OP) als auch in deren Kontrollen. In Abb. 14 sind die Gewebeschnitte der Sham- und Shunt-operierten Mäuse dargestellt. Dabei war auffällig, dass die transplantierten Zellen nach 2 d (Abb. 14 A, D) sehr große Zellkerne aufwiesen, die sich nach 2 und $4 \mathrm{w}$ verlängerten. Wie auch schon in den histologischen Untersuchungen gezeigt, verstreuten sich die anfangs noch dichten Zellansammlungen im Laufe der Zeit (Abb. 14B, C, E, F). Dies war ebenfalls in allen 4 Gruppen, den Shunt-, TAC- und jeweiligen Sham-Tieren, festzustellen (TAC- und Sham-Daten nicht gezeigt).

Insgesamt lässt sich festhalten, dass die injizierten maGSCs im Laufe der ersten $2 \mathrm{w}$ nach Transplantation in Last-induzierten Mäusen und deren Kontrollen ihre Pluripotenz verlieren. 

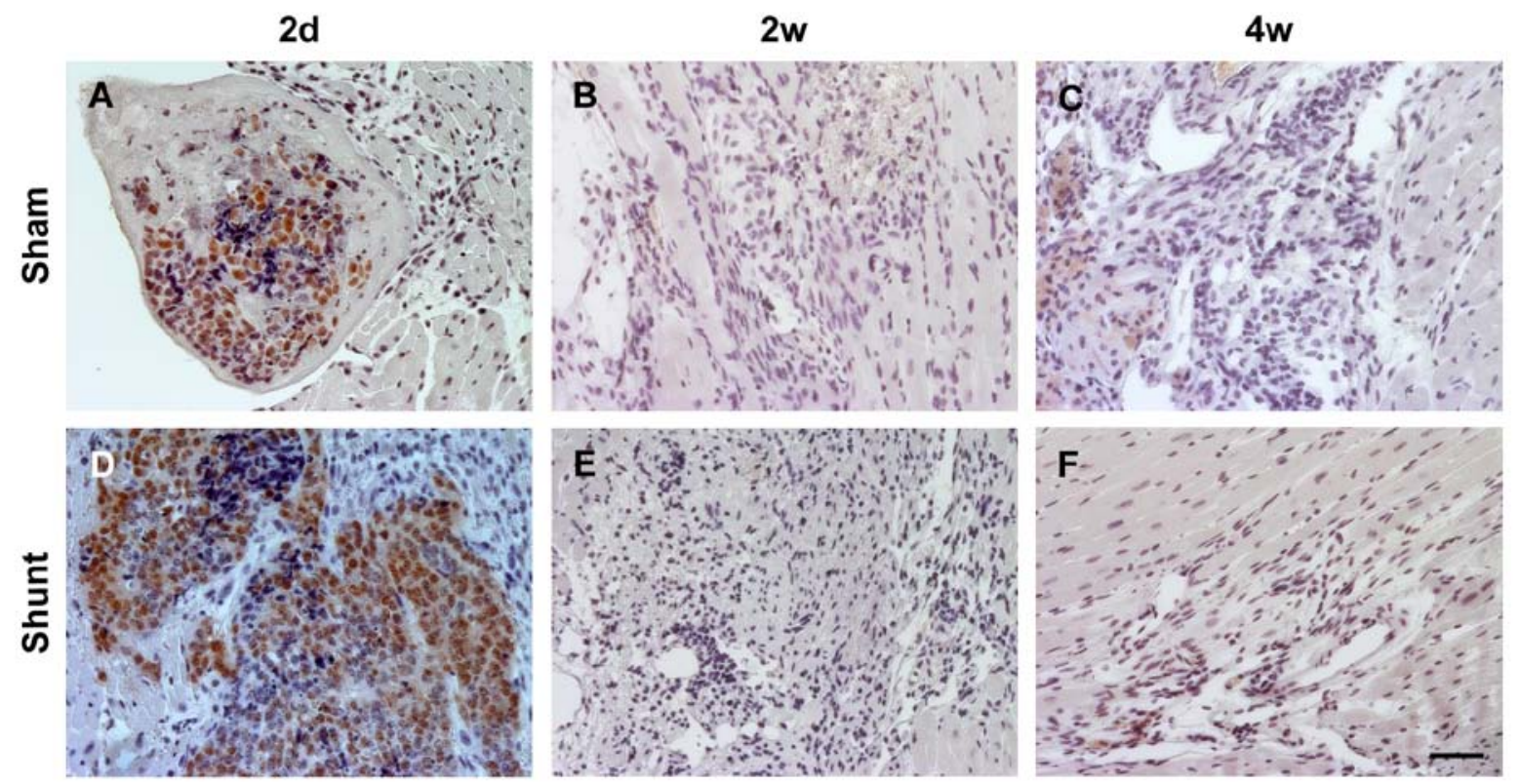

Abbildung 14: Oct4-Färbung der Myokardschnitte von Sham- und Shunt-operierten Tieren. Oct4-Färbung in Herzschnitten von Sham Mäusen (A-C) und von Shunt Tieren (D-F). Nur nach 2 d konnten injizierte Oct $4^{+}$Zellen in den Herzen Sham- und Shunt-operierter Mäusen analysiert werden (A, D). Nach 2 und 4 w waren die transplantierten Zellen in beiden Maus-Gruppen Oct4- (B, C, E, F). Skalierung $50 \mu \mathrm{m}$.

Nachdem nachgewiesen wurde, dass sich injizierte maGSCs in den Mausherzen ansiedeln, sollte überprüft werden, ob diese Zellen in der Lage sind, sich in verschiedene Zelltypen zu differenzieren. Dazu wurden indirekte Immunfluoreszenz-Färbungen durchgeführt um SMA, vWF und cTnT nachzuweisen. SMA ist ein Marker für glatte Muskelzellen, während der vWF vaskuläre endotheliale Zellen charakterisiert. Das Protein cTnT kann in Kardiomyozyten nachgewiesen werden. In den Gewebeschnitten von TAC-operierten Mäusen konnten nach $2 \mathrm{w} \mathrm{SMA}^{+}$Zellen detektiert werden (Abb. 15 A-C), was auf die Entstehung glatter Muskulatur hinweist. Diese Zellen zeigten komplexe Strukturen (großflächig und miteinander vernetzt), so dass man davon ausgehen kann, dass viele Zellen differenziert sind (Abb. 15A und C). Dies könnte evtl. auch erklären, warum nur noch wenige DiI positive Zellen zu detektieren waren (Abb. 15B). Allerdings ist eine deutlich Veränderung des Myokardgewebes durch die injizierten Zellen im Vergleich zu Herzen ohne Zellinjektion zu sehen. In Abb. 15 B und $\mathrm{E}$ ist zu erkennen, dass die typische Myokardstruktur unterbrochen und von anderem Gewebe, welches aus den transplantierten Zellen entstanden ist, ersetzt wurde.

Als Nachweis für reife glatte Muskulatur ist rechts unten in Abb. 15A und C ein Gefäß des Empfängermyokards mit $\mathrm{SMA}^{+}$Zellen zu sehen, bei denen das Protein stärker als in den transplantierten Zellen detektiert wurde. Die komplexen $\mathrm{SMA}^{+}$Strukturen bestehen wahrscheinlich aus frühen glatten Muskelzellen, die sich aus den injizierten Zellen entwickelt 
haben. Daher exprimierten diese Zellen das SMA-Protein noch nicht so stark wie Zellen reifer glatter Muskulatur.

In parallelen Herzschnitten konnte ebenfalls der Endothelzell-Marker vWF nachgewiesen werden (Abb. 15D-F). Es sind stark ausgeprägte und noch dichtere Zell-Strukturen als in den SMA-Analysen zu erkennen, was auf eine gute Differenzierung der injizierten maGSCs in vWF$^{+}$Zellen hinweist. In Abb. 15D und F sind $\mathrm{vWF}^{+}$Zellen zu sehen, die ein Gefäß im Empfängermyokard auskleiden. Eine gute Abgrenzung zu SMA und ein Nachweis der Spezifität der Färbung sind also gegeben. Es war zu beobachten, dass die transplantierten Zellen mehr vWF exprimieren, als die das Gefäß auskleidenden $v \mathrm{WF}^{+}$Zellen, was sich eventuell damit erklären lässt, dass viele der injizierten Zellen sehr weit differenziert sind und daher den vWF stark exprimieren.
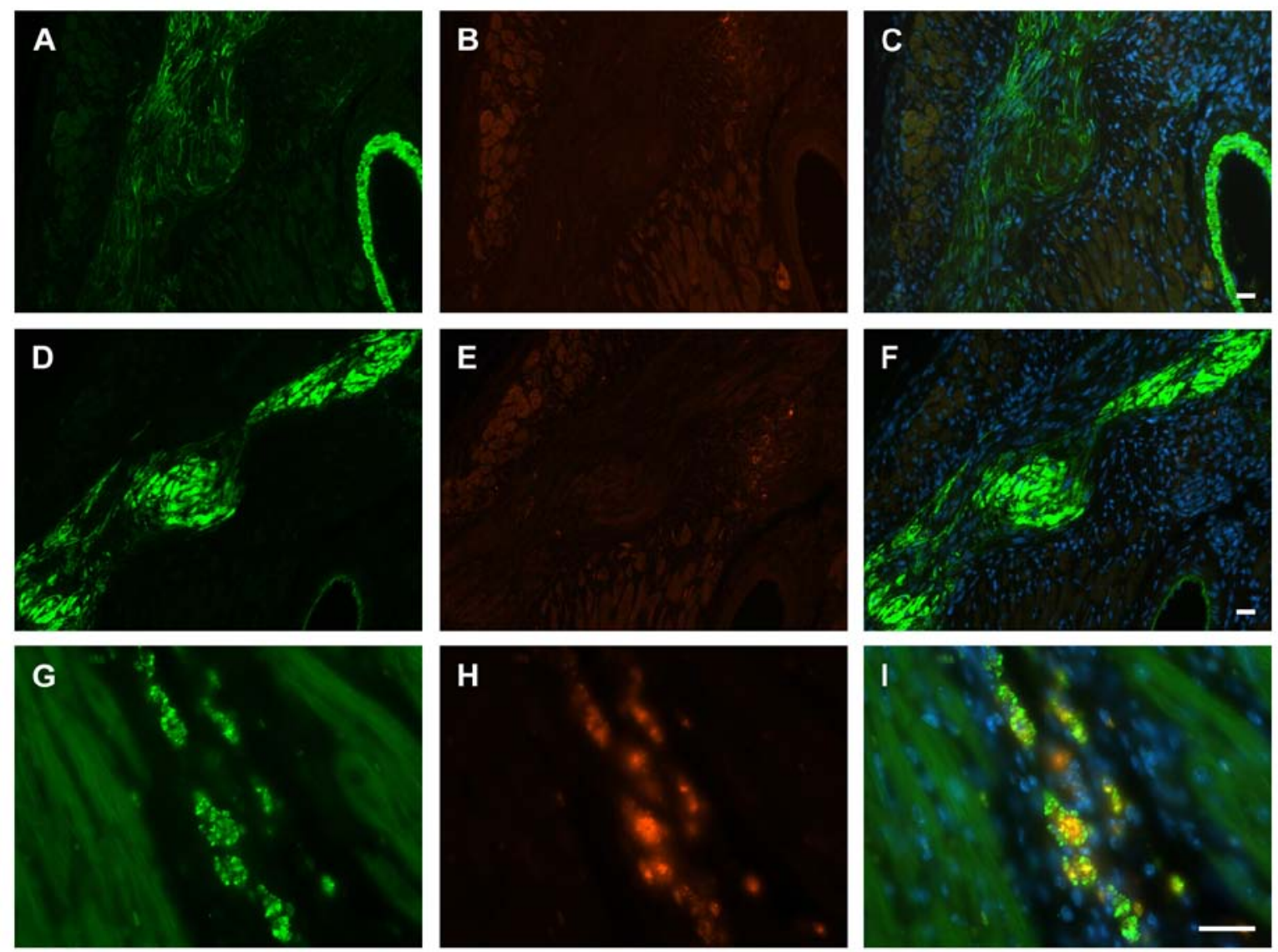

Abbildung 15: Nachweis der Marker SMA (glatte Muskulatur), vWF (Endothelzellen) und cTnT (Kardiomyozyten) in TAC-operierten Mäusen via indirekter Immunfluoreszenz-Färbungen. AC: SMA, D-F: vWF und G-I: cTnT. SMA und vWF wurden nach $2 \mathrm{w}$ und cTnT nach $4 \mathrm{w}$ nachgewiesen. Links sind die Einzelfärbungen der Proteine zu sehen, mittig DiI-Zellen und rechts die Überlagerung der Kanäle inklusive DAPI gefärbter Zellkerne. Die injizierten Zellen sind in der Lage sich in TAC-operierten Mäusen nach $2 \mathrm{w}$ in $\mathrm{SMA}^{+}, \mathrm{vWF}^{+}$Zellen und nach $4 \mathrm{w}$ in $\mathrm{cTnT}^{+}$Zellen zu differenzieren. Skalierung $20 \mu \mathrm{m}$. 
Nach $2 \mathrm{w}$ konnten keine injizierten Zellen überzeugend und spezifisch positiv für cTnT gefunden werden (nicht gezeigt), wohingegen nach $4 \mathrm{w}$ positive Signale detektiert wurden (Abb. 15G-I). Es konnte vereinzelt gezeigt werden, dass DiI-positive Zellen ebenfalls positive Signale für cTnT aufweisen. Dabei konnten keine sonst typischen Streifen von Kardiomyozyten, sondern eher punktuelle Signale visualisiert werden, so dass es sich bei diesen Zellen wahrscheinlich um sehr frühe kardiale Zellen handelt.

Ähnliche Ergebnisse waren in Mäusen nach Shunt-OP zu sehen. Nach 2 w konnten SMA ${ }^{+}$ und $\mathrm{vWF}^{+}$und nach $4 \mathrm{w} \mathrm{cTnT}^{+}$Zellen detektiert werden (nicht gezeigt).

In den Sham-Tieren beider Gruppen konnten die hier verwendeten Markerproteine wie in normalen Mausherzen nur sehr schwach (SMA und vWF) oder gar nicht nachgewiesen werden (cTnT) (Daten nicht gezeigt). Zusammenfassend lässt sich sagen, dass die injizierten Zellen in dem Empfängermyokard TAC- und Shunt-operierter Mäuse im Vergleich zu den Kontrolltieren gut in frühe glatte Muskulatur-, Endothel- und Herzmuskelzellen differenzieren können, was auf einen Einfluss der Überlast im Herzen auf die Differenzierung der transplantierten Zellen hinweist.

\subsubsection{Echokardiographie der Shunt- und TAC-operierten Mäuse}

Um zu überprüfen, ob eine Last-induzierte Hypertrophie-Entwicklung tatsächlich aufgrund der Maus-OPs vorlag und welchen Einfluss die Zellen auf die Herzmorphologie hatten, wurde das Herzgewicht (heart weight, HW in mg) im Vergleich zum Körpergewicht (body weight, BW in g) analysiert. Die HW/BW-Werte wurden mit Hilfe von echokardiographischen Messungen ermittelt. Bei erfolgreicher Intervention sollten die Herzen nach $2 \mathrm{w}$ und noch stärker nach $4 \mathrm{w}$ vergrößert sein, da sich bei einer erhöhten Vor- oder Nachlast eine Hypertrophie des Herzens entwickelt.

In den Shunt-operierten Mäusen zeigte sich nach 2 und 4 w sowohl bei NaCl- als auch bei Zellinjektion ein tendenziell erhöhtes HW/BW im Vergleich zu den Sham-Mäusen (Abb. 16A). Nur nach 4 w konnte eine signifikante Erhöhung des HW/BW in den Shunt-operierten Tieren mit Zellinjektion im Vergleich zu den Sham-Tieren mit Zellinjektion gezeigt werden. In den Kontrolltieren mit $\mathrm{NaCl}$ oder Zellen ließen sich keine Veränderungen in den HW/BWDaten feststellen. Es war also kein Effekt der injizierten Zellen auf das HW/BW der Shuntoperierten Tiere zu sehen. 
A

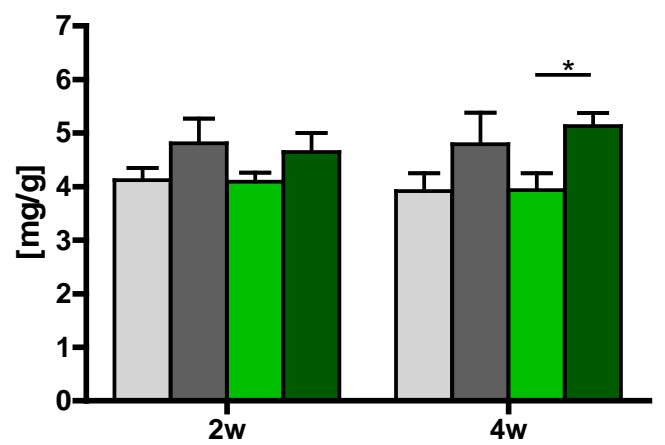

Zeitraum Intervention
B

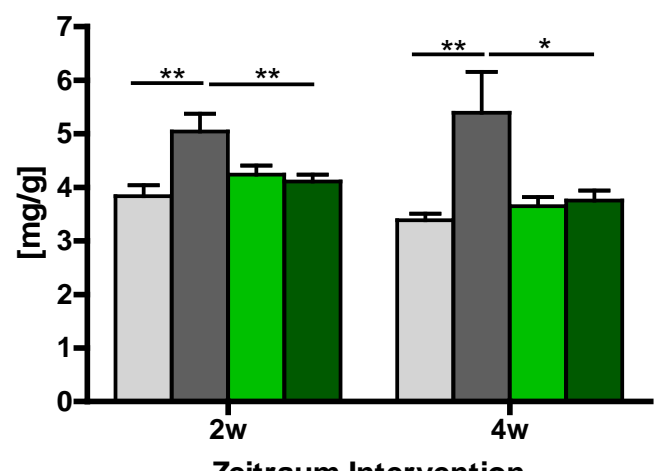

Zeitraum Intervention $\square$ Sham+NaCl
$\square$ Intervention+NaCl
Sham+Zellen
$\square$ Intervention+Zellen

Abbildung 16: Vergleich der heart weight (HW)/body weight (BW)-Werte in den Shunt- und TAC-operierten Mäusen und deren Kontrollen (n=3-10). A: HW/BW-Daten der Shunt-Mäuse, B: HW/BW-Daten der TAC-Mäuse. Die Fehlerbalken entsprechen dem Standardfehler (standard error of mean, SEM). Signifikanzen des Student's t-tests wurden mit *p $<0,05$ und ${ }^{* *} \mathrm{p}<0,01$ angegeben.

In den TAC-Mäusen mit NaCl-Injektion zeigte sich eine stark signifikante Erhöhung des HW/BW nach 2 und $4 \mathrm{w}$ im Vergleich zu den Sham-Mäusen mit NaCl (Abb. 16B). Zu den beiden Zeitpunkten zeigte sich kein erhöhtes HW/BW der TAC-operierten Tiere mit Zellinjektion im Vergleich zu entsprechenden Sham-Tieren. Nach $2 \mathrm{w}$ konnte ein stark signifikant reduziertes HW/BW der TAC-operierten und zelltransplantierten Mäuse im Vergleich zu den Mäusen mit $\mathrm{NaCl}$ festgestellt werden. Nach $4 \mathrm{w}$ ließ sich dieser Effekt immer noch signifikant ermitteln.

Im Gegensatz zu den Shunt-operierten Mäusen zeigten die injizierten Zellen einen positiven Einfluss bezüglich einer Reduktion der hypertrophischen Entwicklung der TAC-operierten Mäuseherzen.

Um die Herzfunktion der Mäuse nach Shunt- und TAC-OP einschätzen und vergleichen zu können, wurden echokardiographische Untersuchungen zu verschiedenen Zeitpunkten (2 und $4 \mathrm{w}$ ) durchgeführt.

Nachfolgend wird auf die 3 aussagekräftigen Parameter EF, FS und LVEDD eingegangen. Die EF zeigt an, wie gut das Herz pumpen kann und ist bei geringerer Herzfunktion erniedrigt. Das FS veranschaulicht das Kontraktionspotential des Herzens und ist bei schlechter Herzfunktion verringert. Der LVEDD zeigt an, wie groß der enddiastolische Diameter im linken Ventrikel ist und ist bei einer hypertrophen Entwicklung des Herzens vergrößert. 
Betrachtet man zunächst die EF-Werte der Shunt-operierten Mäuse und ihrer Kontrollen (Abb. 17A), ist zu sehen, dass Sham-Mäuse mit NaCl-Injektion nach $2 \mathrm{w}$ und $4 \mathrm{w}$ eine vergleichbare EF von fast $44 \%$ bzw. 45\% besaßen. In der Shunt-Gruppe mit NaCl lag die EF nach $2 \mathrm{w}$ bei $40 \%$ und nach $4 \mathrm{w}$ nicht signifikant reduziert bei 34\% vor. Vergleicht man die jeweiligen Sham- mit den Shunt-Mäusen sieht man bei den Shunt-Tieren mit NaCl-Injektion eine nicht signifikante Erniedrigung der EF nach 2 und $4 \mathrm{w}$, die nach $4 \mathrm{w}$ aber ausgeprägter ist als nach $2 \mathrm{w}$, was auf eine verschlechterte Herzfunktion hindeutet Die Sham-Mäuse mit Zellinjektion wiesen nach $2 \mathrm{w}$ eine im Vergleich zu den Sham-Tieren mit $\mathrm{NaCl}$ eine erhöhte EF von fast 50\% auf. Nach 4 w war die EF in den Sham-Mäusen mit Zellen nicht signifikant auf 45\% reduziert und damit auf dem Niveau der EF der Sham-Mäuse mit NaCl. Die Zellinjektion hatte also keinen Einfluss auf die EF in den Sham-Mäusen. Vergleicht man Shunt- und Sham-Mäuse mit Zellinjektion ist eine signifikante Reduktion der EF auf $40 \% \mathrm{zu}$ erkennen, die nach $4 \mathrm{w}$ nicht bestätigt wurde (45\% Sham auf $41 \%$ Shunt). Damit zeigten die Shunt-Mäuse mit Zellinjektion nach $4 \mathrm{w}$ eine geringere Reduktion der EF, als die ShuntMäuse mit $\mathrm{NaCl}$, jeweils im Vergleich zu den Sham-Mäusen. Dies bedeutet, dass die EF durch Zellinjektion bei Shunt-operierten Tieren nach $4 \mathrm{w}$ tendenziell verbessert war.

Das FS (Abb. 17B) lag in den Sham-Tieren mit NaCl-Injektion nach 2 und $4 \mathrm{w}$ auf einem ähnlichen Niveau (23 bzw. 24\%), während es in den Shunt-Tieren mit NaCl nicht signifikant von 21\% (2 w) auf 15\% (4 w) reduziert war. Dies bestätigt zusammen mit den reduzierten EFWerten eine verschlechterte Herzfunktion in den Shunt-Tieren. Im Vergleich der ShamMäuse mit NaCl- bzw. Zellinjektion konnten keine signifikanten Änderungen der FS festgestellt werden, was bedeutet, dass die transplantierten Zellen keinen Einfluss auf das FS in den Sham-Mäusen hatten. In den Shunt-Mäusen mit Zellinjektion war zu dem 2 wZeitpunkt eine signifikante FS-Reduktion von 25\% auf 19\% im Vergleich zu den ShamTieren zu sehen, nicht aber nach $4 \mathrm{w}$ (22 auf 20\%). Vergleicht man Shunt-Mäuse mit Zellbzw. NaCl-Injektion, war nach $4 \mathrm{w}$ ein nicht signifikant erhöhtes, aber so verbessertes FS (15 auf 20\%) der Mäuse mit Zellinjektion festzustellen.

Bei der Betrachtung des LVEDD (Abb. 17C) konnte in den Sham-Mäusen mit NaCl-Injektion nach 2 w und 4 w ein vergleichbarer LVEDD von ca. $4 \mathrm{~mm}$ festgestellt werden. In den ShuntMäusen mit $\mathrm{NaCl}$ zeigte sich nach $2 \mathrm{w}$ ein LVEDD von 4,7 mm, was sich nach $4 \mathrm{w}$ nicht signifikant verändert hatte $(4,5 \mathrm{~mm})$ und somit den hypertrophen Effekt der OP bestätigte. Die Sham-Tiere mit Zellen zeigten nach 2 und $4 \mathrm{w}$ ähnliche LVEDD wie die Sham-Tiere mit $\mathrm{NaCl}$. 
Shunt

A

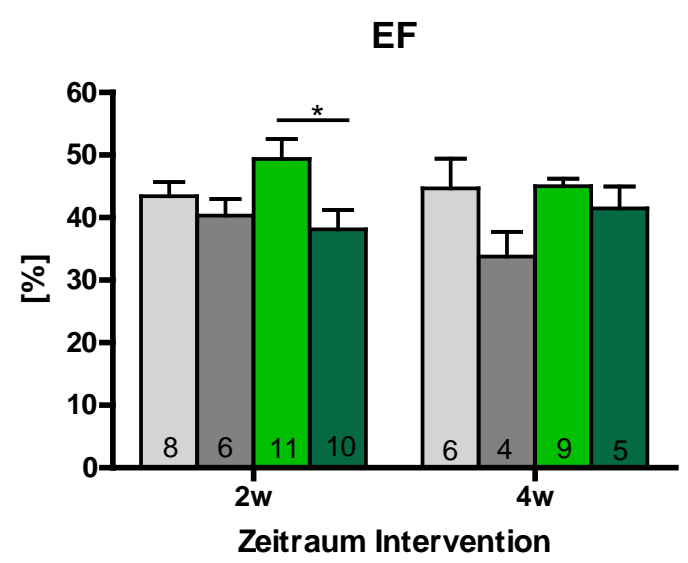

B

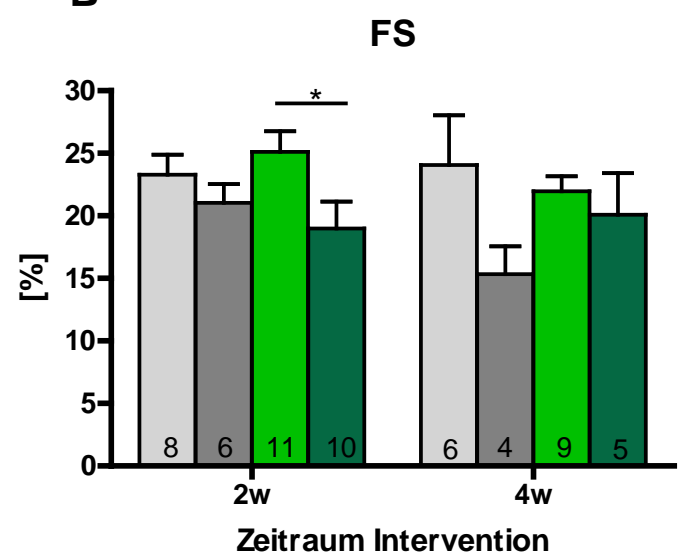

C

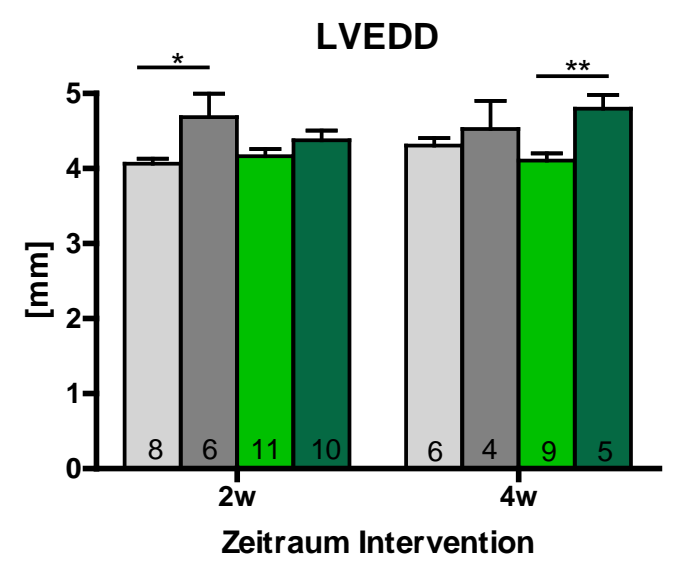

TAC

D

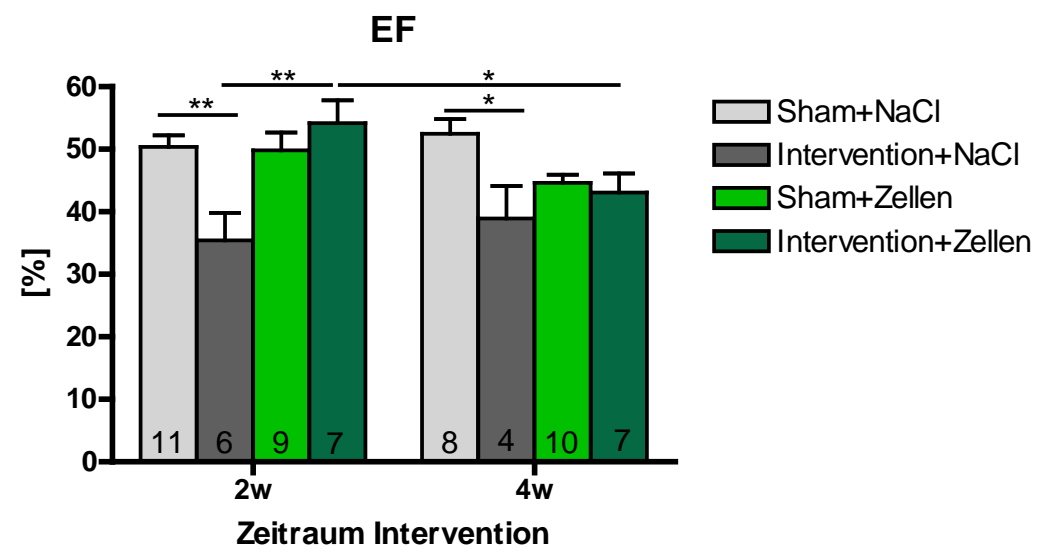

$\mathbf{E}$

FS

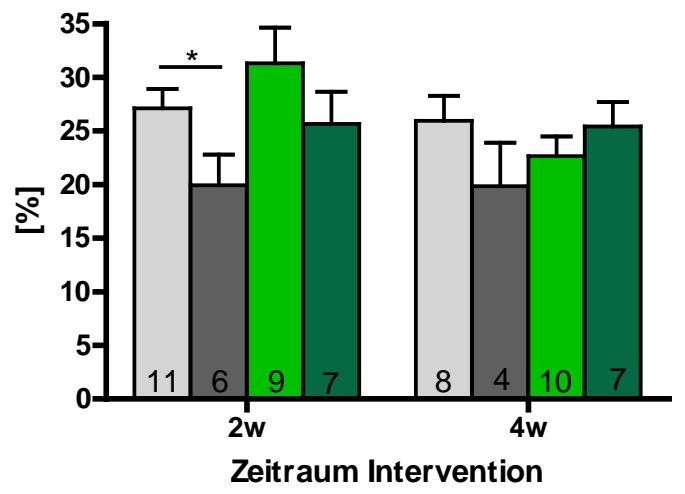

$\mathbf{F}$

\section{LVEDD}

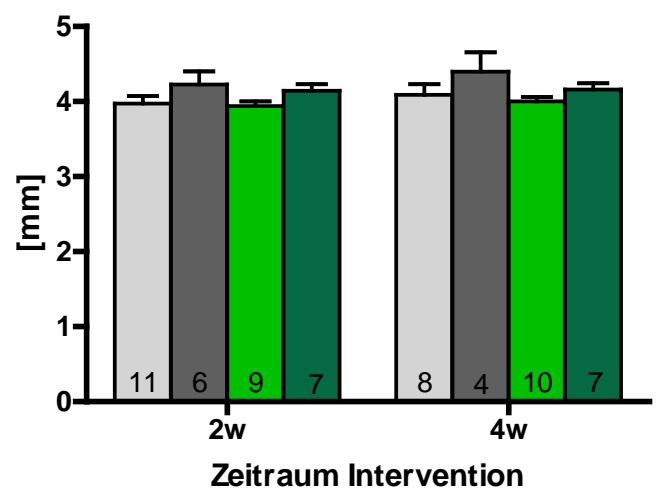

Abbildung 17: Echokardiographische Analysen von Shunt- und TAC-operierten Mäusen nach $2 \mathrm{w}$ und $4 \mathrm{w}$. A-C: Ejektionsfraktion, EF; fractional shortening, FS und left ventricular enddiastolic diameter, LVEDD, der analysierten Mäuse $2 \mathrm{w}$ und $4 \mathrm{w}$ nach Shunt-OP, D-F: EF, FS und LVEDD der Mäuse $2 \mathrm{w}$ und $4 \mathrm{w}$ nach TAC-OP. In den Balken steht die jeweilige Tierzahl (n). Die Fehlerbalken entsprechen dem Standardfehler. Signifikanzen des Student's t-tests sind für die Last-induzierten Tiere und ihre entsprechenden Kontrollen mit ${ }^{*} \mathrm{p}<0,05$ und ${ }^{* *} \mathrm{p}<0,01$ angegeben. 
Die Shunt-operierten Mäuse mit Zellapplikation wiesen nur nach $4 \mathrm{w}$ einen signifikant erhöhten LVEDD von 4,8 mm im Vergleich zu den Shunt-Mäusen mit NaCl-Injektion auf.

Es konnte also kein ausgleichender Effekt der Zellen bei der Analyse des LVEDD beobachtet werden.

Des Weiteren wurden die eben beschriebenen Parameter in Tieren untersucht, in denen eine erhöhte Nachlast induziert wurde (TAC, Abb. 17D-F).

In den NaCl-injizierten Sham-Tieren waren nach 2 und $4 \mathrm{w}$ ähnliche EF-Werte von 50 und $52 \%$ zu messen, während diese Werte in den TAC-operierten Tieren mit NaCl signifikant reduziert waren ( $2 \mathrm{w}$ : $35 \%$ und $4 \mathrm{w}$ 39\%), was auf eine erfolgreich induzierte Nachlast hindeutet. Während die EF in den Sham-Mäusen mit Zellen bzw. NaCl-Injektion nach 2 w noch auf gleichem Niveau lagen (50\%), sank die EF in den zellinjizierten Mäusen nach $4 \mathrm{w}$ auf $45 \%$ ab, was bedeutet, dass die Zellen keinen positive Wirkung auf die EF in den ShamMäusen hatten.Vergleicht man die TAC-operierten und zelltransplantieren Mäuse mit den entsprechenden Sham-Tieren zeigte sich nach 2 w ein tendenzieller Anstieg der EF von 50 auf 54\%. Die 4 w-Analyse der EF ergab allerdings eine generelle Reduktion in den Sham- und TAC-Mäusen mit Zelltransplantation (45 und 43\%). Betrachtete man die TAC-Mäuse mit $\mathrm{NaCl}$ oder Zellinjektion fiel auf, dass die EF in den Tieren mit Zellinjektion nach $2 \mathrm{w}$ hochsignifikant erhöht war (von 35 auf 54\%). Dieser Effekt bestätigte sich nach 4 w nicht. Es konnte also eine zellinduzierte verbesserte EF nach $2 \mathrm{w}$ in den Shunt-operierten Tieren festgestellt werden.

In den Sham-Mäusen mit NaCl-Applikation lag das FS nach 2 und $4 \mathrm{w}$ auf einem ähnlichen Niveau (27 und 26\%), während es in den TAC-Mäusen mit $\mathrm{NaCl}$ nach 2 w signifikant und nach $4 \mathrm{w}$ tendenziell herunterreguliert war (jeweils 20\%). Das FS der Sham-Mäuse wurde nicht durch die injizierten Zellen beeinflusst, da keine signifikanten Änderungen im Vergleich zu Sham-Mäusen mit NaCl-Injektion vorlagen. Vergleicht man Sham- und TAC-Mäuse ist das Level des FS durch Zellinjektion nach $2 \mathrm{w}$ erniedrigt (von 31 auf 25\%) und nach $4 \mathrm{w}$ leicht erhöht (von 24 auf 25\%, jeweils nicht signifikant).

In den Shunt-Mäusen mit Zell-Applikation konnte nach 2 und $4 \mathrm{w}$ ein tendenziell erhöhtes FS im Vergleich zu den Shunt-Mäusen mit NaCl-Injektion ermittelt werden (jeweils von 20 auf 25\%). Hier zeigte sich also ein positiver Effekt durch die Zelltransplantation.

Die Untersuchung des LVEDD ergab keine signifikanten Änderungen zwischen 2 und $4 \mathrm{w}$ bei den Sham-Mäusen mit NaCl- oder Zellapplikation (3,9- 4 mm). In den TAC-Tieren mit NaCl lag nach $2 \mathrm{w}$ ein LVEDD von 4,2 mm vor, der sich nach $4 \mathrm{w}$ nicht signifikant auf 4,3 mm erhöht hatte. 
In den TAC-operierten und den Sham-Mäusen mit Zellinjektion wurden nach 2 und $4 \mathrm{w}$ ähnliche LVEDD-Werte analysiert (3,9-4,1mm). Betrachtet man den LVEDD der TAC-Tiere mit NaCl- oder Zellinjektion ist nach $2 \mathrm{w}$ kein Unterschied festzustellen, während er nach $4 \mathrm{w}$ in den zelltransplantierten Tieren tendenziell reduziert ist (4,3 auf 4,1 mm).

Zusammenfassend lässt sich sagen, dass die Shunt- und die TAC-OP erfolgreich etabliert waren und eine Verschlechterung der Herzfunktion anhand der untersuchten Parameter EF, FS und LVEDD in den operierten Tieren mit NaCl-Injektion nachzuweisen war.

Weiterhin konnte analysiert werden, dass in den Shunt-operierten Tieren mit Zellinjektion eine leicht verbesserte EF und ein erhöhtes FS im Vergleich zu den NaCl-applizierten ShuntTieren vorlagen, während sich kein positiver Effekt beim Betrachten der LVEDD ergab. In den TAC-Tieren mit Zelltransplantation zeigte sich ebenfalls eine tendenzielle Verbesserung der Herzfunktion im Vergleich zu TAC-Mäusen mit $\mathrm{NaCl}$, da die EF-Werte nach $2 \mathrm{w}$ signifikant und die FS-Werte nach $4 \mathrm{w}$ tendenziell erhöht waren und der LVEDD sich zu keinem Zeitpunkt signifikant vergrößert hatte. Diese Daten korrelieren mit den HW/BWDaten (Abb. 16)

\subsection{MaGSCs in immundefizienten RAG2 ${ }^{-/-} \mathrm{Cgc}^{-/-}$Mäusen}

In den normalen und Last-induzierten Herzen waren nach Zelltransplantation undifferenzierter maGSCs und Behandlung mit dem Immunsuppressivum Ciclosporin A (CsA) keine Teratome aufgetreten, im Gegensatz zur Teratombildung in immundefizienten Mäusen nach subkutaner Stammzell-Injektion ohne CsA-Behandlung (Guan et al. 2006). Um zu überprüfen, ob CsA einen Effekt auf die in Mausherzen transplantierten maGSCs ausübt, wurden immundefizienten RAG2 ${ }^{-/-} \mathrm{Cgc}^{-/-}$Mäusen DiI-markierte undifferenzierte maGSCs ins Myokard injiziert und diese Mäuse mit CsA ( $n=5)$ oder ohne CsA (n=7) behandelt. Nach $4 \mathrm{w}$ wurden die Mäuse finalisiert, die Herzen entnommen, perfundiert und fixiert. Es erfolgte eine Charakterisierung der DiI-markierten maGSCs nach Injektion mittels HE- und Oct4Färbungen.

Es konnte beobachtet werden, dass bei den nicht-CsA behandelten Mäusen zum Ende des Beobachtungszeitraumes von 4 Wochen eine Lähmung der Hinterpfoten auftrat, während keine der CsA behandelten Mäuse eine solche Lähmung zeigte. Des Weiteren wurde die Entwicklung von Tumoren in den verwendeten Mäusen untersucht. Hierbei konnte ein weiterer dominanter Unterschied zwischen den beiden Gruppen festgestellt werden: Die 
Mäuse ohne CsA (n=7) hatten bis auf eine Ausnahme mehrere und teils sehr große Tumore/Teratome im gesamten Körper. Im Durchschnitt betrug das Gewicht der Teratome in diesen Mäusen 865 mg. Eine Maus hatte aber auch Teratome mit einem Gesamtgewicht von fast 2500 mg, während eine andere Maus einen sehr großen einzelnen Körper-Tumor mit einem Gewicht von über $2000 \mathrm{mg}$ besaß. Die Teratome hatten also einen prozentualen Körpergewichts-Anteil von 5-10\% und beeinträchtigten die Mäuse gesundheitlich stark.

Mittels HE-Färbung der Myokardschnitte konnte festgestellt werden, dass sowohl Mäuse mit als auch ohne CsA-Behandlung Teratome im und am Herzen entwickelt hatten. Bei den Mäusen mit CsA wurden in 3 von 5 Mäusen und bei der Gruppe ohne CsA in 100\% der Mäuse (7 von 7) Teratome gefunden. Allerdings wurde beobachtet, dass die Teratome in der Gruppe mit CsA signifikant kleiner waren als in der Gruppe ohne CsA (Abbildung 18).

In den CsA behandelten Mäusen beschränkten sich die Teratome nur aufs Herz, während in der Gruppe ohne CsA Teratome in den Herzen und im ganzen Körper zu finden waren, vor allem an Leber, Niere und Darm. Die Teratome in beiden Maus-Gruppen wiesen Zellen auf, die sich aus allen 3 Keimblättern entwickelt haben. In Abbildung 19 sind Strukturen des Endoderms (hier: Interstitium, A), des Ektoderms (hier: neuronale Rosette, D) und des Mesoderms (Muskel- und Knorpelgewebe, B und C) zu sehen.

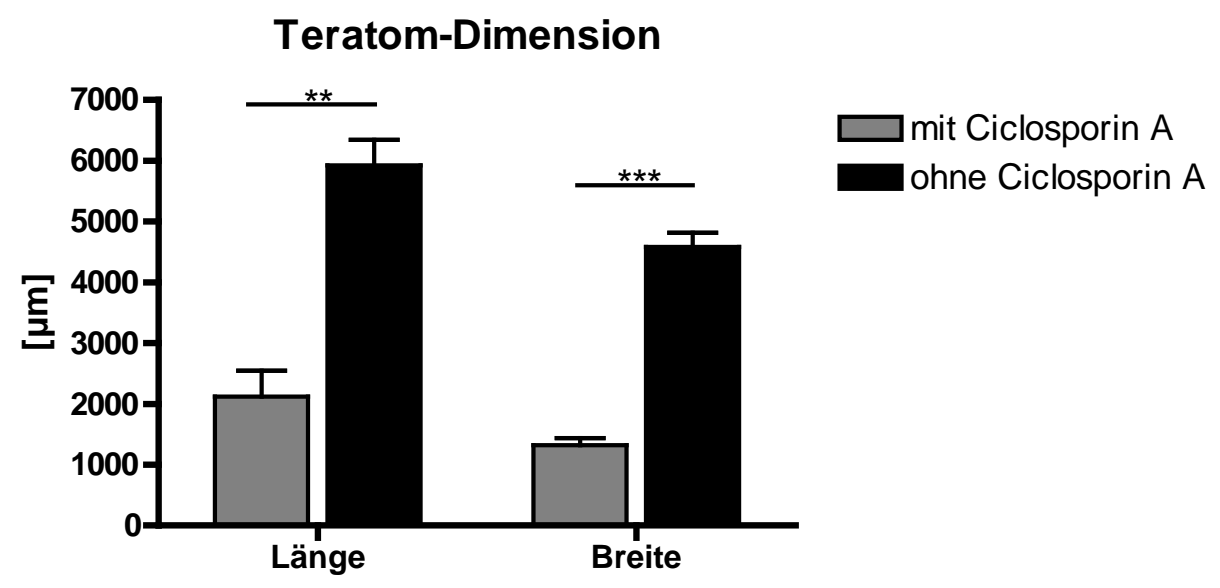

Abbildung 18: Darstellung der Teratom-Dimension im und am Herzen von RAG2 ${ }^{-/}$cgc $^{-/-}$Mäusen mit und ohne CsA-Gabe. Graue Balken: Länge und Breite der Teratome in den Mäusen mit CsA, schwarze Balken: Länge und Breite der Teratome in den Mäusen ohne CsA. Es konnte festgestellt werden, dass die Tumore in den Mäusen ohne CsA signifikant größer waren als die Tumore in den Mäusen mit CsA-Behandlung. Die Signifikanzen des t-Tests sind mit ${ }^{* *} \mathrm{p}<0,01$ und ${ }^{* * *} \mathrm{p}<0,001$ angegeben. 

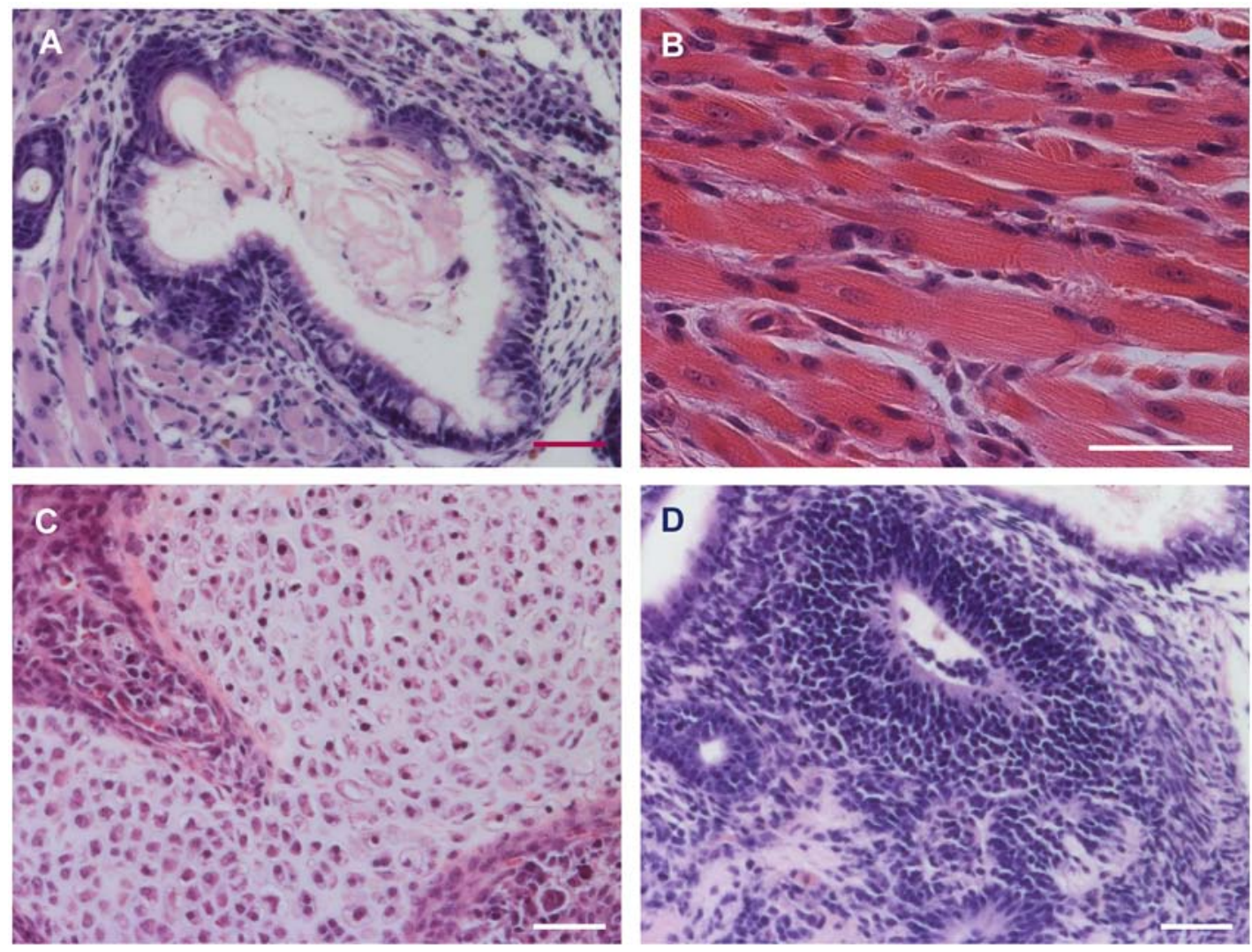

Abbildung 19: HE-Analyse der Tumore in Herzen der RAG2 ${ }^{-/}$.gc $^{-/-}$Mäuse. Die transplantierten Zellen entwickelten Teratome, in denen Gewebe aller 3 Keimblätter zu finden waren. A: Interstitium (Endoderm), B: muskuläres Gewebe (Mesoderm), C: Knorpelgewebe (Mesoderm) und D: neuronale Rosette (Ektoderm). Skalierung $20 \mu \mathrm{m}$.

Zusammenfassend kann festgehalten werden, dass die maGSCs auch in immundefizienten $\mathrm{RAG}^{-/-} \mathrm{Cgc}^{-/-}$Mäusen Teratome hervorrufen, und dass CsA einen wachstumsinhibierenden Effekt auf die durch die maGSC-Injektion hervorgerufenen Teratome hat. Möglicherweise hätte eine höhere Dosis CsA das Tumorwachstum noch mehr verringert oder sogar verhindert.

Um zu überprüfen, ob noch undifferenzierte Zellen in den Teratomen vorhanden sind, wurde der für undifferenzierte Stammzellen charakteristische Marker Oct4 mittels Immunhistochemie detektiert (Abb. 20B, D). In den parallelen HE-Färbungen sind die injizierten Zellen anhand der vermehrten Zellkernansammlungen zu erkennen (Abb. 20A, B). Deutlich ist zu sehen, dass in den $\mathrm{RAG2}^{-/-} \mathrm{Cgc}^{-/-}$Mäusen mit CsA weniger Zellen Oct4 exprimieren als in den Mäusen ohne CsA (Vergleich Abb. 20B und D). Dieses Resultat deutet darauf hin, dass CsA die Differenzierung der injizierten maGSCs stimuliert. 

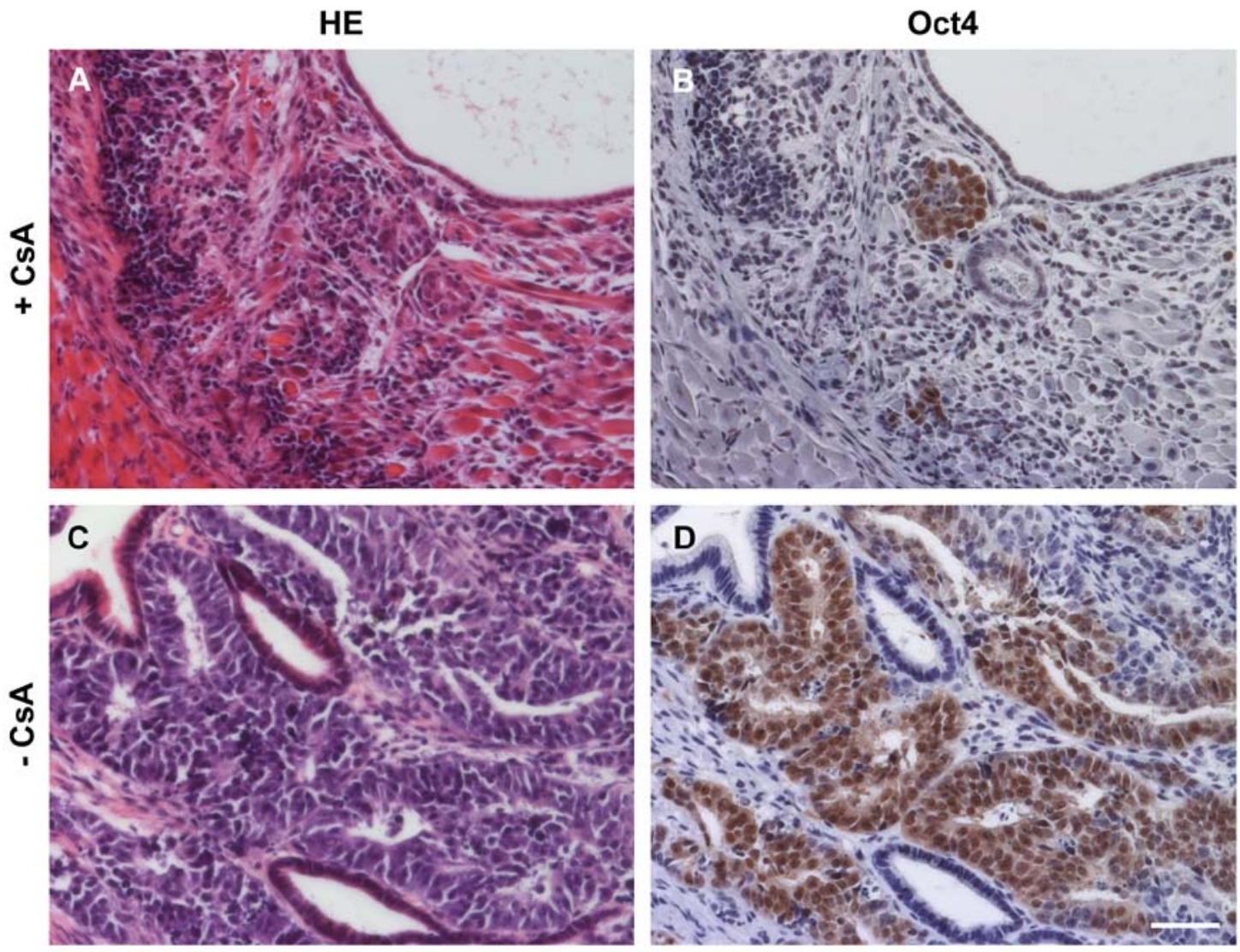

Abbildung 20: HE- und Oct4-Färbungen in RAG2 ${ }^{-/}$cgc $^{-/-}$Mäusen mit und ohne CsA-Gabe. Dargestellt sind Gewebeschnitte der Herzen der RAG2 ${ }^{-1-\mathrm{Cgc}^{-/-}}$Mäuse, in denen Teratome zu finden waren. A, B: Färbungen an Herzschnitten einer Maus mit CsA-Gabe und C, D: Färbungen an Herzschnitten einer Maus ohne CsA. A, C: HE-Färbungen und B, D: Oct4-Färbungen. In A und C sind die Zelltransplantate, die in Tumore differenziert sind, mittels dunkelblauer Zellkernansammlungen zu sehen. Zwischen den Bildern B und D besteht ein deutlicher Unterschied in der Anzahl der Oct4 ${ }^{+}$ Zellen. In den Mäusen mit CsA sind nur sehr wenige transplantierte Zellen Oct $4^{+}$, während in den Mausherzen der Mäuse ohne CsA viele Zellen Oct4 exprimierten. Skalierung $20 \mu \mathrm{m}$.

\subsection{Generation kardiovaskulärer Vorläuferzellen}

Die direkte Transplantation pluripotenter maGSCs ohne gerichtete Selektion könnte einen therapeutischen Effekt haben, wenn ein ausreichender Grad an spontaner kardialer Differenzierung stattfindet. Bisherige Ergebnisse deuten an, dass eine ungerichtete Differenzierung wahrscheinlicher ist. Deshalb ist es notwendig, linienspezifische Selektionsprotokolle zu etablieren.

Ein weiteres Ziel dieser Arbeit war daher die Differenzierung multipotenter adulter Keimbahnstammzellen (maGSCs) in $\mathrm{Flk1}^{+}$Vorläuferzellen, da gezeigt wurde, dass diese Zellen ein kardiovaskuläres Potential besitzen (Ema et al. 2006; Kattman et al. 2006) und somit einen Beitrag zur zellbasierten kardialen Therapie leisten könnten. 
Ergebnisse

\subsubsection{Etablierung eines Co-Kultursystems für die Generation kardiovaskulärer Vorläuferzellen}

Es wurden maGSC-Differenzierungsversuche via Co-Kultur mit mitotisch inaktiven OP9Stromazellen auf $10 \mathrm{~cm}$ Zellkulturschalen angesetzt. Die OP9-Zellen fördern aufgrund einer Mutation im M-CSF-Gen eine Differenzierung in die mesodermale Richtung (Nakano et al. 1994). Für die Differenzierungsversuche wurden Stra8-EGFP ${ }^{+}$maGSCs (SSC5) verwendet.

Die co-kultiviertierten maGSCs wurden jeden Tag mit einem Phasenkontrastmikroskop fotografiert, um ihren Differenzierungsgrad morphologisch charakterisieren zu können (Abb. 21).
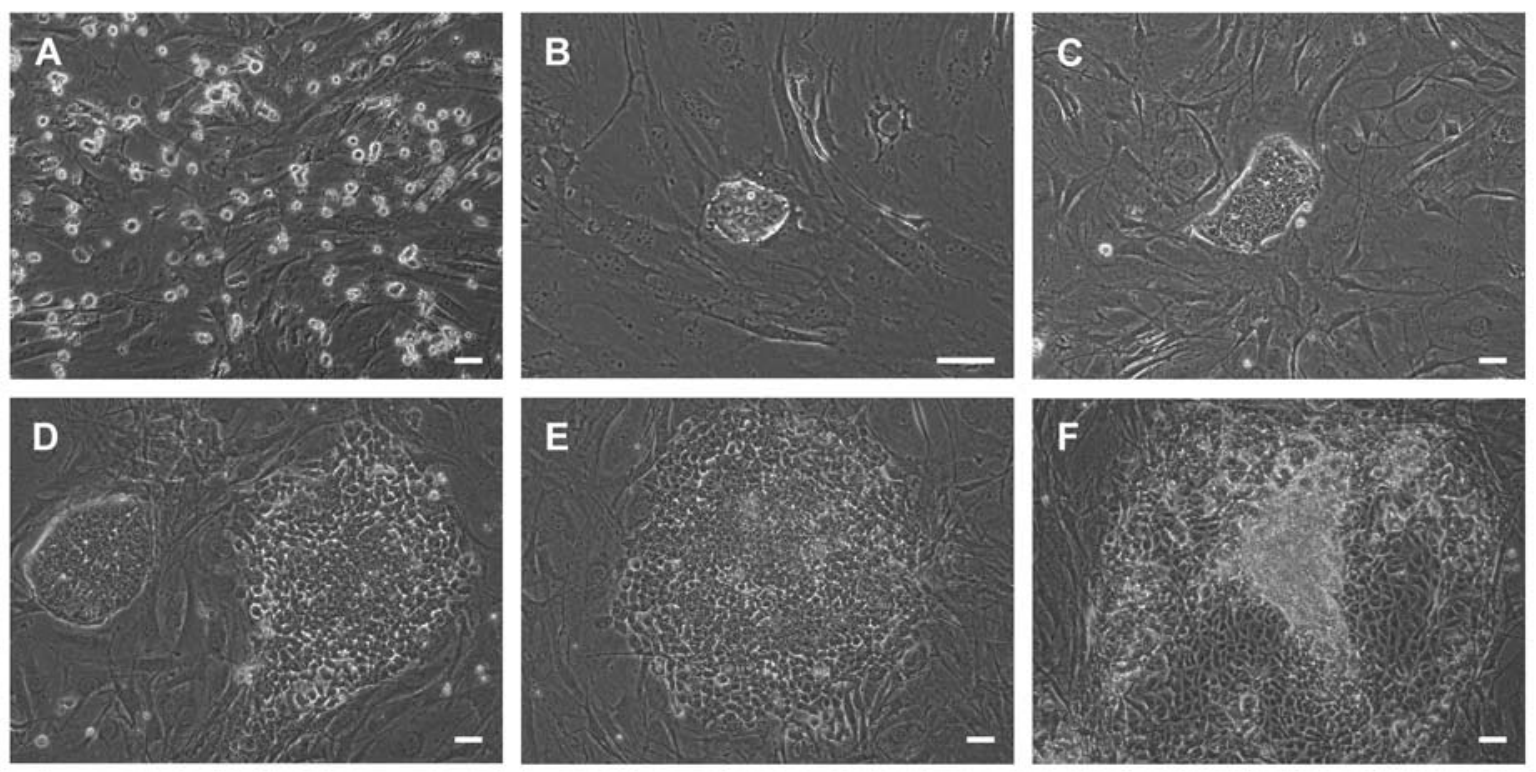

Abbildung 21: Morphologie der maGSCs während ihrer Differenzierung auf OP9-Stromazellen. A: Tag 0 (undifferenzierte maGSCs), B: Tag 1, C: Tag 2, D: Tag 3, E: Tag 4 und F: Tag 5. A-F: Verlauf der maGSC-Differenzierung auf OP9-Stromazellen im Differenzierungsmedium bis Tag 5. Während ihrer Differenzierung proliferierten die maGSCs und bildeten immer größere Cluster mit teils kopfsteinpflasterartigen Zellstrukturen. Skalierung $50 \mu \mathrm{m}$.

Zum Zeitpunkt der Ausplattierung (d0) zeigten die undifferenzierten maGSCs eine für Stammzellen typische, kompakte Morphologie mit scharfen, leuchtenden Rändern (Abb. 21A). Am Tag 1 der Differenzierung konnten leicht vergrößerte Zell-Cluster beobachtet werden (Abb. 21B), die am Tag 2 noch weiter proliferierten (Abb. 21C). Zusätzliche Veränderungen konnten an den folgenden Tagen registriert werden: Die maGSCs zeigten weitere Anzeichen von Proliferation und Differenzierung, indem sie am Tag 3 der Differenzierung in größeren Clustern und Kolonien, die oft ein kopfsteinpflasterartiges Muster aufwiesen, auftraten (Abb. 21D). Am Tag 4 waren sehr viele Cluster weiter flach nach 
außen gewachsen (Abb. 21E) und zeigten weiterhin ein typisches kopfsteinpflasterartiges Muster, welches für eine mesodermale Differenzierung sprach. Am letzten Tag der Differenzierung (d5) waren die Zellkulturschalen mit weiter differenzierten Zellkolonien sehr voll gewachsen (Abb. 21F). Im Hintergrund aller Bilder sieht man die OP9-Stromazellen mit ihrer spindelförmigen Morphologie.

Während der Differenzierung auf OP9-Zellen nimmt die Expression des Stra8-Promotor getriebenen GFPs der maGSCs ab, da Stra8 als Marker für undifferenzierte Zellen (Miyamoto et al. 2002) in den weiter differenzierten Zellen sukzessiv weniger exprimiert wird (Abb. 22). Am Tag 1 der Differenzierung waren nahezu alle Zellen des Clusters GFP-positiv (Abb. 22AC). Bereits 2 Tage später exprimierten die weiter gewachsenen und differenzierten Zellkolonien weniger GFP als am Tag 1 (Abb. 22D-F). Am Tag 5 der maGSCDifferenzierung zeigten viele Zellen vor allem am Rand von noch größeren Zellclustern eine weitere Reduktion der GFP-Expression, was auf eine fortschreitende Differenzierung der maGSCs hindeutete (Abb. 22G-I).
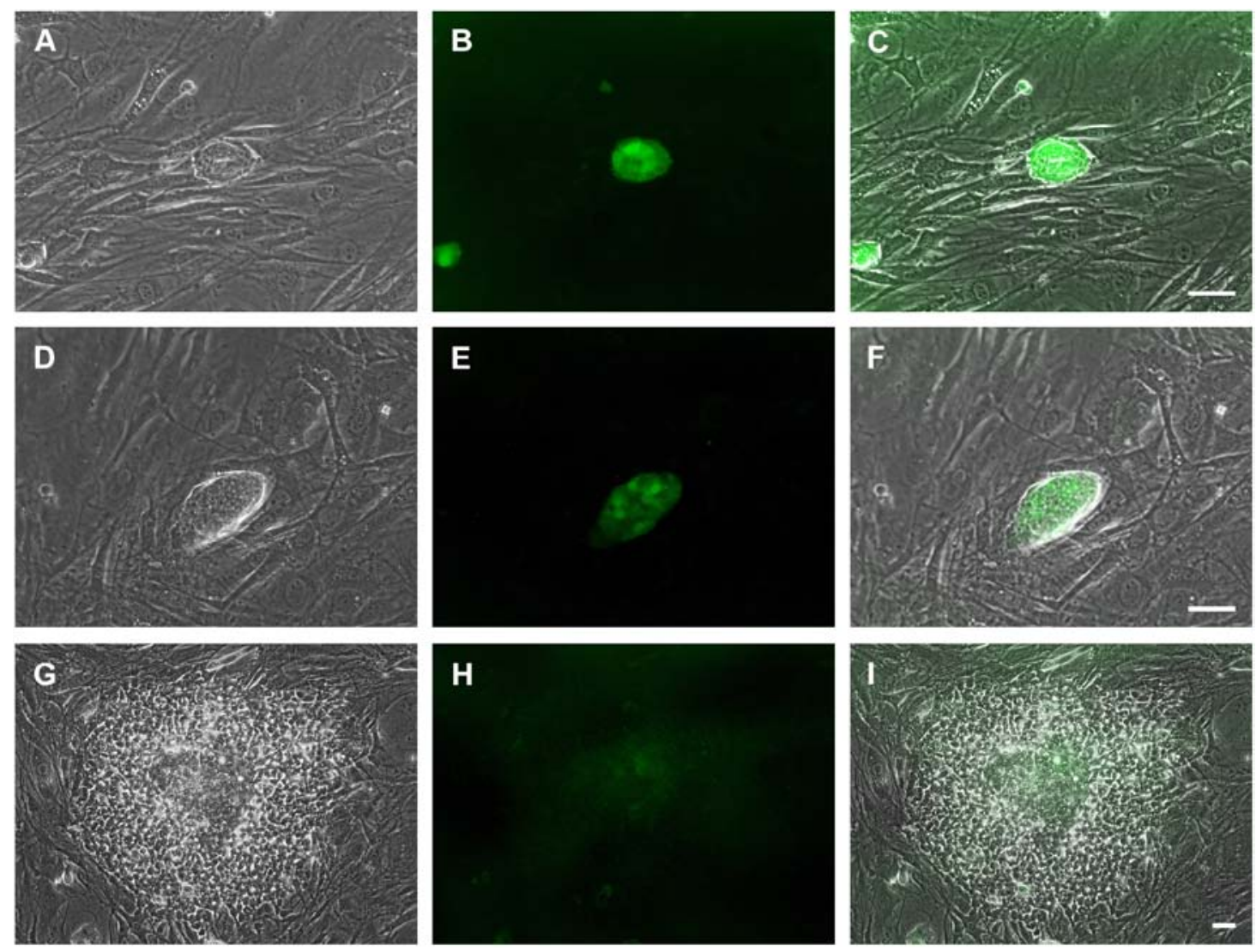

Abbildung 22: Verlust des GFPs während der Differenzierung. Dargestellt sind Tag 1 (A-C), Tag 3 (D-F) und Tag 5 (G-I) der maGSC-Differenzierung auf OP9-Zellen und der bei fortschreitender Differenzierung zu beobachtende Verlust des GFPs in den Zellen. A, D, G: Phasenkontrastaufnahmen der Zellcluster, B, E, H: GFP und C, F, I: Überlagerung der 2 Kanäle. Skalierung 50 $\mu$ m. 
Am d5 wurden durchflusszytometrische Untersuchungen mit Hilfe eines PE-gekoppelten Antikörpers gegen Flk1 durchgeführt, um den Anteil Flk1 positiver Zellen zu diesem Zeitpunkt zu bestimmen. Als Kontrolle dienten undifferenzierte und somit GFP ${ }^{+}$Zellen. Diese Zellpopulation befindet sich bei der Durchflusszytometrie im rechten unteren Quadranten (Abb. 23A). In der Negativkontrolle, die aus einer d5-vordifferenzierten Zell-Population ohne Antikörperzugabe besteht, sieht man die GFP ${ }^{-}$Zellen im linken unteren Quadranten, im Gegensatz zu den undifferenzierten $\mathrm{GFP}^{+}$Zellen im rechten unteren Quadranten (Abb. 23B). nach Antikörperfärbung sind drei Populationen vorhanden: die Flk1/GFP (Abb. 23C, unten links), die $\mathrm{GFP}^{+}$Zellen (unten rechts) und die Flk1 ${ }^{+}$Zellen (oben links).

A

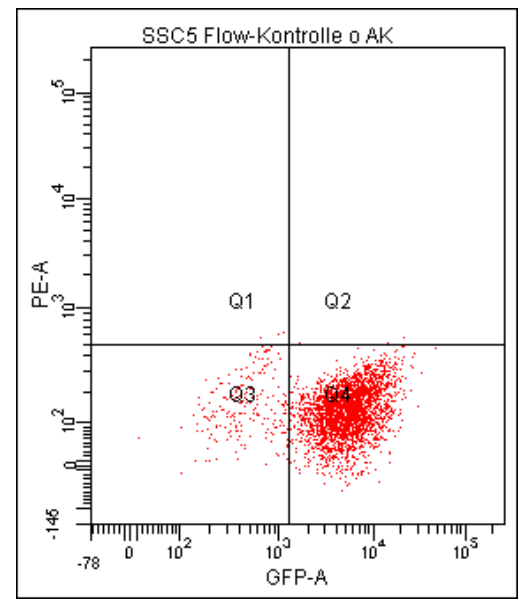

B

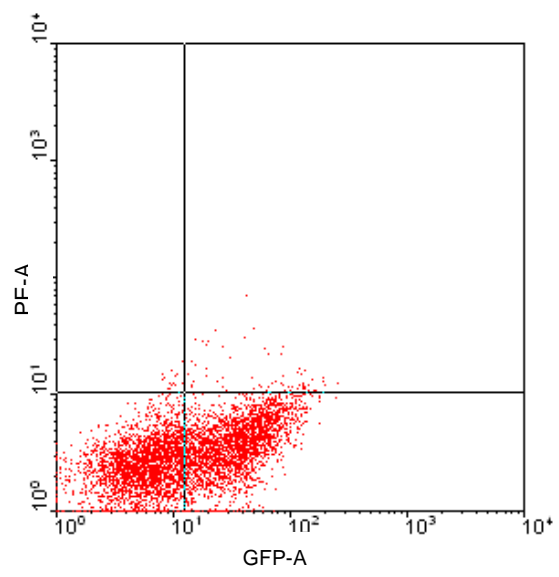

C

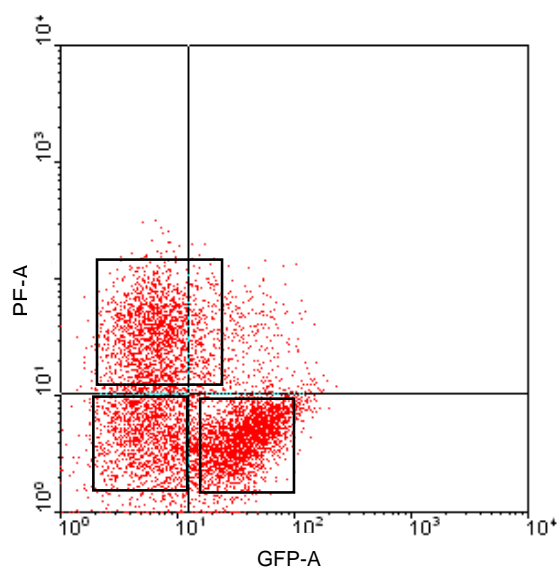

Abbildung 23: Durchflusszytometrie der 5 Tage auf OP9 differenzierten und anschließend Flk1 gefärbten maGSCs. A: SSC5 an d0, B: Negativkontrolle ohne Zugabe eines Antikörpers. Im linken unteren Quadranten sind negative Zellen ohne Fluoreszenz zu sehen, im Gegensatz zu den $\mathrm{GFP}^{+}$ (undifferenzierten) Zellen rechts unten. C: Flk1 gefärbte Zellen an d5, Flk1 ${ }^{+}$Zellen im linken oberen Quadranten (26,7\%). Die drei Populationen wurden markiert (Rechtecke, gates). 
Um zu analysieren in welcher Dichte sich die maGSCs auf einer $10 \mathrm{~cm}$ Zellkulturschale auf inaktivierten OP9-Stromazellen am besten in Flk1 ${ }^{+}$Zellen differenzieren, wurden verschiedene maGSC-Ausgangs-Zellzahlen getestet. Folgende Zellzahlen wurden verwendet: $15 \times 10^{4}$ (hellgrau), $7 \times 10^{4}$ (dunkelgrau) und $3 \times 10^{4}$ (schwarz, Abb. 24).

Am d5 der Differenzierung fand nach einem Preplating eine Durchflusszytometrie mit Hilfe eines PE-gekoppelten Flk1-Antikörpers statt, wobei festgestellt wurde, dass die Versuchsansätze mit $3 \times 10^{4}$ Zellen an d5 der Differenzierung die höchste Effizienz an Flk1 ${ }^{+}$ Zellen aufwiesen (ca. 32\%). Im Gegensatz dazu konnten bei einem Einsatz von $15 \times 10^{4}$ Zellen nur ca. 5,5\% Flk1 $^{+}$Zellen und mit $7 \times 10^{4}$ Zellen ca. $10 \% \quad$ Flk1 $^{+}$Zellen am d5 durchflusszytometrisch detektiert werden.

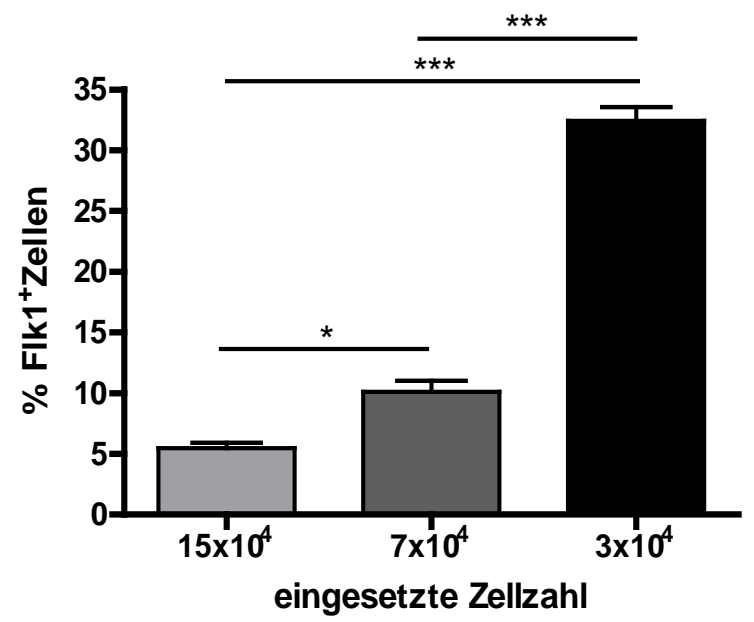

Abbildung 24: Austestung verschiedener Ausgangs-Zellzahlen für die optimale Differenzierung von maGSCs in Flk1 ${ }^{+}$Zellen. Dargestellt sind die aus verschiedenen Ansätzen durch Durchflusszytometrie resultierenden Flk1 ${ }^{+}$Zellen am d5 in \%. Mit absteigender eingesetzter Zellzahl am d0 nahm der prozentuale Anteil der Flk1 ${ }^{+}$Zellen signifikant von 5,5\% (15x10 ${ }^{4}$ Ausgangs-Zellen

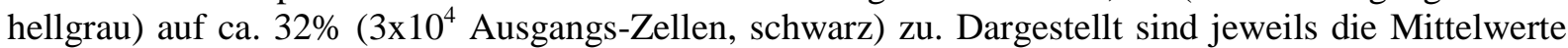
von 3 unabhängigen Experimenten und dem daraus ermittelten SEM. Signifikanzen des t-Tests wurden mit ${ }^{*} \mathrm{p}<0,05$ und ${ }^{* * *} \mathrm{p}<0,001$ angegeben.

Um zu überprüfen, an welchem Differenzierungstag die Ausbeute an Flk1 ${ }^{+}$Zellen am höchsten ist, wurden Differenzierungsversuche durchflusszytometrisch am Tag 4, 5 und 6 bezüglich Flk1 ${ }^{+}$Zellen analysiert (Abb. 25). Für den Differenzierungsansatz wurden 3x10 maGSCs verwendet, da sich diese Zellzahl als optimal für eine effiziente Flk1 Differenzierung erwiesen hatte (Abb. 24).

Wie schon beschrieben, konnten mittels Durchflusszytometrie die drei Populationen Flk1 ${ }^{+}$ Zellen, undifferenzierte $\mathrm{GFP}^{+}$Zellen und Flk1\%/GFP' Zellen dargestellt werden. Es konnten 
starke Unterschiede im Prozentsatz, sowohl zwischen den Populationen an einem Tag, als auch innerhalb einer Population im Verlauf der Differenzierung festgestellt werden.

Am Tag 4 der Differenzierung lagen 28\% Flk1 ${ }^{+}$Zellen im Vergleich zu ca. 55\% GFP ${ }^{+}$Zellen und ca. 13\% negativen Zellen vor. Einen Tag später stieg die Anzahl der Flk1 ${ }^{+}$Zellen auf fast $40 \%$ signifikant an, was auf eine erhöhte Differenzierung schließen lässt. Auf demselben Level befanden sich die $\mathrm{GFP}^{+}$Zellen, bei denen somit eine stark signifikante Reduktion im Vergleich zu d4 zu verzeichnen war. Dies lässt auf eine Abhnahme der undifferenzierten GFP $^{+}$Zellen schließen. Die Zahl der Flk/GFP Zellen erhöhte sich am d5 auf ca. 20\% und weiter am Tag 6 stark signifikant auf ca. 43\%. Der Prozentsatz der Flk1 ${ }^{+}$Zellen reduzierte sich am d6 signifikant auf ca. 26\% (von 40\% an d5), was auf einen Verlust des Flk1 hindeutet. Nur noch ca. 25\% der Zellen waren an d6 $\mathrm{GFP}^{+}$, was auf eine weitere Differenzierung der Zellen und den damit verbundenen Verlust des GFP schließen lässt und gut mit dem gestiegenen Anteil der anders differenzierten (Flk1/GFP') Zellen korreliert.

Es konnte gezeigt werden, dass der Differenzierungstag 5 am besten geeignet ist, um eine hohe Ausbeute an Flk1 ${ }^{+}$Zellen zu erhalten.

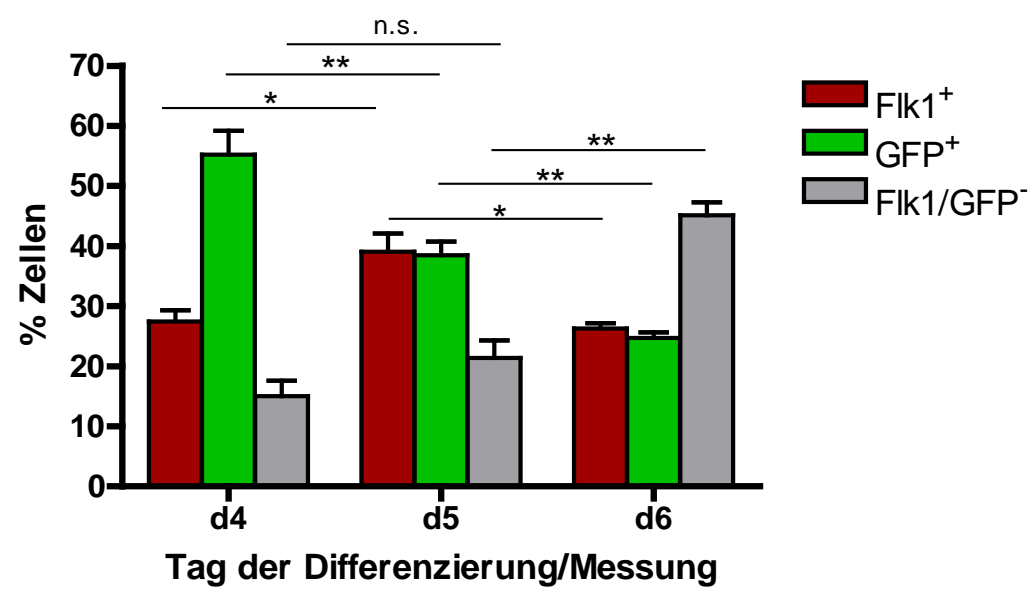

Abbildung 25: Durchflusszytometrie der vordifferenzierten Zellen. Dargestellt ist die Prozentzahl der Flk1 $1^{+}$Zellen (rot) im Vergleich zu den undifferenzierten $\mathrm{GFP}^{+}$(grün) und den Flk1 $1^{-}$und GFP Zellen (grau), gemessen am Tag 4, 5 und 6 der maGSC-Differenzierung mit ursprünglich 30.000 Zellen auf OP9 $(10 \mathrm{~cm}$ Zellkulturschale). Dargestellt sind jeweils die Mittelwerte von 3-5 unabhängigen Experimenten und dem daraus ermittelten SEM. Nur Tag 4 mit Tag 5 und Tag 5 mit Tag 6 wurden statistisch miteinander verglichen. Signifikanzen des t-Tests sind mit ${ }^{*} \mathrm{p}<0,05$ und ${ }^{* *} \mathrm{p}<0,01$ angegeben. Das nicht signifikante Resultat ist als n.s. beschrieben. 
Um die mesodermale Differenzierung der maGSCs noch zu verstärken, wurden dem Differenzierungsmedium Wachstumsfaktoren (AA, Wnt11 und BMP4) zugefügt. Die verwendeten Wachstumsfaktoren sollten die undifferenzierten maGSCs in ihrer Differenzierung stimulieren, um den Prozentsatz der in Flk1 ${ }^{+}$Zelldifferenzierung zu erhöhen. Die aus den verschiedenen Versuchsansätzen resultierende Ausbeute an Flk1 ${ }^{+}$Zellen wurde mittels Durchflusszytometrie analysiert (Abb. 26). In den Differenzierungsversuchen wurden den Zellen BMP4 in einer Konzentration von $10 \mathrm{ng} / \mathrm{ml}$ Medium ab d0 (schwarz) oder AA in einer Konzentration von 50 ng/ml Medium (schräg gestreift) zugeführt. Der Faktor Wnt11 ist nicht kommerziell erhältlich, so dass ein Wnt11-konditioniertes Medium mit Hilfe von NIH3T3-Wnt11-produzierenden Zellen hergestellt wurde (Pandur et al. 2002). Mit den modifizierten Medien wurden die Zellen entweder ab d0-d2 (grau) oder von d3-d5 (grau kariert) inkubiert. Als Vergleich sieht man im hellgrauen Balken die Anzahl der Flk1 ${ }^{+}$Zellen bei einer maGSC-Differenzierung ohne Faktorenzugabe, die an d5 ca. 39\% beträgt. Durch Einsatz von Wnt11 (mittels konditioniertem Medium) konnte die Differenzierung in Flk1 ${ }^{+}$ Zellen nicht erhöht werden. Beide Wnt11-Austestungen ab d0 oder d3 der Differenzierung führten zu einer leichten Erniedrigung der Flk1 ${ }^{+}$Zellzahl auf ca. 31-33\%. Ebenso zeigte eine Zugabe von AA an den ersten 2 Tagen der Differenzierung keinen positiven Einfluss auf die mesodermale Entwicklung der maGSCs (schräg gestreift).

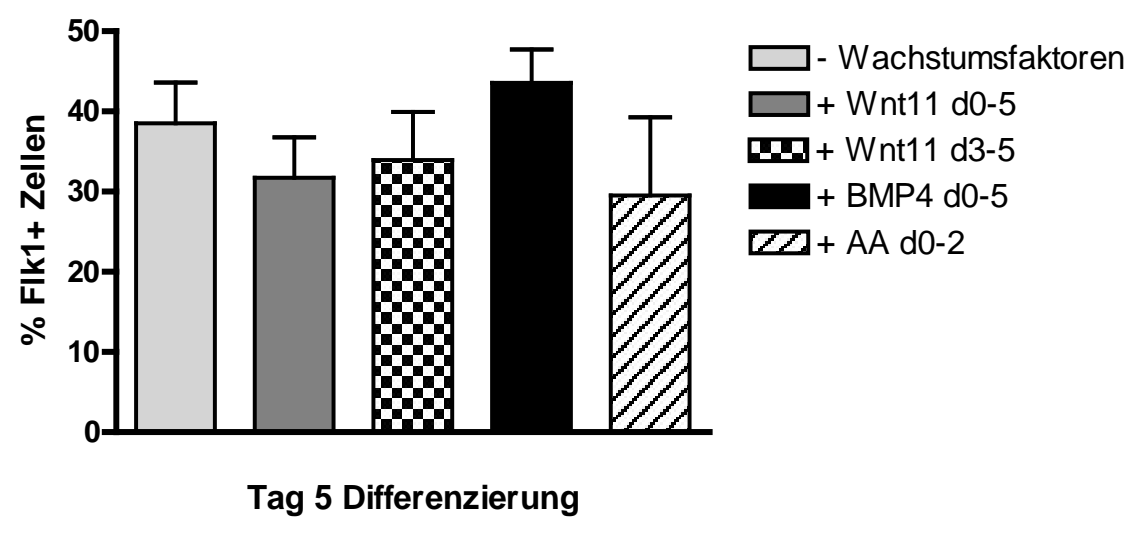

Abbildung 26: Vergleich verschiedener Wachstumsfaktoren bezüglich der maGSCDifferenzierung durch die Analyse des Markers Flk1 an d5 mittels Durchflusszytometrie. Flk1 ${ }^{+}$ Zellen nach Differenzierung ohne Wachstumsfaktoren (hellgrau), mit Wnt11 von d0-d5 (mittelgrau), mit Wnt11 von d3-d5 (kariert), mit BMP4 von d0-d5 (schwarz) und mit AA ab d0 (schräg gestreift). Es sind jeweils 3-5 unabhängige Experimente analysiert worden. Die Fehlerbalken entsprechen dem SEM. Die statistische Untersuchung mittels Student's t-test ergab keine Signifikanzen unter den verschiedenen Ansätzen. 
Nur BMP4 zeigte einen positiven Einfluss auf die mesodermale Differenzierung, sichtbar durch einen leichten, aber nicht signifikanten Anstieg auf ca. 43\% Flk1 ${ }^{+}$Zellen (im Vergleich zur Differenzierung ohne Faktoren). Nach diesen Tests wurde entschieden, auf Wachstumsfaktoren zu verzichten, da keiner der Faktoren einen signifikant positiven Effekt auf die Entwicklung der maGSCs in OP9-Co-Kultursystem in Richtung Mesoderm bzw. Flk1 ${ }^{+}$Zellen hatte.

\subsubsection{Charakterisierung der vordifferenzierten maGSCs am Tag 5}

Am Tag 5 der maGSC-Differenzierung mittels OP9-Co-Kultur wurden die Zellen nach einem Preplating mit einem Flk1 erkennenden und PE-gekoppelten Antikörper angefärbt und mit dem FACS-Gerät FACS-AriaII sortiert. Wenn die drei Populationen so deutlich wie in Abb. 23C zu erkennen waren, wurden sie eingegrenzt und konnten in getrennte Röhrchen sortiert werden.

Um zu überprüfen, ob das FACS erfolgreich war und die erwünschte Flk1 ${ }^{+}$Zellpopulation für weitere Versuche verwendet werden konnte, wurden im Anschluss an die Sortierung PCRProben der drei Populationen genommen und verschiedene Analysen auf mRNA-Ebene durchgeführt. Die Expression der frühen kardiovaskulären Gene Flk1 (Yamashita et al. 2000), Nkx2.5 (Harvey et al. 2002), Isl1 (Laugwitz et al. 2005) und C-Kit (Beltrami et al. 2003) und des frühen mesodermalen Markergens Bry (Herrmann et al. 1990) wurde in sortierten Flk1 ${ }^{+}$ Zellen, GFP ${ }^{+}$Zellen, GFP $/ F l k 1^{-}$Zellen und als Vergleich in Tag 5 differenzierten und undifferenzierten Zellen untersucht (Abb. 27). Als interner Standard diente das housekeeping Gen GAPDH. Bei dieser Analyse war deutlich zu erkennen, dass in der Flk1 ${ }^{+}$sortierten Zellpopulation, gemäß den Erwartungen, eine stärkere Flk1-Expression detektiert wurde als in den anderen Fraktionen. Auch Bry, als Markergen für frühes Mesoderm, war im Vergleich zu den undifferenzierten, d5 differenzierten oder den $\mathrm{GFP}^{-} / \mathrm{Flk1}^{`}$ sortierten Zellpopulationen hoch reguliert. Dies traf ebenso auf die frühen kardialen Transkriptionsfaktoren Nkx2.5 und Isl1 sowie auf den kardialen Stammzellmarker C-Kit zu, deren erhöhte Expression auf eine Differenzierung der Zellen in die kardiovaskuläre Richtung hinweist. 


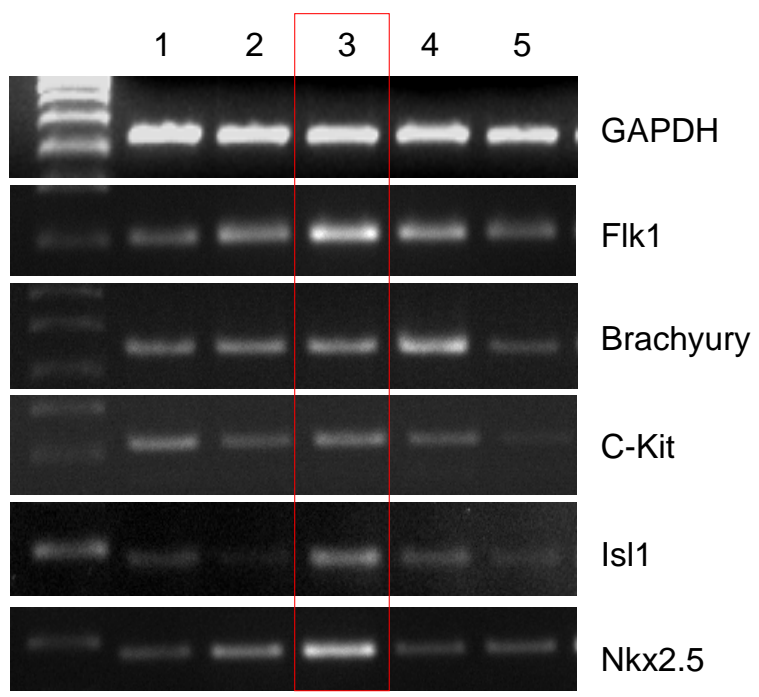
1: undifferenzierte maGSCs
2: d5 differenzierte Zellen
3: $\mathrm{Flk1}^{+}$sortierte Zellen
4: $\mathrm{GFP}^{+}$sortierte Zellen
5: Flk1\%GFP sortierte Zellen

Abbildung 27: Untersuchung früher mesodermaler und früher kardialer Markergene in undifferenzierten Zellen, in Zellen am Tag 5 der Differenzierung und in sortierten Zellen. Der rot markierte Bereich zeigt die sortierte Flk1 $1^{+}$Population, in der das frühe mesodermale Gen Bry und die frühen kardiovaskulären Gene Flk1, C-Kit, Isl1 und Nkx2.5 im Vergleich zu den undifferenzierten, d5 differenzierten und den GFP ${ }^{+}$bzw. Flk1\%/GFP Zellen hochreguliert waren. Das housekeeping Gen GAPDH diente als interner Standard.

Um den Anteil Oct4 ${ }^{+}$undifferenzierter und Flk1 $^{+}$vordifferenzierter Zellen zum Differenzierungs-Zeitpunkt d5 zu analysieren, wurden spezifische Antikörper gegen diese beiden Markerproteine in einer Doppelfärbung verwendet. Für die Differenzierung wurde hierbei die maGSC-Zelllinie SSC15 verwendet, da diese kein GFP exprimieren und somit für die Doppelfärbung geeignet sind.

Es konnte gezeigt werden, dass am d5 der maGSC-Differenzierung viele Zellbereiche für den Oberflächenmarker Flk1 positiv sind (Abb. 28A, C, rote Fluoreszenz), im Gegensatz zu vereinzelt Oct4-gefärbten Zellen (Abb. 28B, D grüne Fluoreszenz). Entsprechend den Erwartungen war deutlich zu erkennen, dass die meisten Flk1 ${ }^{+}$Zellen Oct4 negativ sind (Abb. 28D). 

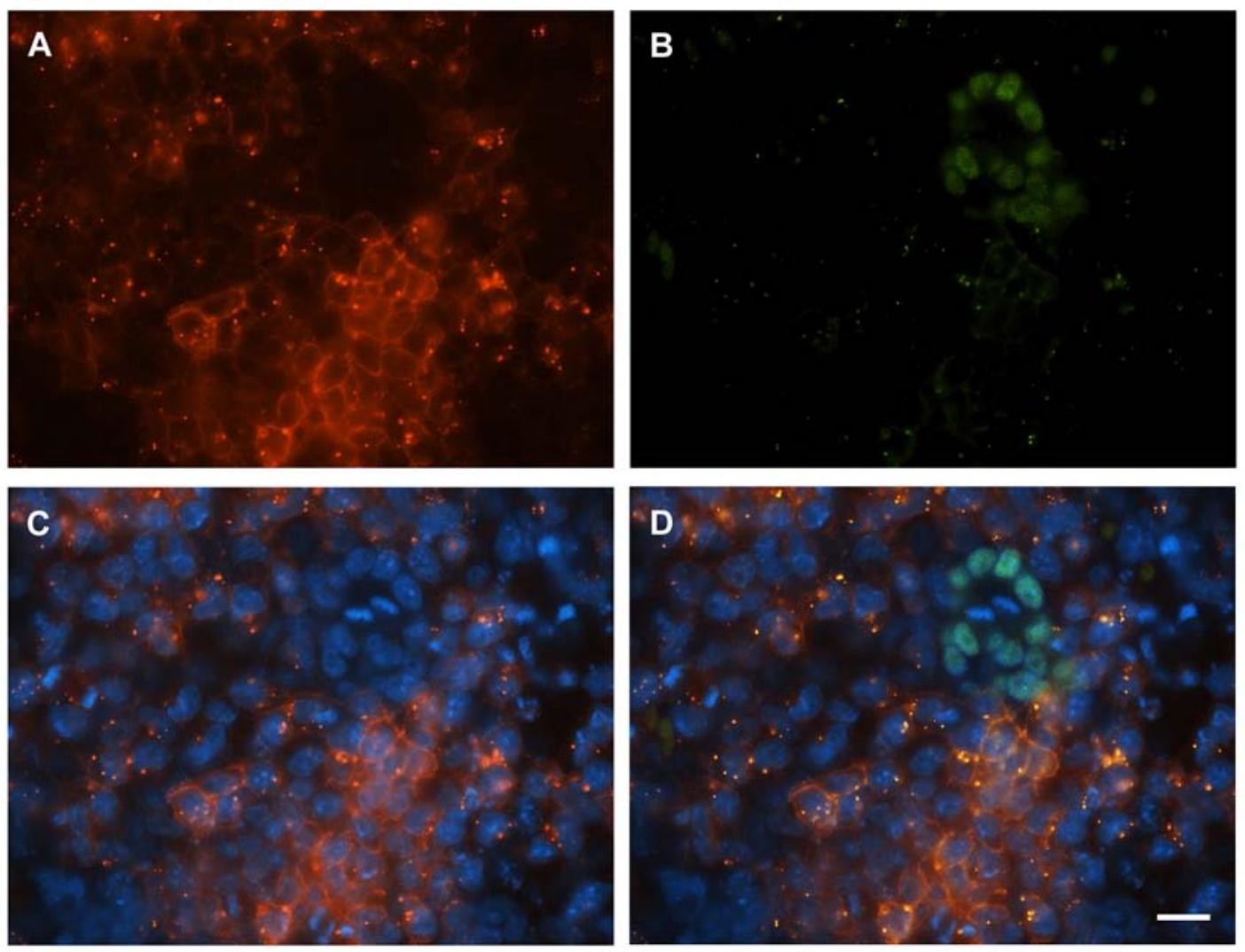

Abbildung 28: Indirekte Immunfluoreszenzfärbung von Flk1 und Oct4 positiven Zellen am d5. A: Flk1-Färbung (rot), B: Oct4-Färbung (grün). C: Flk1 (rot) und DAPI (blau). D: Überlagerung aller Kanäle. Skalierung $20 \mu \mathrm{m}$.

Da es während der Differenzierung zum Verlust des Pluripotenzmarkers Oct4 kommt, sollte der Differenzierungsgrad der maGSCs an d5 ausführlich bezüglich einer mesodermalen Richtung via Immunfluoreszenz untersucht werden (Abb. 29). Viele Zellen zeigten eine positive Färbung des bereits vorher beschriebenen frühen mesodermalen Transkriptionsfaktors Bry (Abb. 29 D-F) sowie der frühen kardialen Transkriptionsfaktoren Isl1 (Abb. 29 A-C) und Nkx2.5 (Abb. 29J-L). GATA4, ebenfalls ein Transkriptionsfaktor, der in der Herzentwicklung eine große Rolle spielt (Molkentin et al. 1994), konnte auch an d5 der maGSC-Differenzierung in den meisten Zellen detektiert werden (Abb. 29G-I). Da sich die Signale dieser Proteine größtenteils mit der DAPI-Nucleus-Färbung deckten, ist auch die Spezifität der Färbung durch die nukleäre Lokalisation der Transkriptionsfaktoren nachgewiesen. Ein Teil der maGSCs wies Nestin positive Zellen an d5 der Differenzierung auf (Abb. 29M, N, O). Nestin ist ein Intermediär-Filament-Protein, das u.a in frühen Entwicklungsstadien des Zentralen Nervensystems und in myogenen Strukturen nachgewiesen wurde (Michalczyk and Ziman 2005). Als Negativkontrolle dienten OP9Zellen (Daten nicht gezeigt). 

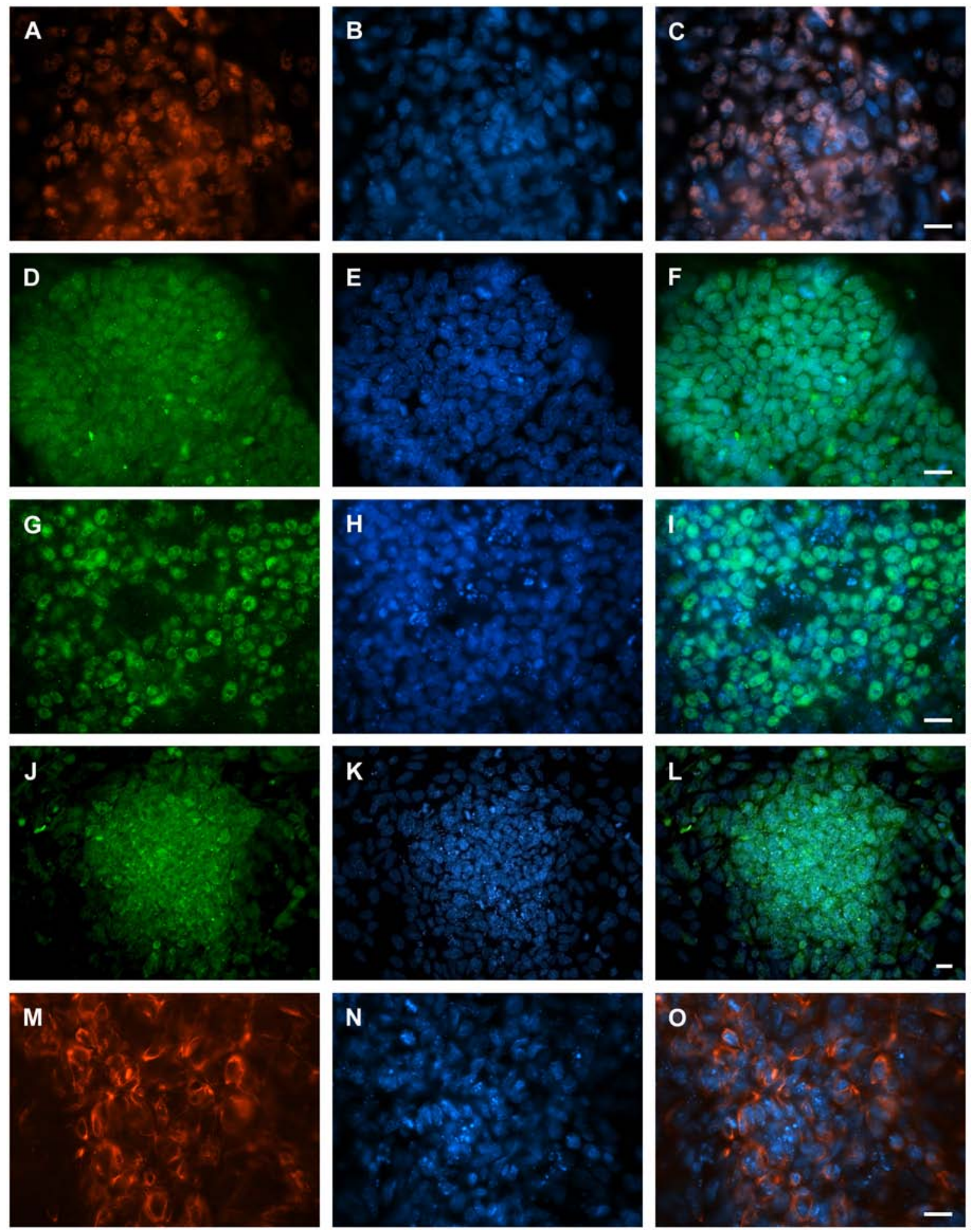

Abbildung 29: Indirekte Immunfluoreszenz-Analysen von Isl1, Bry, GATA4, Nkx2.5 und Nestin am d5. Dargestellt sind Immunfluoreszenzfärbungen früher Differenzierungsmarker. In der ersten Spalte ist die jeweilige Einzelfärbung zu sehen, mittig die DAPI-Färbung und rechts die Überlagerung der beiden Kanäle. A-C: Isl1, D-F: Bry, G-I: GATA4, J-L: Nkx2.5 und M-O: Nestin. Skalierung $20 \mu \mathrm{m}$. 
Um die qualitative Charakterisierung der aus maGSCs differenzierten Vorläuferzellen via Immunfluoreszenzfärbungen zu ergänzen, wurden an d5 der maGSC-Differenzierung (und zum Vergleich am d0) durchflusszytometrische Untersuchungen zur quantitativen Analyse durchgeführt (Abb. 30). Dabei konnten an d0 78,1\% und an d5 der Differenzierung 11,8\% Oct4 positive Zellen detektiert werden (grau). Die Anzahl der undifferenzierten maGSCs reduzierte sich also sehr stark. Die Anzahl der Flk1 ${ }^{+}$Zellen verfünffachte sich von d0 zu d5 (von 6,3 auf 29,6\%, rot). An d0 waren 15,9\% der maGSCs Isl1 ${ }^{+}$, und 5 Tage später hatte sich die Anzahl der Isl1 ${ }^{+}$Zellen mit 71,7\% auf das 4,5fache erhöht (orange), was zusammen mit der Flk1-Analyse auf eine gute Differenzierung in Richtung Mesoderm deutet. In einer Durchflusszytometrie-Doppelfärbung an d5 konnten noch ca. 63\% Isl1 ${ }^{+}$und ca. 33\% Isl1 ${ }^{+} / \mathrm{Flk1} 1^{+}$Zellen analysiert werden, was darauf schließen lässt, dass ca. die Hälfte der Isl1 ${ }^{+}$ Zellen auch Flk1 exprimiert (Daten nicht gezeigt). Der frühe mesodermale Marker Bry konnte ebenfalls mittels Durchflusszytometrie nachgewiesen werden (grün). Dabei wurden an d0 17,6\% und an d5 37,7\% Bry ${ }^{+}$Zellen detektiert. Nkx2.5 konnte an d0 in 19,8\% und an d5 der maGSC-Differenzierung in 64\% der Zellen nachgewiesen werden (blau). Alle Marker zeigten jeweils eine hochsignifikante Veränderung im Vergleich zwischen d0 und d5, wobei Oct4 stark herab und alle anderen Proteine gemäß einer frühen mesodermalen und frühen kardialen Differenzierung hochreguliert wurden.

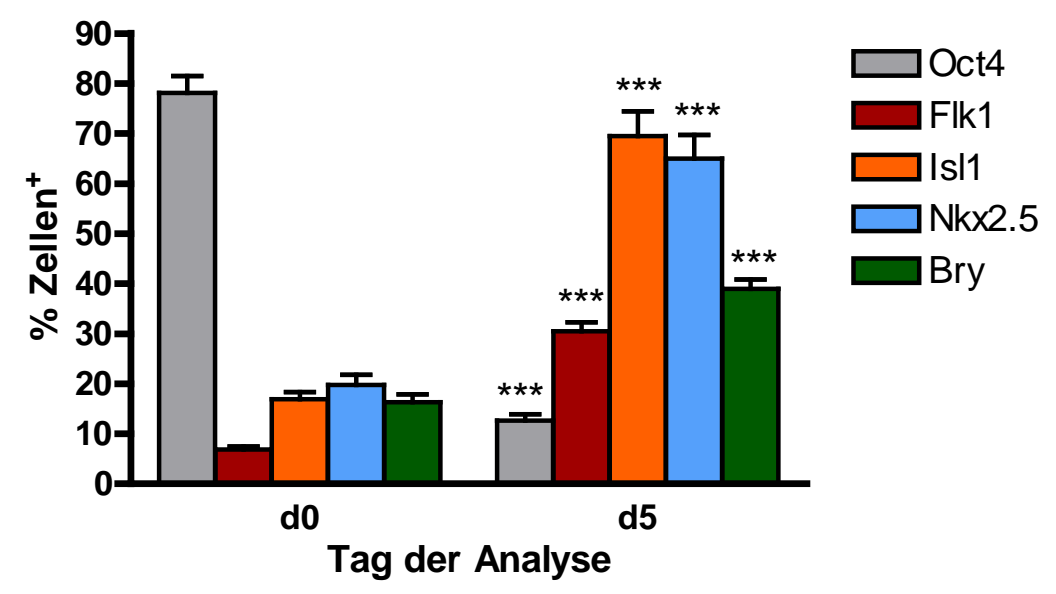

Abbildung 30: Vergleich verschiedener früher Differenzierungsmarker mittels Durchflusszytometrie an d0 und d5 (graue Balken: Oct4, rote Balken: Flk1, orange Balken: Isl1, blaue Balken: Nkx2.5 und grüne Balken: Bry). Bei allen Proteinen wurde jeweils eine hochsignifikante Veränderung zwischen d0 und d5 festgestellt. Signifikanzen des Student's t-tests, der für die Analyse zwischen d0 und d5 angewandt wurde, sind mit ***p $<0,001$ angegeben. 


\subsubsection{Kardiovaskuläres Differenzierungspotential der maGSCs mittels OP9-Co- Kultursystem}

Um zu untersuchen, ob maGSCs mittels OP9-Co-Kultursystem zu kardialen und vaskulären Zellen differenzieren können, wurden die Zellen an d5 der Differenzierung auf neue OP9Zellen umgesetzt und bis d5+15 im Differenzierungsmedium kultiviert, um anschließend die Genexpression spezifischer Marker in den alle 5 Tage genommenen Proben mittels RT-PCR zu untersuchen (Abb. 31).

Als Standard wurde das housekeeping Gen GAPDH verwendet. Es ist zu sehen, dass Flk1 und Isl1 durchgehend ab d5 exprimiert wurden. Der frühe kardiale Marker GATA4 war ab d5+5 bis d5+15 stark exprimiert. Die späteren kardialen Gene MHC und MLC2v wurden schwach an d5+10 und dann stärker an d5+15 angeschaltet. ANF (atrial natriuric factor) (Bilder et al. 1989) und Mef2c konnten als kardiale Gene ebenfalls ab d5+10 gleichbleibend nachgewiesen werden. Die vaskulären Marker SMA und vWF waren während der Langzeit-Differenzierung zu detektieren: Die Expression von SMA begann sehr schwach an d5+5 und steigerte sich konstant bis d5+15, während der vWF schon schwach am d5 exprimiert war und sich ab d5+5 in einem stärkeren gleichbleibenden Expressions-Level bis d5+15 zeigte. Zusammenfassend lässt sich nach Auswertung der RT-PCR-Analyse feststellen, dass die maGSCs während einer längeren Differenzierung auf OP9-Zellen sowohl in kardiale, kardiovaskuläre und endotheliale Zellen als auch in glatte Muskelzellen differenzieren können.

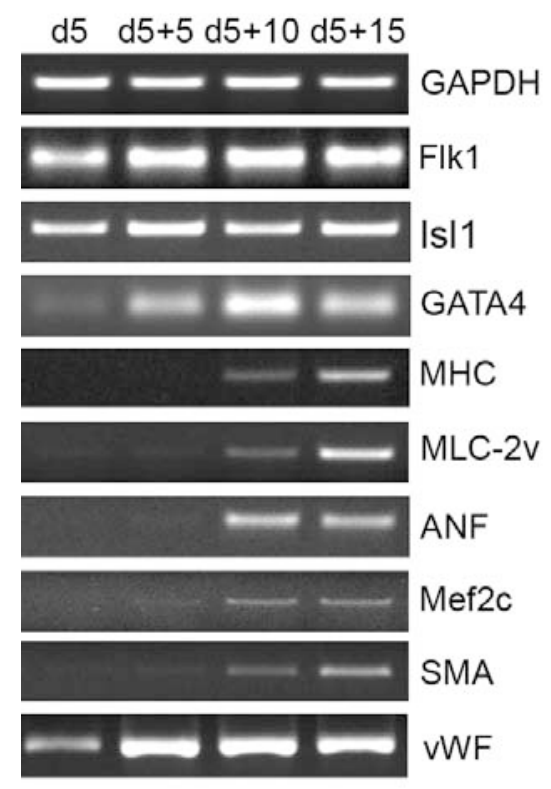

Abbildung 31: Genexpressions-Analyse kardialer und vaskulärer Markergene zu verschiedenen Zeitpunkten der maGSC-Differenzierung auf OP9-Zellen. Aufgeführt sind die RT-PCRErgebnisse der kardiovaskulären Vorläuferzellmarker Flk1 und Isl1, der kardialen Marker GATA4, MHC, MLC2v, ANF und Mef2c und der vaskulären Marker SMA und vWF. Als interner Standard diente GAPDH. 
Des Weiteren wurden die maGSCs bei längerer Differenzierung mittels indirekter Immunfluoreszenz-Untersuchungen gegen die Proteine $\alpha \mathrm{MHC}$, SMA und vWF analysiert.

Zur weiteren Charakterisierung der maGSC-Differenzierung wurden die Zellen mittels Antikörper (MF20) gegen das von Kardiomyozyten produzierte Sarkomerprof\&itHC gefärbt (Abb. 32) (Sweeney and Kelley 1990). An d5+10 konnten nur sehr wenige $\alpha \mathrm{MHC}$ positive Zellen detektiert werden, die noch nicht das typische gestreifte Sarkomer-Muster zeigten (Abb. 32A-C). Daher handelte es sich hier wahrscheinlich um frühe kardiale Zellen. An d5+15 konnten größere $\alpha \mathrm{MHC}^{+}$Zellcluster mit deutlich positiver sarkomerer StreifenFärbung visualisiert werden (Abb. 32D-F). 5 Tage später wurden $\mathrm{MHC}^{+}$quergestreifte Muskelfasern detektiert (Abb. 32G-I).
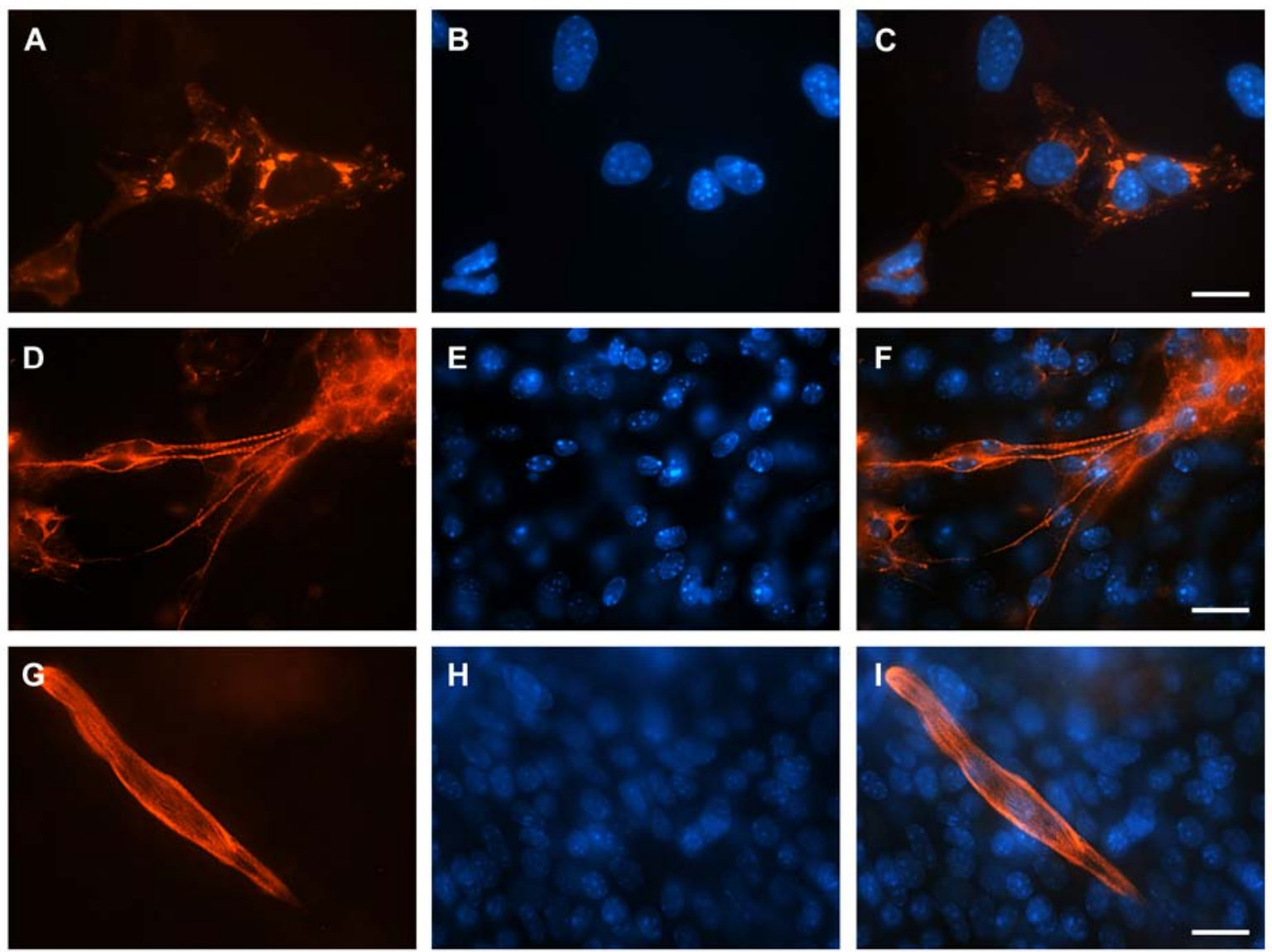

Abbildung 32: $\alpha$ MHC-Immunfluoreszenz bei fortschreitender maGSC-Differenzierung auf OP9. Indirekte Immunfluoreszenzfärbung von $\alpha \mathrm{MHC}$ an d5+10 (A-C), d5+15 (D-F), d5+20 (G-I). In der linken Spalte ist die aMHC-Einzelfärbung zu sehen (rot), in der mittleren Spalte die Zellkerne anhand der DAPI-Färbung (blau) und rechts die Überlagerung der beiden Kanäle. Zu jedem Zeitpunkt der Analyse konnten $\alpha \mathrm{MHC}^{+}$Zellen detektiert werden, besonders gut aufgrund der gestreiften Sarkomerfärbung jedoch an d5+15 und d5+20. Skalierung $20 \mu \mathrm{m}$. 
Das von glatten Muskelzellen produzierte SMA-Protein wurde bereits an $\mathrm{d} 5+10$ im Zytoskelett vieler Zellen mittels Immunfluoreszenz nachgewiesen (Abb. 33A-C), was auf eine weitere kardiovaskuläre Differenzierung der maGSCs schließen lässt. Im Laufe der Differenzierung konnte eine Zunahme von $\mathrm{SMA}^{+}$Bereichen festgestellt werden, die an $\mathrm{d} 5+10$ größere gefäßähnliche Strukturen (Abb. 33D-F) und 5 Tage später noch mehr zusammenhängende und langgezogene Zellstrukturen aufwiesen (Abb. 33G-I).
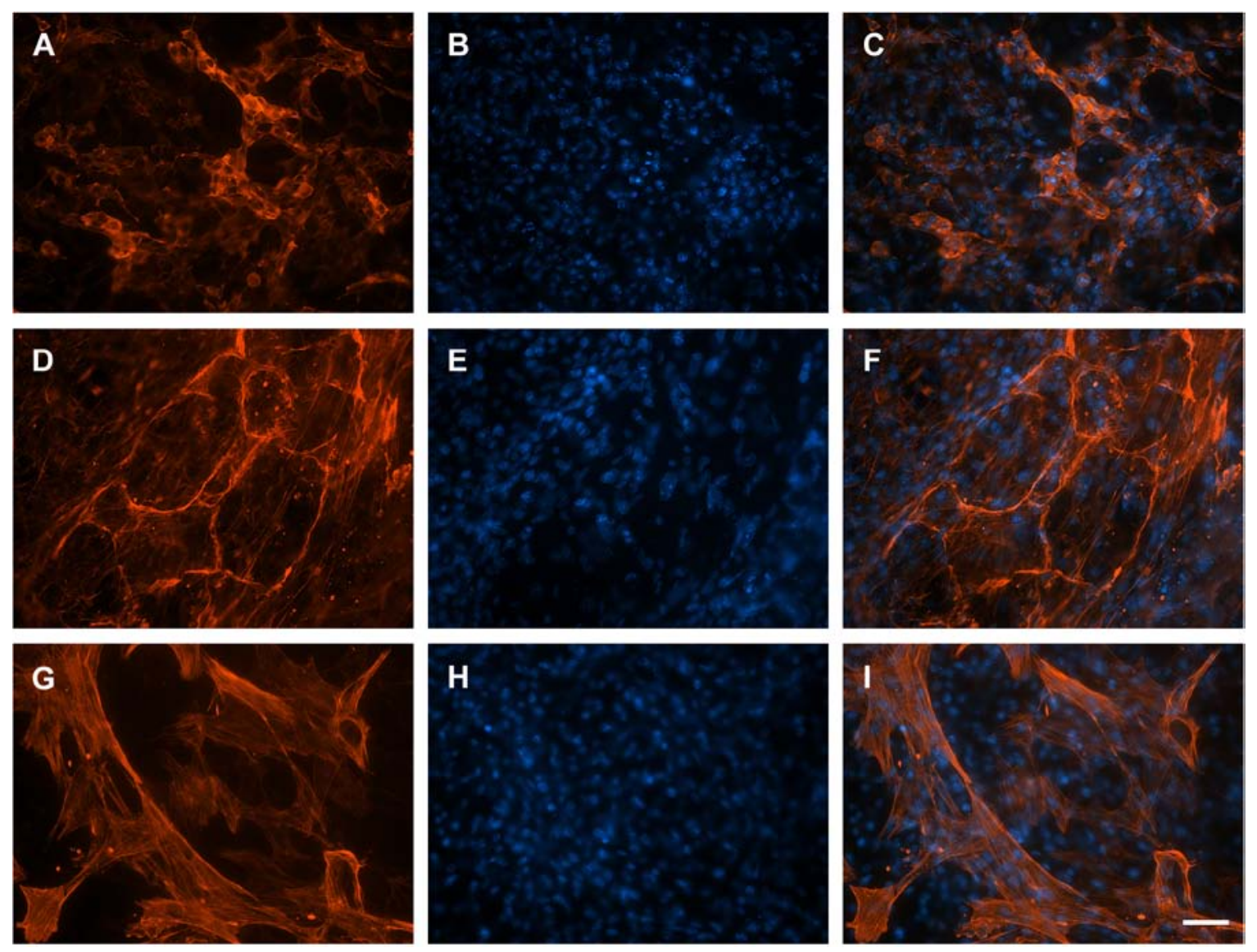

Abbildung 33: SMA-Immunfluoreszenz bei fortschreitender maGSC-Differenzierung auf OP9. Indirekte Immunfluoreszenzfärbung von SMA an d5+10 (A-C), d5+15 (D-F), d5+20 (G-I). In der linken Spalte ist die SMA-Einzelfärbung zu sehen (rot), in der mittleren Spalte die Zellkerne anhand der DAPI-Färbung (blau) und rechts die Überlagerung der beiden Kanäle. Zu jedem Zeitpunkt sind $\mathrm{SMA}^{+}$Zellen nachzuweisen, wobei SMA ${ }^{+}$Strukturen bei längerer maGSC-Differenzierung zunehmen (d5+20). Skalierung $50 \mu \mathrm{m}$.

Neben $\mathrm{SMA}^{+}$glatten Muskelzellen konnten auch Endothelzellen mittels Immunfluoreszenzfärbung nachgewiesen werden, indem Antikörper gegen den zytoplasmatischen Endothelzell-Marker vWF zu verschiedenen Zeitpunkten der maGSCDifferenzierung verwendet wurden (Abb. 34). 
Der vWF war bereits ab d5+10 in kleineren runden und verzweigten Strukturen zu detektieren (Abb. 34A, C). 5 Tage später konnten noch mehr $\mathrm{vWF}^{+}$Zellen in größeren und weiter verzweigten Mustern analysiert werden (Abb. 34D, F), die sich auch an d5+20 zeigten (Abb. 34G, I).
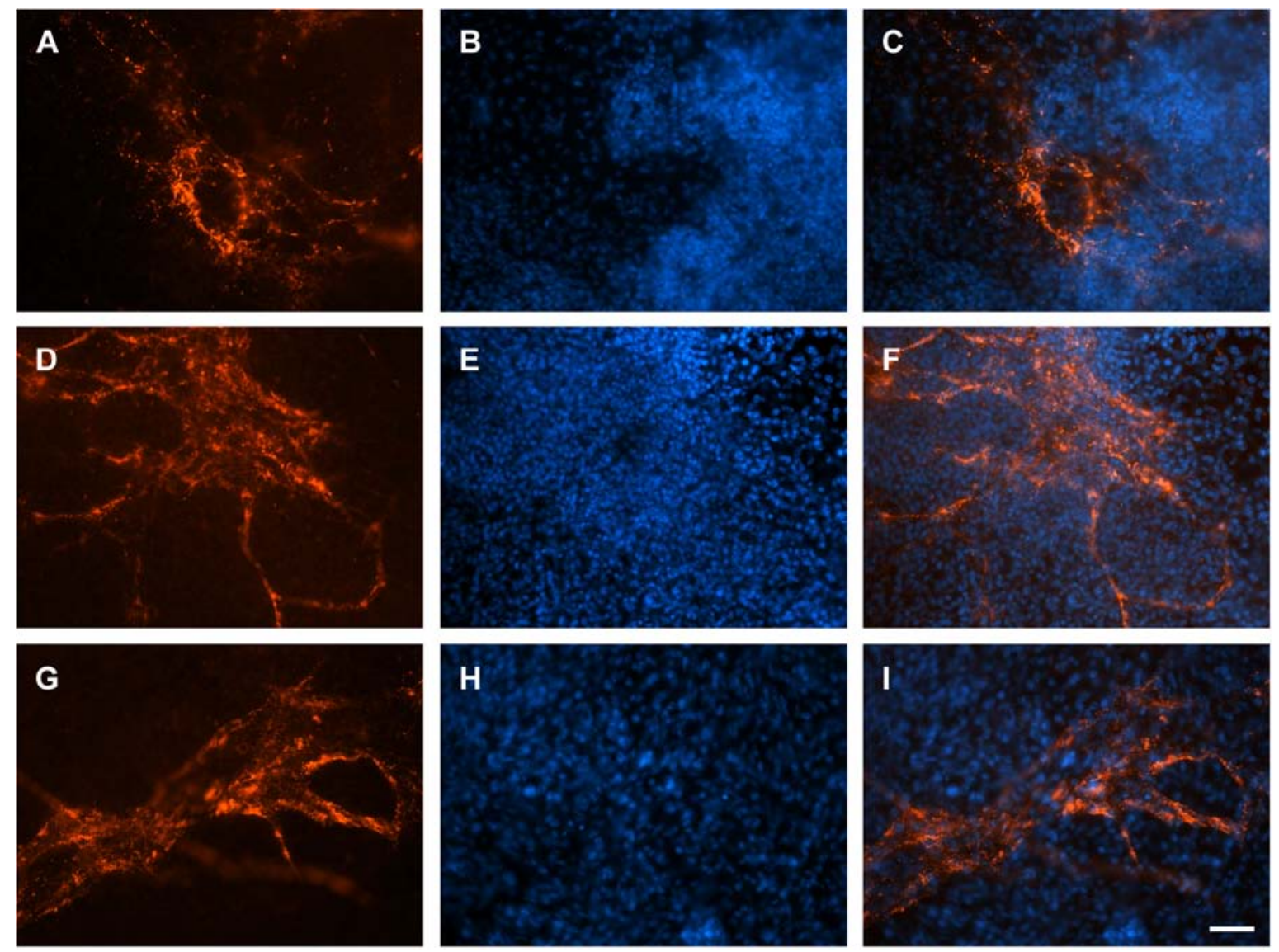

Abbildung 34: vWF-Immunfluoreszenz bei fortschreitender maGSC-Differenzierung auf OP9. Indirekte Immunfluoreszenzfärbung des vWF an d5+10 (A-C), d5+15 (D-F), d5+20 (G-I). In der linken Spalte ist die vWF-Einzelfärbung zu sehen (rot), in der mittleren Spalte die Zellkerne anhand der DAPI-Färbung (blau) und rechts die Überlagerung der beiden Kanäle. Der vWF ist zu allen drei Zeitpunkten zu detektieren. Bei fortschreitender Differenzierung vergrößern und verzweigen sich die $\mathrm{vWF}^{+}$Zellen immer mehr und nehmen endotheliale Formen an. Skalierung 50 $\mu \mathrm{m}$.

Zusammenfassend zeigen die durchgeführten Immunfluoreszenz-Analysen, dass die maGSCs bei weiterer Differenzierung auf OP9-Zellen in der Lage sind, zu $\alpha$ MHC, SMA, vWF positiven Zellen zu differenzieren, was auf ihr kardiales und vaskuläres Differenzierungspotential schließen lässt. 


\subsubsection{Differenzierungspotential der Flk1 ${ }^{+}$Zellen}

Um das Differenzierungspotential der sortierten Flk1 ${ }^{+}$Zellpopulation zu überprüfen, wurden die sortierten Flk1 ${ }^{+}$Zellen weiter auf OP9-Zellen kultiviert (Abb. 35). Diese Zellen konnten sich dann sowohl in schlagende Kardiomyozyten (Abb. 35A), Gefäßvorläuferzellen (Abb. 35B) und Zellen mit hämatopoetischer Morphologie (Abb. 35C) entwickeln. Abb. 35A zeigt den Ausschnitt eines Videos von rhythmisch schlagenden Kardiomyozyten an d21 nach Sortierung. Es sind dicht gewachsene Zellen zu sehen, die auf gute Zell-Zell-Interaktionen schließen lassen und die gemeinsame Kontraktion der Zellen ermöglichen. Ebenso konnte eine Differenzierung von Flk1 ${ }^{+}$Zellen in die vaskuläre Richtung nachgewiesen werden (Abb.35 B). Hier sind deutlich gefäßähnliche Vorläuferstrukturen als rundliche, abgeschlossene Bereiche sichtbar. Dass $\mathrm{Flk1}^{+}$Zellen als Hämangioblasten auch hämatopoetische Zellen hervorbringen, ist lange bekannt (Nakano et al. 1994). Auch in unseren Experimenten differenzierten die $\mathrm{Flk}^{+}$sortierten Zellen auf OP9-Zellen u.a. zu hämatopoetischen Progenitorzellen, die in kleineren, traubenartigen Zellformationen zu sehen waren (Ab. 35C).
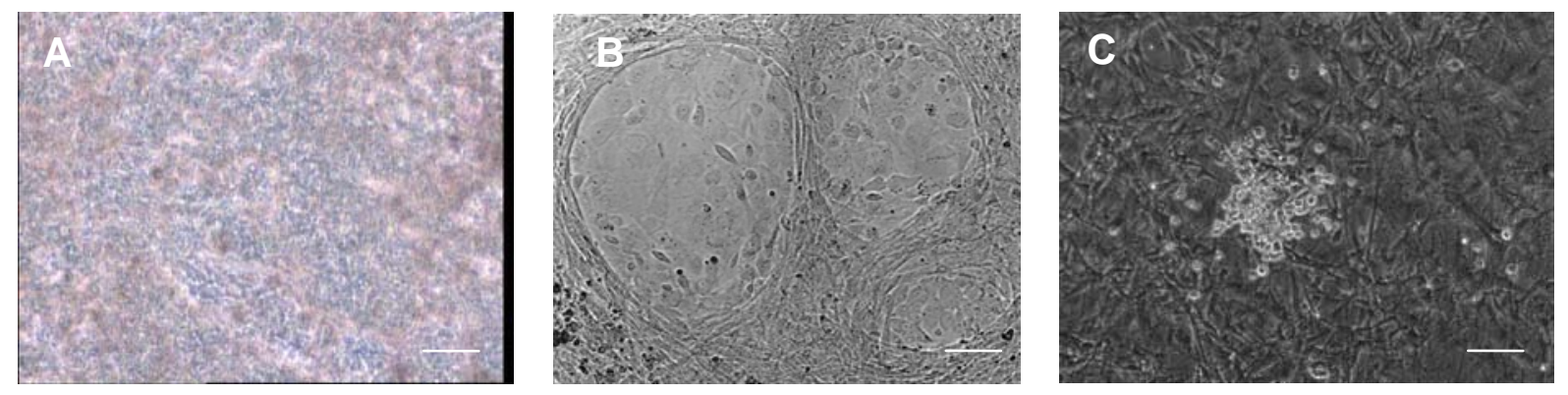

Abbildung 35: Kultivierung FACSortierter Flk1 ${ }^{+}$Zellen auf OP9. A-C: Flk1 ${ }^{+}$Zellen nach 21 Tagen weiterer Kultivierung auf OP9-Zellen. A: Kardiomyozyten, B: Gefäßstrukturen und C hämatopoetische Vorläuferzellen. Skalierung $100 \mu \mathrm{m}$.

Für den Nachweis des Differenzierungspotentials der Flk1 ${ }^{+}$Zellen auf Proteinebene, wurden Immunfluoreszenzfärbungen gegen SMA und vWF durchgeführt, nachdem die Flk1 ${ }^{+}$Zellen zunächst sortiert und dann weiter auf OP9-Zellen kultiviert wurden. Es konnten erfolgreich Nachweise des glatten Muskelzellproteins SMA und des Endothelzellmarkers vWF geführt werden (Abb. 36). Viele sortierte Flk1 ${ }^{+}$Zellen entwickelten sich nach weiterer Kultivierung auf OP9 zu glatten Muskelzellen (Abb. 36A). Der vWF ist noch nicht so stark in größeren Zellclustern exprimiert wie SMA, aber auch gut nachzuweisen (Abb. 36B). Es konnte zwar keine gute Färbung gegen cTnT durchgeführt werden, aber wie in Abbildung 35 zu sehen, 
sind die Flk1 ${ }^{+}$Zellen zusätzlich in der Lage, wenn auch später, sich in Kardiomyozyten zu differenzieren.

Zusammenfassend lässt sich sagen, dass sortierte Flk1 ${ }^{+}$Zellen das Potential besitzen, in glatte Muskel- und Endothelzellen und Kardiomyozyten zu differenzieren.
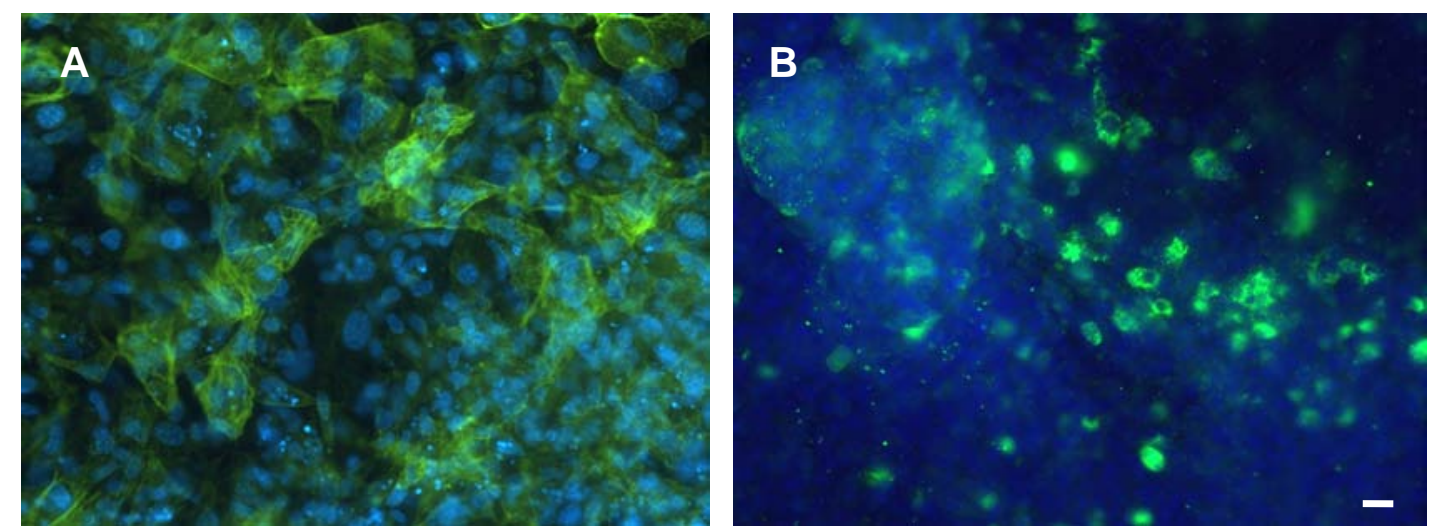

Abbildung 36: Nachweis der Differenzierung Flk1 ${ }^{+}$Zellen an d13 nach FACS in glatte Muskelund endotheliale Vorläuferzellen durch indirekter Immunfluoreszenz gegen $\operatorname{SMA}^{+}(\mathrm{A})$ und $\mathbf{v W F}^{+}$(B). Skalierung $20 \mu \mathrm{m}$.

\subsection{In vitro-Dehnungsversuche mit maGSCs}

Um zu überprüfen, ob eine Dehnung der maGSCs in vitro einen Einfluss auf die Differenzierung der Zellen hatte, wurden undifferenzierte maGSCs auf speziellen Bio-FlexZellkulturschalen für 1d kultiviert und dann 15, 30 oder 60 min lang bei $1 \mathrm{~Hz}$ und Raumtemperatur gedehnt. Zu diesen Zeitpunkten wurden PCR-Proben genommen oder die gedehnten Zellen für 5d weiter auf OP9 kultiviert und anschließend Flk1 mittels Durchflusszytometrie charakterisiert.

In den RT-PCR-Analysen mit Proben vom selben Tag der Dehnung wurden die Marker Oct4 und Bry untersucht. Dabei konnten in den verschiedenen Dehnungsansätzen (15, 30 und 60 min) keine signifikanten Unterschiede zu den ungedehnten Kontrollen in der relativen Expression der untersuchten Gene festgestellt werden (Abb. 36A). Allerdings ist Oct4 als Marker für undifferenzierte Stammzellen nach den Dehnungsphasen leicht, aber nicht signifikant erhöht exprimiert (Abb. 36B). 
A

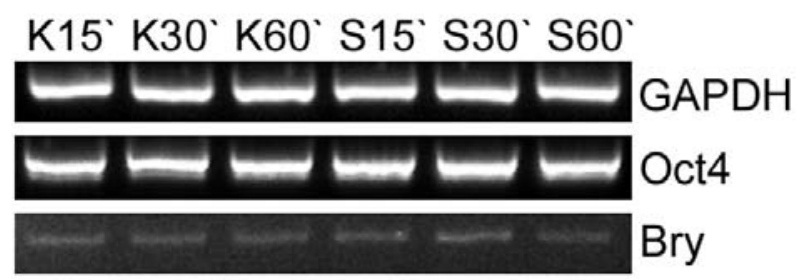

B

Oct4/GAPDH

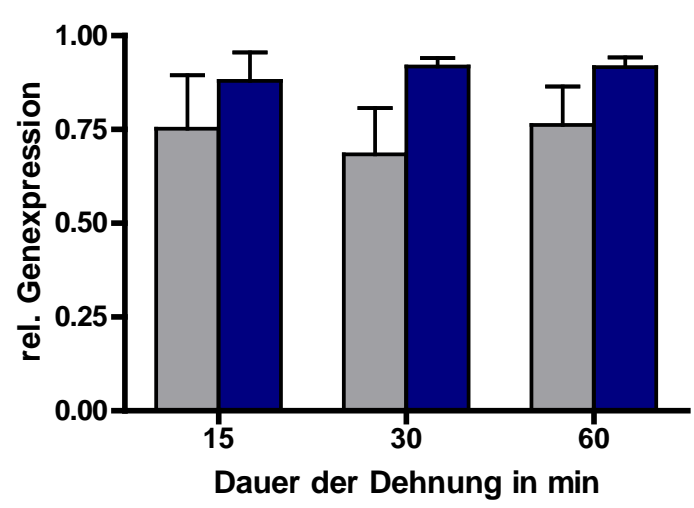

C

\section{Bry/GAPDH}

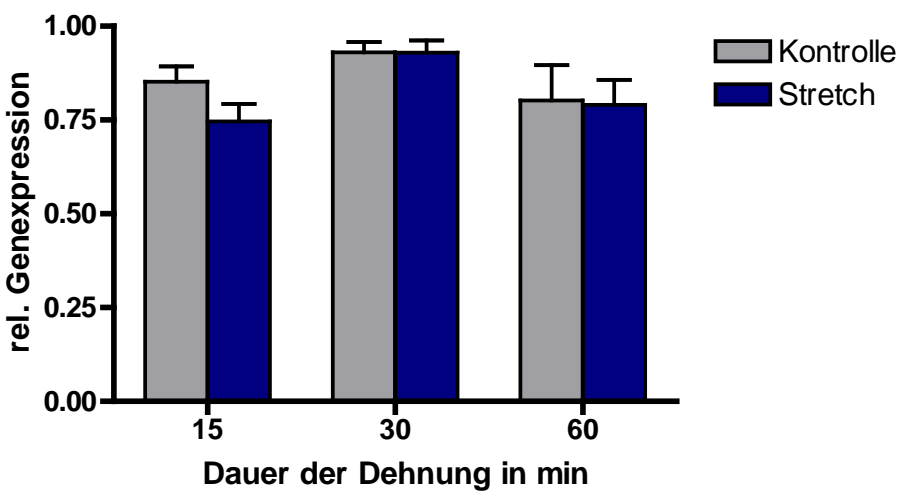

Abbildung 36: Analyse der Dehnungs-Versuche auf mRNA-Ebene. A: RT-PCR-Analyse der Marker Oct4 und Bry im Vergleich zu dem housekeeping-Gen GAPDH. K= Kontrolle, S= Stretch. Relative Genexpression von Oct4 (B) und Bry (C), ermittelt durch quantitative Analyse 5 unabhängiger Experimente und normalisiert gegen GAPDH.

Der frühe mesodermale Marker Bry scheint durch das Stretchen der Zellen kaum beeinflusst zu sein (Abb. 36C). Hier zeigt sich in den Genexpressionsdaten keine signifikante Reduktion der Bry-Genexpression nach 15, 30 und 60 min.

Für die Durchflusszytometrie-Tests wurden die Zellen vor weiterer Kultivierung auf OP9 noch länger gedehnt (1 und $2 \mathrm{~h}$ ), da bei der vorherigen Analyse auf mRNA-Ebene kaum Differenzen zwischen den Stretch-Zeitpunkten festgestellt werden konnten. Um zu untersuchen, ob ein induzierender Effekt der Dehnung auf die Flk1 Differenzierung vorliegt, wurden die gedehnten maGSCs weiter auf OP9-Zellen im Differenzierungs-Medium kultiviert. Es konnten nur marginale Unterschiede zwischen den gestretchten Zellen und den entsprechenden Kontrollen analysiert werden (Abb. 37). Dabei fiel allerdings auf, dass die Differenzierung in $\mathrm{Flk}^{+}$Zellen wesentlich schlechter verlief als bei den früheren Differenzierungsversuchen auf OP9-Zellen ohne vorangegangene Dehnung der maGSCs. Es 
wurden nur wenige Flk1 ${ }^{+}$Zellen an d5 der Differenzierung analysiert. Von den 1 h gedehnten Zellen entwickelten sich nur ca. 7,5\% in Flk1 ${ }^{+}$Zellen, in den entsprechenden Kontrollen waren es unter 5\%. Wurden die maGSCs 2 h gedehnt, differenzierten ca. 7\% zu Flk1 ${ }^{+}$Zellen (Kontrollen: ca.7,5\%).

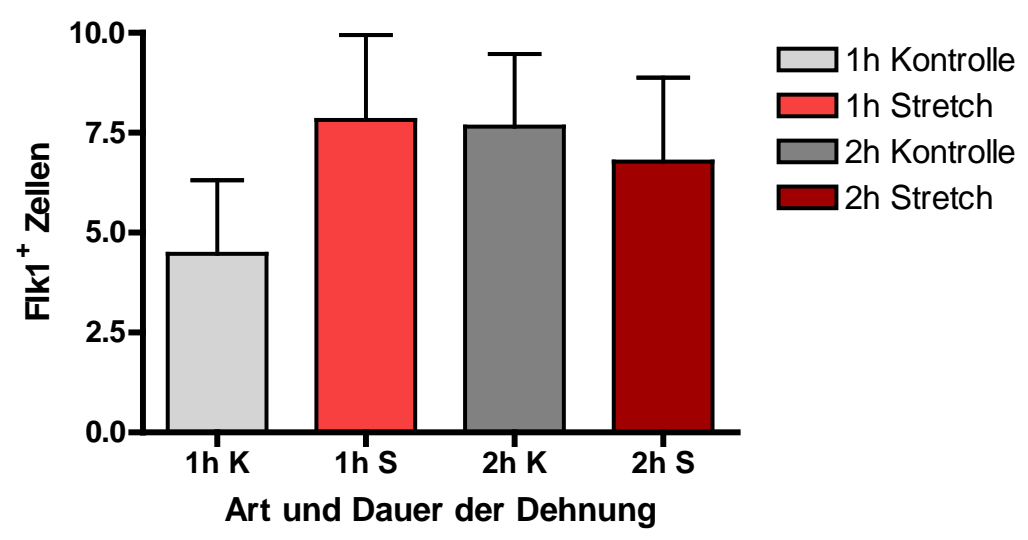

Abbildung 37: Flk1 Durchflusszytometrie an d5 der weiteren Kultivierung gedehnter Zellen auf OP9-Zellen. In den grauen Balken sind die Durchflusszytometrie-Analysen der ungedehnten Zelldifferenzierung und in den roten Balken die Ergebnisse der gedehnten Zelldifferenzierung nach 5 d weiterer Kultivierung auf OP9 graphisch dargestellt. K= Kontrolle, S= Stretch. Die Fehlerbalken entsprechen dem SEM. Es konnten keine signifikanten Ergebnisse durch den Student's t-test ermittelt werden.

Zusammenfassend lässt sich also sagen, dass die in vitro-Dehnung der maGSCs in unseren Experimenten bei Raumtemperatur keinen stimulativen Einfluss auf die Differenzierung der maGSCs in Richtung Mesoderm ausübt. 


\section{Diskussion}

\section{Diskussion}

Im Rahmen der vorliegenden Arbeit wurden maGSCs der Maus in vivo und in vitro im Hinblick auf ihr Differenzierungspotential unter bestimmten Bedingungen untersucht.

In vivo konnte gezeigt werden, dass sich undifferenzierte maGSCs in normalen Mausherzen ansiedeln und proliferieren können. Obwohl die injizierten maGSCs in vaskuläre endotheliale und glatte Muskelzellen differenzieren können, wurde keine kardiale Differenzierung beobachtet. Es wurden keine Tumore, aber Fibrose bis zu vier Wochen nach der Transplantation gefunden. Die Modelle zur erhöhten Vorlast und Nachlast im Herzen der Maus wurden durch Shunt- und TAC-Operationen etabliert. Vier Wochen nach der Shunt-OP zeigte die Myokardstruktur kaum Veränderungen, während die TAC-OP zu starken Veränderungen der Myokardstruktur und zu vermehrter Fibrose führte.

Auch in Vorlast- und Nachlast-induzierten Mäusen wurden die injizierten maGSCs im Empfängermyokard detektiert. Allerdings zeigte sich in den Tieren mit Zellinjektion in allen Gruppen (Shunt-, TAC- und jeweilige Sham operierte Tiere) $2 \mathrm{w}$ und $4 \mathrm{w}$ nach Operationen vermehrte Bindegewebsbildung. Dabei war zu beobachten, dass sich die maGSCs in Shuntund TAC-operierten Mäusen $2 \mathrm{w}$ nach den Operationen schon zu glatten Muskel- und endothelialen Zellen entwickelt hatten. Eine kardiale Differenzierung der transplantierten maGSCs konnte in den Shunt- und TAC-operierten Mäusen $4 \mathrm{w}$ nach den OPs detektiert werden. Allerdings ergaben die echokardiographischen Analysen der herzkranken Mäuse mit maGSC-Transplantaten kaum signifikante, aber einige tendenzielle Verbesserungen der Herzfunktion im Vergleich zu den Kontrollmäusen.

In vitro konnten die maGSCs durch kurzzeitige Dehnung allerdings nicht in ihrem Differenzierungsverhalten beeinflusst werden.

Wurden undifferenzierte maGSCs in Herzen von immundefizienten RAG2 ${ }^{-/} \mathrm{Cgc}^{-/-}$Mäusen injiziert, entwickelten sich weniger und kleinere Teratome in den Mäusen mit CsABehandlung als in den Mäusen ohne das immunsupprimierende Medikament. Außerdem waren bei ersteren nur wenige transplantierte Zellen noch Oct4 positiv im Gegensatz zu den Zellen in den Mäusen, die kein CsA erhalten hatten. Dies lässt auf eine Hemmung der Pluripotenz und eine Stimulation der Differenzierung der maGSCs durch CsA schließen.

In vitro konnte ein optimales Protokoll für die effiziente Differenzierung der maGSCs in $\mathrm{Flk1}^{+}$kardiale und vaskuläre Progenitorzellen unter Verwendung eines Co-Kultur-Systems mit OP9-Stromazellen etabliert werden. Weiterhin zeigte sich, dass das Co-Kultursystem die Differenzierung der maGSCs in kardiale, endotheliale und glatte Muskelzellen induzieren konnte. Die Flk1 ${ }^{+}$Zellen wurden mittels FACS zum Zeitpunkt Tag 5 der Differenzierung 
erfolgreich sortiert. Es zeigte sich, dass die aus Flk1 positiven, weiter differenzierten Zellen in vitro kardiale, endotheliale und glatte Muskelzell-Marker exprimieren.

\subsection{MaGSCs als alternative Zellquelle für Herzregeneration}

Herzkrankheiten, die z.B. aus einem Herzinfarkt oder einer Stenose durch Ablagerungen in Herzgefäßen resultieren und meist in einer Herzinsuffizienz enden, sind eine der Haupttodesursachen weltweit. Da medikamentöse oder chirurgische Behandlungen nur bis zu einem bestimmten Punkt helfen, ist die Erforschung alternativer Therapien zur Regeneration von geschädigtem oder abgestorbenem Herzgewebe von unschätzbarem Wert. Dabei spielen zellbasierte und v.a. Stammzellbasierte Ansätze eine große Rolle. Solche Ansätze wurden bisher in Tiermodellen unter Verwendung von ES-Zellen und adulten Stammzellen vorgestellt.

Es wurden große, teils multizentrische humane Studien an Patienten mit AMI oder Ischämien unter Verwendung von Knochenmarkzellen durchgeführt, die zwar die Sicherheit und Anwendbarkeit von Knochenmarkstammzellen in AMI und ischämischen Patienten, aber keine signifikante und zellbasierte Funktionsverbesserung des Herzens zeigten (Janssens et al. 2006; Lunde et al. 2006; Schachinger et al. 2006a; Schachinger et al. 2006b).

Einige Studien zeigen eine Einschränkung des Transdifferenzierungspotentials von HSCs zu Kardiomyozyten (Balsam et al. 2004; Murry et al. 2004) oder berichten, dass Fusionen von Stammzellen und Kardiomyozyten auftreten können (Terada et al. 2002; Ying et al. 2002).

In MI-Herzen konnten transplantierte ES-Zellen in alle drei großen Herzzelltypen differenzieren: Kardiomyozyten, vaskuläre Endothelzellen und glatte Muskelzellen (Behfar et al. 2002; Min et al. 2002; Hodgson et al. 2004; Singla et al. 2006). Humane ES-Zellen sind wegen ihrer gesetzlichen Limitierung und ihrer ethischen Problematik keine ideale Quelle für zellbasierte Therapien. Daher wären adulte Stammzellen mit ES-Zell-Eigenschaften eine gute Alternative für zellbasierte Regenerationstherapien. Kürzlich konnten iPS Zellen durch Überexpression von vier Transkriptionsfaktoren (Oct4, Sox2, c-Myc und Klf4 oder Oct4, Sox2, Nanog und Lin28) mittels viraler Infektion adulter humaner somatischer Zellen generiert werden (Takahashi et al., 2007; Yu et al., 2007). Allerdings könnten diese ins Genom integrierten viralen Vektoren genetische Dysfunktionen oder Tumore auslösen (Okita et al., 2007). Aus diesem Grund müssen vor der Verwendung von iPS-Zellen noch viele Hürden überwunden werden. 


\section{Diskussion}

Es wurde gezeigt, dass murine maGSCs, generiert aus adulten spermatogonialen Stammzellen, unter bestimmten Kulturbedingungen ähnliche Eigenschaften wie ES-Zellen aufweisen. Kultiviert man die maGSCs als EBs in hanging drops differenzierten sie zu funktionalen Kardiomyozyten, ähnlich effizient wie Kardiomyozyten aus ES-Zellen (Guan et al. 2006; Guan et al. 2007).

Auch aus humanem Hodengewebe wurden inzwischen pluripotente Zellen isoliert (Conrad et al. 2008; Golestaneh et al. 2009; Kossack et al. 2009). Da maGSCs ohne genetische Manipulation entstanden sind, haben sie zum heutigen Stand der Forschung sogar auch Vorteile gegenüber den zuvor beschriebenen iPS-Zellen.

\subsection{Das Schicksal von maGSCs in normalen und Shunt oder TAC operierten Mäusen}

In unseren in vivo-Experimenten konnte nachgewiesen werden, dass transplantierte maGSCs im normalen, gesunden Mausherzen ihr Proliferationspotential nach 1 Monat verlieren und in vaskuläre endotheliale und glatte Muskelzellen, aber nicht in Kardiomyozyten differenzieren (Guan et al. 2007). Obwohl die maGSCs als EBs am d5+8 in Kardiomyozyten differenzieren konnten, differenzierten sie nach Transplantation in Mausherzen nicht spontan in Herzmuskelzellen. Möglicherweise tritt eine kardiale Differenzierung erst zu einem späteren, noch nicht untersuchten Zeitpunkt auf. Außerdem könnte die lokale Umgebung des Empfängermyokards eine entscheidende Rolle bezüglich des Schicksals der injizierten maGSCs spielen.

In Herzgewebeschnitten von Shunt- und TAC- operierten Tieren konnten die Ergebnisse aus der vorangegangenen Untersuchung in normalen Mausherzen bezüglich der Abnahme der Pluripotenz transplantierter maGSCs mittels Oct4-Färbung bestätigt werden. In den Lastinduzierten Mäusen und deren Kontrollen mit Zellinjektion konnten Oct4 ${ }^{+}$Zellen nach $2 \mathrm{~d}$ detektiert werden, im Gegensatz zu 2 w und 4 w. In den Shunt- und TAC-operierten Mäusen zeigten sich bereits nach $2 \mathrm{w}$ vWF und SMA positive, also endotheliale Zellen und glatte Muskelzellen, während erst nach $4 \mathrm{w}$ aMHC positive Zellen, also Kardiomyozyten nachgewiesen werden konnten. In den Vor- und Nachlast-induzierten Tieren mit transplantierten Zellen wurden mehr und stärker exprimierende $\mathrm{vWF}^{+}, \mathrm{SMA}^{+}$Zellen als in den Kontroll-Mäusen mit Zellen (und überhaupt $\mathrm{cTnT}^{+}$Zellen) gesichtet, was darauf hindeutet, dass die mechanische Überlast in diesen Herzen die maGSCs stimuliert, in die endotheliale, glatte Muskulatur und kardiale Richtung zu differenzieren. 


\section{Diskussion}

Dieses Ergebnis korreliert mit den früheren Studien, in denen nur sehr wenige transplantierte ES-Zellen in normalen Nagerherzen ohne MI $2 \mathrm{w}$ nach Transplantation wiedergefunden wurden. Jedoch konnten sich die transplantierten ES-Zellen im Empfängermyokard mit MI in die drei großen Zelltypen des Herzen entwickeln (Hodgson et al. 2004; Singla et al. 2006).

Es ist bekannt, dass sich bei erhöhter Vor- oder Nachlast im Herzen auch Genexpression und Signalwege verändern (Yan et al. 2008; Sheehy et al. 2009; Dias et al. 2010). Vor- und Nachlast beeinflussen Last-abhängige Ionenkanäle und intrazelluläre Ionenkonzentrationen und somit die kardiale Genexpression und Funktion (El-Armouche et al. 2008). Des Weiteren zeigen die Ergebnisse einer aktuellen Studie, dass im Shunt-Modell Akt (Proteinkinase B) durch erhöhte Dehnung aktiviert wird, während sich im TAC-Modell der Calciumstoffwechsel ändert und die CaMKII aktiviert wird (Toischer et al. 2010). Der maladaptive Phänotyp der TAC-OP lässt sich teilweise auf das CaMKII-Signaling zurückführen, welches mit einem gestörten Calciumstoffwechsel assoziiert ist. Außerdem ist in den TAC-Tieren die brain natriuretic peptide (BNP)-Expression erhöht. Dieses Hormon wird bei einer Herzinsuffizienz in den Ventrikeln gebildet und sezerniert. Der Calciumstoffwechsel ist in den Shunt-operierten Tieren normal und keines des Nachlastvermittelten Signale ist aktiviert, während die Kinase Akt, die eher adaptive Hypertrophie fördert (Shiojima and Walsh 2006), hochreguliert ist. Möglicherweise wird diese Aktivierung von Akt durch die Vorlast-vermittelte Dehnung von Titin oder verwandten Proteinen ausgelöst. BNP spielt eine wichtige Rolle bei der Aufrechterhaltung des Proliferationspotentials von murinen ES-Zellen (Abdelalim and Tooyama 2009). Außerdem wurde gezeigt, dass BNP die Vaskulogenese in Mäusen durch Stimulation der funktionalen Eigenschaften endothelialer Vorläuferzellen (Shmilovich et al. 2009) verstärkt. Wachstumsfaktoren wie VEGF, Endothelin-1 und tumor growth factor $\beta$ (TGF-ß) werden durch mechanische Dehnung aus dem Myokard exprimiert und sezerniert. Dadurch stehen para- und autokrine Signale zur Verfügung (Loennechen et al. 2001; van Wamel et al. 2002; Tomanek et al. 2004). VEGF stimuliert die Differenzierung von mES-Zellen über den extracellular signal-regulated kinase (Erk)-vermittelten Flk1-Signalweg in Richtung Kardiomyozyten (Chen et al. 2006). Erk wird in den Nucleus transportiert und aktiviert dort Transkriptionsfaktoren, die Erk-Phosphorylierungsstellen aufweisen (Davis 1993). In Kardiomyozyten könnten die durch mechanischen Stress ausgelösten Signale über eine Protein-Kinase-Kaskade aus u.a. MAP-Kinase-Kinasen und Erks weitergeleitet werden (Komuro et al. 1990b). Außerdem wurde gezeigt, dass mechanische Last in kultivierten 
Rattenmyozyten zelluläre Hypertrophie und eine spezifische Genexpression verursacht, wobei die Protein-Kinase C eine Rolle spielt (Komuro et al. 1991).

Aufgrund der Tatsache, dass sich die Genexpression und Signalwege in Last-induzierten Tieren verändert, sollten in zukünftigen Studien mit Vorlast- oder Nachlast-induzierten Tieren ebenfalls Analysen der Genexpression durchgeführt werden, um die erhaltenen Resultate besser einschätzen zu können.

Da die erzielten Ergebnisse unserer maGSC-Untersuchungen mit den Resultaten der ES-ZellExperimente vergleichbar sind, gehen wir davon aus, dass Methoden zur Gewebsregeneration, die bisher mittels ES-Zellen angewandt wurden, auch erfolgreich mit maGSCs etabliert werden können. Diese Resultate könnten dann wahrscheinlich auch auf andere pluripotente Stammzellen wie z.B. iPS-Zellen übertragen werden. Wären immun-kompatible Gewebe für Autotransplantationen verfügbar, könnten immunologische Probleme, die mit ES-ZellTherapien verbunden sind, umgangen werden.

\subsection{Welchen Einfluss hat die in vitro Dehnung auf maGSCs?}

In der vorliegenden Arbeit verwendeten wir ein Vakuum-betriebenes BioFlex-System um undifferenzierte maGSCs in vitro zu dehnen um die Herzkontraktionen in vivo nachzuahmen. Aufgrund der Limitierung des Systems wurden die Zellen nur bis zu 2 h in vitro gedehnt. Die ermittelten Daten zeigten, dass die maGSCs in vitro nicht durch kurzzeitige Dehnung beeinflusst werden konnten.

Mechanische Last kann verschiedene Auswirkungen auf Zellen haben. Dies ist besonders gut an Kardiomyozyten untersucht, in denen mechanische Stimuli z.B. rasche Änderungen der Genexpression und Hypertrophie bewirken (Komuro et al. 1990a; Komuro et al. 1991). Dehnung adulter oder neonataler Kardiomyozyten in Serum-freiem Medium auf bis zu 1020\% ihrer normalen Länge führt zu einer erhöhten Protein- ohne DNA-Synthese, was ein Anzeichen für Hypertrophie ist (Mann et al. 1989; Komuro et al. 1990a; Sadoshima et al. 1992). Lineare Dehnung von Kardiomyozyten verursacht eine transkriptionale Änderung der Genexpression früher und fetaler Gene, wie ANF und MHC (Sadoshima et al. 1992). Der Phänotyp gedehnter Myozyten ist denen in einer Last-induzierten Hypertrophie in vivo ähnlich (Izumo et al. 1988). Bei der Untersuchung zellulärer Signalwege konnte festgestellt werden, dass Dehnung verschiedene Moleküle wie Transkriptionsfaktoren aktiviert (Vandenburgh 1992; Sadoshima and Izumo 1993). Eine weitere Studie belegt, dass zyklische

Dehnung neonataler Kardiomyozyten und kardialer Fibroblasten zu einer Ausschüttung 


\section{Diskussion}

verschiedener Wachstumsfaktoren wie z.B. TGF $\beta_{1}$ führt. Dabei wurden die Zellen unterschiedlich lang (2-24 h) bei $1 \mathrm{~Hz}$ gedehnt (Ruwhof et al. 2000).

Ebenso konnten verschiedene Effekte bei Stammzellen, wie z.B. MSCs beobachtet werden. Equiaxiale Dehnungen dieser Zellen zu 10\% einen Tag lang führten in einer Studie aus dem Jahr 2004 zu einer niedrigeren Expression von SMA, zyklische uniaxiale Dehnung verursachte allerdings eine Erhöhung der SMA-Expression (Park et al. 2004). Dies deutet darauf hin, dass uniaxiale Dehnung die Differenzierung von MSCs in SMA ${ }^{+}$Zellen stimuliert. Mehrere Studien belegen die Effekte mechanischer Aktivierung auf die Reifung von aus ESZellen differenzierten Kardiomyozyten-ähnlichen Zellen (Guo et al. 2006; Gwak et al. 2008; Shimko and Claycomb 2008). Gwak et al. dehnten schlagende Kolonien, die MHC, GATA4 und Nkx2.5 exprimierten, über 2 w bei 10\% Dehnung und einer Frequenz von $1 \mathrm{~Hz}$. Gedehnte Zellen zeigten eine höhere Expression kardialer Marker als die ungedehnten Kontrollen und integrierten besser ins Myokard von infarzierten Rattenherzen.

In unseren Dehnungsexperimenten haben wir unbeschichtete 6-Well BioFlexZellkulturschalen verwendet. Zu Beginn stellte es sich als besonders schwierig heraus, die maGSCs auf den BioFlex-Schalen zu kultivieren, da sie eine geringe Adhärenz aufwiesen. Beschichtete man die BioFlex-Schalen allerdings mit Collagen 1 und $1 \%$ Gelatine, adhärierten die maGSCs gut. Bei wiederholter Verwendung der Schalen, nachdem sie immer gründlich mit PBS gewaschen worden waren, erhöhte sich das Adhärenzverhalten der maGSCs sogar noch. Schmelter et al. dagegen kultivierten drei Tage alte EBs auf Collagenbeschichtete Bio-Flex-Schalen und dehnten die EBs 2 h lang zu 5, 10 und 20\% PC-gesteuert (Schmelter et al. 2006). Unsere Dehnung konnte nicht PC-gesteuert werden, daher ist eine Angabe der Dehnungsverlängerung der Zellen nicht möglich. Die maGSCs zeigten nach Dehnung für 15, 30 min und 1 h keine morphologischen Veränderungen im Vergleich zu den Kontrollen. Dies änderte sich nach 2 h Dehnung: viele Zellen adhärierten nicht mehr auf den Flex-Schalen, lösten sich teilweise ab und schwammen im Medium. Vermutlich konnten die Zellen die ständige Dehnung nicht tolerieren. In der Schmelter-Studie wurde keine Beeinträchtigung der Lebens- und Entwicklungsfähigkeit der EBs gezeigt. Möglicherweise adhärierten die EBs besser auf den FlexSchalen als die beschriebenen undifferenzierten maGSCs.

Ein weiteres Problem der durchgeführten Stretch-Experimente stellte die Temperatur während der Experimente dar. Da die Stretch-Apparatur nicht bei $37^{\circ} \mathrm{C}$ untergebracht werden konnte, sondern nur bei Raumtemperatur, wurden die Zellen bis zu 2 h unter nicht-physiologischen Bedingungen gedehnt. Dies könnte ihnen zusätzlich Stress bereitet und Ergebnisse verfälscht 


\section{Diskussion}

haben. Untersuchungen auf molekularer Ebene der nach 15, 30 und 60 min Dehnung genommenen Proben ergaben kaum Änderungen in der relativen Genexpression von Oct4 und Bry. In der Schmelter-Studie waren z.B. Mef2c, GATA4 und VEGF hochreguliert, was für eine Induktion der kardiovaskulären Differenzierung spricht. In dieser Studie wurde ebenfalls beschrieben, dass durch mechanische Dehnung ROS (reaktive Sauerstoffspezies) erhöht produziert wurden und die NADPH-Oxidase-Expression induziert wird.

Es wurde keine signifikante Erhöhung der $\mathrm{Flk}^{+}$Zellen in den 1 oder $2 \mathrm{~h}$ gedehnten gegenüber den ungedehnten Zellen festgestellt. Insgesamt war die Ausbeute mit ca. 7,5\%. Flk1 ${ }^{+}$Zellen im Vergleich zur sonstigen Differenzierung (ca. 35\%) stark erniedrigt. Dieses schlechte Resultat kann auf die lange Dehnung der Zellen bei Raumtemperatur und die Kultivierung auf BioFlexSchalen zurück geführt werden.

Zusammenfassend lässt sich sagen, dass es nicht gelungen ist, unsere maGSCs durch mechanische Last in vitro zur Differenzierung zu stimulieren, wie es bei anderen Zellen, z.B. Kardiomyozyten, MSCs oder EBs möglich ist. Um diese Dehnungs-Experimente zu optimieren, wäre es also sinnvoll, die Zellen unter physiologischen Bedingungen in einer PCgesteuerten Apparatur zu dehnen. Weiterhin könnten die maGSCs z.B. auf OP9 gedehnt, für 5 Tage differenziert und anschließend analysiert werden.

\subsection{Vermehrte Fibrose im Herzen der CsA-immunsupprimierten Mäuse nach Zelltransplantation}

Um auszuschließen, dass das Gewebe durch Zellinjektion verletzt oder vernarbt wurde, haben wir in unseren Experimenten durch die MG-Färbung, die Fibrose visualisiert, untersucht. Es war zu beobachten, dass in den Shunt-operierten Tieren und den Sham-Tieren mit NaClInjektion zu keinem Zeitpunkt Fibrose zu sehen war. In den TAC-operierten Tieren trat nach $4 \mathrm{w}$ starke Fibrose auf. Die Ergebnisse der NaCl-injizierten Mäuse stimmen mit anderen Daten überein und zeigen, dass TAC-OPs im Gegensatz zu Shunt-OPs Fibrose auslösen, (Toischer et al. 2010). Allerdings wurde vermehrte Fibrose in allen 4 Gruppen (Shunt-, TAC-, und jeweilige Sham-Gruppen) unserer Experimente mit Zellinjektion beobachtet. Da man Fibrose nicht in den Shunt- und Sham-Tieren mit NaCl-Applikation sieht (und in den TACund Sham-Gruppen nach $2 \mathrm{w}$ ), obwohl auch hier Injektionen $(\mathrm{NaCl})$ appliziert wurden, muss es eine andere Ursache als die Injektionsverletzung für die Entstehung des vermehrten Bindegewebes geben. Möglich wäre eine Induktion der Fibrose, der eine gesteigerte Collagenbildung zugrunde liegt, durch CsA. 
CsA ist ein Medikament, welches Abstoßungsreaktionen verhindern soll, indem es als Immunsuppressivum wirkt und wird oft nach Transplantationen verwendet (Barnhart et al. 1985). CsA bindet an Ciclophilin A und dieser Komplex an Calcineurin, womit im Zellplasma die Bindung an NFAT (nuclear factor of activating $T$ cells) blockiert ist. Calcineurin ist eigentlich in den T-Zellen für die Dephosphorylierung von NFAT verantwortlich. NFAT wird anschließend in den Zellkern transloziert und aktiviert dort die Transkription von zahlreichen Zytokinen und Zelloberflächenrezeptoren (u.a. Interleukin-2 und $\gamma$-Interferon), wodurch T-Lymphozyten aktiviert werden. Da diese Kaskade durch CsA inhibiert wird, ist die Aktivierung und Vermehrung von Lymphozyten gehemmt (Immunsuppression).

Es wurde berichtet, dass CsA glomeruläre Atrophie, Sklerose oder tubulo-interstitielle Fibrose induziert (Perico et al. 1996). Diese nephrotoxischen oder fibrotischen Nebeneffekte von CsA sind teilweise auf die Induktion der epithelial-mesenchymalen Transition (EMT) zurückzuführen (Xu et al. 2010). In vitro wurde zuvor gezeigt, dass CsA EMT induziert und der connective tissue growth factor (CTGF) hochreguliert ist (McMorrow et al. 2005). CTGF ist ein Mediator durch CsA induzierten fibrinogenen Effekte (Reed et al. 2005). Die Anwendung von CsA beeinflusst Zelltypen unterschiedlich und induziert die Ansammlung der extrazellulären Matrix durch erhöhte Collagen-Synthese in endothelialen und epithelialen Zellen (Esposito et al. 2000). Die Auswirkungen von CsA wurden auch in Vorläuferzellen aus dem Hippocampus von Rattenembryonen untersucht. Dabei wurde eine Inhibierung der Proliferation dieser embryonalen Progenitorzellen nach CsA-Applikation in vitro gezeigt. Außerdem beeinflusste CsA die Differenzierung der neuralen Stammzellen und führte zu einer erhöhten Astrozyten-Entstehung und einer verminderten Neuronen-Differenzierung (Guo et al. 2007). Die Wirkung von CsA auf pluripotente Stammzellen wurde bisher noch nicht untersucht. Daher ist nicht bekannt, ob CsA die Differenzierung pluripotenter Stammzellen oder die Collagen-Synthese induzieren kann.

\subsection{Tragen die maGSCs zu einer besseren Herzfunktion in Last-induzierten Mäusen bei?}

Dass die Erhöhung von Vorlast oder Nachlast verschiedene Effekte im Herzen verursacht, ist längst bekannt. In einer kürzlich veröffentlichten Studie wurde das kardiale Remodeling in Shunt- und TAC-operierten Mäusen intensiv untersucht (Toischer et al. 2010). Dabei wurde gezeigt, dass die erhöhte Nachlast des Herzens zu einer maladaptiven fibrotischen 
Hypertrophie führt, während die erhöhte Vorlast in geringerer Apoptose und Mortalität resultiert.

In den $\mathrm{NaCl}$ bzw. zellinjizierten Shunt-operierten Mäusen wurde im Vergleich zu den jeweiligen Kontrollen nach $2 \mathrm{w}$ und $4 \mathrm{w}$ ein erhöhtes HW/BW festgestellt. Diese Ergebnisse korrelieren mit den erhöhten LVEDD-Werten. Dies lässt darauf schließen, dass die Shunt-OP im Hinblick auf vergrößerte Herzen durch die erhöhte Last erfolgreich war, aber auch, dass die Zellen keine schützende Funktion bezüglich der Entwicklung einer Hypertrophie ausübten. In den TAC-Mäusen war das HW/BW in den Sham-Mäusen mit NaCl nach 2 w und $4 \mathrm{w}$ erwartungsgemäß stark erhöht. Allerdings war die Erhöhung des LVEDD nach TAC nicht so ausgeprägt wie in den Shunt-operierten Mäusen. Ähnliche Daten wurden in einer aktuellen Studie gezeigt (Toischer et al. 2010). Jedoch lag das HW/BW der TAC-operierten Mäuse mit Zellinjektion zu beiden Zeitpunkten auf dem Niveau der entsprechenden ShamTiere. Dieses Ergebnis spricht dafür, dass die undifferenzierten maGSCs eine antihypertrophe Wirkung ausüben, da die TAC-operierten Tiere keine vergrößerten Herzen im Vergleich zu den entsprechenden Sham-Tieren und den TAC-intervenierten Tieren mit NaClInjektion aufweisen.

Weitere echokardiographische Messdaten (EF und FS) zeigten, dass die Herzfunktion in den Vorlast-erhöhten Shunt-operierten Tieren durch die Zelltransplantation nicht signifikant verbessert wird, sich nach $4 \mathrm{w}$ aber Tendenzen zu einer besseren EF und einem erhöhten FS im Vergleich zu den Shunt-operierten Tieren mit NaCl-Injektion ergeben. Die Herzfunktion der Nachlast-erhöhten TAC-operierten Mäuse ließ sich durch die injizierten maGSCs mehr beeinflussen als die der Shunt-Mäuse. In den TAC-Mäusen konnte nach 2 w eine signifikant verbesserte EF im Vergleich zu den NaCl-injizierten Mäusen festgestellt werden, wobei dieser Effekt nach $4 \mathrm{w}$ nicht aufrecht erhalten worden war. Aber auch das FS zeigte eine tendenzielle Funktionsverbesserung des Herzens nach $4 \mathrm{w}$ an.

In der MI-Studie von Behfar et al. verbesserte sich die Kontraktilität der Herzen in Ratten mit injizierten Stammzellen, sichtbar an einer erhöhten EF von 50\% auf 75\% (Behfar et al. 2002). In zwei weiteren Studien wurde ebenfalls von einer Verbesserung der Herzfunktion in MIRatten mit ES-Zellinjektion berichtet (Min et al. 2002; Hodgson et al. 2004).

Des Weiteren wurde gezeigt, dass es durch den Einsatz von Stammzellen möglich ist, eine sich entwickelnde Herzinsuffizienz in transgenen und TAC-operierten Mäusen zu therapieren (Yamada et al. 2008). Hier wurden die ES-Zellen erst $2 \mathrm{w}$ nach TAC-OP injiziert. Dies wäre auch eine weitere Option für zukünftige in vivo-Modelle mit maGSC-Injektion, da wir unseren Mäusen in der vorliegenden Arbeit schon Stammzellen injiziert hatten, bevor sie eine 
Herzschwäche entwickeln konnten. Vielleicht wäre dann in den neu operierten Mäusen ein eindeutig positiver Effekt der maGSCs auf die Herzfunktion zu sehen.

Um noch genauere Aussagen durch signifikante Werte treffen zu können, sollten noch mehr Tiere operiert werden. Außerdem sollte man in das Myokard dieser Shunt- und TACoperierten Tiere Flk1 ${ }^{+}$Vorläuferzellen injizieren, um zu sehen, ob sie die Herzfunktion eher verbessern können als undifferenzierte Zellen.

\subsection{Einfluss des Immunsuppressivums Ciclosporin A auf maGSCs bezüglich Teratomentwicklung in vivo}

Unsere murinen maGSCs, die ES-Zell-Eigenschaften besitzen (Guan et al. 2006; Zovoilis et al. 2008; Zechner et al. 2009) und sich in verschiedene Zelltypen, auch in Kardiomyozyten (Guan et al. 2007) und neuronale Zellen (Glaser et al. 2008; Streckfuss-Bomeke et al. 2009), in vitro differenzieren können, formen in vivo Teratome, wenn sie subkutan in immundefiziente SCID-beige Mäuse transplantiert werden (Guan et al. 2006; Guan et al. 2009). In der vorliegenden Arbeit wurde gezeigt, dass nach Transplantation undifferenzierter maGSCs in normalen und Last-induzierten Mäusen mit CsA-Behandlung keine Teratome auftreten. Allerdings ist noch unklar, ob die Mikroumwelt des Herzens vor einer Teratombildung schützt und die Differenzierung der maGSCs induziert oder ob CsA und das Immunsystem eine wichtige Rolle spielen.

Es ist bekannt, dass Säuger-ES-Zellen komplexe Teratome formen können, wenn man sie in immundefiziente Organismen transplantiert, da jene pluripotent sind (Thomson et al. 1998; Reubinoff et al. 2000). Diese Teratome enthalten hochorganisierte und differenzierte Zellarten aus allen drei Keimblättern, die durch Zell-spezifische Marker für z.B. Haarfollikel, Muskelzellen, Epithelzellen, Kardiomyozyten und neurale Zellen nachgewiesen wurden (Thomson et al. 1998; Reubinoff et al. 2000; Gertow et al. 2004; Singla and Sobel 2005). Die Entstehung von Teratomen ist ein erheblich limitierender Faktor bezüglich der Therapiemöglichkeiten von ES-Zellen.

Es ist schwierig, ES-Zellpotential nach in vivo-Transplantation zu untersuchen, da sie sich in alle drei Keimblätter differenzieren können, verschiedensten Cytokinen und Wachstumsfaktoren ausgesetzt sind und in direkten zellulären Kontakten mit dem Empfängergewebe stehen. Studien zeigen, dass die lokale Mikroumwelt des Empfängergewebes die transplantierten Zellen zur Differenzierung anregt (Kuai et al. 2006; Singla et al. 2006; Moriya et al. 2007). So ließen sich in den genannten Studien eingepflanzte Zellen durch Organ-spezifische Faktoren in eine bestimmte zellspezifische Richtung ohne 
Teratomformation dirigieren. Allerdings gab es auch konträre Publikationen, die von Teratomen nach ES-Zell-Transplantation berichteten (Swijnenburg et al. 2005; Nussbaum et al. 2007). Daher muss man davon ausgehen, dass die Anzahl der Stammzellen und das Gewebe mit seiner Mikroumwelt eine entscheidende Rolle bei einer möglichen Teratomformation spielen. Einige Studien, in denen bis zu 3x10 5 Stammzellen in Herzen von Ratten und Mäusen injiziert wurden, berichten, dass keine Teratome aufgetreten sind (Min et al. 2002; Hodgson et al. 2004; Kofidis et al. 2004; Kofidis et al. 2005; Singla and Sobel 2005).

In der vorliegenden Arbeit wurde gezeigt, dass sich in allen sieben Mäusen (ohne CsABehandlung) 4 Wochen nach Transplantation undifferenzierter maGSCs in das Myokard von $\mathrm{RAG2}^{-/} \mathrm{Cgc}^{-/-}$Mäuse Teratome im Herzen und im Körper entwickelten. Diese Ergebnisse korrelieren mit einer vorherigen Studie, in der die Zellen subkutan in SCID-beige-Mäuse injiziert wurden. Diese Daten zeigen, dass die Mikroumwelt des Herzens nicht vor einer Teratombildung durch pluripotente Stammzellen schützt. Injizierten wir die undifferenzierten maGSCs in Herzen von $\mathrm{RAG}^{-/-} \mathrm{Cgc}^{-/-}$Mäusen mit CsA-Behandlung, zeigte sich eine signifikante Reduktion der Teratombildung. Von den 5 Mäusen mit CsA wiesen nur 3 Mäuse kleine Tumore/Teratome im Herzen, aber keine im Körper und auch sonst keine offensichtlichen Veränderungen auf. Die Unterschiede in der Teratomgröße zwischen den Maus-Gruppen (mit oder ohne CsA-Behandlung) waren stark signifikant, was darauf schließen lässt, dass CsA auf jeden Fall einen Einfluss auf unsere maGSCs hat. Um diesen näher zu untersuchen, wurden die Herzgewebeschnitte histologisch untersucht. Dabei konnte durch HE-Färbungen nachgewiesen werden, dass die Teratome Gewebe aus allen drei Keimblättern enthalten. Außerdem wurden Oct4-Färbungen durchgeführt, wobei festgestellt wurde, dass in den Mäusen mit CsA viel weniger transplantierte Zellen Oct4 ${ }^{+}$waren als in den Mäusen ohne CsA. Dies deutet darauf hin, dass CsA die Pluripotenz der maGSCs hemmt und deren Differenzierung fördert. Dies würde mit den Ergebnissen einer in vitro-Studie aus dem Jahr 2007 korrelieren, in der eine verringerte Proliferation und geringere Anzahl von Vorläuferzellen aus dem Hippocampus in Anwesenheit von CsA beobachtet wurde (Guo et al. 2007). CsA zeigte auch einen anti-proliferativen Effekt auf endotheliale und epitheliale Zellen, der in vitro mit einer Induktion von Apoptose assoziiert ist (Esposito et al. 2000). Derzeit wird der Einfluss von CsA auf die maGSCs im Hinblick auf die Induktion von Apoptose, die Inhibierung der Selbsterneuerung und die Induktion der Differenzierung in vitro untersucht. 


\section{Diskussion}

Wie oben beschrieben, konnten keine Teratome in allen Maus-Gruppen (normale und Shuntoder TAC-operierte Mäuse) nach maGSC-Transplantation in Herzen von CsAimmunsupprimierten Mäusen beobachtetet werden. Allerdings wurden in drei von fünf $\mathrm{RAG2}^{-/} \mathrm{Cgc}^{-/-}$Mäusen, die mit CsA behandelt worden waren, Teratome im Herzen gefunden. Dieses Resultat deutet darauf hin, dass nicht nur CsA, sondern auch das Immunsystem der Mäuse eine wichtige Rolle bei der Entstehung von Teratomen spielt. RAG2/- $\mathrm{Cgc}^{-/-}$Mäuse besitzen weder B- und T-Zellen noch NK-Zellen (Koch et al. 2006).

CsA kann nur die Aktivität von T-Zellen unterdrücken, beeinflusst aber nicht die Aktivität der NK-Zellen. Undifferenzierte maGSCs exprimieren kaum major histocompatibility complex I (MHCI), der einen Inhibitor für NK-Zellen darstellt (Dressel et al. 2009). Stattdessen exprimieren maGSCs Liganden für NKG2D (natural killer group 2, member D), den aktiven NK Rezeptor. Daher können maGSCs leicht von NK-Zellen erkannt und eliminiert werden. In einer weiteren Studie wurden ES-Zellen und in vitro differenzierte neuronale Zellen in immunkompetente oder -defiziente Mäuse und Ratten injiziert (Dressel et al. 2008). Subkutane Injektionen der ES- oder differenzierten Zellen $\left(1 \times 10^{6}\right)$ führten in den immundefizienten Mäusen zu 95\% zu Teratomen, aber nicht in den immunkompetenten Mäusen oder Ratten. In 61\% der CsA behandelten Ratten führte die Injektion von differenzierten Zellen zu Teratomen, aber nicht bei Injektion von undifferenzierten. ES-Zellen können, wie bereits beschrieben, leicht von NK-Zellen erkannt und vernichtet werden, da sie Liganden für den NK-Rezeptor exprimieren. In differenzierten Zellen sind diese Liganden herunter reguliert. Die NK-Zellaktivität wird nicht durch CsA unterdrückt, was die Entstehung von Teratomen vielleicht verhindert. Allerdings müssen die differenzierten Zellen eine tumorigene Zellpopulation enthalten, die nicht in ES-Zellen vorkommt und die wahrscheinlich gegenüber NK-Zell-vermittelter Eliminierung resistent ist. Dies ist auch bei unseren maGSCs zu vermuten, da auch hier Teratome durch Injektion vordifferenzierter maGSCs entstanden sind (nicht publiziert Daten).

Die Verwendung autologer adulter Stammzellen würde immunologische Probleme stark reduzieren, die bei allogenenen ES-Zelltherapien auftreten (Bradley et al. 2002; Saric et al. 2008). Aber auch bei Transplantationen mit autologen Stammzellen könnten durch cytotoxische T-Lymphozyten (CTLs) „onkofetale“ Antigene erkannt werden, die pluripotente Stammzellen (Boghaert et al. 2008) oder Differenzierungsantigene (Engelhard et al. 2002) exprimieren, wie aus der Tumorbiologie bekannt. Ein weiteres Problem ist das hohe Risiko der Teratombildung, da auch allogene Zelltransplantate undifferenzierte enthalten können (Dressel et al. 2008). In einer aktuellen Studie wurde untersucht, ob maGSCs und iPS-Zellen 
gegen CTLs geschützt sind, wie von ESCs berichtet (Abdullah et al. 2007). Dressel et al. untersuchten die Anfälligkeit von drei maGSC-Linien, ES-Zellen, iPS-Zellen und F9Teratom-Zellen gegenüber CTLs (Dressel et al. 2009). Dabei wurden kaum MHCI-Moleküle auf diesen Stammzellen via Durchflusszytometrie detektiert, aber alle pluripotenten Stammzellen durch aktivierte CTLs getötet. Das bedeutet, dass diese Zellen nach Transplantation durch diesen Mechanismus abgestoßen werden können.

In der vorliegenden Dissertation erhielten die normalen sowie die operierten und maGSCinjizierten Mäuse täglich $20 \mu \mathrm{g} / \mathrm{kg}$ CsA, damit die transplantierten Zellen nicht abgestoßen wurden. Allerdings wissen wir nicht, ob die T-Zell-Aktivität vollständig durch CsA unterdrückt wird. Zukünftig sollte die Aktivität der T-Zellen sowie NK-Zellen in den Mäusen nach CsA-Behandlung untersucht werden.

Zusammenfassend zeigen unsere in vivo-Daten, dass die undifferenzierten maGSCs nach Transplantation in normale Herzen CsA-behandelter Wildtyp-Mäuse ihre Pluripotenz verlieren und in vaskuläre endotheliale und glatte Muskelzellen, aber nicht in Kardiomyozyten differenzieren. Vorlast und Nachlast des Herzens erhöhen die Differenzierung der maGSCs sowohl in die kardiale als auch in die vaskuläre Richtung. Allerdings war die Herzfunktion nach Zelltransplantation nicht signifikant verbessert, obwohl sich eine tendenzielle Verbesserung der Herzfunktion zeigte. Unsere Daten lassen vermuten, dass sowohl CsA als auch das Immunsystem eine wichtige Rolle bei der durch pluripotente Stammzellen hervorgerufenen Teratombildung im Herzen spielen. Dies sollte bei zukünftigen Transplantations-Experimenten beachtet und untersucht werden. Außerdem lassen unsere Daten vermuten, dass die Transplantation undifferenzierter maGSCs nicht ausreicht um die Herzfunktion signifikant zu verbessern. Daher wäre es interessant zu untersuchen, ob maGSC-abgeleitete kardiovaskuläre Progenitorzellen oder funktionale Kardiomyozyten nach Zelltransplantation in herzkranke Tiermodelle zur Reparatur der Gewebeschäden beitragen und die Herzfunktion verbessern können.

\subsection{Erfolgreiche Etablierung von Flk1 ${ }^{+}$kardiovaskulären Vorläuferzellen aus maGSCs}

Stammzelltherapien, basierend auf pluripotenten Stammzellen, zur de novo Kardiogenese waren bisher vielversprechend bezüglich kardialer Regeneration (Behfar et al. 2002; Hodgson et al. 2004; Menard et al. 2005; Nelson et al. 2006; Singla et al. 2006). Jedoch tritt bei der Organregeneration mittels pluripotenter Stammzellen die Problematik der Teratomentstehung

auf, wie bereits diskutiert. Im Gegensatz dazu bestehen bei der Transplantation 


\section{Diskussion}

ausdifferenzierter Zellen die Hürden der arretierten Proliferation und der ungenügenden Zellquellen. Deshalb müssen Protokolle entwickelt werden, die eine geeignete Strategie für die Verwendung pluripotenter Stammzellen bei Organregeneration festlegen. Für eine klinische Anwendung sind gewebsspezifische Vorläuferzellen nötig, die sowohl noch proliferieren als auch sicher in eine kardiale und vaskuläre Richtung differenzieren (Srivastava 2006; Behfar et al. 2007). Multipotente Zellen, die das primäre Herzfeld formen, entwickeln sich zu einer spezialisierten und aus dem Mesoderm stammenden Population von kardialen Vorläuferzellen (Buckingham et al. 2005; Srivastava 2006). Verschiedene Gruppen haben gezeigt, dass es möglich ist multipotente Vorläuferzellen mittels spezifischen Markern wie Bry, Isl1 oder Nkx2.5 aus embryonalen Stammzellen zu isolieren und zu charakterisieren (Kattman et al. 2006; Moretti et al. 2006; Wu et al. 2006).

In dieser Arbeit war es möglich, maGSCs mittels Co-Kultur auf OP9-Zellen in Flk1 kardiovaskuläre Vorläuferzellen zu differenzieren. Das dazu etablierte Differenzierungsprotokoll basiert auf einer Arbeit von T. Nakano, bei der eine CoKultivierung von mES-Zellen mit der Stromazelllinie OP9 für die in vitro Differenzierung zu hämatopoetischen Zellen genutzt wurde (Nakano et al. 1994). OP9-Zellen besitzen durch eine Mutation kein funktionsfähiges M-CSF, ein Faktor, der für die Differenzierung von Makrophagen nötig ist (Yoshida et al. 1990). Bereits in einer früheren Studie wurden OP9Zellen zur Co-Kultur mit Flk1 ${ }^{+}$Zellen zur Induktion einer kardialen Differenzierung verwendet (Hirata et al. 2007). In der vorliegenden Arbeit wurde gezeigt, dass die Differenzierung der maGSCs zu Kardiomyozyten, vaskulären endothelialen und glatten Muskelzellen durch eine langzeitige Co-Kultur von maGSCs mit OP9-Zellen induziert wird, was auf molekularer und Proteinebene nachgewiesen werden konnte.

Bisherige Studien verwendeten andere Methoden um u.a. Flk1 ${ }^{+}$Vorläuferzellen zu gewinnen. Kattman et al. zeigten 2006 in einer cell tracing-Studie, dass kardiale Zellen aus einer Flk1 ${ }^{+}$ Zellpopulation entstehen, so dass sie einem Vorläufer mit vaskulärem Potential entspringen können (Kattman et al. 2006). In einem Modell mit embryonalen Stammzellen wurden kardiovaskuläre Vorläuferzellen mittels Bry- und Flk1-Expression identifiziert, die in Kardiomyozyten, Endothel- und glatte Muskelzellen differenzierten. Bry wird maximal in frühen mesodermalen Stadien exprimiert (King et al. 1998). Kattmann et al. sortierten bereits an d3,25 der Differenzierung von ES-Zellen ca. 20\% GFP-Bry ${ }^{+} / \mathrm{Flk1}^{+}$und ca. 62\% GFP$\mathrm{Bry}^{+} /$Flk1- Zellen (Kattman et al. 2006). Es war aber auch möglich Flk1 ${ }^{+}$Zellen mittels GeneChip-Arrays zu identifizieren (Nelson et al. 2008). Bei dieser Studie wurde eine 
$\mathrm{CXCR}^{+} / \mathrm{Flk}^{+}$Zellpopulation aus ES-Zellen herausgefiltert, die kardiale Transkriptionsfaktoren wie Mef2c oder Nkx2.5 überexprimiert.

In verschiedenen Studien wurde auch ein Coating mit Collagen IV verwendet um eine Differenzierung von ES-Zellen in Flk1 ${ }^{+}$Zellen zu induzieren (Nishikawa et al. 1998; Yamashita et al. 2000; Hirata et al. 2007). Wurde diese Methode verwendet, konnten ca. 2427\% der Zellen am Tag 5 der Differenzierung positiv für Flk1 analysiert werden.

In einer genetic fate-Studie wurden $\mathrm{Isl} 1^{+} / \mathrm{Nkx} 2.5^{+} / \mathrm{Flk} 1^{+}$multipotente kardiovaskuläre Progenitorzellen aus ES-Zellen identifiziert, die sich in alle drei während der Kardiogenese wichtigen Zelltypen (endotheliale, kardiale, glatte Muskelzellen) differenzieren können (Moretti et al. 2006). Die Zellen mit einem Schicksal in die muskuläre oder endotheliale Richtung zu differenzieren, konnten sogar aus einer einzigen Isl1 ${ }^{+}$Vorläuferzelle generiert werden. Auch in einer ebenfalls 2006 veröffentlichten Studie von Wu et al. wurde nach Progenitorzellen im Herzen gesucht ( $\mathrm{Wu}$ et al. 2006). Hier wurden Nkx2.5 ${ }^{+}$Zellen aus Mausembryonen isoliert und untersucht, wobei festgestellt wurde, dass sich ein großer Teil dieser Zellen in kardiale Zellen und wenige in glatte Muskelzellen entwickelte. Um die klonale Herkunft der Zellen zu sichern, wurden Nkx2.5 $5^{+}$Zellen aus murinen ES-Zellen isoliert. Über 25\% dieser Zellen exprimierten C-Kit, was ebenfalls auf ein kardiales Potential deutete. Anschließend wurden bipotente C-Kit ${ }^{+} / \mathrm{Nkx} 2.5^{+}$Zellen aus Mausembryonen isoliert, die sich in die Kardiomyozyten und glatte Muskulatur differenzieren konnten.

In der vorliegenden Dissertation wird gezeigt, dass bei der Kultivierung unserer maGSCs auf OP9-Zellen im Differenzierungsmedium an d5 durchschnittlich 35\% Flk1 ${ }^{+}$Zellen via FACS analysiert werden konnten. Ein Vergleich oben genannten Studien mit der vorliegenden Arbeit ist nur bedingt möglich, weil andere Ausgangszellen verwendet wurden. Aber wenn man davon ausgeht, dass unsere maGSCs ähnliche Eigenschaften wie ES-Zellen aufweisen (Guan et al. 2006), dann kann man hier deutlich sehen, dass die Art der Kultivierung einen sehr großen Einfluss auf die Differenzierung der Zellen hat. Über den Mediumwechsel während der Differenzierung wurden in anderen Studien keine Angaben gemacht, aber wir wechselten das Differenzierungsmedium alle 2-3 Tage nur zur Hälfte. Dieser halbe Mediumwechsel verhinderte einen kompletten Verlust der im Medium enthaltenen, von den OP9 sezernierten Wachstumsfaktoren, wie z.B. dem stem cell factor, SCF (Vegh et al. 2010). Diese wichtigen Faktoren müssen nach dem Mediumwechsel erst wieder neu produziert werden, und dadurch könnte eine Stimulation der Differenzierung reduziert werden.

Eine wichtige Voraussetzung für die optimale Differenzierung war außerdem der Zustand der verwendeten Zellen. Waren die OP9 zu konfluent oder die undifferenzierten maGSCs etwas 
zu weit gewachsen, konnten die maGSCs nicht effizient in Flk1 ${ }^{+}$Zellen differenziert werden. Die besten Resultate wurden mit Versuchen erzielt, bei denen die OP9 mit MMC behandelt worden, als sie ca.70\% Konfluenz aufwiesen und die maGSCs einen Tag alt waren. Es gab dabei auch Versuche, bei denen die Flk1 ${ }^{+}$Zellen am d5 der Differenzierung bis zu 50\% der untersuchten Zellen ausmachten, aber im Durchschnitt wurden ca. 35\% Flk1 ${ }^{+}$Zellen detektiert.

Um den Ertrag Flk1 ${ }^{+}$Zellen am d5 zu erhöhen, wurden dem Differenzierungsmedium verschiedene Faktoren zugefügt, die bereits einen Einfluss auf mesodermale Entwicklungsprozesse gezeigt hatten. Dazu gehörten AA, BMP4 und Wnt11. Der Effekt von AA auf die mesodermale Differenzierung wurde in ES-Zellen und transgenen Mäusen nachgewiesen (Johansson and Wiles 1995; Ben-Haim et al. 2006). Dies konnte in unseren Differenzierungsversuchen nicht bestätigt werden, da sich am d5 der Differenzierung keine erhöhte Anzahl Flk1 ${ }^{+}$Zellen feststellen ließ. Auch Wnt11 führte nicht zu einer vermehrten Differenzierung zu Flk1 ${ }^{+}$Zellen, obwohl der positive Einfluss von Wnts, vor allem im noncanonischen Signalweg, in der kardialen Entwicklung gezeigt wurde (Eisenberg et al. 1997; Pandur et al. 2002; Terami et al. 2004; Koyanagi et al. 2005a). Nur der Einsatz von BMP4 zeigte einen positiven, aber nicht signifikanten Einfluss auf die Differenzierung der maGSCs in Flk1 ${ }^{+}$Zellen. Dies würde mit Veröffentlichungen korrelieren, die einen Einfluss von BMPs auf die kardiovaskulären Entwicklung zeigt (Monzen et al. 2002; Varga and Wrana 2005; van Wijk et al. 2007).

Außerdem war es in dieser Arbeit möglich die Flk1 $1^{+}$Zellen mittels FACS zu sortieren und weiter zu kultivieren. Wie auch in anderen Studien wurde die Effizienz der einzelnen sortierten Populationen durch nochmalige Analyse durch FACS bestätigt. Dabei sollte die Reinheit bei 98-99,9\% liegen, was bei unseren Zellpopulationen der Fall war. Die sortierte $\mathrm{Flk1}^{+}$Zellpopulation exprimiert außer Flk1 auch andere kardiovaskuläre Vorläufermarker, wie Bry, Isl1, Nkx2.5 und C-Kit, die mittels RT-PCR- Analyse detektiert werden konnten.

Um aber auch die Flk1 ${ }^{+}$Zellen weiter kultivieren und charakterisieren zu können, entschieden wir uns weiterhin für OP9 als Grundlage für die sortierten Flk1 ${ }^{+}$Zellen, wie auch in der Studie von Hirata et al. gezeigt. Unter diesen Bedingungen differenzierten die Flk1 ${ }^{+}$Zellen in hämatopoetische, endotheliale, glatte Muskel- und kardiale Zellen. Die Daten zeigen, dass die sortierten Flk1 ${ }^{+}$Zellen kardiovaskuläre Vorläuferzellen sind.

Außerdem ist es gelungen Flk1 ${ }^{+}$Zellen länger in Kultur zu halten, und es konnte gezeigt werden, dass Flk1 ${ }^{+}$Zellen sich in vitro vermehren (I-Fen Cheng, Kardiologie). Nach der Langzeitkultur können Flk1 ${ }^{+}$Zellen in endotheliale, glatte Muskelzellen und schlagende 
Kardiomyozyten differenzieren. Die Zellen mit einem Schicksal in die muskuläre oder endotheliale Richtung zu differenzieren, konnten sogar aus einer einzigen Flk1 ${ }^{+}$ Vorläuferzelle generiert werden.

Derzeit läuft in unserer Arbeitsgruppe eine MI-Studie, bei der Flk1 ${ }^{+}$Zellen in infarzierte Mausherzen injiziert werden. Vielleicht siedeln sich diese vordifferenzierten Herzen noch besser im Myokard an und differenzieren noch effizienter und schneller in kardiovaskuläre Zellen. Ein sinnvolles Experiment für die Zukunft wäre die Injektion Flk1 ${ }^{+}$Zellen in Herzen Shunt und TAC operierte Mäuse, um zu überprüfen, ob diese Zellen sich effizienter ansiedeln und differenzieren.

Auch in Experimenten mit hESCs war es möglich, $\mathrm{KDR}^{+}$(humanes Homolog zu murinem Flk1) Zellen zu generieren, zu sortieren und weiter zu kultivieren (Yang et al. 2008). In dieser Studie generierten hES-Zellen nach Kultivierung in serumfreiem Medium mit AA, BMP4, bFGF, VEGF, und DKK1 (Dickkopf Homolog 1) eine $\mathrm{KDR}^{\text {schwach }^{+}} / \mathrm{C}-\mathrm{Kit}^{-}$Population, die in vitro und in vivo kardiovaskuläres Potential zeigte.

Zusammenfassend kann man sagen, dass eine sehr gute Differenzierung der maGSCs in Flk1 ${ }^{+}$ Zellen mittels Co-Kultur auf OP9-Zellen gelang. Auch die nachfolgende Kultivierung und Charakterisierung der sortierten Zellen konnte erfolgreich durchgeführt werden. Dabei stellte sich heraus, dass vor allem die Flk1 ${ }^{+}$Zellen gut in endotheliale, glatte Muskelzellen und kardiale Zellen differenzieren können. Außerdem sollten Flk1 ${ }^{+}$Zellen noch weiter auf unterschiedlichen Matrices weiter kultiviert werden, so dass es letztendlich gelingt, eine stabile $\mathrm{Flk1}^{+}$Zelllinie herzustellen, die bisher weltweit noch nicht existiert, aber angesichts des enormen Potentials dieser Zellen von großer Bedeutung für die kardiovaskuläre Forschung wäre. 


\section{Zusammenfassung}

Stammzellen spielen eine wichtige Rolle bei der Erforschung neuer Therapiemöglichkeiten für viele Krankheiten, wie z.B. Herzkrankheiten. Da die Verwendung embryonaler Stammzellen mit Problemen behaftet ist, wird heutzutage nach Alternativen gesucht. In unserem Labor wurden im Jahr 2006 multipotente adulte Stammzellen aus Maushoden (maGSCs) generiert, die ähnliche Eigenschaften wie embryonale Stammzellen aufweisen, aber nicht mit ethischen Problemen einhergehen und daher für die Stammzell-TherapieForschung geeignet sind.

In der vorliegenden Arbeit sollte die Beeinflussung des Differenzierungspotentials der maGSCs unter mechanischer Last auf die kardiale Regeneration untersucht werden. In vivo wurden 2 Hypertrophie-Modelle der Maus (Aortenkonstriktion, TAC, und Aorto-cavaler Shunt) im Vergleich zu einem normalen, gesunden Maus-Modell etabliert.

In normalen Ciclosporin A-immunsupprimierten Mäusen wurden 1 Woche nach Zelltransplantation noch pluripotente und proliferierende Zellen detektiert, nach 4 Wochen nicht mehr. Teratomformation wurde nicht beobachtet. Die injizierten maGSCs entwickelten sich in diesen normalen Mäusen nach 4 Wochen zu endothelialen Zellen und glatten Muskelzellen, aber nicht zu Kardiomyozyten. Die transplantierten Zellen konnten sich in den Last-induzierten Shunt- und TAC-operierten Mäusen nach 2 Wochen in $\mathrm{vWF}^{+}$vaskuläre endotheliale Zellen und $\mathrm{SMA}^{+}$glatte Muskelzellen und nach 4 Wochen in $\alpha \mathrm{MHC}^{+}$ Kardiomyozyten differenzieren, was in den Sham-Tieren beider Gruppen mit Zellinjektion weniger oder gar nicht der Fall war. Diese Ergebnisse lassen also darauf schließen, dass sich die transplantierten maGSCs gut im Empfängermyokard ansiedeln und in den Vor- und Nachlast-induzierten Mäusen besser in die kardiovaskuläre Richtung differenzieren als in den normalen Mäusen. Dies bedeutet, dass die erhöhte mechanische Last einen Einfluss auf das Entwicklungspotential unserer maGSCs in vivo ausübt. Die maGSCs konnten allerdings in vitro nicht durch kurzzeitige Dehnung in ihrem Differenzierungsverhalten beeinflusst werden. Echokardiographische Analysen zeigten keine signifikanten, teilweise aber tendenzielle Funktionsverbesserungen der Herzen Shunt-und TAC-operierter Mäuse nach Transplantation undifferenzierter maGSCs.

Weiterhin konnte eine vermehrte Fibrose in den Ciclosporin A-immunsupprimierten normalen und Last-induzierten Mäusen nach Zelltransplantation gezeigt werden. Nach Transplantation undifferenzierter maGSCs in das Myokard von immundefizienten RAG2 ${ }^{-/-}$ $\mathrm{Cgc}^{-/-}$Mäusen, die keine B-, T und NK-Zellen besitzen, konnte festgestellt werden, dass sich 
weniger und kleinere Teratome in den Mäusen mit Ciclosporin A-Behandlung als in den Mäusen ohne das Medikament entwickelten. In den immundefizienten RAG2 ${ }^{-/-} \mathrm{Cgc}^{-/-} \mathrm{Mäusen}^{-}$ mit Ciclosporin A-Behandlung waren nach 4 Wochen nur noch wenige transplantierte Zellen Oct4 positiv im Gegensatz zu den Zellen in den Mäusen, die kein Ciclosporin A erhalten hatten. Diese Ergebnisse lassen auf eine Inhibierung der Pluripotenz und eine Stimulation der Differenzierung der maGSCs durch Ciclosporin A schließen. Außerdem weisen diese Daten darauf hin, dass sowohl Ciclosporin A als auch das Immunsystem eine eine große Rolle bei der Differenzierung von maGSCs in vivo spielen.

Ein weiterer Teil der Arbeit war die Etablierung eines in vitro-Protokolls, um aus maGSCs Flk1 ${ }^{+}$Zellen zu generieren. Die maGSCs konnten mittels OP9-Co-Kultur sehr effizient in $\mathrm{Flk1}^{+}$Zellen differenziert werden, nachdem verschiedene Ausgangszellzahlen und finale Differenzierungstage ausgetestet waren. Nach Kultivierung der maGSCs auf OP9-Zellen über einen längeren Zeitraum, konnte sowohl auf molekularer als auch auf Proteinebene eine gesteigerte Expression kardiovaskulärer Marker wiaMHC, vWF und SMA nachgewiesen werden. Nach 5 Tagen Co-Kultivierung mit OP9-Zellen wurden ca. 35\% Flk1 ${ }^{+}$Zellen mittels Durchflusszytometrie detektiert. Die Ausbeute an Flk1 ${ }^{+}$Zellen konnte jedoch nicht signifikant durch Zugabe von Wachstumsfaktoren erhöht werden. Nach FACS-Analyse wies vor allem die Flk1 ${ }^{+}$Population eine erhöhte Genexpression mesodermaler und spezifisch auch kardialer Marker wie Bry, Isl1, C-Kit und Nkx2.5 auf. Die anschließende Kultivierung sortierter Flk1 ${ }^{+}$ Zellen auf OP9 bewirtkte eine Stimulation der Differenzierung Flk1 ${ }^{+}$Zellen in kardiale, endotheliale Zellen und glatte Muskelzellen. Diese in vitro-Ergebnisse weisen also darauf hin, dass Flk1 ${ }^{+}$Zellen kardiovaskuläre Vorlauferzellen sind.

Insgesamt zeigen die ermittelten Daten, dass das Differenzierungspotential der maGSCs in der vorliegenden Arbeit durch mechanische Last in vivo, aber nicht in vitro beeinflusst werden konnte. Das Immunsystem und Ciclosporin A haben vielfältige Auswirkungen auf das Differenzierungspotential der maGSCs in vivo. Außerdem konnten maGSCs effizient in Flk1 ${ }^{+}$ kardiovaskuläre Vorläuferzellen differenziert werden, die ein enormes Potential für die zellbasierte Therapieforschung zur kardialen Regeneration besitzen. 


\section{Literaturverzeichnis}

\section{Literaturverzeichnis}

Abdelalim, E.M. and Tooyama, I. 2009. BNP signaling is crucial for embryonic stem cell proliferation. PLoS One 4(4): e5341.

Abdullah, Z., Saric, T., Kashkar, H., Baschuk, N., Yazdanpanah, B., Fleischmann, B.K., Hescheler, J., Kronke, M., and Utermohlen, O. 2007. Serpin-6 expression protects embryonic stem cells from lysis by antigen-specific CTL. J Immunol 178(6): 33903399.

Abraham, M.R., Henrikson, C.A., Tung, L., Chang, M.G., Aon, M., Xue, T., Li, R.A., B, O.R., and Marban, E. 2005. Antiarrhythmic engineering of skeletal myoblasts for cardiac transplantation. Circ Res 97(2): 159-167.

Abu-Issa, R., Waldo, K., and Kirby, M.L. 2004. Heart fields: one, two or more? Dev Biol 272(2): 281-285.

Alvarez-Dolado, M., Pardal, R., Garcia-Verdugo, J.M., Fike, J.R., Lee, H.O., Pfeffer, K., Lois, C., Morrison, S.J., and Alvarez-Buylla, A. 2003. Fusion of bone-marrow-derived cells with Purkinje neurons, cardiomyocytes and hepatocytes. Nature 425(6961): 968973.

Anversa, P., Kajstura, J., and Olivetti, G. 1996. Myocyte death in heart failure. Curr Opin Cardiol 11(3): 245-251.

Asahara, T., Masuda, H., Takahashi, T., Kalka, C., Pastore, C., Silver, M., Kearne, M., Magner, M., and Isner, J.M. 1999. Bone marrow origin of endothelial progenitor cells responsible for postnatal vasculogenesis in physiological and pathological neovascularization. Circ Res 85(3): 221-228.

Asahara, T., Murohara, T., Sullivan, A., Silver, M., van der Zee, R., Li, T., Witzenbichler, B., Schatteman, G., and Isner, J.M. 1997. Isolation of putative progenitor endothelial cells for angiogenesis. Science 275(5302): 964-967.

Badorff, C., Brandes, R.P., Popp, R., Rupp, S., Urbich, C., Aicher, A., Fleming, I., Busse, R., Zeiher, A.M., and Dimmeler, S. 2003. Transdifferentiation of blood-derived human adult endothelial progenitor cells into functionally active cardiomyocytes. Circulation 107(7): 1024-1032.

Balsam, L.B., Wagers, A.J., Christensen, J.L., Kofidis, T., Weissman, I.L., and Robbins, R.C. 2004. Haematopoietic stem cells adopt mature haematopoietic fates in ischaemic myocardium. Nature 428(6983): 668-673.

Barnhart, G.R., Goldman, M.H., Hastillo, A., Szentpetery, S., Wolfgang, T., Thompson, J., Mohanakumar, T., Katz, M.R., Rider, S., Hanrahan, J., and et al. 1985. Comparison of immunosuppression therapy following heart transplantation: pretransfusion/azathioprine/ATG/prednisone versus cyclosporine/prednisone. J Heart Transplant 4(4): 381-384.

Behfar, A., Perez-Terzic, C., Faustino, R.S., Arrell, D.K., Hodgson, D.M., Yamada, S., Puceat, M., Niederlander, N., Alekseev, A.E., Zingman, L.V., and Terzic, A. 2007. Cardiopoietic programming of embryonic stem cells for tumor-free heart repair. $J$ Exp Med 204(2): 405-420. 


\section{Literaturverzeichnis}

Behfar, A., Zingman, L.V., Hodgson, D.M., Rauzier, J.M., Kane, G.C., Terzic, A., and Puceat, M. 2002. Stem cell differentiation requires a paracrine pathway in the heart. Faseb J 16(12): 1558-1566.

Beltrami, A.P., Barlucchi, L., Torella, D., Baker, M., Limana, F., Chimenti, S., Kasahara, H., Rota, M., Musso, E., Urbanek, K., Leri, A., Kajstura, J., Nadal-Ginard, B., and Anversa, P. 2003. Adult cardiac stem cells are multipotent and support myocardial regeneration. Cell 114(6): 763-776.

Ben-Haim, N., Lu, C., Guzman-Ayala, M., Pescatore, L., Mesnard, D., Bischofberger, M., Naef, F., Robertson, E.J., and Constam, D.B. 2006. The nodal precursor acting via activin receptors induces mesoderm by maintaining a source of its convertases and BMP4. Dev Cell 11(3): 313-323.

Bilder, G.E., Sweet, C.S., Emmert, S.E., Schofield, T.L., Medina, R., Stabilito, II, and Friedman, P.A. 1989. Cardiac and noncardiac atrial natriuretic factor (ANF) biosynthesis and storage and plasma ANF in the rat model of chronic ventricular dysfunction. Endocrinology 124(3): 1515-1521.

Boghaert, E.R., Sridharan, L., Khandke, K.M., Armellino, D., Ryan, M.G., Myers, K., Harrop, R., Kunz, A., Hamann, P.R., Marquette, K., Dougher, M., DiJoseph, J.F., and Damle, N.K. 2008. The oncofetal protein, 5T4, is a suitable target for antibody-guided anti-cancer chemotherapy with calicheamicin. Int J Oncol 32(1): 221-234.

Bongso, A. and Richards, M. 2004. History and perspective of stem cell research. Best Pract Res Clin Obstet Gynaecol 18(6): 827-842.

Bouwens, L. 1998. Transdifferentiation versus stem cell hypothesis for the regeneration of islet beta-cells in the pancreas. Microsc Res Tech 43(4): 332-336.

Bradley, J.A., Bolton, E.M., and Pedersen, R.A. 2002. Stem cell medicine encounters the immune system. Nat Rev Immunol 2(11): 859-871.

Buckingham, M., Meilhac, S., and Zaffran, S. 2005. Building the mammalian heart from two sources of myocardial cells. Nat Rev Genet 6(11): 826-835.

Bullwinkel, J., Baron-Luhr, B., Ludemann, A., Wohlenberg, C., Gerdes, J., and Scholzen, T. 2006. Ki-67 protein is associated with ribosomal RNA transcription in quiescent and proliferating cells. J Cell Physiol 206(3): 624-635.

Cai, C.L., Liang, X., Shi, Y., Chu, P.H., Pfaff, S.L., Chen, J., and Evans, S. 2003. Isl1 identifies a cardiac progenitor population that proliferates prior to differentiation and contributes a majority of cells to the heart. Dev Cell 5(6): 877-889.

Capi, O. and Gepstein, L. 2006. Myocardial regeneration strategies using human embryonic stem cell-derived cardiomyocytes. J Control Release 116(2): 211-218.

Carson, C.T., Kinzler, E.R., and Parr, B.A. 2000. Tbx12, a novel T-box gene, is expressed during early stages of heart and retinal development. Mech Dev 96(1): 137-140.

Caspi, O., Huber, I., Kehat, I., Habib, M., Arbel, G., Gepstein, A., Yankelson, L., Aronson, D., Beyar, R., and Gepstein, L. 2007. Transplantation of human embryonic stem cellderived cardiomyocytes improves myocardial performance in infarcted rat hearts. $J$ Am Coll Cardiol 50(19): 1884-1893.

Chambers, I. and Smith, A. 2004. Self-renewal of teratocarcinoma and embryonic stem cells. Oncogene 23(43): 7150-7160. 
Chen, S.L., Fang, W.W., Ye, F., Liu, Y.H., Qian, J., Shan, S.J., Zhang, J.J., Chunhua, R.Z., Liao, L.M., Lin, S., and Sun, J.P. 2004. Effect on left ventricular function of intracoronary transplantation of autologous bone marrow mesenchymal stem cell in patients with acute myocardial infarction. Am J Cardiol 94(1): 92-95.

Chen, Y., Amende, I., Hampton, T.G., Yang, Y., Ke, Q., Min, J.Y., Xiao, Y.F., and Morgan, J.P. 2006. Vascular endothelial growth factor promotes cardiomyocyte differentiation of embryonic stem cells. Am J Physiol Heart Circ Physiol 291(4): H1653-1658.

Christoforou, N., Miller, R.A., Hill, C.M., Jie, C.C., McCallion, A.S., and Gearhart, J.D. 2008. Mouse ES cell-derived cardiac precursor cells are multipotent and facilitate identification of novel cardiac genes. J Clin Invest 118(3): 894-903.

Conrad, S., Renninger, M., Hennenlotter, J., Wiesner, T., Just, L., Bonin, M., Aicher, W., Buhring, H.J., Mattheus, U., Mack, A., Wagner, H.J., Minger, S., Matzkies, M., Reppel, M., Hescheler, J., Sievert, K.D., Stenzl, A., and Skutella, T. 2008. Generation of pluripotent stem cells from adult human testis. Nature 456(7220): 344-349.

Coultas, L., Chawengsaksophak, K., and Rossant, J. 2005. Endothelial cells and VEGF in vascular development. Nature 438(7070): 937-945.

Dai, W., Hale, S.L., Martin, B.J., Kuang, J.Q., Dow, J.S., Wold, L.E., and Kloner, R.A. 2005. Allogeneic mesenchymal stem cell transplantation in postinfarcted rat myocardium: short- and long-term effects. Circulation 112(2): 214-223.

Davis, R.J. 1993. The mitogen-activated protein kinase signal transduction pathway. $J$ Biol Chem 268(20): 14553-14556.

Dawn, B., Stein, A.B., Urbanek, K., Rota, M., Whang, B., Rastaldo, R., Torella, D., Tang, X.L., Rezazadeh, A., Kajstura, J., Leri, A., Hunt, G., Varma, J., Prabhu, S.D., Anversa, P., and Bolli, R. 2005. Cardiac stem cells delivered intravascularly traverse the vessel barrier, regenerate infarcted myocardium, and improve cardiac function. Proc Natl Acad Sci U S A 102(10): 3766-3771.

Dias, F.A., Urboniene, D., Yuzhakova, M.A., Biesiadecki, B.J., Pena, J.R., Goldspink, P.H., Geenen, D.L., and Wolska, B.M. 2010. Ablation of iNOS delays cardiac contractile dysfunction in chronic hypertension. Front Biosci (Elite Ed) 2: 312-324.

Dib, N., McCarthy, P., Campbell, A., Yeager, M., Pagani, F.D., Wright, S., MacLellan, W.R., Fonarow, G., Eisen, H.J., Michler, R.E., Binkley, P., Buchele, D., Korn, R., Ghazoul, M., Dinsmore, J., Opie, S.R., and Diethrich, E. 2005. Feasibility and safety of autologous myoblast transplantation in patients with ischemic cardiomyopathy. Cell Transplant 14(1): 11-19.

Dickstein, K., Cohen-Solal, A., Filippatos, G., McMurray, J.J., Ponikowski, P., Poole-Wilson, P.A., Stromberg, A., van Veldhuisen, D.J., Atar, D., Hoes, A.W., Keren, A., Mebazaa, A., Nieminen, M., Priori, S.G., and Swedberg, K. 2008. ESC guidelines for the diagnosis and treatment of acute and chronic heart failure 2008: the Task Force for the diagnosis and treatment of acute and chronic heart failure 2008 of the European Society of Cardiology. Developed in collaboration with the Heart Failure Association of the ESC (HFA) and endorsed by the European Society of Intensive Care Medicine (ESICM). Eur J Heart Fail 10(10): 933-989.

Dimos, J.T., Rodolfa, K.T., Niakan, K.K., Weisenthal, L.M., Mitsumoto, H., Chung, W., Croft, G.F., Saphier, G., Leibel, R., Goland, R., Wichterle, H., Henderson, C.E., and Eggan, K. 2008. Induced pluripotent stem cells generated from patients with ALS can be differentiated into motor neurons. Science 321(5893): 1218-1221. 
Drab, M., Haller, H., Bychkov, R., Erdmann, B., Lindschau, C., Haase, H., Morano, I., Luft, F.C., and Wobus, A.M. 1997. From totipotent embryonic stem cells to spontaneously contracting smooth muscle cells: a retinoic acid and db-cAMP in vitro differentiation model. Faseb J 11(11): 905-915.

Dressel, R., Guan, K., Nolte, J., Elsner, L., Monecke, S., Nayernia, K., Hasenfuss, G., and Engel, W. 2009. Multipotent adult germ-line stem cells, like other pluripotent stem cells, can be killed by cytotoxic $\mathrm{T}$ lymphocytes despite low expression of major histocompatibility complex class I molecules. Biol Direct 4: 31.

Dressel, R., Schindehutte, J., Kuhlmann, T., Elsner, L., Novota, P., Baier, P.C., Schillert, A., Bickeboller, H., Herrmann, T., Trenkwalder, C., Paulus, W., and Mansouri, A. 2008. The tumorigenicity of mouse embryonic stem cells and in vitro differentiated neuronal cells is controlled by the recipients' immune response. PLoS One 3(7): e2622.

Ebert, A.D., Yu, J., Rose, F.F., Jr., Mattis, V.B., Lorson, C.L., Thomson, J.A., and Svendsen, C.N. 2009. Induced pluripotent stem cells from a spinal muscular atrophy patient. Nature 457(7227): 277-280.

Edmondson, D.G., Lyons, G.E., Martin, J.F., and Olson, E.N. 1994. Mef2 gene expression marks the cardiac and skeletal muscle lineages during mouse embryogenesis. Development 120(5): 1251-1263.

Eisenberg, C.A., Gourdie, R.G., and Eisenberg, L.M. 1997. Wnt-11 is expressed in early avian mesoderm and required for the differentiation of the quail mesoderm cell line QCE-6. Development 124(2): 525-536.

El-Armouche, A., Wittkopper, K., Degenhardt, F., Weinberger, F., Didie, M., Melnychenko, I., Grimm, M., Peeck, M., Zimmermann, W.H., Unsold, B., Hasenfuss, G., Dobrev, D., and Eschenhagen, T. 2008. Phosphatase inhibitor-1-deficient mice are protected from catecholamine-induced arrhythmias and myocardial hypertrophy. Cardiovasc Res 80(3): 396-406.

Elsherif, L., Jiang, Y., Saari, J.T., and Kang, Y.J. 2004. Dietary copper restriction-induced changes in myocardial gene expression and the effect of copper repletion. Exp Biol Med (Maywood) 229(7): 616-622.

Ema, M., Takahashi, S., and Rossant, J. 2006. Deletion of the selection cassette, but not cisacting elements, in targeted Flk1-lacZ allele reveals Flk1 expression in multipotent mesodermal progenitors. Blood 107(1): 111-117.

Engelhard, V.H., Bullock, T.N., Colella, T.A., Sheasley, S.L., and Mullins, D.W. 2002. Antigens derived from melanocyte differentiation proteins: self-tolerance, autoimmunity, and use for cancer immunotherapy. Immunol Rev 188: 136-146.

Engler, A.J., Carag-Krieger, C., Johnson, C.P., Raab, M., Tang, H.Y., Speicher, D.W., Sanger, J.W., Sanger, J.M., and Discher, D.E. 2008. Embryonic cardiomyocytes beat best on a matrix with heart-like elasticity: scar-like rigidity inhibits beating. J Cell Sci 121(Pt 22): 3794-3802.

Esposito, C., Fornoni, A., Cornacchia, F., Bellotti, N., Fasoli, G., Foschi, A., Mazzucchelli, I., Mazzullo, T., Semeraro, L., and Dal Canton, A. 2000. Cyclosporine induces different responses in human epithelial, endothelial and fibroblast cell cultures. Kidney Int 58(1): 123-130.

Evans, M.J. and Kaufman, M.H. 1981. Establishment in culture of pluripotential cells from mouse embryos. Nature 292(5819): 154-156. 


\section{Literaturverzeichnis}

Faerber, G., Barreto-Perreia, F., Schoepe, M., Gilsbach, R., Schrepper, A., Schwarzer, M., Mohr, F.W., Hein, L., and Doenst, T. 2010. Induction of heart failure by minimally invasive aortic constriction in mice: Reduced peroxisome proliferator-activated receptor gamma coactivator levels and mitochondrial dysfunction. $J$ Thorac Cardiovasc Surg.

Ferrari, G., Cusella-De Angelis, G., Coletta, M., Paolucci, E., Stornaiuolo, A., Cossu, G., and Mavilio, F. 1998. Muscle regeneration by bone marrow-derived myogenic progenitors. Science 279(5356): 1528-1530.

Fina, L., Molgaard, H.V., Robertson, D., Bradley, N.J., Monaghan, P., Delia, D., Sutherland, D.R., Baker, M.A., and Greaves, M.F. 1990. Expression of the CD34 gene in vascular endothelial cells. Blood 75(12): 2417-2426.

Garry, D.J. and Olson, E.N. 2006. A common progenitor at the heart of development. Cell 127(6): 1101-1104.

Gehling, U.M., Ergun, S., Schumacher, U., Wagener, C., Pantel, K., Otte, M., Schuch, G., Schafhausen, P., Mende, T., Kilic, N., Kluge, K., Schafer, B., Hossfeld, D.K., and Fiedler, W. 2000. In vitro differentiation of endothelial cells from AC133-positive progenitor cells. Blood 95(10): 3106-3112.

Gertow, K., Wolbank, S., Rozell, B., Sugars, R., Andang, M., Parish, C.L., Imreh, M.P., Wendel, M., and Ahrlund-Richter, L. 2004. Organized development from human embryonic stem cells after injection into immunodeficient mice. Stem Cells Dev 13(4): 421-435.

Ghostine, S., Carrion, C., Souza, L.C., Richard, P., Bruneval, P., Vilquin, J.T., Pouzet, B., Schwartz, K., Menasche, P., and Hagege, A.A. 2002. Long-term efficacy of myoblast transplantation on regional structure and function after myocardial infarction. Circulation 106(12 Suppl 1): I131-136.

Glaser, T., Opitz, T., Kischlat, T., Konang, R., Sasse, P., Fleischmann, B.K., Engel, W., Nayernia, K., and Brustle, O. 2008. Adult germ line stem cells as a source of functional neurons and glia. Stem Cells 26(9): 2434-2443.

Goh, G., Self, T., Barbadillo Munoz, M.D., Hall, I.P., Young, L., and Denning, C. 2005. Molecular and phenotypic analyses of human embryonic stem cell-derived cardiomyocytes: opportunities and challenges for clinical translation. Thromb Haemost 94(4): 728-737.

Golestaneh, N., Kokkinaki, M., Pant, D., Jiang, J., DeStefano, D., Fernandez-Bueno, C., Rone, J.D., Haddad, B.R., Gallicano, G.I., and Dym, M. 2009. Pluripotent stem cells derived from adult human testes. Stem Cells Dev 18(8): 1115-1126.

Goodell, M.A., Brose, K., Paradis, G., Conner, A.S., and Mulligan, R.C. 1996. Isolation and functional properties of murine hematopoietic stem cells that are replicating in vivo. $J$ Exp Med 183(4): 1797-1806.

Grimaldi, P.A., Teboul, L., Inadera, H., Gaillard, D., and Amri, E.Z. 1997. Transdifferentiation of myoblasts to adipoblasts: triggering effects of fatty acids and thiazolidinediones. Prostaglandins Leukot Essent Fatty Acids 57(1): 71-75.

Grodzinsky, A.J., Levenston, M.E., Jin, M., and Frank, E.H. 2000. Cartilage tissue remodeling in response to mechanical forces. Annu Rev Biomed Eng 2: 691-713.

Gruh, I., Beilner, J., Blomer, U., Schmiedl, A., Schmidt-Richter, I., Kruse, M.L., Haverich, A., and Martin, U. 2006. No evidence of transdifferentiation of human endothelial 


\section{Literaturverzeichnis}

progenitor cells into cardiomyocytes after coculture with neonatal rat cardiomyocytes. Circulation 113(10): 1326-1334.

Guan, K., Furst, D.O., and Wobus, A.M. 1999. Modulation of sarcomere organization during embryonic stem cell-derived cardiomyocyte differentiation. Eur J Cell Biol 78(11): 813-823.

Guan, K., Nayernia, K., Maier, L.S., Wagner, S., Dressel, R., Lee, J.H., Nolte, J., Wolf, F., Li, M., Engel, W., and Hasenfuss, G. 2006. Pluripotency of spermatogonial stem cells from adult mouse testis. Nature 440(7088): 1199-1203.

Guan, K., Wagner, S., Unsold, B., Maier, L.S., Kaiser, D., Hemmerlein, B., Nayernia, K., Engel, W., and Hasenfuss, G. 2007. Generation of functional cardiomyocytes from adult mouse spermatogonial stem cells. Circ Res 100(11): 1615-1625.

Guan, K., Wolf, F., Becker, A., Engel, W., Nayernia, K., and Hasenfuss, G. 2009. Isolation and cultivation of stem cells from adult mouse testes. Nat Protoc 4(2): 143-154.

Guo, J., Zeng, Y., Liang, Y., Wang, L., Su, H., and Wu, W. 2007. Cyclosporine affects the proliferation and differentiation of neural stem cells in culture. Neuroreport 18(9): 863-868.

Guo, X.M., Zhao, Y.S., Chang, H.X., Wang, C.Y., E, L.L., Zhang, X.A., Duan, C.M., Dong, L.Z., Jiang, H., Li, J., Song, Y., and Yang, X.J. 2006. Creation of engineered cardiac tissue in vitro from mouse embryonic stem cells. Circulation 113(18): 2229-2237.

Gussoni, E., Soneoka, Y., Strickland, C.D., Buzney, E.A., Khan, M.K., Flint, A.F., Kunkel, L.M., and Mulligan, R.C. 1999. Dystrophin expression in the mdx mouse restored by stem cell transplantation. Nature 401(6751): 390-394.

Gwak, S.J., Bhang, S.H., Kim, I.K., Kim, S.S., Cho, S.W., Jeon, O., Yoo, K.J., Putnam, A.J., and Kim, B.S. 2008. The effect of cyclic strain on embryonic stem cell-derived cardiomyocytes. Biomaterials 29(7): 844-856.

Hamazaki, T., Iiboshi, Y., Oka, M., Papst, P.J., Meacham, A.M., Zon, L.I., and Terada, N. 2001. Hepatic maturation in differentiating embryonic stem cells in vitro. FEBS Lett 497(1): 15-19.

Han, B., Bai, X.H., Lodyga, M., Xu, J., Yang, B.B., Keshavjee, S., Post, M., and Liu, M. 2004. Conversion of mechanical force into biochemical signaling. J Biol Chem 279(52): 54793-54801.

Harvey, R.P., Lai, D., Elliott, D., Biben, C., Solloway, M., Prall, O., Stennard, F., Schindeler, A., Groves, N., Lavulo, L., Hyun, C., Yeoh, T., Costa, M., Furtado, M., and Kirk, E. 2002. Homeodomain factor Nkx2-5 in heart development and disease. Cold Spring Harb Symp Quant Biol 67: 107-114.

He, J.Q., Ma, Y., Lee, Y., Thomson, J.A., and Kamp, T.J. 2003. Human embryonic stem cells develop into multiple types of cardiac myocytes: action potential characterization. Circ Res 93(1): 32-39.

Herreros, J., Prosper, F., Perez, A., Gavira, J.J., Garcia-Velloso, M.J., Barba, J., Sanchez, P.L., Canizo, C., Rabago, G., Marti-Climent, J.M., Hernandez, M., Lopez-Holgado, N., Gonzalez-Santos, J.M., Martin-Luengo, C., and Alegria, E. 2003. Autologous intramyocardial injection of cultured skeletal muscle-derived stem cells in patients with non-acute myocardial infarction. Eur Heart J 24(22): 2012-2020.

Herrmann, B.G., Labeit, S., Poustka, A., King, T.R., and Lehrach, H. 1990. Cloning of the T gene required in mesoderm formation in the mouse. Nature 343(6259): 617-622. 


\section{Literaturverzeichnis}

Hirata, H., Kawamata, S., Murakami, Y., Inoue, K., Nagahashi, A., Tosaka, M., Yoshimura, N., Miyamoto, Y., Iwasaki, H., Asahara, T., and Sawa, Y. 2007. Coexpression of platelet-derived growth factor receptor alpha and fetal liver kinase 1 enhances cardiogenic potential in embryonic stem cell differentiation in vitro. J Biosci Bioeng 103(5): 412-419.

Hochedlinger, K. and Plath, K. 2009. Epigenetic reprogramming and induced pluripotency. Development 136(4): 509-523.

Hodgson, D.M., Behfar, A., Zingman, L.V., Kane, G.C., Perez-Terzic, C., Alekseev, A.E., Puceat, M., and Terzic, A. 2004. Stable benefit of embryonic stem cell therapy in myocardial infarction. Am J Physiol Heart Circ Physiol 287(2): H471-479.

Hori, Y., Rulifson, I.C., Tsai, B.C., Heit, J.J., Cahoy, J.D., and Kim, S.K. 2002. Growth inhibitors promote differentiation of insulin-producing tissue from embryonic stem cells. Proc Natl Acad Sci U S A 99(25): 16105-16110.

Hu, H. and Sachs, F. 1997. Stretch-activated ion channels in the heart. J Mol Cell Cardiol 29(6): 1511-1523.

Hu, P., Zhang, D., Swenson, L., Chakrabarti, G., Abel, E.D., and Litwin, S.E. 2003. Minimally invasive aortic banding in mice: effects of altered cardiomyocyte insulin signaling during pressure overload. Am J Physiol Heart Circ Physiol 285(3): H12611269.

Huber, T.L., Kouskoff, V., Fehling, H.J., Palis, J., and Keller, G. 2004. Haemangioblast commitment is initiated in the primitive streak of the mouse embryo. Nature 432(7017): 625-630.

Hubner, K., Fuhrmann, G., Christenson, L.K., Kehler, J., Reinbold, R., De La Fuente, R., Wood, J., Strauss, J.F., 3rd, Boiani, M., and Scholer, H.R. 2003. Derivation of oocytes from mouse embryonic stem cells. Science 300(5623): 1251-1256.

Huikuri, H.V., Kervinen, K., Niemela, M., Ylitalo, K., Saily, M., Koistinen, P., Savolainen, E.R., Ukkonen, H., Pietila, M., Airaksinen, J.K., Knuuti, J., and Makikallio, T.H. 2008. Effects of intracoronary injection of mononuclear bone marrow cells on left ventricular function, arrhythmia risk profile, and restenosis after thrombolytic therapy of acute myocardial infarction. Eur Heart J 29(22): 2723-2732.

Illi, B., Scopece, A., Nanni, S., Farsetti, A., Morgante, L., Biglioli, P., Capogrossi, M.C., and Gaetano, C. 2005. Epigenetic histone modification and cardiovascular lineage programming in mouse embryonic stem cells exposed to laminar shear stress. Circ Res 96(5): 501-508.

Ingber, D.E. 2002. Mechanical signaling and the cellular response to extracellular matrix in angiogenesis and cardiovascular physiology. Circ Res 91(10): 877-887.

Iwasa, T., Baba, S., Doi, H., Kaichi, S., Yokoo, N., Mima, T., Kanatsu-Shinohara, M., Shinohara, T., Nakahata, T., and Heike, T. 2010. Neonatal mouse testis-derived multipotent germline stem cells improve the cardiac function of acute ischemic heart mouse model. Biochem Biophys Res Commun 400(1): 27-33.

Izumo, S., Nadal-Ginard, B., and Mahdavi, V. 1988. Protooncogene induction and reprogramming of cardiac gene expression produced by pressure overload. Proc Natl Acad Sci U S A 85(2): 339-343.

Jackson, K.A., Majka, S.M., Wang, H., Pocius, J., Hartley, C.J., Majesky, M.W., Entman, M.L., Michael, L.H., Hirschi, K.K., and Goodell, M.A. 2001. Regeneration of 


\section{Literaturverzeichnis}

ischemic cardiac muscle and vascular endothelium by adult stem cells. $J$ Clin Invest 107(11): 1395-1402.

James, M.A., Saadeh, A.M., and Jones, J.V. 2000. Wall stress and hypertension. J Cardiovasc Risk 7(3): 187-190.

Janssens, S., Dubois, C., Bogaert, J., Theunissen, K., Deroose, C., Desmet, W., Kalantzi, M., Herbots, L., Sinnaeve, P., Dens, J., Maertens, J., Rademakers, F., Dymarkowski, S., Gheysens, O., Van Cleemput, J., Bormans, G., Nuyts, J., Belmans, A., Mortelmans, L., Boogaerts, M., and Van de Werf, F. 2006. Autologous bone marrow-derived stemcell transfer in patients with ST-segment elevation myocardial infarction: doubleblind, randomised controlled trial. Lancet 367(9505): 113-121.

Johansson, B.M. and Wiles, M.V. 1995. Evidence for involvement of activin A and bone morphogenetic protein 4 in mammalian mesoderm and hematopoietic development. Mol Cell Biol 15(1): 141-151.

Kabrun, N., Buhring, H.J., Choi, K., Ullrich, A., Risau, W., and Keller, G. 1997. Flk-1 expression defines a population of early embryonic hematopoietic precursors. Development 124(10): 2039-2048.

Kajstura, J., Rota, M., Whang, B., Cascapera, S., Hosoda, T., Bearzi, C., Nurzynska, D., Kasahara, H., Zias, E., Bonafe, M., Nadal-Ginard, B., Torella, D., Nascimbene, A., Quaini, F., Urbanek, K., Leri, A., and Anversa, P. 2005. Bone marrow cells differentiate in cardiac cell lineages after infarction independently of cell fusion. Circ Res 96(1): 127-137.

Kanatsu-Shinohara, M., Inoue, K., Lee, J., Yoshimoto, M., Ogonuki, N., Miki, H., Baba, S., Kato, T., Kazuki, Y., Toyokuni, S., Toyoshima, M., Niwa, O., Oshimura, M., Heike, T., Nakahata, T., Ishino, F., Ogura, A., and Shinohara, T. 2004. Generation of pluripotent stem cells from neonatal mouse testis. Cell 119(7): 1001-1012.

Kattman, S.J., Huber, T.L., and Keller, G.M. 2006. Multipotent flk-1+ cardiovascular progenitor cells give rise to the cardiomyocyte, endothelial, and vascular smooth muscle lineages. Dev Cell 11(5): 723-732.

Kaufman, D.S. and Thomson, J.A. 2002. Human ES cells--haematopoiesis and transplantation strategies. J Anat 200(Pt 3): 243-248.

Kawasaki, H., Mizuseki, K., Nishikawa, S., Kaneko, S., Kuwana, Y., Nakanishi, S., Nishikawa, S.I., and Sasai, Y. 2000. Induction of midbrain dopaminergic neurons from ES cells by stromal cell-derived inducing activity. Neuron 28(1): 31-40.

Kehat, I., Kenyagin-Karsenti, D., Snir, M., Segev, H., Amit, M., Gepstein, A., Livne, E., Binah, O., Itskovitz-Eldor, J., and Gepstein, L. 2001. Human embryonic stem cells can differentiate into myocytes with structural and functional properties of cardiomyocytes. J Clin Invest 108(3): 407-414.

Kehat, I., Khimovich, L., Caspi, O., Gepstein, A., Shofti, R., Arbel, G., Huber, I., Satin, J., Itskovitz-Eldor, J., and Gepstein, L. 2004. Electromechanical integration of cardiomyocytes derived from human embryonic stem cells. Nat Biotechnol 22(10): 1282-1289.

Kelly, R.G., Brown, N.A., and Buckingham, M.E. 2001. The arterial pole of the mouse heart forms from Fgf10-expressing cells in pharyngeal mesoderm. Dev Cell 1(3): 435-440.

King, T., Beddington, R.S., and Brown, N.A. 1998. The role of the brachyury gene in heart development and left-right specification in the mouse. Mech Dev 79(1-2): 29-37. 


\section{Literaturverzeichnis}

Klug, M.G., Soonpaa, M.H., Koh, G.Y., and Field, L.J. 1996. Genetically selected cardiomyocytes from differentiating embronic stem cells form stable intracardiac grafts. J Clin Invest 98(1): 216-224.

Ko, K., Arauzo-Bravo, M.J., Tapia, N., Kim, J., Lin, Q., Bernemann, C., Han, D.W., Gentile, L., Reinhardt, P., Greber, B., Schneider, R.K., Kliesch, S., Zenke, M., and Scholer, H.R. 2010. Human adult germline stem cells in question. Nature 465(7301): E1; discussion E3.

Ko, K., Tapia, N., Wu, G., Kim, J.B., Bravo, M.J., Sasse, P., Glaser, T., Ruau, D., Han, D.W., Greber, B., Hausdorfer, K., Sebastiano, V., Stehling, M., Fleischmann, B.K., Brustle, O., Zenke, M., and Scholer, H.R. 2009. Induction of pluripotency in adult unipotent germline stem cells. Cell Stem Cell 5(1): 87-96.

Koch, C.A., Jordan, C.E., and Platt, J.L. 2006. Complement-dependent control of teratoma formation by embryonic stem cells. J Immunol 177(7): 4803-4809.

Kofidis, T., de Bruin, J.L., Yamane, T., Balsam, L.B., Lebl, D.R., Swijnenburg, R.J., Tanaka, M., Weissman, I.L., and Robbins, R.C. 2004. Insulin-like growth factor promotes engraftment, differentiation, and functional improvement after transfer of embryonic stem cells for myocardial restoration. Stem Cells 22(7): 1239-1245.

Kofidis, T., de Bruin, J.L., Yamane, T., Tanaka, M., Lebl, D.R., Swijnenburg, R.J., Weissman, I.L., and Robbins, R.C. 2005. Stimulation of paracrine pathways with growth factors enhances embryonic stem cell engraftment and host-specific differentiation in the heart after ischemic myocardial injury. Circulation 111(19): 2486-2493.

Komuro, I., Kaida, T., Shibazaki, Y., Kurabayashi, M., Katoh, Y., Hoh, E., Takaku, F., and Yazaki, Y. 1990a. Stretching cardiac myocytes stimulates protooncogene expression. $J$ Biol Chem 265(7): 3595-3598.

Komuro, I., Katoh, Y., Kaida, T., Shibazaki, Y., Kurabayashi, M., Hoh, E., Takaku, F., and Yazaki, Y. 1991. Mechanical loading stimulates cell hypertrophy and specific gene expression in cultured rat cardiac myocytes. Possible role of protein kinase C activation. J Biol Chem 266(2): 1265-1268.

Komuro, I., Kurabayashi, M., Shibazaki, Y., Katoh, Y., Hoh, E., Kaida, T., Ieki, K., Takaku, F., and Yazaki, Y. 1990b. Molecular mechanism of cardiac hypertrophy. Jpn Circ J 54(5): 526-534.

Kopen, G.C., Prockop, D.J., and Phinney, D.G. 1999. Marrow stromal cells migrate throughout forebrain and cerebellum, and they differentiate into astrocytes after injection into neonatal mouse brains. Proc Natl Acad Sci U S A 96(19): 10711-10716.

Kossack, N., Meneses, J., Shefi, S., Nguyen, H.N., Chavez, S., Nicholas, C., Gromoll, J., Turek, P.J., and Reijo-Pera, R.A. 2009. Isolation and characterization of pluripotent human spermatogonial stem cell-derived cells. Stem Cells 27(1): 138-149.

Koyanagi, M., Haendeler, J., Badorff, C., Brandes, R.P., Hoffmann, J., Pandur, P., Zeiher, A.M., Kuhl, M., and Dimmeler, S. 2005a. Non-canonical Wnt signaling enhances differentiation of human circulating progenitor cells to cardiomyogenic cells. $J$ Biol Chem 280(17): 16838-16842.

Koyanagi, M., Urbich, C., Chavakis, E., Hoffmann, J., Rupp, S., Badorff, C., Zeiher, A.M., Starzinski-Powitz, A., Haendeler, J., and Dimmeler, S. 2005b. Differentiation of circulating endothelial progenitor cells to a cardiomyogenic phenotype depends on Ecadherin. FEBS Lett 579(27): 6060-6066. 


\section{Literaturverzeichnis}

Kraus, F., Haenig, B., and Kispert, A. 2001. Cloning and expression analysis of the mouse Tbox gene tbx20. Mech Dev 100(1): 87-91.

Krause, D.S., Theise, N.D., Collector, M.I., Henegariu, O., Hwang, S., Gardner, R., Neutzel, S., and Sharkis, S.J. 2001. Multi-organ, multi-lineage engraftment by a single bone marrow-derived stem cell. Cell 105(3): 369-377.

Kuai, X.L., Cong, X.Q., Du, Z.W., Bian, Y.H., and Xiao, S.D. 2006. Treatment of surgically induced acute liver failure by transplantation of HNF4-overexpressing embryonic stem cells. Chin J Dig Dis 7(2): 109-116.

LaBarge, M.A. and Blau, H.M. 2002. Biological progression from adult bone marrow to mononucleate muscle stem cell to multinucleate muscle fiber in response to injury. Cell 111(4): 589-601.

Laflamme, M.A., Chen, K.Y., Naumova, A.V., Muskheli, V., Fugate, J.A., Dupras, S.K., Reinecke, H., Xu, C., Hassanipour, M., Police, S., O'Sullivan, C., Collins, L., Chen, Y., Minami, E., Gill, E.A., Ueno, S., Yuan, C., Gold, J., and Murry, C.E. 2007. Cardiomyocytes derived from human embryonic stem cells in pro-survival factors enhance function of infarcted rat hearts. Nat Biotechnol 25(9): 1015-1024.

Laflamme, M.A., Gold, J., Xu, C., Hassanipour, M., Rosler, E., Police, S., Muskheli, V., and Murry, C.E. 2005. Formation of human myocardium in the rat heart from human embryonic stem cells. Am J Pathol 167(3): 663-671.

Lagasse, E., Connors, H., Al-Dhalimy, M., Reitsma, M., Dohse, M., Osborne, L., Wang, X., Finegold, M., Weissman, I.L., and Grompe, M. 2000. Purified hematopoietic stem cells can differentiate into hepatocytes in vivo. Nat Med 6(11): 1229-1234.

Laugwitz, K.L., Moretti, A., Lam, J., Gruber, P., Chen, Y., Woodard, S., Lin, L.Z., Cai, C.L., Lu, M.M., Reth, M., Platoshyn, O., Yuan, J.X., Evans, S., and Chien, K.R. 2005. Postnatal isl1+ cardioblasts enter fully differentiated cardiomyocyte lineages. Nature 433(7026): 647-653.

Lee, S.H., Lumelsky, N., Studer, L., Auerbach, J.M., and McKay, R.D. 2000. Efficient generation of midbrain and hindbrain neurons from mouse embryonic stem cells. Nat Biotechnol 18(6): 675-679.

Leobon, B., Garcin, I., Menasche, P., Vilquin, J.T., Audinat, E., and Charpak, S. 2003. Myoblasts transplanted into rat infarcted myocardium are functionally isolated from their host. Proc Natl Acad Sci U S A 100(13): 7808-7811.

Leor, J., Gerecht, S., Cohen, S., Miller, L., Holbova, R., Ziskind, A., Shachar, M., Feinberg, M.S., Guetta, E., and Itskovitz-Eldor, J. 2007. Human embryonic stem cell transplantation to repair the infarcted myocardium. Heart 93(10): 1278-1284.

Levenberg, S., Golub, J.S., Amit, M., Itskovitz-Eldor, J., and Langer, R. 2002. Endothelial cells derived from human embryonic stem cells. Proc Natl Acad Sci U S A 99(7): 4391-4396.

Linke, A., Muller, P., Nurzynska, D., Casarsa, C., Torella, D., Nascimbene, A., Castaldo, C., Cascapera, S., Bohm, M., Quaini, F., Urbanek, K., Leri, A., Hintze, T.H., Kajstura, J., and Anversa, P. 2005. Stem cells in the dog heart are self-renewing, clonogenic, and multipotent and regenerate infarcted myocardium, improving cardiac function. Proc Natl Acad Sci U S A 102(25): 8966-8971. 


\section{Literaturverzeichnis}

Lints, T.J., Parsons, L.M., Hartley, L., Lyons, I., and Harvey, R.P. 1993. Nkx-2.5: a novel murine homeobox gene expressed in early heart progenitor cells and their myogenic descendants. Development 119(3): 969.

Liu, M. and Post, M. 2000. Invited review: mechanochemical signal transduction in the fetal lung. J Appl Physiol 89(5): 2078-2084.

Loennechen, J.P., Stoylen, A., Beisvag, V., Wisloff, U., and Ellingsen, O. 2001. Regional expression of endothelin-1, ANP, IGF-1, and LV wall stress in the infarcted rat heart. Am J Physiol Heart Circ Physiol 280(6): H2902-2910.

Lunde, K., Solheim, S., Aakhus, S., Arnesen, H., Abdelnoor, M., Egeland, T., Endresen, K., Ilebekk, A., Mangschau, A., Fjeld, J.G., Smith, H.J., Taraldsrud, E., Grogaard, H.K., Bjornerheim, R., Brekke, M., Muller, C., Hopp, E., Ragnarsson, A., Brinchmann, J.E., and Forfang, K. 2006. Intracoronary injection of mononuclear bone marrow cells in acute myocardial infarction. $N$ Engl J Med 355(12): 1199-1209.

Maehr, R., Chen, S., Snitow, M., Ludwig, T., Yagasaki, L., Goland, R., Leibel, R.L., and Melton, D.A. 2009. Generation of pluripotent stem cells from patients with type 1 diabetes. Proc Natl Acad Sci U S A 106(37): 15768-15773.

Maherali, N., Sridharan, R., Xie, W., Utikal, J., Eminli, S., Arnold, K., Stadtfeld, M., Yachechko, R., Tchieu, J., Jaenisch, R., Plath, K., and Hochedlinger, K. 2007. Directly reprogrammed fibroblasts show global epigenetic remodeling and widespread tissue contribution. Cell Stem Cell 1(1): 55-70.

Mandinov, L., Mandinova, A., Kyurkchiev, S., Kyurkchiev, D., Kehayov, I., Kolev, V., Soldi, R., Bagala, C., de Muinck, E.D., Lindner, V., Post, M.J., Simons, M., Bellum, S., Prudovsky, I., and Maciag, T. 2003. Copper chelation represses the vascular response to injury. Proc Natl Acad Sci U S A 100(11): 6700-6705.

Mann, D.L., Kent, R.L., and Cooper, G.t. 1989. Load regulation of the properties of adult feline cardiocytes: growth induction by cellular deformation. Circ Res 64(6): 10791090.

Martin, C.M., Meeson, A.P., Robertson, S.M., Hawke, T.J., Richardson, J.A., Bates, S., Goetsch, S.C., Gallardo, T.D., and Garry, D.J. 2004. Persistent expression of the ATPbinding cassette transporter, Abcg2, identifies cardiac SP cells in the developing and adult heart. Dev Biol 265(1): 262-275.

Martin, G.R. 1981. Isolation of a pluripotent cell line from early mouse embryos cultured in medium conditioned by teratocarcinoma stem cells. Proc Natl Acad Sci U S A 78(12): 7634-7638.

McMorrow, T., Gaffney, M.M., Slattery, C., Campbell, E., and Ryan, M.P. 2005. Cyclosporine A induced epithelial-mesenchymal transition in human renal proximal tubular epithelial cells. Nephrol Dial Transplant 20(10): 2215-2225.

Meilhac, S.M., Esner, M., Kelly, R.G., Nicolas, J.F., and Buckingham, M.E. 2004. The clonal origin of myocardial cells in different regions of the embryonic mouse heart. Dev Cell 6(5): 685-698.

Menard, C., Hagege, A.A., Agbulut, O., Barro, M., Morichetti, M.C., Brasselet, C., Bel, A., Messas, E., Bissery, A., Bruneval, P., Desnos, M., Puceat, M., and Menasche, P. 2005. Transplantation of cardiac-committed mouse embryonic stem cells to infarcted sheep myocardium: a preclinical study. Lancet 366(9490): 1005-1012. 
Menasche, P., Alfieri, O., Janssens, S., McKenna, W., Reichenspurner, H., Trinquart, L., Vilquin, J.T., Marolleau, J.P., Seymour, B., Larghero, J., Lake, S., Chatellier, G., Solomon, S., Desnos, M., and Hagege, A.A. 2008. The Myoblast Autologous Grafting in Ischemic Cardiomyopathy (MAGIC) trial: first randomized placebo-controlled study of myoblast transplantation. Circulation 117(9): 1189-1200.

Messina, E., De Angelis, L., Frati, G., Morrone, S., Chimenti, S., Fiordaliso, F., Salio, M., Battaglia, M., Latronico, M.V., Coletta, M., Vivarelli, E., Frati, L., Cossu, G., and Giacomello, A. 2004. Isolation and expansion of adult cardiac stem cells from human and murine heart. Circ Res 95(9): 911-921.

Michalczyk, K. and Ziman, M. 2005. Nestin structure and predicted function in cellular cytoskeletal organisation. Histol Histopathol 20(2): 665-671.

Millauer, B., Wizigmann-Voos, S., Schnurch, H., Martinez, R., Moller, N.P., Risau, W., and Ullrich, A. 1993. High affinity VEGF binding and developmental expression suggest Flk-1 as a major regulator of vasculogenesis and angiogenesis. Cell 72(6): 835-846.

Min, J.Y., Yang, Y., Converso, K.L., Liu, L., Huang, Q., Morgan, J.P., and Xiao, Y.F. 2002. Transplantation of embryonic stem cells improves cardiac function in postinfarcted rats. J Appl Physiol 92(1): 288-296.

Miyamoto, T., Sengoku, K., Takuma, N., Hasuike, S., Hayashi, H., Yamauchi, T., Yamashita, T., and Ishikawa, M. 2002. Isolation and expression analysis of the testis-specific gene, STRA8, stimulated by retinoic acid gene 8. J Assist Reprod Genet 19(11): 531535.

Mizrak, S.C., Chikhovskaya, J.V., Sadri-Ardekani, H., van Daalen, S., Korver, C.M., Hovingh, S.E., Roepers-Gajadien, H.L., Raya, A., Fluiter, K., de Reijke, T.M., de la Rosette, J.J., Knegt, A.C., Belmonte, J.C., van der Veen, F., de Rooij, D.G., Repping, S., and van Pelt, A.M. Embryonic stem cell-like cells derived from adult human testis. Hum Reprod 25(1): 158-167.

Molkentin, J.D., Kalvakolanu, D.V., and Markham, B.E. 1994. Transcription factor GATA-4 regulates cardiac muscle-specific expression of the alpha-myosin heavy-chain gene. Mol Cell Biol 14(7): 4947-4957.

Monzen, K., Nagai, R., and Komuro, I. 2002. A role for bone morphogenetic protein signaling in cardiomyocyte differentiation. Trends Cardiovasc Med 12(6): 263-269.

Moretti, A., Caron, L., Nakano, A., Lam, J.T., Bernshausen, A., Chen, Y., Qyang, Y., Bu, L., Sasaki, M., Martin-Puig, S., Sun, Y., Evans, S.M., Laugwitz, K.L., and Chien, K.R. 2006. Multipotent embryonic isl1+ progenitor cells lead to cardiac, smooth muscle, and endothelial cell diversification. Cell 127(6): 1151-1165.

Moriya, K., Yoshikawa, M., Saito, K., Ouji, Y., Nishiofuku, M., Hayashi, N., Ishizaka, S., and Fukui, H. 2007. Embryonic stem cells develop into hepatocytes after intrasplenic transplantation in CCl4-treated mice. World J Gastroenterol 13(6): 866-873.

Moses, K.A., DeMayo, F., Braun, R.M., Reecy, J.L., and Schwartz, R.J. 2001. Embryonic expression of an Nkx2-5/Cre gene using ROSA26 reporter mice. Genesis 31(4): 176180.

Motoike, T., Markham, D.W., Rossant, J., and Sato, T.N. 2003. Evidence for novel fate of Flk1+ progenitor: contribution to muscle lineage. Genesis 35(3): 153-159. 
Murohara, T., Ikeda, H., Duan, J., Shintani, S., Sasaki, K., Eguchi, H., Onitsuka, I., Matsui, K., and Imaizumi, T. 2000. Transplanted cord blood-derived endothelial precursor cells augment postnatal neovascularization. J Clin Invest 105(11): 1527-1536.

Murry, C.E., Soonpaa, M.H., Reinecke, H., Nakajima, H., Nakajima, H.O., Rubart, M., Pasumarthi, K.B., Virag, J.I., Bartelmez, S.H., Poppa, V., Bradford, G., Dowell, J.D., Williams, D.A., and Field, L.J. 2004. Haematopoietic stem cells do not transdifferentiate into cardiac myocytes in myocardial infarcts. Nature 428(6983): 664-668.

Murry, C.E., Wiseman, R.W., Schwartz, S.M., and Hauschka, S.D. 1996. Skeletal myoblast transplantation for repair of myocardial necrosis. J Clin Invest 98(11): 2512-2523.

Nakajima, H., Nakajima, H.O., Dembowsky, K., Pasumarthi, K.B., and Field, L.J. 2006. Cardiomyocyte cell cycle activation ameliorates fibrosis in the atrium. Circ Res 98(1): 141-148.

Nakano, T., Kodama, H., and Honjo, T. 1994. Generation of lymphohematopoietic cells from embryonic stem cells in culture. Science 265(5175): 1098-1101.

Nakayama, H., Bodi, I., Maillet, M., Desantiago, J., Domeier, T.L., Mikoshiba, K., Lorenz, J.N., Blatter, L.A., Bers, D.M., and Molkentin, J.D. 2010. The IP3 Receptor Regulates Cardiac Hypertrophy in Response to Select Stimuli. Circ Res 107(5): 659-666.

Narazaki, G., Uosaki, H., Teranishi, M., Okita, K., Kim, B., Matsuoka, S., Yamanaka, S., and Yamashita, J.K. 2008. Directed and systematic differentiation of cardiovascular cells from mouse induced pluripotent stem cells. Circulation 118(5): 498-506.

Nelson, T.J., Faustino, R.S., Chiriac, A., Crespo-Diaz, R., Behfar, A., and Terzic, A. 2008. CXCR4+/FLK-1+ biomarkers select a cardiopoietic lineage from embryonic stem cells. Stem Cells 26(6): 1464-1473.

Nelson, T.J., Ge, Z.D., Van Orman, J., Barron, M., Rudy-Reil, D., Hacker, T.A., Misra, R., Duncan, S.A., Auchampach, J.A., and Lough, J.W. 2006. Improved cardiac function in infarcted mice after treatment with pluripotent embryonic stem cells. Anat Rec A Discov Mol Cell Evol Biol 288(11): 1216-1224.

Nelson, T.J., Martinez-Fernandez, A., Yamada, S., Perez-Terzic, C., Ikeda, Y., and Terzic, A. 2009. Repair of acute myocardial infarction by human stemness factors induced pluripotent stem cells. Circulation 120(5): 408-416.

Nishikawa, S.I., Nishikawa, S., Hirashima, M., Matsuyoshi, N., and Kodama, H. 1998. Progressive lineage analysis by cell sorting and culture identifies FLK1+VEcadherin+ cells at a diverging point of endothelial and hemopoietic lineages. Development 125(9): 1747-1757.

Nussbaum, J., Minami, E., Laflamme, M.A., Virag, J.A., Ware, C.B., Masino, A., Muskheli, V., Pabon, L., Reinecke, H., and Murry, C.E. 2007. Transplantation of undifferentiated murine embryonic stem cells in the heart: teratoma formation and immune response. Faseb J 21(7): 1345-1357.

Nygren, J.M., Jovinge, S., Breitbach, M., Sawen, P., Roll, W., Hescheler, J., Taneera, J., Fleischmann, B.K., and Jacobsen, S.E. 2004. Bone marrow-derived hematopoietic cells generate cardiomyocytes at a low frequency through cell fusion, but not transdifferentiation. Nat Med 10(5): 494-501.

Oh, H., Bradfute, S.B., Gallardo, T.D., Nakamura, T., Gaussin, V., Mishina, Y., Pocius, J., Michael, L.H., Behringer, R.R., Garry, D.J., Entman, M.L., and Schneider, M.D. 


\section{Literaturverzeichnis}

2003. Cardiac progenitor cells from adult myocardium: homing, differentiation, and fusion after infarction. Proc Natl Acad Sci U S A 100(21): 12313-12318.

Okita, K., Ichisaka, T., and Yamanaka, S. 2007. Generation of germline-competent induced pluripotent stem cells. Nature 448(7151): 313-317.

Okita, K., Nakagawa, M., Hyenjong, H., Ichisaka, T., and Yamanaka, S. 2008. Generation of mouse induced pluripotent stem cells without viral vectors. Science 322(5903): 949953.

Orlic, D., Kajstura, J., Chimenti, S., Jakoniuk, I., Anderson, S.M., Li, B., Pickel, J., McKay, R., Nadal-Ginard, B., Bodine, D.M., Leri, A., and Anversa, P. 2001. Bone marrow cells regenerate infarcted myocardium. Nature 410(6829): 701-705.

Pandur, P., Lasche, M., Eisenberg, L.M., and Kuhl, M. 2002. Wnt-11 activation of a noncanonical Wnt signalling pathway is required for cardiogenesis. Nature 418(6898): 636-641.

Park, I.H., Zhao, R., West, J.A., Yabuuchi, A., Huo, H., Ince, T.A., Lerou, P.H., Lensch, M.W., and Daley, G.Q. 2008. Reprogramming of human somatic cells to pluripotency with defined factors. Nature 451(7175): 141-146.

Park, J.S., Chu, J.S., Cheng, C., Chen, F., Chen, D., and Li, S. 2004. Differential effects of equiaxial and uniaxial strain on mesenchymal stem cells. Biotechnol Bioeng 88(3): 359-368.

Passier, R. and Mummery, C. 2003. Origin and use of embryonic and adult stem cells in differentiation and tissue repair. Cardiovasc Res 58(2): 324-335.

Perico, N., Detcheva, A., Khalil, E.I., and Remuzzi, G. 1996. Cyclosporine induces glomerulosclerosis: three-dimensional definition of the lesions in a rat model of renal transplant. Kidney Int 49(5): 1283-1288.

Pfister, O., Mouquet, F., Jain, M., Summer, R., Helmes, M., Fine, A., Colucci, W.S., and Liao, R. 2005. CD31- but Not CD31+ cardiac side population cells exhibit functional cardiomyogenic differentiation. Circ Res 97(1): 52-61.

Pittenger, M.F., Mackay, A.M., Beck, S.C., Jaiswal, R.K., Douglas, R., Mosca, J.D., Moorman, M.A., Simonetti, D.W., Craig, S., and Marshak, D.R. 1999. Multilineage potential of adult human mesenchymal stem cells. Science 284(5411): 143-147.

Rambhatla, L., Chiu, C.P., Kundu, P., Peng, Y., and Carpenter, M.K. 2003. Generation of hepatocyte-like cells from human embryonic stem cells. Cell Transplant 12(1): 1-11.

Reed, C.A., Peralta, E.R., Wenrich, L.M., Wong, C.A., Bennett, C.F., Freier, S., and Lollo, B. 2005. Transfection protocol for antisense oligonucleotides affects uniformity of transfection in cell culture and efficiency of mRNA target reduction. Oligonucleotides 15(1): 12-22.

Reinecke, H. and Murry, C.E. 2000. Transmural replacement of myocardium after skeletal myoblast grafting into the heart. Too much of a good thing? Cardiovasc Pathol 9(6): 337-344.

Reinecke, H., Poppa, V., and Murry, C.E. 2002. Skeletal muscle stem cells do not transdifferentiate into cardiomyocytes after cardiac grafting. J Mol Cell Cardiol 34(2): 241-249. 


\section{Literaturverzeichnis}

Reinecke, H., Zhang, M., Bartosek, T., and Murry, C.E. 1999. Survival, integration, and differentiation of cardiomyocyte grafts: a study in normal and injured rat hearts. Circulation 100(2): 193-202.

Reppel, M., Boettinger, C., and Hescheler, J. 2004. Beta-adrenergic and muscarinic modulation of human embryonic stem cell-derived cardiomyocytes. Cell Physiol Biochem 14(4-6): 187-196.

Resnick, J.L., Bixler, L.S., Cheng, L., and Donovan, P.J. 1992. Long-term proliferation of mouse primordial germ cells in culture. Nature 359(6395): 550-551.

Reubinoff, B.E., Itsykson, P., Turetsky, T., Pera, M.F., Reinhartz, E., Itzik, A., and Ben-Hur, T. 2001. Neural progenitors from human embryonic stem cells. Nat Biotechnol 19(12): 1134-1140.

Reubinoff, B.E., Pera, M.F., Fong, C.Y., Trounson, A., and Bongso, A. 2000. Embryonic stem cell lines from human blastocysts: somatic differentiation in vitro. Nat Biotechnol 18(4): 399-404.

Rideout, W.M., 3rd, Hochedlinger, K., Kyba, M., Daley, G.Q., and Jaenisch, R. 2002. Correction of a genetic defect by nuclear transplantation and combined cell and gene therapy. Cell 109(1): 17-27.

Rohwedel, J., Maltsev, V., Bober, E., Arnold, H.H., Hescheler, J., and Wobus, A.M. 1994. Muscle cell differentiation of embryonic stem cells reflects myogenesis in vivo: developmentally regulated expression of myogenic determination genes and functional expression of ionic currents. Dev Biol 164(1): 87-101.

Rose, R.A., Keating, A., and Backx, P.H. 2008. Do mesenchymal stromal cells transdifferentiate into functional cardiomyocytes? Circ Res 103(9): e120.

Rottbauer, W., Greten, T., Muller-Bardorff, M., Remppis, A., Zehelein, J., Grunig, E., and Katus, H.A. 1996. Troponin T: a diagnostic marker for myocardial infarction and minor cardiac cell damage. Eur Heart J 17 Suppl F: 3-8.

Ruwhof, C., van Wamel, A.E., Egas, J.M., and van der Laarse, A. 2000. Cyclic stretch induces the release of growth promoting factors from cultured neonatal cardiomyocytes and cardiac fibroblasts. Mol Cell Biochem 208(1-2): 89-98.

Sadoshima, J. and Izumo, S. 1993. Mechanical stretch rapidly activates multiple signal transduction pathways in cardiac myocytes: potential involvement of an autocrine/paracrine mechanism. EMBO J 12(4): 1681-1692.

Sadoshima, J., Jahn, L., Takahashi, T., Kulik, T.J., and Izumo, S. 1992. Molecular characterization of the stretch-induced adaptation of cultured cardiac cells. An in vitro model of load-induced cardiac hypertrophy. J Biol Chem 267(15): 10551-10560.

Saha, S., Ji, L., de Pablo, J.J., and Palecek, S.P. 2006. Inhibition of human embryonic stem cell differentiation by mechanical strain. J Cell Physiol 206(1): 126-137.

Saric, T., Frenzel, L.P., and Hescheler, J. 2008. Immunological barriers to embryonic stem cell-derived therapies. Cells Tissues Organs 188(1-2): 78-90.

Sarig, R., Fuchs, O., Tencer, L., Panski, A., Nudel, U., and Yaffe, D. 2010. Cloned myogenic cells can transdifferentiate in vivo into neuron-like cells. PLoS One 5(1): e8814.

Schachinger, V., Erbs, S., Elsasser, A., Haberbosch, W., Hambrecht, R., Holschermann, H., Yu, J., Corti, R., Mathey, D.G., Hamm, C.W., Suselbeck, T., Assmus, B., Tonn, T., 


\section{Literaturverzeichnis}

Dimmeler, S., and Zeiher, A.M. 2006a. Intracoronary bone marrow-derived progenitor cells in acute myocardial infarction. $N$ Engl J Med 355(12): 1210-1221.

Schachinger, V., Erbs, S., Elsasser, A., Haberbosch, W., Hambrecht, R., Holschermann, H., Yu, J., Corti, R., Mathey, D.G., Hamm, C.W., Suselbeck, T., Werner, N., Haase, J., Neuzner, J., Germing, A., Mark, B., Assmus, B., Tonn, T., Dimmeler, S., and Zeiher, A.M. 2006b. Improved clinical outcome after intracoronary administration of bonemarrow-derived progenitor cells in acute myocardial infarction: final 1-year results of the REPAIR-AMI trial. Eur Heart J 27(23): 2775-2783.

Scheuermann-Freestone, M., Freestone, N.S., Langenickel, T., Hohnel, K., Dietz, R., and Willenbrock, R. 2001. A new model of congestive heart failure in the mouse due to chronic volume overload. Eur J Heart Fail 3(5): 535-543.

Schmelter, M., Ateghang, B., Helmig, S., Wartenberg, M., and Sauer, H. 2006. Embryonic stem cells utilize reactive oxygen species as transducers of mechanical strain-induced cardiovascular differentiation. Faseb J 20(8): 1182-1184.

Schmidt, A.G., Kadambi, V.J., Ball, N., Sato, Y., Walsh, R.A., Kranias, E.G., and Hoit, B.D. 2000. Cardiac-specific overexpression of calsequestrin results in left ventricular hypertrophy, depressed force-frequency relation and pulsus alternans in vivo. $J \mathrm{Mol}$ Cell Cardiol 32(9): 1735-1744.

Schöler, H.R., Balling, R., Hatzopoulos, A.K., Suzuki, N., and Gruss, P. 1989a. Octamer binding proteins confer transcriptional activity in early mouse embryogenesis. EMBO J 8(9): 2551-2557.

Schöler, H.R., Hatzopoulos, A.K., Balling, R., Suzuki, N., and Gruss, P. 1989b. A family of octamer-specific proteins present during mouse embryogenesis: evidence for germline-specific expression of an Oct factor. EMBO J 8(9): 2543-2550.

Schuldiner, M., Eiges, R., Eden, A., Yanuka, O., Itskovitz-Eldor, J., Goldstein, R.S., and Benvenisty, N. 2001. Induced neuronal differentiation of human embryonic stem cells. Brain Res 913(2): 201-205.

Seandel, M., James, D., Shmelkov, S.V., Falciatori, I., Kim, J., Chavala, S., Scherr, D.S., Zhang, F., Torres, R., Gale, N.W., Yancopoulos, G.D., Murphy, A., Valenzuela, D.M., Hobbs, R.M., Pandolfi, P.P., and Rafii, S. 2007. Generation of functional multipotent adult stem cells from GPR125+ germline progenitors. Nature 449(7160): 346-350.

Shalaby, F., Rossant, J., Yamaguchi, T.P., Gertsenstein, M., Wu, X.F., Breitman, M.L., and Schuh, A.C. 1995. Failure of blood-island formation and vasculogenesis in Flk-1deficient mice. Nature 376(6535): 62-66.

Sheehy, S.P., Huang, S., and Parker, K.K. 2009. Time-warped comparison of gene expression in adaptive and maladaptive cardiac hypertrophy. Circ Cardiovasc Genet 2(2): 116124.

Shimko, V.F. and Claycomb, W.C. 2008. Effect of mechanical loading on three-dimensional cultures of embryonic stem cell-derived cardiomyocytes. Tissue Eng Part A 14(1): 4958.

Shiojima, I. and Walsh, K. 2006. Regulation of cardiac growth and coronary angiogenesis by the Akt/PKB signaling pathway. Genes Dev 20(24): 3347-3365.

Shiota, M., Heike, T., Haruyama, M., Baba, S., Tsuchiya, A., Fujino, H., Kobayashi, H., Kato, T., Umeda, K., Yoshimoto, M., and Nakahata, T. 2007. Isolation and characterization 


\section{Literaturverzeichnis}

of bone marrow-derived mesenchymal progenitor cells with myogenic and neuronal properties. Exp Cell Res 313(5): 1008-1023.

Shmilovich, H., Ben-Shoshan, J., Tal, R., Afek, A., Barshack, I., Maysel-Auslander, S., Harats, D., Keren, G., and George, J. 2009. B-type natriuretic peptide enhances vasculogenesis by promoting number and functional properties of early endothelial progenitor cells. Tissue Eng Part A 15(9): 2741-2749.

Siminiak, T., Fiszer, D., Jerzykowska, O., Grygielska, B., Rozwadowska, N., Kalmucki, P., and Kurpisz, M. 2005. Percutaneous trans-coronary-venous transplantation of autologous skeletal myoblasts in the treatment of post-infarction myocardial contractility impairment: the POZNAN trial. Eur Heart J 26(12): 1188-1195.

Singla, D.K., Hacker, T.A., Ma, L., Douglas, P.S., Sullivan, R., Lyons, G.E., and Kamp, T.J. 2006. Transplantation of embryonic stem cells into the infarcted mouse heart: formation of multiple cell types. J Mol Cell Cardiol 40(1): 195-200.

Singla, D.K. and Sobel, B.E. 2005. Enhancement by growth factors of cardiac myocyte differentiation from embryonic stem cells: a promising foundation for cardiac regeneration. Biochem Biophys Res Commun 335(3): 637-642.

Skalak, T.C. and Price, R.J. 1996. The role of mechanical stresses in microvascular remodeling. Microcirculation 3(2): 143-165.

Skalli, O., Pelte, M.F., Peclet, M.C., Gabbiani, G., Gugliotta, P., Bussolati, G., Ravazzola, M., and Orci, L. 1989. Alpha-smooth muscle actin, a differentiation marker of smooth muscle cells, is present in microfilamentous bundles of pericytes. J Histochem Cytochem 37(3): 315-321.

Smith, A. 2005. The battlefield of pluripotency. Cell 123(5): 757-760.

Solloway, M.J. and Robertson, E.J. 1999. Early embryonic lethality in Bmp5;Bmp7 double mutant mice suggests functional redundancy within the 60A subgroup. Development 126(8): 1753-1768.

Srivastava, D. 2006. Making or breaking the heart: from lineage determination to morphogenesis. Cell 126(6): 1037-1048.

Stadtfeld, M., Nagaya, M., Utikal, J., Weir, G., and Hochedlinger, K. 2008. Induced pluripotent stem cells generated without viral integration. Science 322(5903): 945949.

Stanley, E.G., Biben, C., Elefanty, A., Barnett, L., Koentgen, F., Robb, L., and Harvey, R.P. 2002. Efficient Cre-mediated deletion in cardiac progenitor cells conferred by a 3'UTR-ires-Cre allele of the homeobox gene Nkx2-5. Int J Dev Biol 46(4): 431-439.

Stennard, F.A., Costa, M.W., Lai, D., Biben, C., Furtado, M.B., Solloway, M.J., McCulley, D.J., Leimena, C., Preis, J.I., Dunwoodie, S.L., Elliott, D.E., Prall, O.W., Black, B.L., Fatkin, D., and Harvey, R.P. 2005. Murine T-box transcription factor Tbx20 acts as a repressor during heart development, and is essential for adult heart integrity, function and adaptation. Development 132(10): 2451-2462.

Stevens, K.R., Pabon, L., Muskheli, V., and Murry, C.E. 2009. Scaffold-free human cardiac tissue patch created from embryonic stem cells. Tissue Eng Part A 15(6): 1211-1222.

Streckfuss-Bömeke, K., Vlasov, A., Hulsmann, S., Yin, D., Nayernia, K., Engel, W., Hasenfuss, G., and Guan, K. 2009. Generation of functional neurons and glia from multipotent adult mouse germ-line stem cells. Stem Cell Res 2(2): 139-154. 


\section{Literaturverzeichnis}

Sugden, P.H. 2003. Ras, Akt, and mechanotransduction in the cardiac myocyte. Circ Res 93(12): 1179-1192.

Sun, M., Chen, M., Dawood, F., Zurawska, U., Li, J.Y., Parker, T., Kassiri, Z., Kirshenbaum, L.A., Arnold, M., Khokha, R., and Liu, P.P. 2007. Tumor necrosis factor-alpha mediates cardiac remodeling and ventricular dysfunction after pressure overload state. Circulation 115(11): 1398-1407.

Sweeney, L.J. and Kelley, S.W. 1990. Histochemical and biochemical analysis of myosin heavy chain expression during cardiogenesis in the rat. J Mol Cell Cardiol 22(3): 361370.

Swijnenburg, R.J., Tanaka, M., Vogel, H., Baker, J., Kofidis, T., Gunawan, F., Lebl, D.R., Caffarelli, A.D., de Bruin, J.L., Fedoseyeva, E.V., and Robbins, R.C. 2005. Embryonic stem cell immunogenicity increases upon differentiation after transplantation into ischemic myocardium. Circulation 112(9 Suppl): I166-172.

Takahashi, K., Tanabe, K., Ohnuki, M., Narita, M., Ichisaka, T., Tomoda, K., and Yamanaka, S. 2007. Induction of pluripotent stem cells from adult human fibroblasts by defined factors. Cell 131(5): 861-872.

Takahashi, K. and Yamanaka, S. 2006. Induction of pluripotent stem cells from mouse embryonic and adult fibroblast cultures by defined factors. Cell 126(4): 663-676.

Takahashi, N., Seko, Y., Noiri, E., Tobe, K., Kadowaki, T., Sabe, H., and Yazaki, Y. 1999. Vascular endothelial growth factor induces activation and subcellular translocation of focal adhesion kinase (p125FAK) in cultured rat cardiac myocytes. Circ Res 84(10): 1194-1202.

Tang, M., Li, J., Huang, W., Su, H., Liang, Q., Tian, Z., Horak, K.M., Molkentin, J.D., and Wang, X. 2010. Proteasome functional insufficiency activates the calcineurin-NFAT pathway in cardiomyocytes and promotes maladaptive remodelling of stressed mouse hearts. Cardiovasc Res.

Taylor, D.A., Atkins, B.Z., Hungspreugs, P., Jones, T.R., Reedy, M.C., Hutcheson, K.A., Glower, D.D., and Kraus, W.E. 1998. Regenerating functional myocardium: improved performance after skeletal myoblast transplantation. Nat Med 4(8): 929-933.

Teekakirikul, P., Eminaga, S., Toka, O., Alcalai, R., Wang, L., Wakimoto, H., Nayor, M., Konno, T., Gorham, J.M., Wolf, C.M., Kim, J.B., Schmitt, J.P., Molkentin, J.D., Norris, R.A., Tager, A.M., Hoffman, S.R., Markwald, R.R., Seidman, C.E., and Seidman, J.G. 2010. Cardiac fibrosis in mice with hypertrophic cardiomyopathy is mediated by non-myocyte proliferation and requires Tgf-beta. J Clin Invest.

Tegelenbosch, R.A. and de Rooij, D.G. 1993. A quantitative study of spermatogonial multiplication and stem cell renewal in the C3H/101 F1 hybrid mouse. Mutat Res 290(2): 193-200.

Tendera, M., Wojakowski, W., Ruzyllo, W., Chojnowska, L., Kepka, C., Tracz, W., Musialek, P., Piwowarska, W., Nessler, J., Buszman, P., Grajek, S., Breborowicz, P., Majka, M., and Ratajczak, M.Z. 2009. Intracoronary infusion of bone marrow-derived selected CD34+CXCR4+ cells and non-selected mononuclear cells in patients with acute STEMI and reduced left ventricular ejection fraction: results of randomized, multicentre Myocardial Regeneration by Intracoronary Infusion of Selected Population of Stem Cells in Acute Myocardial Infarction (REGENT) Trial. Eur Heart J 30(11): 1313-1321. 
Terada, N., Hamazaki, T., Oka, M., Hoki, M., Mastalerz, D.M., Nakano, Y., Meyer, E.M., Morel, L., Petersen, B.E., and Scott, E.W. 2002. Bone marrow cells adopt the phenotype of other cells by spontaneous cell fusion. Nature 416(6880): 542-545.

Terami, H., Hidaka, K., Katsumata, T., Iio, A., and Morisaki, T. 2004. Wnt11 facilitates embryonic stem cell differentiation to Nkx2.5-positive cardiomyocytes. Biochem Biophys Res Commun 325(3): 968-975.

Thomson, J.A., Itskovitz-Eldor, J., Shapiro, S.S., Waknitz, M.A., Swiergiel, J.J., Marshall, V.S., and Jones, J.M. 1998. Embryonic stem cell lines derived from human blastocysts. Science 282(5391): 1145-1147.

Toischer, K., Rokita, A.G., Unsold, B., Zhu, W., Kararigas, G., Sossalla, S., Reuter, S.P., Becker, A., Teucher, N., Seidler, T., Grebe, C., Preuss, L., Gupta, S.N., Schmidt, K., Lehnart, S.E., Kruger, M., Linke, W.A., Backs, J., Regitz-Zagrosek, V., Schafer, K., Field, L.J., Maier, L.S., and Hasenfuss, G. 2010. Differential Cardiac Remodeling in Preload Versus Afterload. Circulation.

Tomanek, R.J., Zheng, W., and Yue, X. 2004. Growth factor activation in myocardial vascularization: therapeutic implications. Mol Cell Biochem 264(1-2): 3-11.

Tomita, S., Li, R.K., Weisel, R.D., Mickle, D.A., Kim, E.J., Sakai, T., and Jia, Z.Q. 1999. Autologous transplantation of bone marrow cells improves damaged heart function. Circulation 100(19 Suppl): II247-256.

Turner, C.H., Owan, I., and Takano, Y. 1995. Mechanotransduction in bone: role of strain rate. Am J Physiol 269(3 Pt 1): E438-442.

Urbanek, K., Quaini, F., Tasca, G., Torella, D., Castaldo, C., Nadal-Ginard, B., Leri, A., Kajstura, J., Quaini, E., and Anversa, P. 2003. Intense myocyte formation from cardiac stem cells in human cardiac hypertrophy. Proc Natl Acad Sci U S A 100(18): 10440-10445.

Urbanek, K., Torella, D., Sheikh, F., De Angelis, A., Nurzynska, D., Silvestri, F., Beltrami, C.A., Bussani, R., Beltrami, A.P., Quaini, F., Bolli, R., Leri, A., Kajstura, J., and Anversa, P. 2005. Myocardial regeneration by activation of multipotent cardiac stem cells in ischemic heart failure. Proc Natl Acad Sci U S A 102(24): 8692-8697.

van Berlo, J.H., Elrod, J.W., van den Hoogenhof, M.M., York, A.J., Aronow, B.J., Duncan, S.A., and Molkentin, J.D. 2010. The Transcription Factor GATA-6 Regulates Pathological Cardiac Hypertrophy. Circ Res.

van Wamel, A.J., Ruwhof, C., van der Valk-Kokshoorn, L.J., Schrier, P.I., and van der Laarse, A. 2002. Stretch-induced paracrine hypertrophic stimuli increase TGF-beta1 expression in cardiomyocytes. Mol Cell Biochem 236(1-2): 147-153.

van Wijk, B., Moorman, A.F., and van den Hoff, M.J. 2007. Role of bone morphogenetic proteins in cardiac differentiation. Cardiovasc Res 74(2): 244-255.

Vandenburgh, H.H. 1992. Mechanical forces and their second messengers in stimulating cell growth in vitro. Am J Physiol 262(3 Pt 2): R350-355.

Varga, A.C. and Wrana, J.L. 2005. The disparate role of BMP in stem cell biology. Oncogene 24(37): 5713-5721.

Vegh, P., Winckler, J., and Melchers, F. 2010. Long-term "in vitro" proliferating mouse hematopoietic progenitor cell lines. Immunol Lett 130(1-2): 32-35. 


\section{Literaturverzeichnis}

Vincentelli, A., Susen, S., Le Tourneau, T., Six, I., Fabre, O., Juthier, F., Bauters, A., Decoene, C., Goudemand, J., Prat, A., and Jude, B. 2003. Acquired von Willebrand syndrome in aortic stenosis. N Engl J Med 349(4): 343-349.

Vogeli, K.M., Jin, S.W., Martin, G.R., and Stainier, D.Y. 2006. A common progenitor for haematopoietic and endothelial lineages in the zebrafish gastrula. Nature 443(7109): 337-339.

Wang, X., Hu, Q., Nakamura, Y., Lee, J., Zhang, G., From, A.H., and Zhang, J. 2006. The role of the sca-1+/CD31- cardiac progenitor cell population in postinfarction left ventricular remodeling. Stem Cells 24(7): 1779-1788.

Wei, H., Juhasz, O., Li, J., Tarasova, Y.S., and Boheler, K.R. 2005. Embryonic stem cells and cardiomyocyte differentiation: phenotypic and molecular analyses. J Cell Mol Med 9(4): 804-817.

Wernig, M., Meissner, A., Foreman, R., Brambrink, T., Ku, M., Hochedlinger, K., Bernstein, B.E., and Jaenisch, R. 2007. In vitro reprogramming of fibroblasts into a pluripotent ES-cell-like state. Nature 448(7151): 318-324.

Westfall, M.V., Pasyk, K.A., Yule, D.I., Samuelson, L.C., and Metzger, J.M. 1997. Ultrastructure and cell-cell coupling of cardiac myocytes differentiating in embryonic stem cell cultures. Cell Motil Cytoskeleton 36(1): 43-54.

Wobus, A.M. 2001. Potential of embryonic stem cells. Mol Aspects Med 22(3): 149-164.

Wobus, A.M. and Boheler, K.R. 2005. Embryonic stem cells: prospects for developmental biology and cell therapy. Physiol Rev 85(2): 635-678.

Wollert, K.C., Meyer, G.P., Lotz, J., Ringes-Lichtenberg, S., Lippolt, P., Breidenbach, C., Fichtner, S., Korte, T., Hornig, B., Messinger, D., Arseniev, L., Hertenstein, B., Ganser, A., and Drexler, H. 2004. Intracoronary autologous bone-marrow cell transfer after myocardial infarction: the BOOST randomised controlled clinical trial. Lancet 364(9429): 141-148.

Wu, S.M., Fujiwara, Y., Cibulsky, S.M., Clapham, D.E., Lien, C.L., Schultheiss, T.M., and Orkin, S.H. 2006. Developmental origin of a bipotential myocardial and smooth muscle cell precursor in the mammalian heart. Cell 127(6): 1137-1150.

Xu, C., Police, S., Rao, N., and Carpenter, M.K. 2002. Characterization and enrichment of cardiomyocytes derived from human embryonic stem cells. Circ Res 91(6): 501-508.

Xu, Y., Wan, J., Jiang, D., and Wu, X. 2010. BMP-7 blocks the cyclosporine-A-induced epithelial-to-mesenchymal transition in renal tubular epithelial cells. Nephron Exp Nephrol 114(1): e23-31.

Xue, T., Cho, H.C., Akar, F.G., Tsang, S.Y., Jones, S.P., Marban, E., Tomaselli, G.F., and Li, R.A. 2005. Functional integration of electrically active cardiac derivatives from genetically engineered human embryonic stem cells with quiescent recipient ventricular cardiomyocytes: insights into the development of cell-based pacemakers. Circulation 111(1): 11-20.

Yamada, S., Nelson, T.J., Crespo-Diaz, R.J., Perez-Terzic, C., Liu, X.K., Miki, T., Seino, S., Behfar, A., and Terzic, A. 2008. Embryonic stem cell therapy of heart failure in genetic cardiomyopathy. Stem Cells 26(10): 2644-2653.

Yamaguchi, T.P., Dumont, D.J., Conlon, R.A., Breitman, M.L., and Rossant, J. 1993. flk-1, an flt-related receptor tyrosine kinase is an early marker for endothelial cell precursors. Development 118(2): 489-498. 
Yamamoto, K., Sokabe, T., Watabe, T., Miyazono, K., Yamashita, J.K., Obi, S., Ohura, N., Matsushita, A., Kamiya, A., and Ando, J. 2005. Fluid shear stress induces differentiation of Flk-1-positive embryonic stem cells into vascular endothelial cells in vitro. Am J Physiol Heart Circ Physiol 288(4): H1915-1924.

Yamashita, J., Itoh, H., Hirashima, M., Ogawa, M., Nishikawa, S., Yurugi, T., Naito, M., Nakao, K., and Nishikawa, S. 2000. Flk1-positive cells derived from embryonic stem cells serve as vascular progenitors. Nature 408(6808): 92-96.

Yan, X., Schuldt, A.J., Price, R.L., Amende, I., Liu, F.F., Okoshi, K., Ho, K.K., Pope, A.J., Borg, T.K., Lorell, B.H., and Morgan, J.P. 2008. Pressure overload-induced hypertrophy in transgenic mice selectively overexpressing AT2 receptors in ventricular myocytes. Am J Physiol Heart Circ Physiol 294(3): H1274-1281.

Yang, L., Soonpaa, M.H., Adler, E.D., Roepke, T.K., Kattman, S.J., Kennedy, M., Henckaerts, E., Bonham, K., Abbott, G.W., Linden, R.M., Field, L.J., and Keller, G.M. 2008. Human cardiovascular progenitor cells develop from a KDR+ embryonicstem-cell-derived population. Nature 453(7194): 524-528.

Ying, Q.L., Nichols, J., Evans, E.P., and Smith, A.G. 2002. Changing potency by spontaneous fusion. Nature 416(6880): 545-548.

Yoshida, H., Hayashi, S., Kunisada, T., Ogawa, M., Nishikawa, S., Okamura, H., Sudo, T., and Shultz, L.D. 1990. The murine mutation osteopetrosis is in the coding region of the macrophage colony stimulating factor gene. Nature 345(6274): 442-444.

Young, P.E., Baumhueter, S., and Lasky, L.A. 1995. The sialomucin CD34 is expressed on hematopoietic cells and blood vessels during murine development. Blood 85(1): 96105.

Yu, J., Vodyanik, M.A., Smuga-Otto, K., Antosiewicz-Bourget, J., Frane, J.L., Tian, S., Nie, J., Jonsdottir, G.A., Ruotti, V., Stewart, R., Slukvin, II, and Thomson, J.A. 2007. Induced pluripotent stem cell lines derived from human somatic cells. Science 318(5858): 1917-1920.

Zechner, U., Nolte, J., Wolf, M., Shirneshan, K., Hajj, N.E., Weise, D., Kaltwasser, B., Zovoilis, A., Haaf, T., and Engel, W. 2009. Comparative methylation profiles and telomerase biology of mouse multipotent adult germline stem cells and embryonic stem cells. Mol Hum Reprod 15(6): 345-353.

Zhang, Y.M., Hartzell, C., Narlow, M., and Dudley, S.C., Jr. 2002. Stem cell-derived cardiomyocytes demonstrate arrhythmic potential. Circulation 106(10): 1294-1299.

Zhou, H., Wu, S., Joo, J.Y., Zhu, S., Han, D.W., Lin, T., Trauger, S., Bien, G., Yao, S., Zhu, Y., Siuzdak, G., Scholer, H.R., Duan, L., and Ding, S. 2009. Generation of induced pluripotent stem cells using recombinant proteins. Cell Stem Cell 4(5): 381-384.

Zovoilis, A., Nolte, J., Drusenheimer, N., Zechner, U., Hada, H., Guan, K., Hasenfuss, G., Nayernia, K., and Engel, W. 2008. Multipotent adult germline stem cells and embryonic stem cells have similar microRNA profiles. Mol Hum Reprod 14(9): 521529. 


\section{Danksagung}

Bei Herrn Prof. Dr. Gerd Hasenfuß möchte ich mich ganz herzlich für die Möglichkeit bedanken, in seiner Abteilung forschen und meine Promotion anfertigen zu dürfen.

Herrn Prof. Dr. Uwe Groß und Herrn Prof. Dr. Wolfgang Brück danke ich sehr für die Bereitschaft, meine Promotion zu betreuen, für das Interesse und die konstruktive Kritik an meiner Arbeit.

Ein besonderer Dank geht an Frau Dr. Guan-Schmidt. Ich danke ihr für die Überlassung des Themas, die Betreuung und Unterstützung während der letzten Jahre.

Liebe Katrin (Frau Dr. Streckfuß-Bömeke), Dir möchte ich auch ein ganz großes Dankeschön aussprechen. Du hast mir im und außerhalb des Labors immer wieder viel Unterstützung und Lebensweisheit zukommen lassen. Ohne dich wäre z.B. Photoshop immer noch ein Rätsel! ;-) Alles Andere aufzuführen, würde hier den Rahmen sprengen... Vielen, vielen Dank für Dein offenes Ohr in allen Labor-/Lebenslagen und Deine beständige Hilfe!

Ich danke Yvonne Hintz, Anke Cierpka und Sandra Georgi für die freundschaftliche Zusammenarbeit und die stetige Unterstützung. Yvonne, vielen lieben Dank für die unzähligen Gewebeschnitte und Stunden am FACS u.v.m.! Anke, dir danke ich den Support in der Zellkultur und für die stetige Hilfe. Sandra danke ich für ihre erfrischende und immer freundliche Art und Weise! Mein Dank gilt natürlich auch dem Rest der Stammzell-Truppe für die tolle Arbeitsatmosphäre, den Beistand und die Nachsicht mit mir, v.a. zum Ende der Dissertation! Jörg danke ich für seine erfrischende Art, die Hilfe bei PC-Fragen, das Korrektur-Lesen u.v.m.! Daniela Hübscher danke ich für viele gemeinsam überstandene Stunden im OP und den „biochemischen“ Beistand im Labor! Die Hübscher-KaiserProduction war doch sehr erfolgreich! Michael Stauske gilt mein Dank für die immer optimistische Laune und die spanische Sprache, die er im Labor verbreitet hat. ¿Dónde está el baño? Ich danke Dr. Alex Becker für seine aufrichtige, humorvolle Art und Weise, die mich so oft hat lachen lassen. Dem Seidler-Lab (Dr. Tim Seidler, Dr. Conny Grebe, Nadine Kramann, Jessica Spitalieri und Karina Zimmermann) danke ich für die guten, konstruktiven Gespräche, stetige Zuckerzufuhr mittels Kuchen, Schokolade usw. und Asyl besonders in der letzten Phase der Promotion, wenn's mir am PC mal wieder zu viel wurde! Conny und Nadine danke ich insbesondere für die Konversationen unter Leidensgenossinnen! Dr. Karl Toischer und Dr. Bernhard Unsöld gilt mein Dank für die Anleitung der Maus-OP-Modelle! Ich danke Kirsten Koschel für die echokardiographischen Untersuchungen! Frau WaldmannBeushausen danke ich außerordentlich für ihren selbstlosen Einsatz im Tierstall und für die immer aufbauenden Konversationen! Eva Wagner und Julia Steinbrecher danke ich sehr für die vielen lustigen Mädelsabende vorm TV und in der Stadt. Wir haben uns doch recht gut bei leckerem Essen, Wein, anregenden Gesprächen und Grey's anatomy amüsiert! Das werde ich vermissen! Ich danke euch beiden für den Zuspruch in allen Lebenslagen! Evchen, Dir danke ich auch fürs frühe Aufstehen und schwimmen, egal wie kalt es war! Alles für den shape... Julia, Dir danke ich für das Vermitteln anderer Sichtweisen, für die Gradient-Echos und vieles mehr! Karin Rüter möchte ich an dieser Stelle auch besonders danken, für die aufbauenden Gespräche und für die Möglichkeit mal wieder Kontakt zu sehr großen Vierbeinern zu haben! Meinen Freundinnen Claudi, Kathi, Annegret und Ariane kann ich fast nicht genug danken für den stetigen Beistand, die Freundschaft, die Tipps für alle Lebenslagen und die Geduld, die sie immer wieder für mich aufbringen... Hab euch sehr lieb!

Ohne den Halt meiner Familie wären Studium und Promotion nicht möglich gewesen! Ich danke meiner Mutti besonders für ihre Liebe und Geduld, die langen und interessanten Gespräche und die immer währende Unterstützung mein Leben lang! Meinem Onkel Heinz danke ich für die erquickenden Telefonate, den anhaltenden Beistand und die Neuigkeiten aus einem kleinen thüringischen Dorf! Meiner Omi danke ich ebenfalls für die Unterstützung während der letzten Jahre, die auch für sie nicht immer einfach waren! 


\section{$\underline{\text { Curriculum vitae }}$}

Persönliche Angaben

Name:

Diana Kaiser

Geburtsdatum:

07.12.1981

Geburtsort:

Friedrichroda

Staatsangehörigkeit:

deutsch

$\underline{\text { Schulbildung }}$

08/1988 bis 07/1992

Bernard-Koenen-Grundschule, Halle/Saale

08/1992 bis $07 / 2000$

Christian-Wolff-Gymnasium, Halle/Saale

$\underline{\text { Studium und Promotion }}$

$11 / 2000$ bis $04 / 2006$

Grund- und Hauptstudium im Fach Biologie (Diplom), Universität Hannover

07/2003 bis $10 / 2003$

Studentische Hilfskraft am Institut für Physiologische Chemie, Tierärztliche Hochschule Hannover

$10 / 2004$ bis $02 / 2005$

Auslandsstudium, Universität Zürich

06/2005

Diplomprüfungen (Hauptfach: Zell-und Entwicklungsbiologie, Nebenfächer: Genetik und Virologie)

07/2005 bis $04 / 2006$

Diplomarbeit im Fraunhofer ITEM, Hannover

Titel: „Immuntoxikologische Untersuchungen in Precision cut lung slices“

$10 / 2006$ bis $12 / 2010$

Promotion im Stammzell-Labor der Kardiologie in der Universitätsmedizin Göttingen

Thema: „Der Einfluss mechanischer Last auf das Potential multipotenter adulter Keimbahnstammzellen zur kardialen Regeneration“ 